\title{
ENCOAL Mild Coal Gasification Project Public Design and Construction Report
}

\section{Topical Report}

December 1994

Work Performed Under Contract No.: DE-FC21-90MC27339

For

U.S. Department of Energy

Office of Fossil Energy

Morgantown Energy Technology Center

Morgantown, West Virginia

By

ENCOAL Corporation

Gillette, Wyoming 


\section{DISCLAIMER}

This report was prepared as an account of work sponsored by an agency of the United States Government. Neither the United States Government nor any agency thereof, nor any of their employees, makes any warranty, express or implied, or assumes any legal liability or responsibility for the accuracy, completeness, or usefulness of any information, apparatus, product, or process disclosed, or represents that its use would not infringe privately owned rights. Reference herein to any specific commercial product, process, or service by trade name, trademark, manufacturer, or otherwise does not necessarily constitute or imply its endorsement, recommendation, or favoring by the United States Government or any agency thereof. The views and opinions of authors expressed herein do not necessarily state or reflect those of the United States Government or any agency thereof.

This report has been reproduced directly from the best available copy.

Available to DOE and DOE contractors from the Office of Scientific and Technical Information, 175 Oak Ridge Turnpike, Oak Ridge, TN 37831; prices available at (615) 576-8401.

Available to the public from the National Technical Information Service, U.S. Department of Commerce, 5285 Port Royal Road, Springfield, VA 22161; phone orders accepted at (703) 487-4650. 


\section{DISCLAIMER}

Portions of this document may be illegible in electronic image products. Images are produced from the best available original document. 


\title{
ENCOAL Mild Coal Gasification Project Public Design and Construction Report
}

\author{
Topical Report
}

Work Performed Under Contract No.: DE-FC21-90MC27339

\author{
For \\ U.S. Department of Energy \\ Office of Fossil Energy \\ Morgantown Energy Technology Center \\ P.O. Box 880 \\ Morgantown, West Virginia 26507-0880 \\ ENCOAL Corporation \\ P.O. Box 3038 \\ Gillette, Wyoming
}


ENCOAL MILD COAL GASIFICATION PROJECT

PUBLIC DESIGN AND CONSTRUCTION REPORT

TABLE OF CONTENTS

$\underline{\text { PAGE }}$

LIST OF APPENDICES $\ldots \ldots \ldots \ldots \ldots \ldots \ldots \ldots \ldots \ldots \ldots \ldots$

LIST OF FIGURES $\ldots \ldots \ldots \ldots \ldots \ldots \ldots \ldots \ldots \ldots \ldots \ldots \ldots$

LIST OF TABLES $\ldots \ldots \ldots \ldots \ldots \ldots \ldots \ldots \ldots \ldots \ldots \ldots \ldots \ldots \ldots \ldots$

GLOSSARY $\ldots \ldots \ldots \ldots \ldots \ldots \ldots \ldots \ldots \ldots \ldots \ldots \ldots$

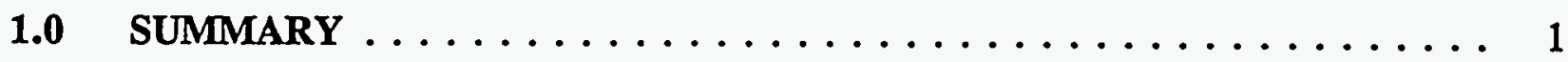

2.0 INTRODUCTION $\ldots \ldots \ldots \ldots \ldots \ldots \ldots \ldots \ldots \ldots \ldots$

3.0 PROJECT BACKGROUND $\ldots \ldots \ldots \ldots \ldots \ldots \ldots \ldots$

4.0 OVERVIEW OF PROCESS $\ldots \ldots \ldots \ldots \ldots \ldots \ldots \ldots \ldots \ldots$

5.0 OVERVIEW OF DESIGN CONSIDERATIONS $\ldots \ldots \ldots \ldots \ldots \ldots$

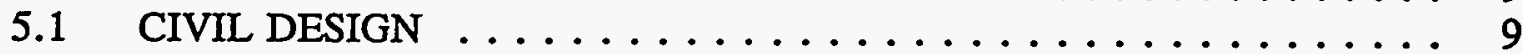

5.2 MECHANICAL DESIGN $\ldots \ldots \ldots \ldots \ldots \ldots \ldots \ldots$

5.3 ELECTRICAL AND INSTRUMENTATION DESIGN . . . . . . . 28

6.0 MAJOR EQUIPMENT FUNCTIONS AND DESCRIPTIONS . . . . . . . 34

6.1 FEED COAL SYSTEM . . . . . . . . . . . . . . . . 34

6.2 COAL DRYER AND CYCLONE $\ldots \ldots \ldots \ldots \ldots \ldots \ldots \ldots \ldots . \ldots \ldots$

6.3 COAL PYROLYZER AND CYCLONE $\ldots \ldots \ldots \ldots \ldots \ldots \ldots \ldots 41$

6.4 QUENCH TABLE .................... 42

6.5 PDF COOLER ...................... 42

6.6 PDF PRODUCT SYSTEM $\ldots \ldots \ldots \ldots \ldots \ldots \ldots \ldots \ldots \ldots \ldots$

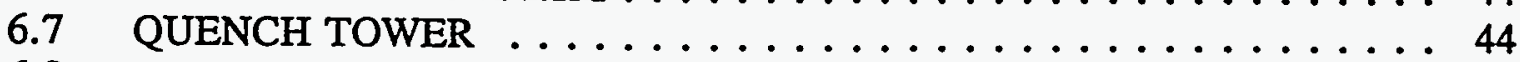

6.8 ELECTROSTATIC PRECIPITATORS . . . . . . . . . . . 47

6.9 COAL DERIVED LIQUID (CDL) HANDLING SYSTEM $\ldots \ldots \ldots \ldots 47$

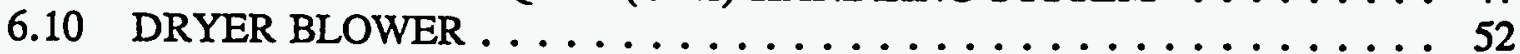

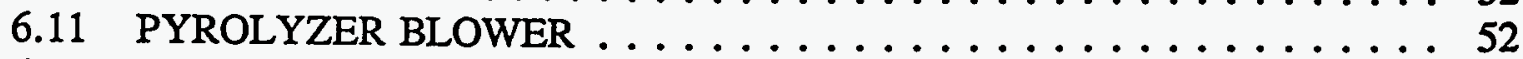

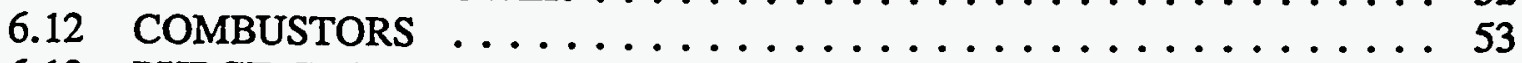

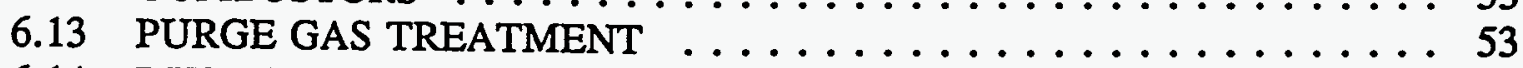

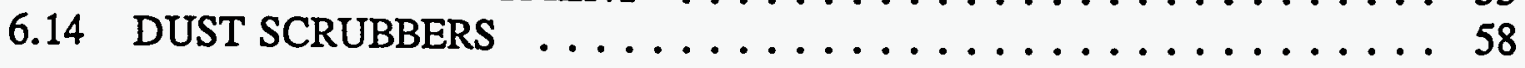




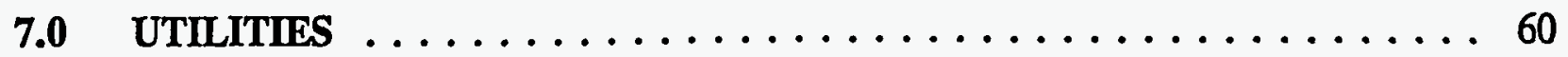

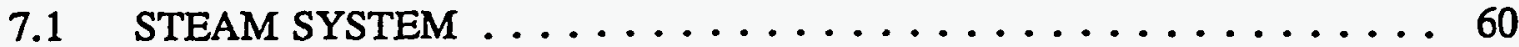

7.2 INSTRUMENT AND PLANT AIR $\ldots \ldots \ldots \ldots \ldots \ldots \ldots \ldots$

7.3 COOLING WATER . . . . . . . . . . . . . . 60

7.4 GLYCOL/WATER CIRCULATING SYSTEM . . . . . . . . 61

7.5 POTABLE WATER ................... 61

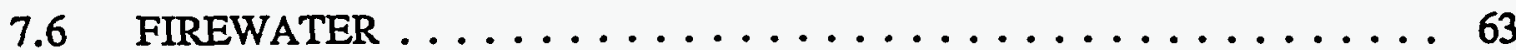

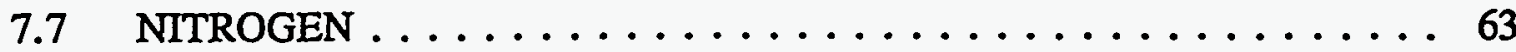

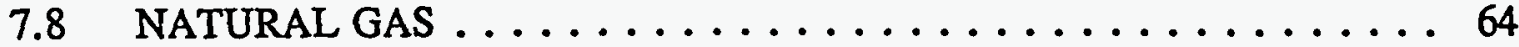

8.0 CONSTRUCTION . . . . . . . . . . . . . . . . . 64

8.1 CONTRACTING METHODOLOGY . . . . . . . . . . 64

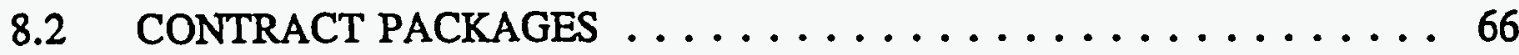

8.3 EARTHWORK, SURVEYING AND TESTING $\ldots \ldots \ldots \ldots 6$

8.4 STORAGE SILOS $\ldots \ldots \ldots \ldots \ldots \ldots \ldots \ldots \ldots \ldots \ldots \ldots \ldots$

8.5 PDF PLANT ...................... 69

8.5 .1 Foundations . . . . . . . . . . . . . 72

8.5.2 Underground Piping, Conduit and Equipment Foundations . . . . 74 8.5.3 Mechanical Erection

8.6 SCREENING BUILDING $\ldots \ldots \ldots \ldots \ldots \ldots \ldots \ldots$

8.7 ABOVE GROUND PIPING $\ldots \ldots \ldots \ldots \ldots \ldots \ldots \ldots \ldots$

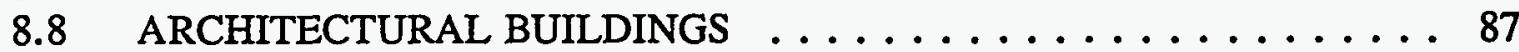

8.9 ELECTRICAL AND INSTRUMENTATION . . . . . . . . . . . . 89

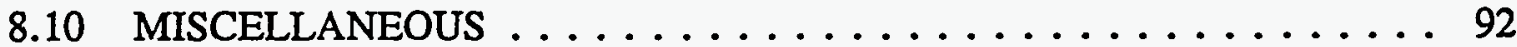

9.0 ENVIRONMENTAL CONCERNS . . . . . . . . . . . . . . 96

9.1 AIR POLLUTANTS . . . . . . . . . . . . . . . 96

9.2 WATER EFFLUENTS $\ldots \ldots \ldots \ldots \ldots \ldots \ldots \ldots \ldots$

9.3 SOLID/HAZARDOUS WASTE GENERATION . . . . . . . . . 97

10.0 SAFETY PRACTICES $\ldots \ldots \ldots \ldots \ldots \ldots \ldots \ldots \ldots \ldots \ldots$

10.1 INDUSTRIAL HYGIENE $\ldots \ldots \ldots \ldots \ldots \ldots \ldots \ldots$

10.2 PHYSICAL HAZARDS $\ldots \ldots \ldots \ldots \ldots \ldots \ldots \ldots$

10.3 CONSTRUCTION SAFETY PRACTICES $\ldots \ldots \ldots \ldots \ldots \ldots$

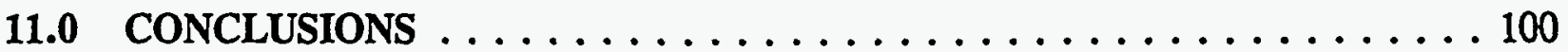




\section{LIMITED RIGHTS LEGEND}

This "proprietary data" furnished under Cooperative Agreement DE-FC21-90MC27339.000 with the United States Department of Energy may be duplicated and used by the Government with the express limitations that the "proprietary data" may not be disclosed outside the Government or be used for purposes of manufacture without prior permission of the Participant, except that further disclosure or use may be made solely for the following purposes:

(1) This "proprietary data" may be disclosed for evaluation purposes under the restriction that the "proprietary data" be retained in confidence and not be further disclosed;

(2) This "proprietary data" may be disclosed to other contractors participating in the Government's program of which this Cooperative Agreement is a part, for information or use in connection with the work performed under these contracts and under the restriction that the "proprietary data" be retained in confidence and not be further disclosed; or

(3) This "proprietary data" may be used by the Government or others on its behalf for emergency repair or overhaul work at the Facility under the restriction that the "proprietary data" be retained in confidence and not be further disclosed.

Appendix B

Appendix C

Appendix D

Appendix E
Pages B1 - B3

Pages $\mathrm{C} 1-\mathrm{C} 3$

Pages D1 - D2

Pages E1 - E2

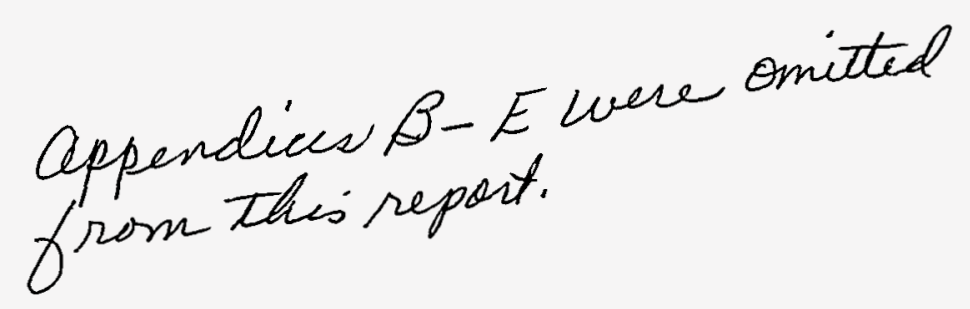




\section{LIST OF APPENDICES}

Appendix A $\ldots \ldots \ldots \ldots \ldots \ldots$ Civil and Mechanical Layouts Appendix B $\ldots \ldots \ldots \ldots \ldots \ldots \ldots \ldots$ Coal Drying (Proprietary)

Appendix C ............... Coal Pyrolysis and CDL Recovery (Proprietary)

Appendix D . . . . . . . . . . . . . Purge Gas Treatment (Proprietary)

Appendix E . . . . . . . . . . . . PDF Stabilization (Proprietary) 


\section{LIST OF FIGURES}

Figure 31

Field Master Schedule ... . . . . . . . . . . . . . . . . . 4

Figure $3.2 \quad$ Location Map ............................ 5

Figure 3.3 Project Site Layout . . . . . . . . . . . . . . . . . . . 6

Figure 4.1

Figure 5.1

Simplified Flow Diagram ..................... 8

Figure 5.2

Overall Site $\operatorname{Plan} \ldots \ldots \ldots \ldots$. . . . . . . . . . . . . . . . 10

Figure 5.3

Figure 5.4

Figure 5.5

Figure 5.6

Figure 5.7

Figure 5.8

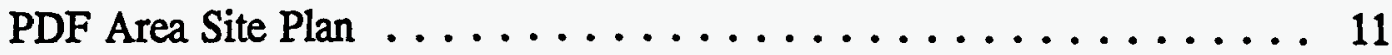

Sedimentation Pond and Pumps .................. 12

CDL Storage Area .......................... 13

Pipe Rack Plan ... . . . . . . . . . . . . . . . . . . . 14

Truck and Rail Loadout . . . . . . . . . . . . . . . . . . . . . . . . . . . . . . . . . . . 15

Raw Coal Silo Area ......................... 16

Figure 5.9

Figure 5.10

Figure 5.11

Figure 5.12

Figure 5.13

Figure 5.14

Figure 5.15

Figure 5.16

Figure 5.17

Figure 5.18

Figure 5.19

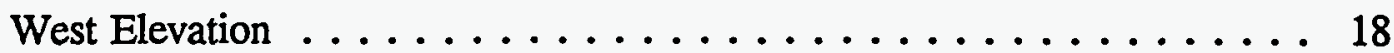

East Elevation . . . . . . . . . . . . . . . . . . . . . 19

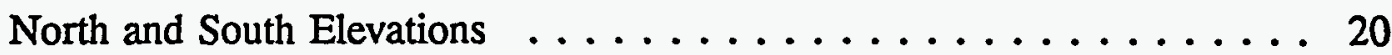

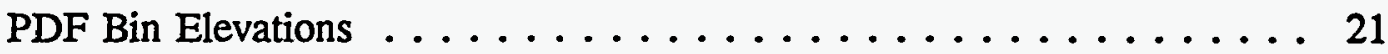

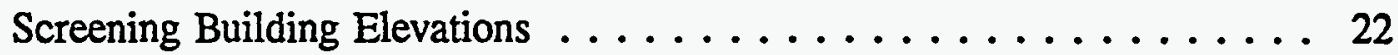

First Floor PDF ........................ 23

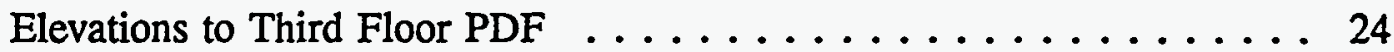

PDF Floors Four Through Six . . . . . . . . . . . . . 25

PDF Floors Seven Through Ten .................. 26

Screening Building Floors ... . . . . . . . . . . . . 27

Overall One Line Diagram . . . . . . . . . . . . . . . . . . 30

Figure 5.20

Figure 5.21

Figure 6.1

Figure 6.2

Figure 6.3

Figure 6.4

Figure 6.5

Figure 6.6

Figure 6.7

Figure 6.8

Figure 6.9

Figure 6.10

Figure 6.11

Figure 6.12

Figure 6.13

Figure 6.14

Figure 6.15

Figure 6.16

Figure 6.17

Figure 6.18

Figure 6.19

High Voltage Switch Gear

High Voltage Motor Controls ................... 32

Low Voltage Substation ..................... 33

Coal Feed Storage Silo . . . . . . . . . . . . . . . . 35

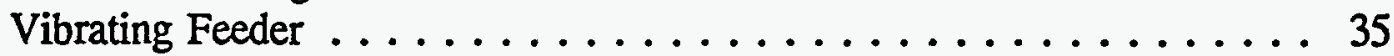

Triple Deck Coal Screen ..................... 36

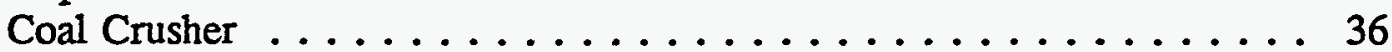

Salem Coal Dryer General Arrangement . . . . . . . . . . . . . . 37

Salem Coal Dryer ......................... . . . 38

Sketch of the Dryer Internals ... . . . . . . . . . . . . 38

Dryer Rabbles Arrangement . . . . . . . . . . . . . . . . 39

Dryer Cyclone ... . . . . . . . . . . . . . . . . . . . 40

Typical Cyclone Design . . . . . . . . . . . . . . . . . . . . 40

Coal Fine Screw Conveyor/Cooler . . . . . . . . . . . . . . . 41

Salem Coal Pyrolyzer ... . . . . . . . . . . . . . . . 42

Salem Quench Table . . . . . . . . . . . . . . . . . . . 43

Quench Steam Condenser . . . . . . . . . . . . . . . . . 43

PDF Cooler . . . . . . . . . . . . . . . . . . . . 44

General Arrangement PDF Cooler ................. 45

Gamma-Metric Coal Analyzer . . . . . . . . . . . . . . . . 46

Top Portion of the Quench Tower ... . . . . . . . . . . . . 46

Sketch of the Quench Tower Internals . . . . . . . . . . . . . . . . . 47

Figure 6.20 General Arrangement Quench Tower . . . . . . . . . . . . . . . . 48 
Figure 6.21 General Arrangement ESP's . . . . . . . . . . . . . . . . 49

Figure 6.22 Top Portion of the Electrostatic Precipitator . . . . . . . . . . . . 50

Figure 6.23 Sketch of Electrode Arrangement ............... 50

Figure 6.24 CDL Storage Tanks $\ldots \ldots \ldots \ldots \ldots \ldots \ldots \ldots \ldots \ldots \ldots \ldots$

Figure 6.25 CDL Meter . . . . . . . . . . . . . . . . 51

Figure 6.26 Dryer Recirculation Blower $\ldots \ldots \ldots \ldots \ldots \ldots \ldots \ldots \ldots \ldots \ldots$

Figure 6.27 Pyrolyzer Recirculation Blower $\ldots \ldots \ldots \ldots \ldots \ldots \ldots \ldots \ldots$

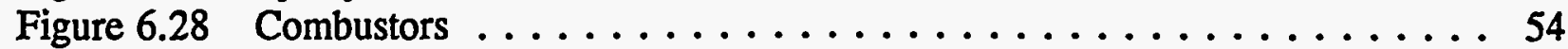

Figure 6.29 General Arrangement Combustor . . . . . . . . . . . 55

Figure 6.30 Sketch of the Combustor Internals $\ldots \ldots \ldots \ldots \ldots \ldots \ldots$

Figure 6.31 Combustion Air Blowers $\ldots \ldots \ldots \ldots \ldots \ldots \ldots \ldots \ldots \ldots \ldots \ldots$

Figure 6.32 Desulfurization Unit $\ldots \ldots \ldots \ldots \ldots \ldots \ldots \ldots \ldots \ldots \ldots$

Figure 6.33 Purge Gas Treatment Internals . . . . . . . . . . . . . 57

Figure 6.34 Temporary Evaporation Pond $\ldots \ldots \ldots \ldots \ldots \ldots \ldots \ldots$

Figure 6.35 Dust Scrubber at Screening Facilities . . . . . . . . . . . . 59

Figure 6.36 Dust Scrubber at Coal Feed silo . . . . . . . . . . . . . . 59

Figure $7.1 \quad$ CDL Cooler . . . . . . . . . . . . . . . . . 62

Figure 7.2 Fin Fan Glycol Cooler $\ldots \ldots \ldots \ldots \ldots \ldots \ldots \ldots \ldots \ldots \ldots \ldots \ldots$

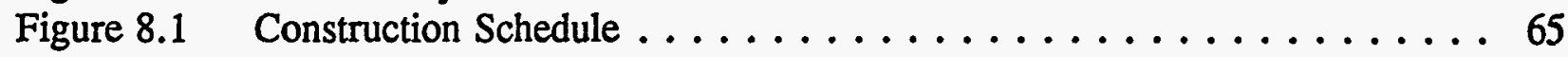

Figure 8.2 Raw Coal Silo Slip Form . . . . . . . . . . . . . . . . 68

Figure 8.3 Completed Raw Coal Silo . . . . . . . . . . . . . . . 69

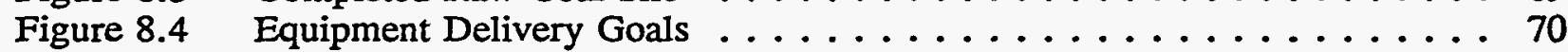

Figure $8.5 \quad$ Construction Schedule $\ldots \ldots \ldots \ldots \ldots \ldots \ldots \ldots \ldots \ldots$

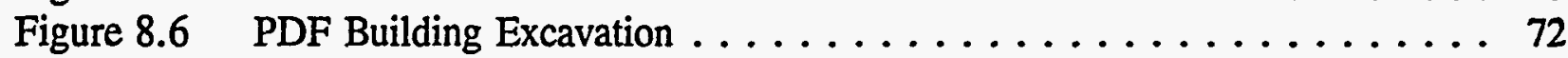

Figure 8.7 PDF Building Rebar Mats $\ldots \ldots \ldots \ldots \ldots \ldots \ldots \ldots \ldots \ldots$

Figure $8.8 \quad$ PDF Building Foundation Pour $\ldots \ldots \ldots \ldots \ldots \ldots \ldots \ldots$

Figure $8.9 \quad$ PDF and Screening Building Foundations $\ldots \ldots \ldots \ldots \ldots \ldots$

Figure 8.10 Backfilled PDF Building Foundation . . . . . . . . . . 75

Figure 8.11 Underground Piping and Equipment Foundations in Progress . . . . . 75

Figure 8.12 Completed Equipment Foundations and Floor Slabs . . . . . . . . 76

Figure 8.13 Quench Column and PDF Quench Table . . . . . . . . . 78

Figure 8.14 PDF Quench Table and 3rd Floor In Place . . . . . . . . . 78

Figure 8.15 Blowers, ESP's and Horizontal Scrubber In Place . . . . . . . . . . 79

Figure 8.16 West View of ESP's and Horizontal Scrubber . . . . . . . . . . 79

Figure 8.17 Pyrolyzer Assembly . . . . . . . . . . . . . . . 80

Figure 8.18 Pyrolyzer In Place. Roof at $106, \ldots \ldots \ldots \ldots \ldots \ldots \ldots \ldots \ldots \ldots$

Figure 8.19 Pyrolyzer Cyclone Installed (Center) $\ldots \ldots \ldots \ldots \ldots \ldots \ldots \ldots \ldots$

Figure 8.20 Start of 6 th Floor Deck and Steel $\ldots \ldots \ldots \ldots \ldots \ldots \ldots \ldots \ldots$

Figure 8.21 Dryer, Inlet Duct and Outlet Duct $\ldots \ldots \ldots \ldots \ldots \ldots \ldots$

Figure 8.22 Dryer In Place Awaiting Cyclone . . . . . . . . . . . 83

Figure 8.23 Dryer Cyclone and Structural Steel in Place . . . . . . . . . . 83

Figure 8.24 All Equipment and Structural Steel Complete . . . . . . . . . . . 84

Figure 8.25 Installation of Raw Coal S-Belt and Roof . . . . . . . . . 84

Figure 8.26 Aerial View of Completed Plant (Center) . . . . . . . . . . . . . 85

Figure 8.27 Screening Building Prior to Siding $\ldots \ldots \ldots \ldots \ldots \ldots \ldots \ldots . \ldots . \ldots$

Figure 8.28 Completed Screening Building $\ldots \ldots \ldots \ldots \ldots \ldots \ldots \ldots \ldots \ldots \ldots \ldots \ldots$

Figure 8.29 Above Ground Piping $\ldots \ldots \ldots \ldots \ldots \ldots \ldots \ldots \ldots$ 
Figure 8.30

Figure 8.31

Figure 8.32

Figure 8.33

Figure 8.34

Figure 8.35

Figure 8.36

Figure 8.37

Figure 8.38

Figure 8.39

Figure 8.40

Figure 10.1

Figure A.1

Figure A.2

Figure A.3

Figure A.4

Figure A.5

Figure A.6

Figure A.7

Figure A.8

Figure A.9

Figure A.10

Figure A.11

Figure A.12

Figure A.13

Figure A.14

Figure A.15

Figure B.1

Figure C.1

Figure D.1

Figure E.1
Tank Farm Piping $\ldots \ldots \ldots \ldots \ldots \ldots \ldots \ldots \ldots$

CDL Truck/Train Loadout Rack $\ldots \ldots \ldots \ldots \ldots \ldots$

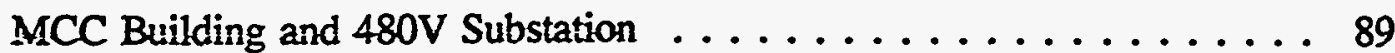

Control Building Near Completion . . . . . . . . . . . 90

Original Control Room Layout $\ldots \ldots \ldots \ldots \ldots \ldots \ldots$

Cooling Water Pump House . . . . . . . . . . . . . . . 91

Cooling Water Intake - Existing Triton Pond . . . . . . . . . 91

CDL Storage Tanks Under Construction . . . . . . . . . . . 93

Rail Siding Under Construction . . . . . . . . . . . . . . 93

Monthly Physical Percent Complete . . . . . . . . . . . 94

Manpower Loading Chart . . . . . . . . . . . . . . 95

Lost Time Incident Rates . . . . . . . . . . . . . . . 99

ENCOAL Facilities Layout . . . . . . . . . . . . . A-1

Control Room . . . . . . . . . . . . . . . . . A-2

Interior of the Control Room . . . . . . . . . . . . A-2

PDF Structure Looking Southwest $\ldots \ldots \ldots \ldots \ldots \ldots \ldots$ A-3

ENCOAL Facilities Looking Northeast $\ldots \ldots \ldots \ldots \ldots \ldots$ A-3

PDF Structure Floor Plan (Elevation 100'-6") . . . . . . . . . A-4

PDF Structure Floor Plan (Elevation 129'-6") . . . . . . . . . A A-5

PDF Structure Floor Plan (Elevation 142'-6") . . . . . . . . . A-6

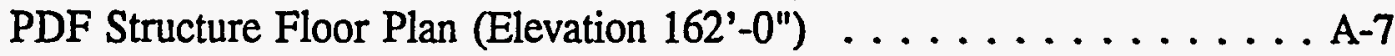

PDF Structure Floor Plan (Elevation 182'-6") . . . . . . . . . . A-8

Floor Plan (Elevations 206'-3") . . . . . . . . . . . . . . . . . . A A-9

PDF Structure Floor Plan (Elevations 225'-6" and 235'-6") . . . . . A-10

PDF Structure Floor Plan (Elevations 260'-6" and 279'-2") . . . . . A A-11

Screening Building . . . . . . . . . . . . . A-12

Screening Building Floor Plan $\ldots \ldots \ldots \ldots \ldots \ldots \ldots \ldots$

Coal Drying . . . . . . . . . . . . . . . B-3

Pyrolysis and CDL Recovery $\ldots \ldots \ldots \ldots \ldots \ldots \ldots \ldots$ C-3

Purge Gas Treatment . . . . . . . . . . . . . D-2

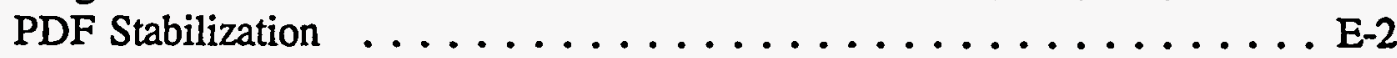




\section{LIST OF TABLES}

PAGE

Table $6.1 \quad$ Purge Gas Composition . . . . . . . . . . . . . . 54

Table 8.1 Subcontractors for ENCOAL Project . . . . . . . . . . . . . 67

Table A.1 Equipment List $\ldots \ldots \ldots \ldots \ldots \ldots \ldots \ldots \ldots \ldots$. . . . . . . . 


\section{GLOSSARY}

ASME

BS\&W

Btu

CDL

$\mathrm{CH}_{4}$

$\mathrm{CO}$

$\mathrm{CO}_{2}$

DOE

ENCOAL

ESP

${ }_{\mathrm{F}}$

$\mathrm{ft}$.

$\mathrm{ft}^{2}$

HP

$\mathrm{H}_{2} \mathrm{O}$

$\mathrm{H}_{2} \mathrm{~S}$

in.

Kellogg

$\mathrm{lb} / \mathrm{hr}$

LFC Technology

MM Btu/hr

Max

MSHA

$\mathrm{NO}_{\mathrm{x}}$

$\mathrm{O}_{2}$

PDF

PLC

$\%$

$\mathrm{pH}$

psia

psig

RPM

SMC

$\mathrm{SO}_{2}$

$\mathrm{SO}_{\mathrm{x}}$

turnkey

vol
American Society of Mechanical Engineers

Basic Sediment \& Water

British Thermal Units

Coal Derived Liquid

Methane

Carbon Monoxide

Carbon Dioxide

U.S. Department of Energy

ENCOAL Corporation, wholly-owned subsidiary of

SMC Mining Company

Electrostatic Precipitators

Degrees Fahrenheit

Feet

Square Feet

Horsepower

Water

Hydrogen Sulfide

Inches

The M. W. Kellogg Company

Pounds per Hour

Liquid From Coal Technology

- Million British Thermal Units per Hour

Maximum

Mine Safety and Health Administration

Nitrogen Oxides

Oxygen

Process Derived Fuel

Programmable Logic Controller

Percent

Measure of alkalinity and acidity on a scale of 0 to 14

Pounds per Square Inch Absolute

Pounds per Square Inch Gauge

Rotations per Minute

SMC Mining Company, wholly owned subsidiary of Zeigler Coal Holding Company, formerly Shell Mining Company

Sulfur Dioxide

Sulfur Oxides

Subcontracting method that includes design, furnishing and installation responsibility

Volume 


\subsection{SUMMARY}

The process engineering, detailed design and construction have been completed for a coal processing demonstration plant whose products will have a significantly greater value than that of the plant feed. The plant is designed to process 1000 ton/day of subbituminous Power River Basin (PRB) low-sulfur coal feed and to produce two products, a solid fuel and a liquid fuel. The solid product, Process Derived Fuel (PDF), is a stable, low-sulfur, high-Btu fuel similar in composition and handling properties to bituminous coal. The liquid product, Coal Derived Liquid (CDL), is a heavy, low-sulfur, liquid fuel similar in properties to heavy industrial fuel oil.

Since this is a demonstration plant, operating flexibility was a major factor in the process design. Environmental concerns, automation, and safety practices were also given a very high priority.

\subsection{INTRODUCTION}

This Public Design Report describes the 1000 ton per day ENCOAL mild coal gasification demonstration plant now in operation at the Buckskin Mine near Gillette, Wyoming. The project is being cost-shared by the U.S. Department of Energy (DOE), under the Clean Coal Technology Program administered by the Morgantown Energy Technology Center under Cooperative Agreement number DE-FC21-90MC27339.

The objective of the project is to demonstrate that the proprietary Liquids From Coal (LFC) technology can reliably and economically convert low Btu PRB coal into a superior, high-Btu solid fuel (PDF), and an environmentally attractive low-sulfur liquid fuel (CDL). The Project's plans also call for the production of sufficient quantities of PDF and CDL to permit utility companies to carry out full scale burn tests.

While some process as well as mechanical design was done in 1988, the continuous design effort was started in July, 1990. Civil construction was started in October, 1990; mechanical erection began in May, 1991. Virtually all of the planned design work was completed by July 1991. Most major construction was complete by April, 1992 followed by plant testing and commissioning. Plant operation began in late May, 1992. This report covers both the detailed design and initial construction aspects of the Project.

\subsection{PROJECT BACKGROUND}

ENCOAL's parent company, Shell Mining Company (SMC), began working on upgrading low rank coal in the early 1970's. In 1986 SMC held discussions with SGI International (SGI), a technology company located in La Jolla, California, to learn of their LFC technology. The LFC technology is a mild pyrolysis process which converts coal into a solid fuel and a liquid fuel. The PDF is a stable, low-moisture, low-sulfur material comparable to bituminous coal except it is more reactive during combustion. The CDL is similar in properties to low-sulfur heavy industrial fuel oil. 
Using coal from the Buckskin Mine as a feed stock, SMC and SGI ran a series of pilot plant tests beginning in 1987 in SGI's small scale pilot plant unit located near Pittsburgh, PA. The tests concentrated on various aspects of the LFC process, such as drying and pyrolyzing of coal, solids carry over, liquid collection and process variables. In addition, PDF and CDL were produced for laboratory testing. Several different flow schemes and process modifications were evaluated during these tests. For instance, the unit was upgraded from a $50 \mathrm{lb}$ per hour batch process to a $200 \mathrm{lb}$ per hour semi-continuous process. The experimental studies were extended into 1988 with the following results:

(1) Semi-continuous operation was achieved

(2) To the extent possible, process variables were evaluated

(3) Acceptable mass balances were calculated

(4) Sufficient quantities of products were produced for characteristic analysis and process evaluation

Extensive product testing was conducted at Shell Development Company's Westhollow Research Center in Houston, Texas. PDF was subjected to a month-long, around-the-clock test bum in a laboratory combustion facility. The results showed that the PDF was a very stable product with very desirable combustion properties. The composition of CDL was analyzed for over 200 compounds. The usual tests to characterize the properties of fuel oils were also run on the CDL. These laboratory results, as well as further discussions with potential customers, led SMC to believe that the LFC technology held significant promise to be technologically and commercially sound. In January, 1988, SMC solicited proposals from five major engineering companies and ultimately selected The M. W. Kellogg Company (Kellogg) to (1) perform a thorough investigation of the process, (2) design a nominal 1000 ton/day plant, and (3) prepare a cost estimate.

To guide the design team, SMC developed the following objectives for the demonstration plant:

(1) Provide products for commercial scale test burns

(2) Obtain data for the design of future commercial plants

(3) Demonstrate plant and process performance

(4) Provide capital and operating costs data

(5) Support future LFC technology licensing efforts

Given these objectives, a project team was assembled and charged with the responsibility of designing the facilities. The team developed a set of guidelines to aid the design:

(1) Keep scale-up from the SGI pilot plant reasonable.

(2) Use currently available commercial equipment as much as possible.

(3) Keep the process simple, postpone the refinement of CDL.

(4) Match the products to existing markets.

(5) Minimize all releases to the environment.

Although SMC was pleased with the results of the LFC technology evaluation, product analysis, and market forecast for the sale of the products, the total cost of the project represented a sizeable undertaking. In 1989, SMC decided to seek funding support from the DOE under the Clean Coal Technology Program. ENCOAL Corporation, a wholly-owned subsidiary of SMC, was formed for the purposes of entering into a Cooperative Agreement with the DOE and of 
designing and constructing the 1000 ton per day demonstration plant. The Cooperative Agreement with the DOE was signed on September 17, 1990. Figure 3.1 shows the Project Master Schedule developed by ENCOAL and accepted by the DOE for completion of design (Phase I) and construction (Phase II) of the demonstration plant facilities. This Project schedule was moderately aggressive and required the use of fast-tracking methods, that is the overlap of design and construction. It was felt at the time that there was some room for improvement if changes in the design could be kept to a minimum and equipment deliveries promised by vendors were met. Neither of these improvements occurred and it took the full effort of all Project team members to maintain the original schedule.

The Buckskin Mine of Triton Coal Company, another wholly-owned subsidiary of SMC, was chosen as the host location for the plant. This large PRB surface mine is located in northeastern Wyoming as shown on Figure 3.2. Selected in part because Triton is a sister company, the Buckskin Mine had an available site, existing roads, railroad, coal storage and handling facilities, utilities and infrastructure sufficient to support both the mine and ENCOAL. In addition, Triton could supply the raw coal for processing. Figure 3.3 shows the site layout for the existing Buckskin Mine facilities and the new ENCOAL Project facilities.

The site is surrounded by active coal mining operations and property that will be mined in the next few years. Geologically, the plant area is an ancient ocean bottom environment that is extremely variable due to its proximity to the burn zone at the subsurface outcrop of the major coal seam. Competent rock is rare and deep in most of the plant site area, and soil bearing conditions vary from poor to 2000 pounds per square foot. Under the actual plant site itself was an exception, however, and the preliminary geotechnical work showed that a spread foundation was acceptable for the PDF plant and screening building structures. All other structures required concrete caissons of various depths. Geographically, the plant site is at approximately 4100 feet elevation and is subject to cold weather extremes. Although not located in a highly active tectonic region, the plant site is subjected daily to nearby blasting activities in the mine. All of these conditions were evaluated in the plant design and appropriate equipment ratings, civil designs and winterization were included.

The home office engineering and design group at Kellogg completed their work in July, 1991. All remaining engineering, which mostly involved review and approval of field changes, was done by ENCOAL and Kellogg Construction Inc.(KCI) on-site engineers. Field engineering was more extensive on this Project because the home office engineering team was demobilized before developing a totally complete design. However, this decision proved to be cost effective, especially considering the impact on the Project Master Schedule if the field construction was delayed. With the design completed and construction in the final stages, commissioning and plant startup began in the 2nd quarter of 1992. Full integrated operation was achieved at near design conditions for 24 continuous hours on June 17, 1992.

\subsection{OVERVIEW OF PROCESS}

The LFC process is a mild gasification or pyrolysis process which involves heating of coal under carefully controlled conditions to produce gaseous compounds. Figure 4.1 shows a simplified flow diagram of ENCOAL's application of the LFC technology. 
ENCOAL CORPORATION

UILD GASIACATON DENONSTRATON PLANT

4.Y. KD1006 J08: 6683

FED UASTER SCHEDUIE

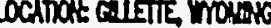

ATT DXTE 31 MLY 1991

\begin{tabular}{|c|c|c|c|c|c|c|c|c|c|c|c|c|c|}
\hline \multirow[b]{2}{*}{ Toak Horne } & \multirow{2}{*}{$\begin{array}{l}\text { Stort } \\
\text { Doto }\end{array}$} & \multirow{2}{*}{$\begin{array}{l}\text { End } \\
\text { Dote }\end{array}$} & \multicolumn{6}{|c|}{1991} & \multicolumn{5}{|c|}{1992} \\
\hline & & & $\tan$ & Neg & sep & odt & Nor & $D_{\infty}$ & $\operatorname{Inn}$ & Feb & $\mathrm{Hor}_{\alpha}$ & Aor & Joy \\
\hline & & & & & & & & & & & & - & $i$ \\
\hline Stecorifucts & $3-D 00-90$ & $15-p p-92$ & & & & & & & & & & & i \\
\hline 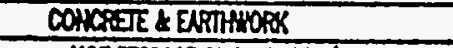 & $3-0 x-90$ & $30-50 p-91$ & & & & & & & & & & & i \\
\hline HOF STORMCE SLOS $2101 \mathrm{~N} 2101 \mathrm{~F}$ & $3-000-90$ & $19-2 d-91$ & & & & & & & & & & & ! \\
\hline 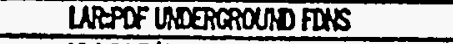 & $4-1 / \sigma-91$ & $10-10 y-91$ & 1 & & & & & & & & & & 1 \\
\hline 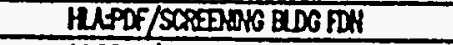 & $|5-1|-x-21$ & $1-\sqrt{2 t-91}$ & & & & & & & & & & & $i$ \\
\hline ACEPDF/SCRDERAG ALDG BCOAL & $3-\ln n-91$ & $\mid-\sqrt{|4|-9 \mid}$ & & & & & & & & & & & 1 \\
\hline $1001000 \& 100$ KEY RML SDOHO & $17-\sqrt{2 n}-81$ & $12-261-81$ & & & & & & & & & & & ! \\
\hline HUDFPSIE FOWRATONS & $1-\sqrt{u \mid-21}$ & $30-\operatorname{sep}-91$ & & & & & & & & & & & i \\
\hline ACEOFFSIES ENRTHWORX & $17 \sqrt{4}+1-91$ & $17-\operatorname{Sop}-91$ & & & & & & & & & & & i \\
\hline HECAUSA & $15-\sqrt{m-91}$ & $2-1 / \alpha-92$ & & & & & & & & & & & ! \\
\hline U/GPPE $\triangle$ AECTRCAL & $17-\sin -81$ & $20-\operatorname{Sep}-91$ & & & 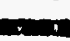 & & & & & & & & i \\
\hline STORAE TMKS \& LWWOS & $26-\sqrt{\ln n-91}$ & $15-$ Kov-91 & & & & & & & & & & & $i$ \\
\hline OFPSIE BrDotos & $1-\sqrt{41-91}$ & $15-0 d-91$ & & & & & & & & & & & i \\
\hline EECTRCLL \& ISTRMUETATOKH & $22-\sqrt{41-91}$ & $30-1 / \sigma-92$ & & & & & & & & & & & 1 \\
\hline RSUATON & $3-500-21$ & $17-H_{\alpha}-92$ & & & & & & & & & & & 1 \\
\hline CORMAC LRNG & $17-0 c t-91$ & $27-1100-91$ & & & & & & & & & & & i \\
\hline 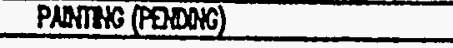 & $2-D \times 0-91$ & $15-$ - ppr-92 & i & & & & & & & & & & 1 \\
\hline & & & & & & & & & & & & & 1 \\
\hline 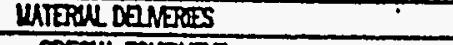 & $20-\Lambda_{p r-21}$ & $11-a t-91$ & & & & & & & & & & & $i$ \\
\hline Srear. EQUPLDT & $29-\operatorname{ler}-91$ & $11-a c t-91$ & & & & & & & & & & & $i$ \\
\hline ROTARG EQUPLENT & $30-\cos -91$ & $10-0 c t-91$ & & & & & & & & - & & & 1 \\
\hline HTERL HWOWG EQPT & $1-1102-81$ & $7-0 c t-91$ & & & & & & & & & & & i \\
\hline BECTRCAL & $31-1 \log _{0}-81$ & $3-\operatorname{sep}-91$ & & & & & & & & & & & $i$ \\
\hline EXTHKGRS & $17-\sqrt{\ln -91}$ & $8-0 d-91$ & & & & & & & & & & & $i$ \\
\hline STRUCTRRL STER & $1-\sqrt{21-91}$ & $21-(149-91$ & & & & & & & & & & & ! \\
\hline TOn.PRS & $15-\sqrt{42}-91$ & $16-240-91$ & i & & & & & & & & & & 1 \\
\hline DPAUS \& TNNSS & $15-\sqrt{4 u-91}$ & $8-0 t-81$ & & & & & & & & & & & 1 \\
\hline 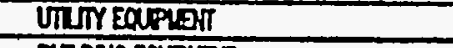 & $26-k u g-01$ & $20-4 u g-91$ & i & & & & & & & & & & 1 \\
\hline 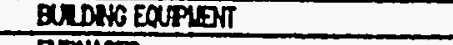 & $6-\operatorname{sog}-91$ & $6-5$ sp-91 & 1 & & & & & & & & & & i \\
\hline Frouces & $20-\operatorname{sep}-91$ & $20-\operatorname{sep}-91$ & $i$ & & A & & & & & & & & i \\
\hline & & & & & & & & & & & & & i \\
\hline Ka moperets & $1-0 d-90$ & $15-1 p r-92$ & & & & & & & & & & & $i$ \\
\hline & & & & & & & & & & & & & $!$ \\
\hline BNGNEREG & $3-\ln n-91$ & $31-\sqrt[b]{a c-91}$ & & & & & & & & & & & $!$ \\
\hline
\end{tabular}

Figure 3.1 


\section{MINE LOCATION MAP EASTERN POWDER RIVER BASIN}

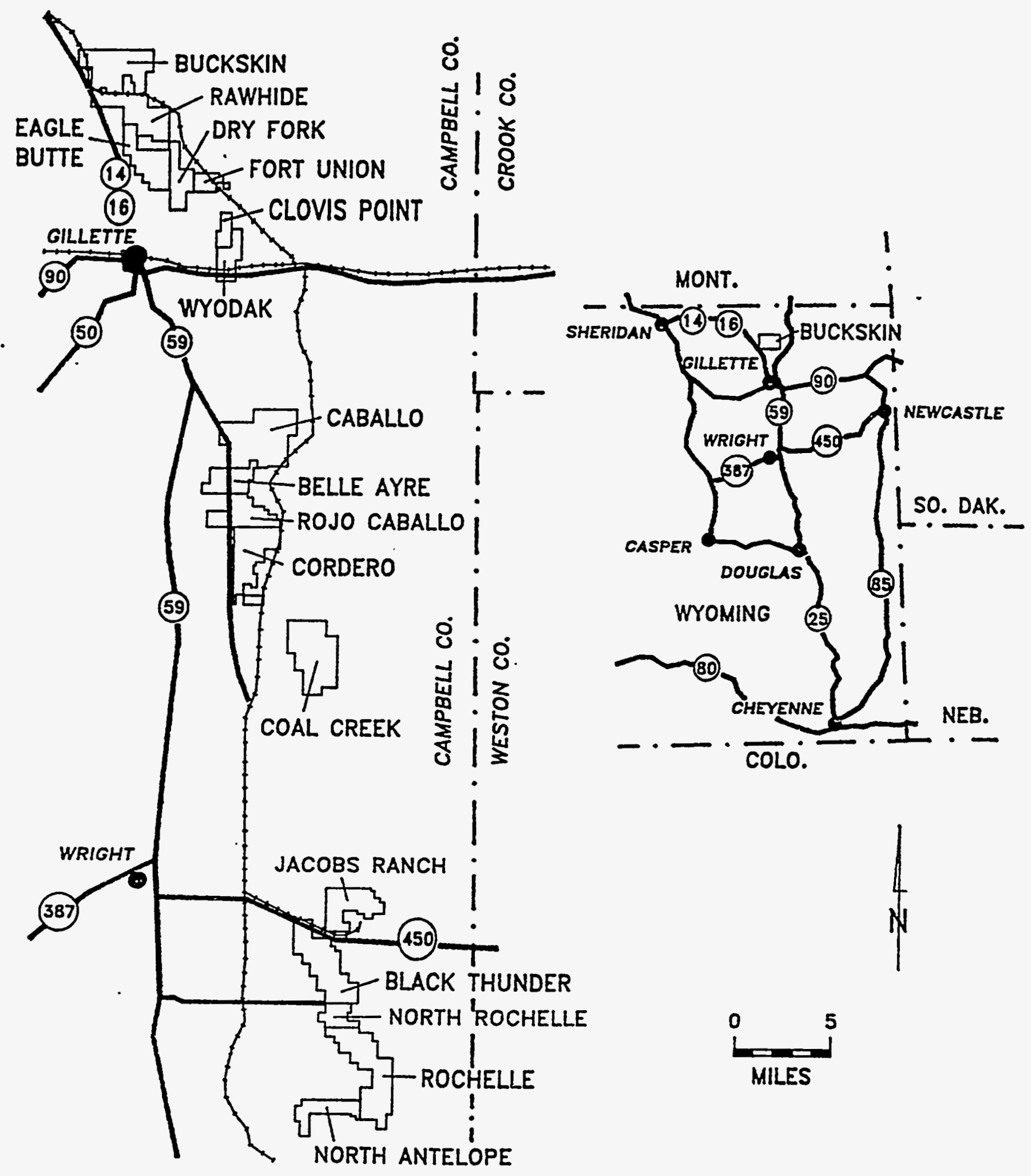

Figure 3.2 


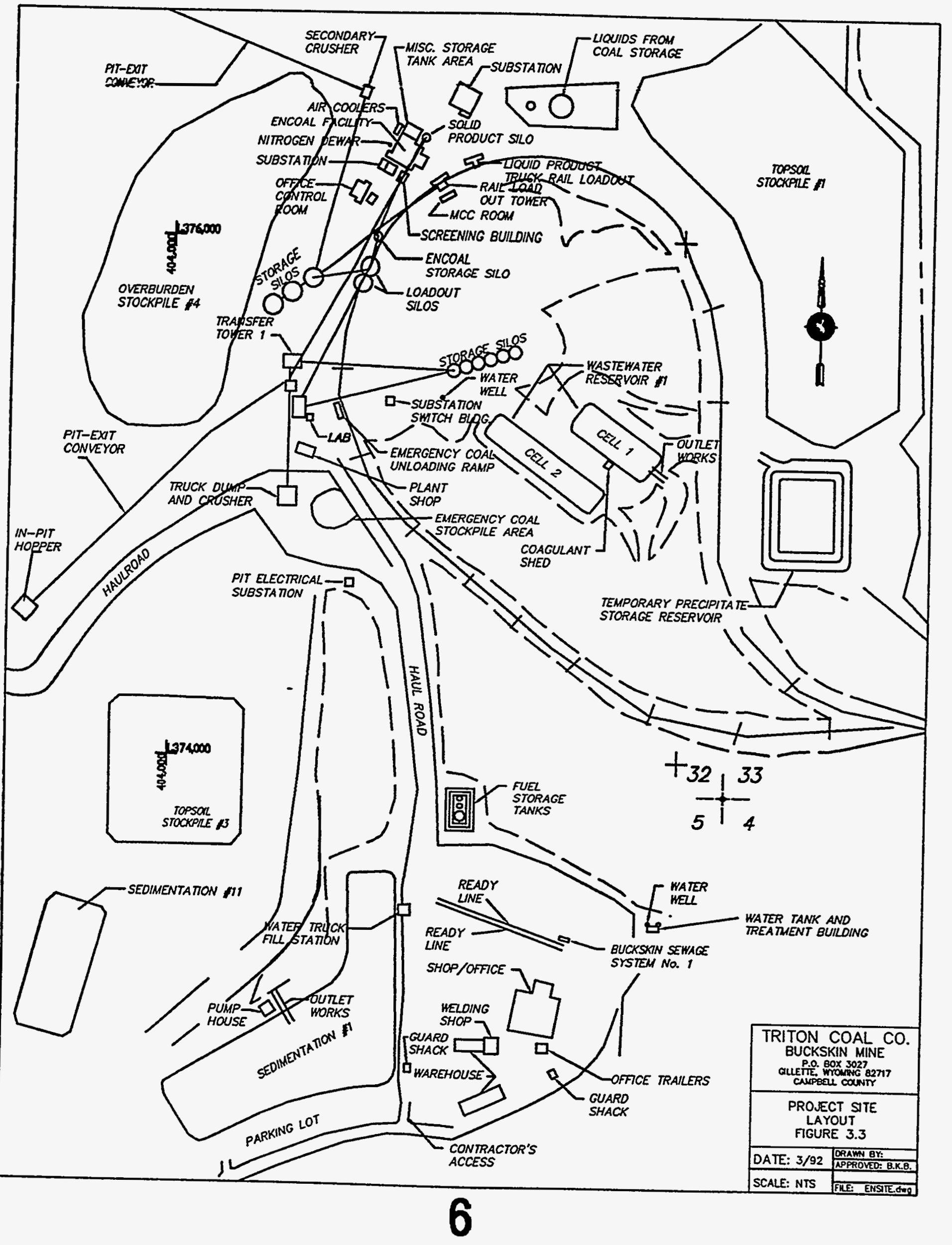


Run-of-mine coal is conveyed from the Buckskin Mine to a storage silo. The coal from this silo is screened to remove oversize and undersize materials. The specification coal feed, 2 " $\times 1 / 8^{\prime \prime}$ size, passes through a GAMMA-METRICS coal analyzer which measures the moisture, ash, carbon, hydrogen, sulfur, and other contents of the feed coal. The coal is then fed into a perforated rotary grate dryer where it is heated by a hot gas stream. The residence time of the coal and temperature of the inlet gas have been selected to reduce the moisture content of the coal without initiating chemical changes. The solid bulk temperature is controlled so that no significant amount of methane, carbon monoxide or carbon dioxide is released from the coal.

The solids from the dryer are then transferred to the pyrolyzer where the temperature of the dried coal is raised to about $1000^{\circ} \mathrm{F}$ by a hot recycled gas stream. The rate of heating of the solids i.e., the inlet temperature and flow rate of the hot recycled gas stream, is carefully controlled because it determines the properties of the solid and liquid products. In the pyrolyzer, a chemical reaction occurs which results in the release of volatile gaseous materials from the coal. Solids exiting the pyrolyzer are quickly quenched to stop the pyrolysis reaction. They are then cooled and transferred to the PDF storage silo. Since the solids have no surface moisture and, therefore, are likely to be dusty, a dust suppressant called MK is added as they leave the PDF product silo as final product.

The gas produced in the pyrolyzer is sent through a cyclone for removal of particulates. It is then sent to a quench tower to stop any secondary reaction and to condense the desired liquids. Only CDL is condensed in this step; the condensation of water is avoided. The gas stream leaving the quench tower may contain some CDL in the form of a fine mist. In order to recover the liquid mist, three electrostatic precipitators (ESP's) operating in parallel were installed. The finished CDL product is pumped from the bottom of the quench tower to storage.

The residual gas from the electrostatic precipitators is divided into three streams. Most of it is recycled directly to the pyrolyzer. Some is burned in the pyrolyzer combustor and then mixed with the recycled gas to provide heat for the mild gasification reaction. The remainder of the gas is burned in the dryer combustor, which converts sulfur compounds to sulfur oxides $\left(\mathrm{SO}_{x}\right)$ and hydrocarbons to carbon oxides $\left(\mathrm{CO}_{x}\right)$. Nitrogen oxide $\left(\mathrm{NO}_{x}\right)$ and carbon monoxide $(\mathrm{CO})$ emissions are controlled by appropriate design of the combustor. The hot flue gas from the dryer combustor is blended with the recycled gas from the dryer to provide heat for drying.

The off-gas from the dryer first passes through a cyclone to remove the entrained particulates. It is then divided into two streams. Most of it is recycled directly to the dryer while the remainder is treated with sodium carbonate solution in a two-stage scrubber system. By spraying the off-gas with sodium carbonate solution, the first stage scrubber captures the fine particulates that escape the dryer cyclone, and the second stage scrubber removes most of the sulfur oxides from the gas stream by converting it into sodium sulfite. The sulfite is then oxidized into sodium sulfate. The treated gas is vented to the atmosphere through a stack while the spent solution is sent into a non-discharging pond for evaporation. 


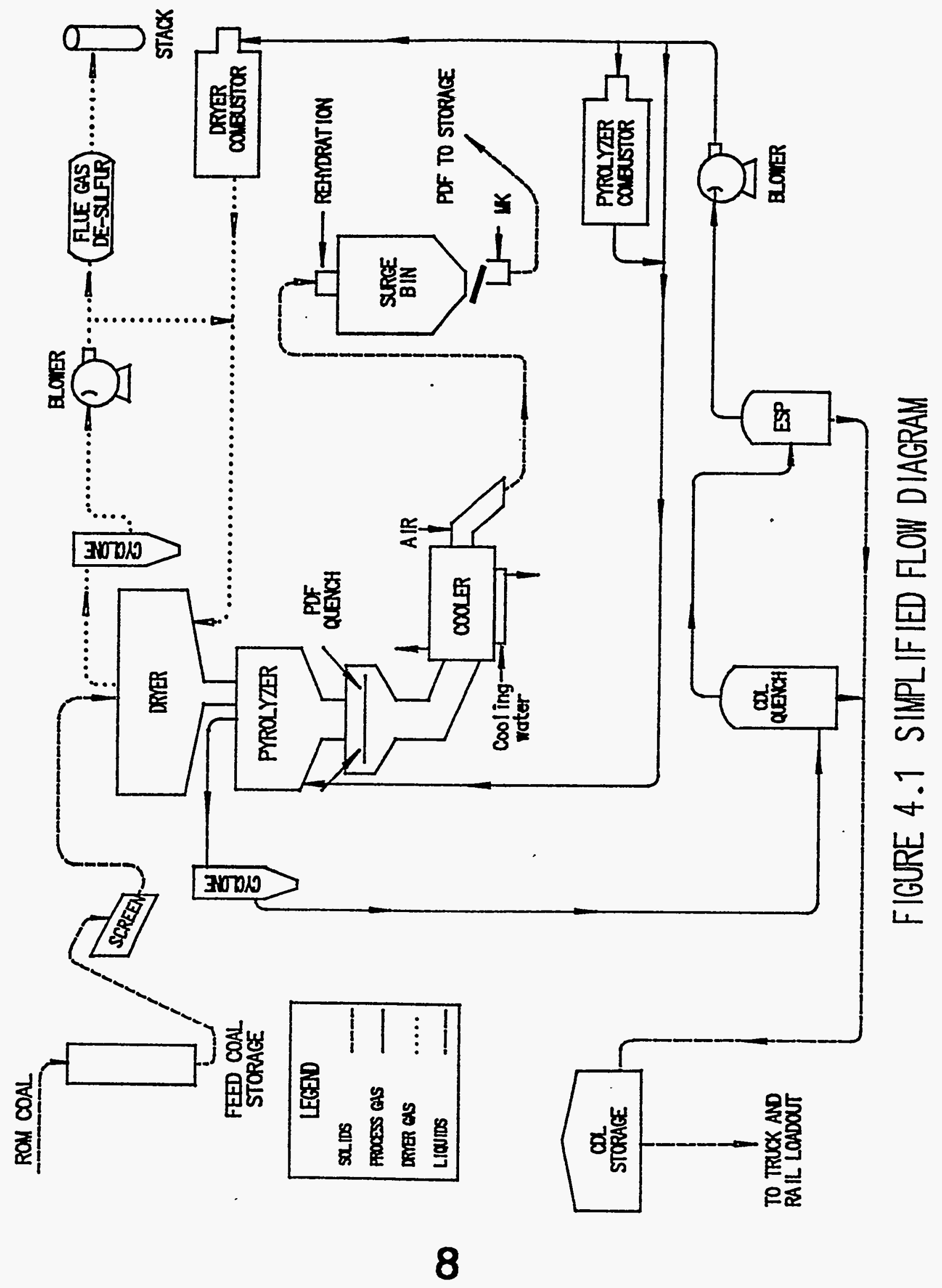




\subsection{OVERVIEW OF DESIGN CONSIDERATIONS}

Early in the design phase of the Project, ENCOAL and Kellogg developed a document called the "Design Basis" which contained the underlying premises for the design of the PDF plant and associated facilities. Site specific information such as elevation, climate, wind and snow conditions, rainfall and tectonic activity was listed. The industry standards to be used in the design and the governing industry codes that must be followed were identified. It was determined that the Project would fall under the jurisdiction of the Mine Safety And Health Administration (MSHA) due to its location on the Buckskin Mine property. This carried a special set of requirements for design, especially in the areas of coal drying, lifting and hoisting, electrical classifications and personnel safety protection.

Other areas covered by the Design Basis were the nominal capacity of the plant, namely 1000 tons feed coal per day and the over-design margin for given conditions. In general, a margin of $15 \%$ over the nominal design for individual pieces of equipment was the guideline, but this margin was defined so that it would not be additive. A "Process Release" document was also produced based on the description in Section 4. The Process Release contained the detailed heat and material balance for all individual process streams.

About halfway through the detailed design effort at Kellogg, after sufficient work had been done to describe the facilities, a Hazards of Operations (HazOps) review was performed. A group of experts was assembled from the design team and from external sources at Kellogg and Shell. The group produced a report with recommendations for design modifications, training provisions and operating procedures. The HazOps recommendations were followed carefully, and the design modifications were implemented.

\subsection{CIVIL DESIGN}

The category called civil design on the ENCOAL Project includes the site preparation, drainage, ponds, foundations and structures as well as the architectural features of the buildings. Since the ENCOAL Project is located on an active mine site, the civil design had to be coordinated with the mine, especially the drainage and ponds. Run-off from the mine passes through the PDF plant site in several places and had to be handled. Wastewater and run-off collection ponds were combined for the mine and new facilities wherever possible. At the same time as the ENCOAL Project was in construction, the mine installed a major expansion project, further emphasizing the need for close coordination of the Project designs. Detailed plot plans are shown in Figures 5.1 through 5.7.

The Civil Engineering group developed a set of guidelines for their designs. Some of the highlights were:

(1) Use a safety factor of four for structural design.

(2) In the absence of local building codes for the site, use standard industrial codes.

(3) Enclose and heat all buildings due to the weather factor.

(4) Design for wind load of $100 \mathrm{mph}$ and snow load of $30 \mathrm{psf}$.

(5) A ventilation system must cool the PDF building in hot weather and exhaust noxious gases in emergencies. 


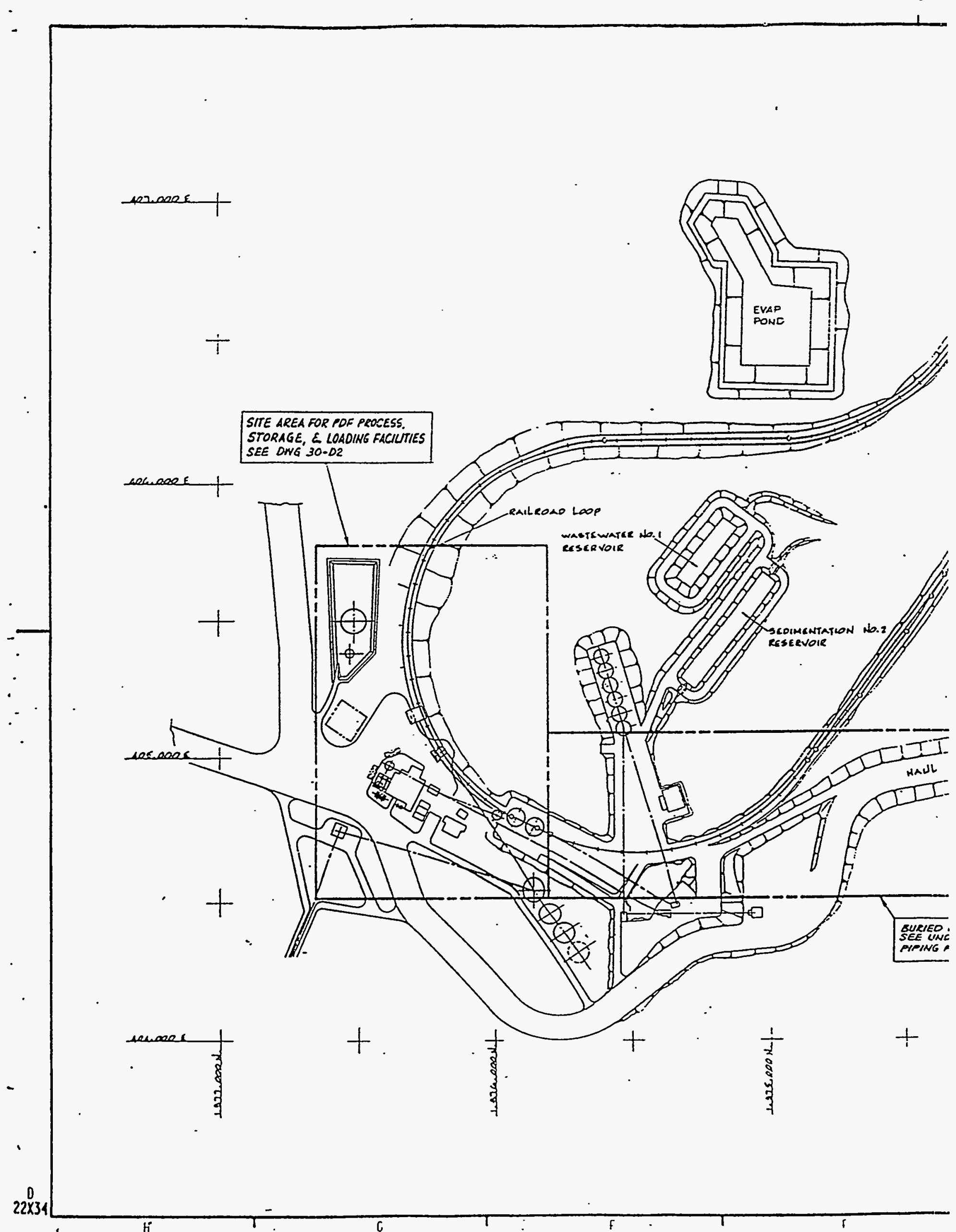




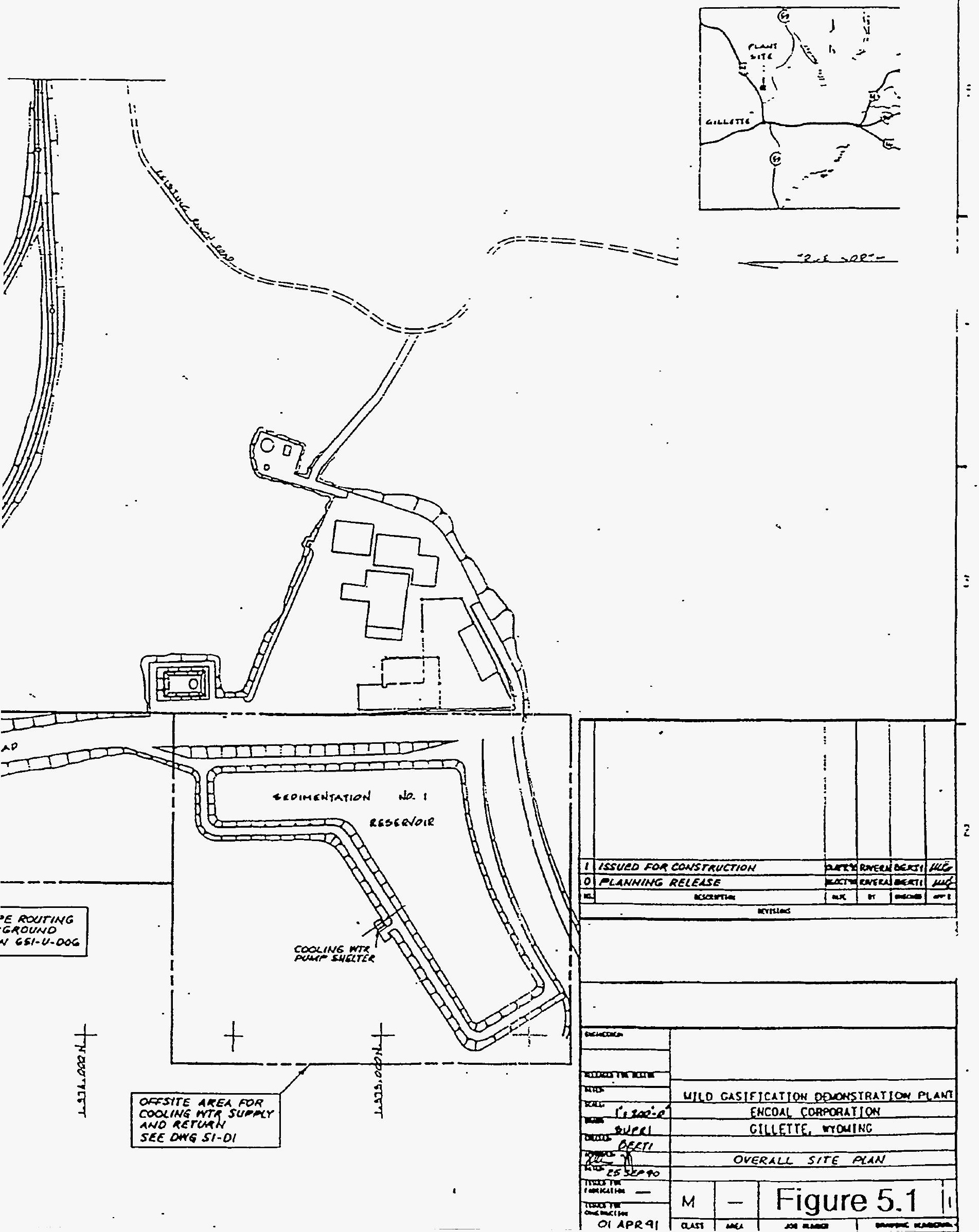




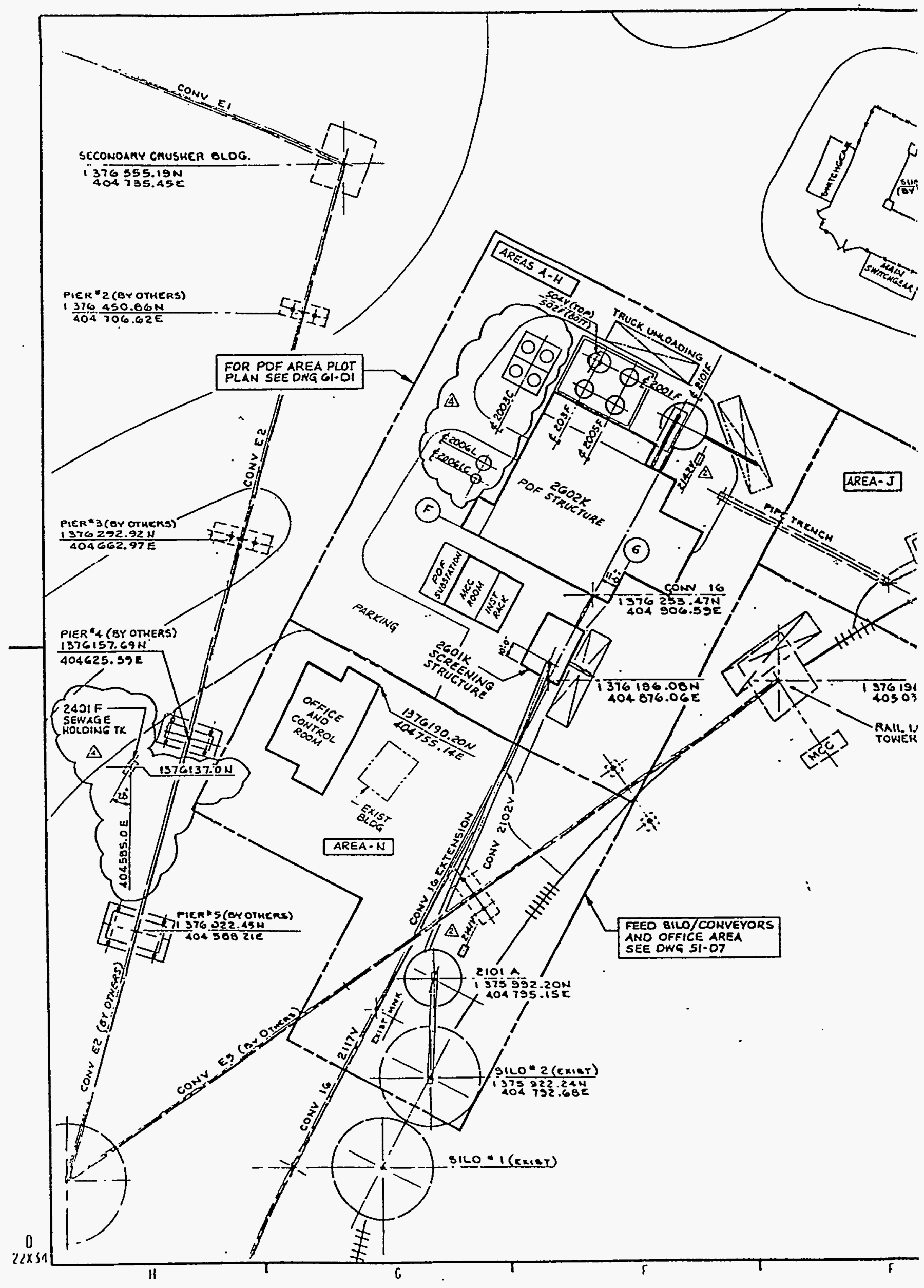




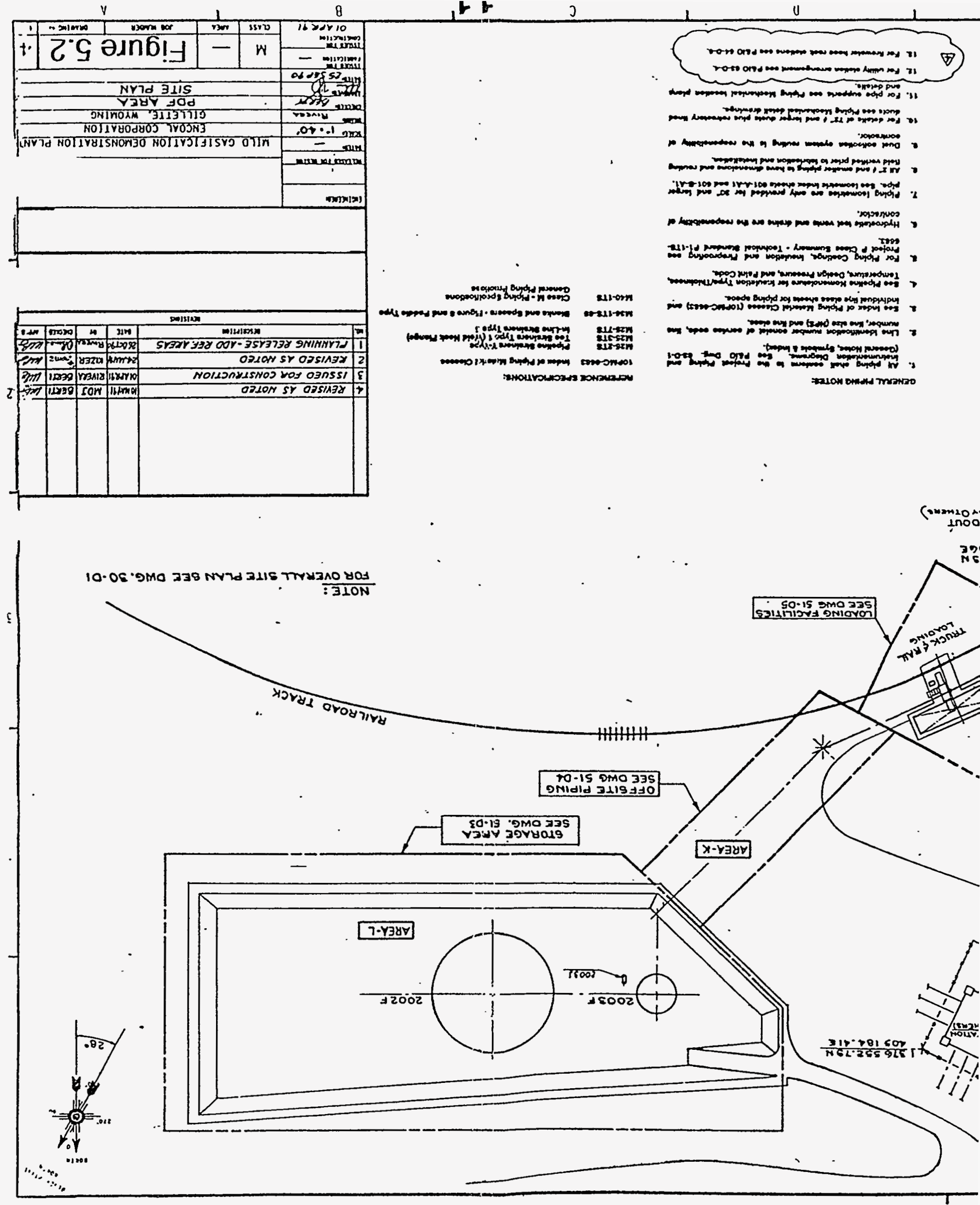




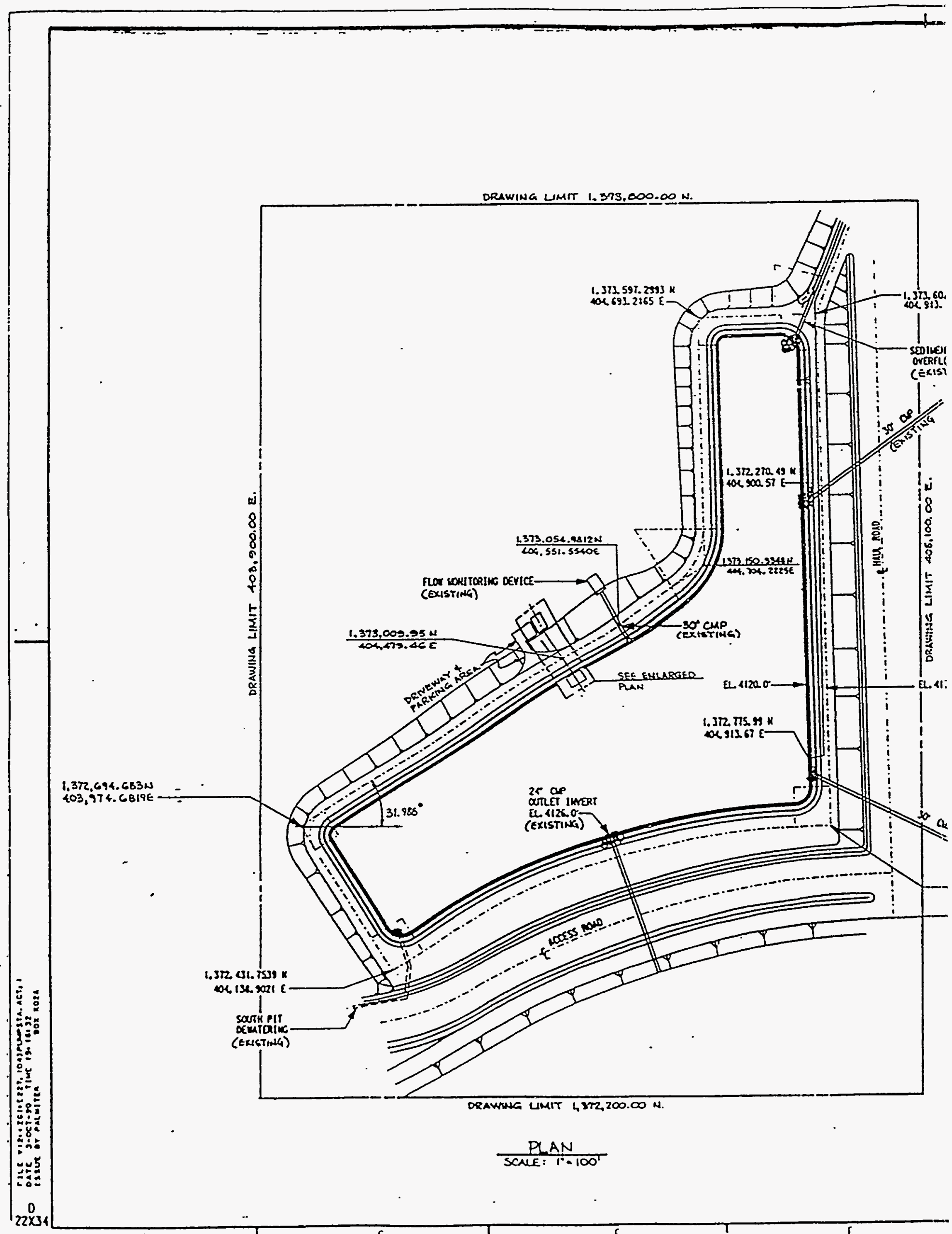



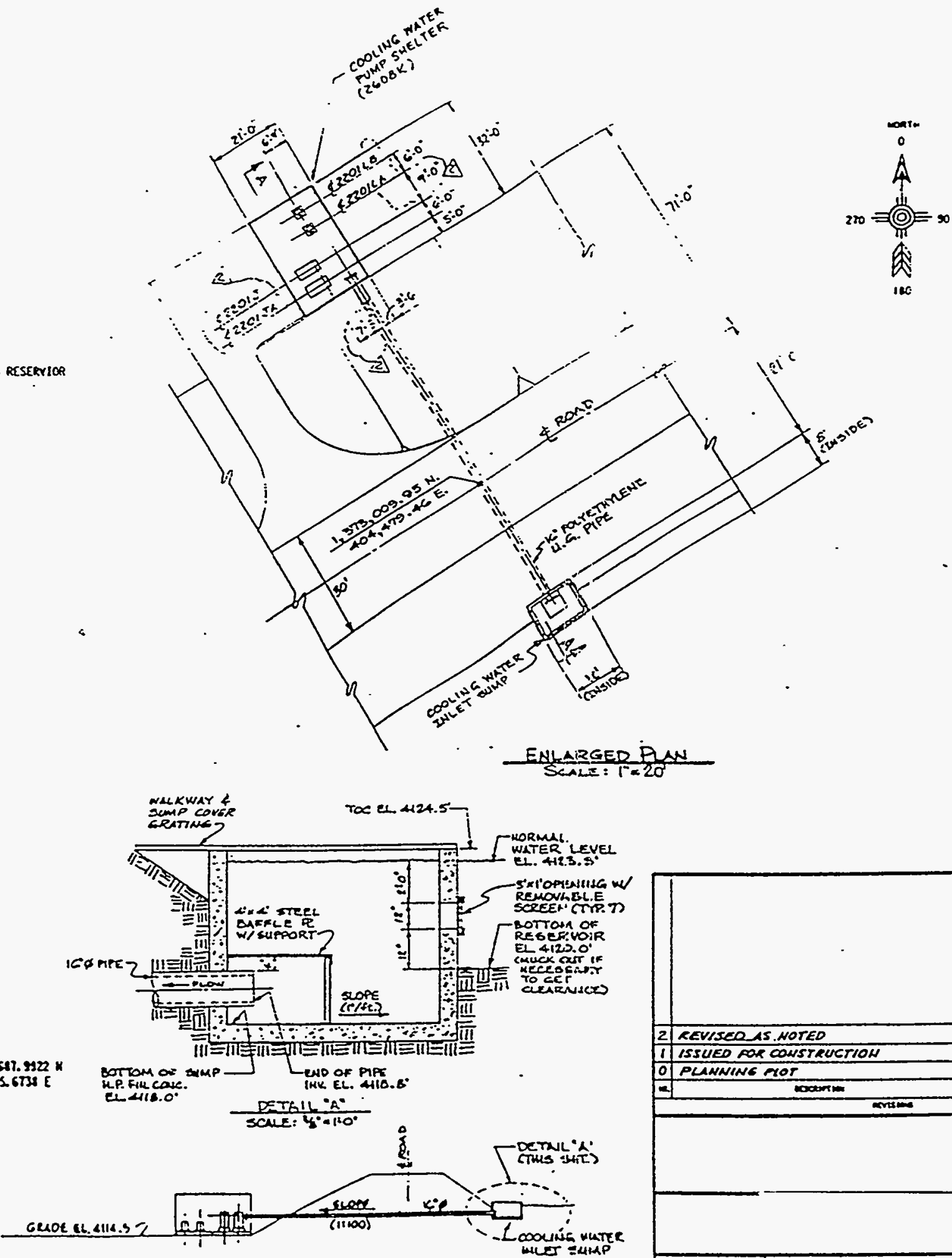

SECTION $A-A^{\circ}$ SCALE: $1 " .90$

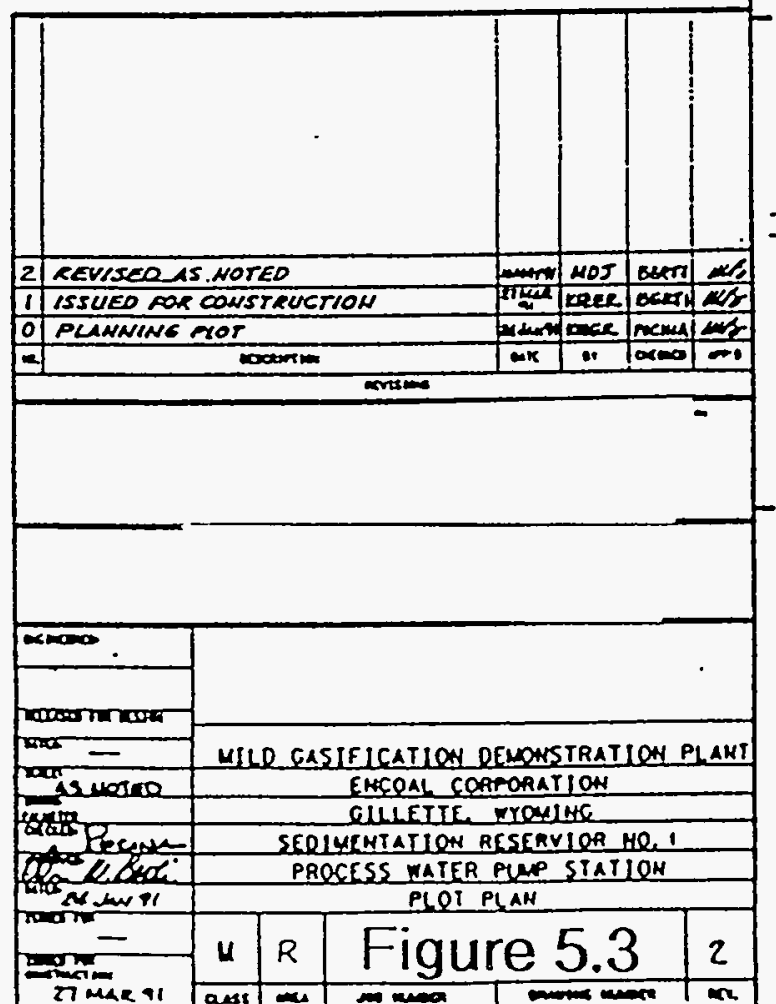




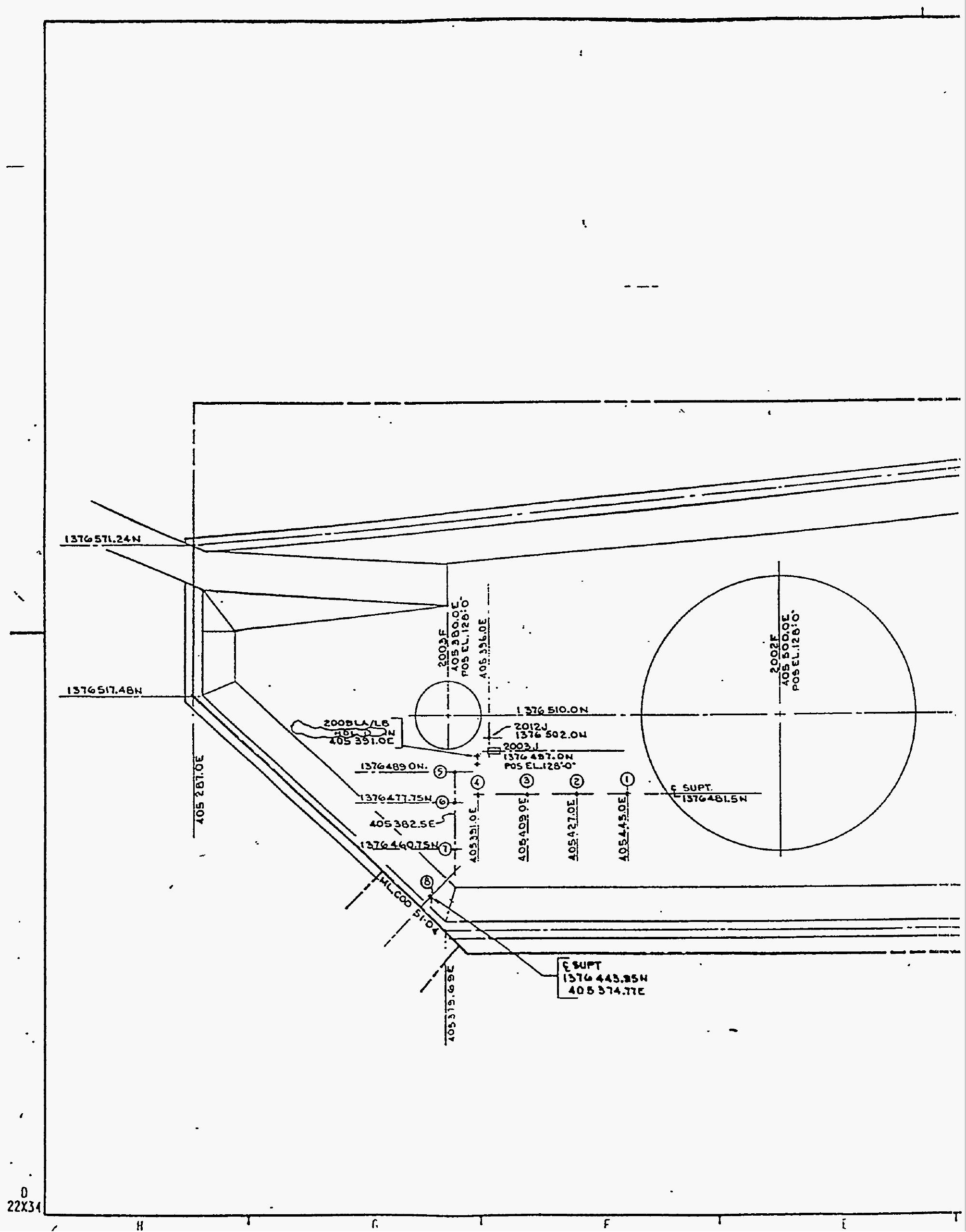




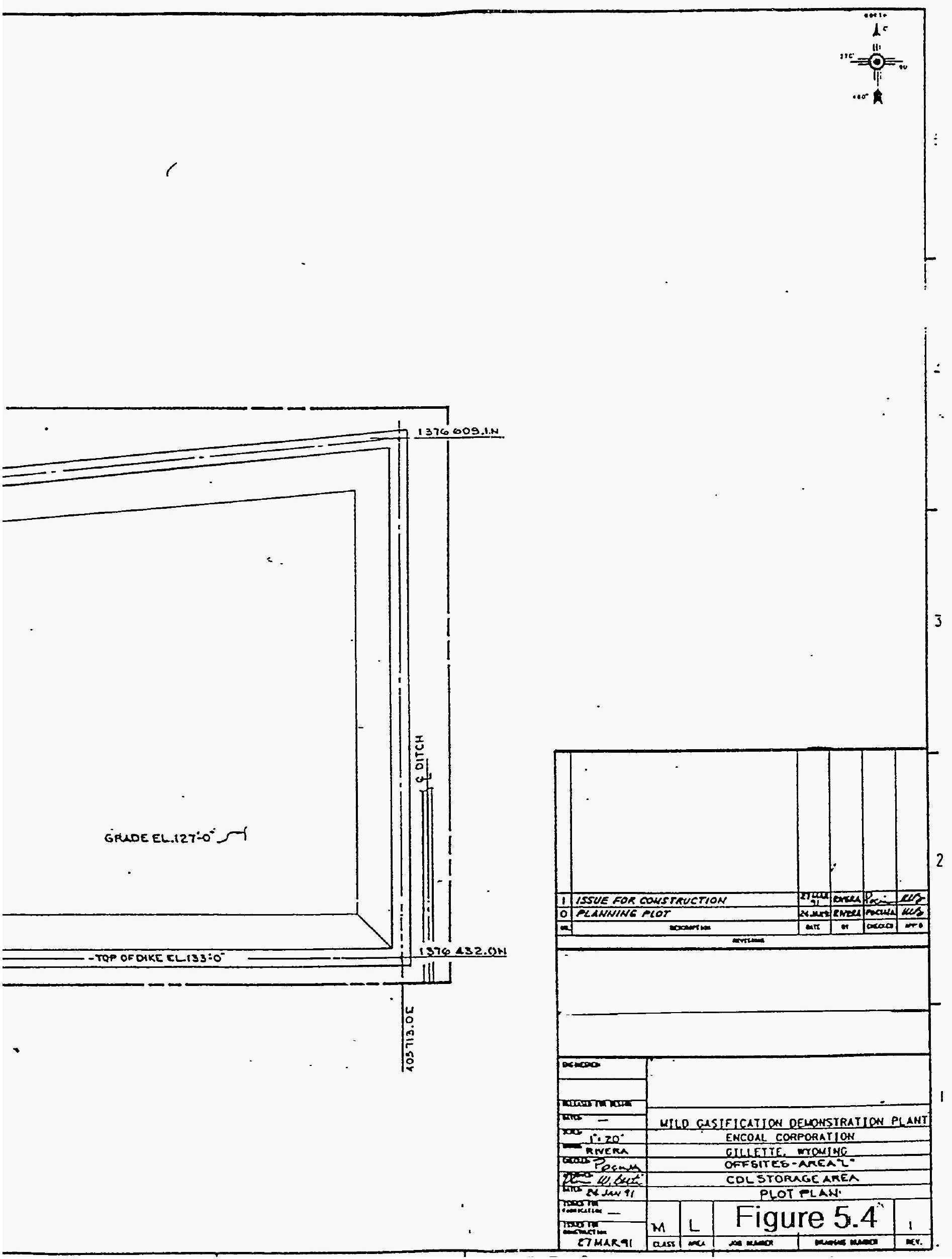


1
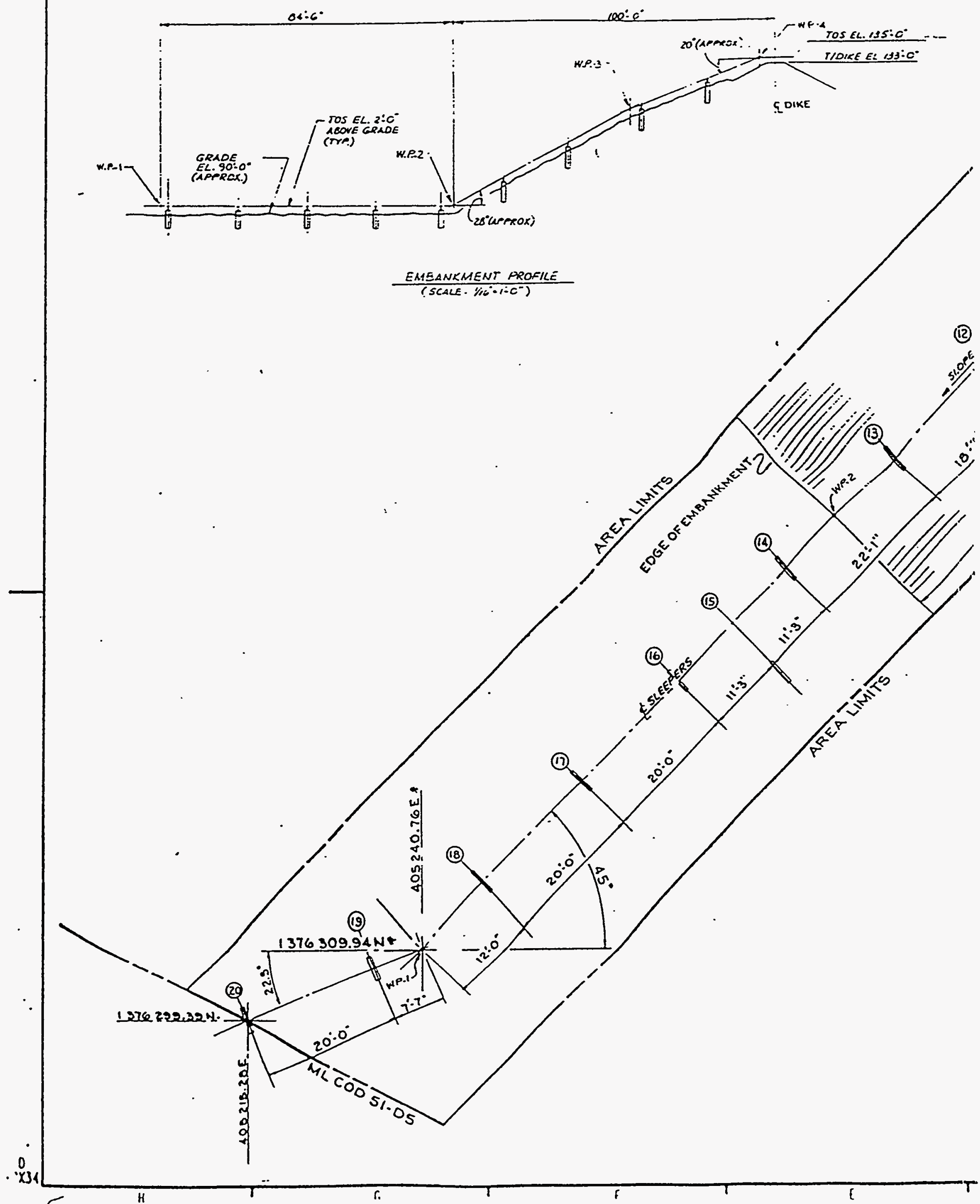


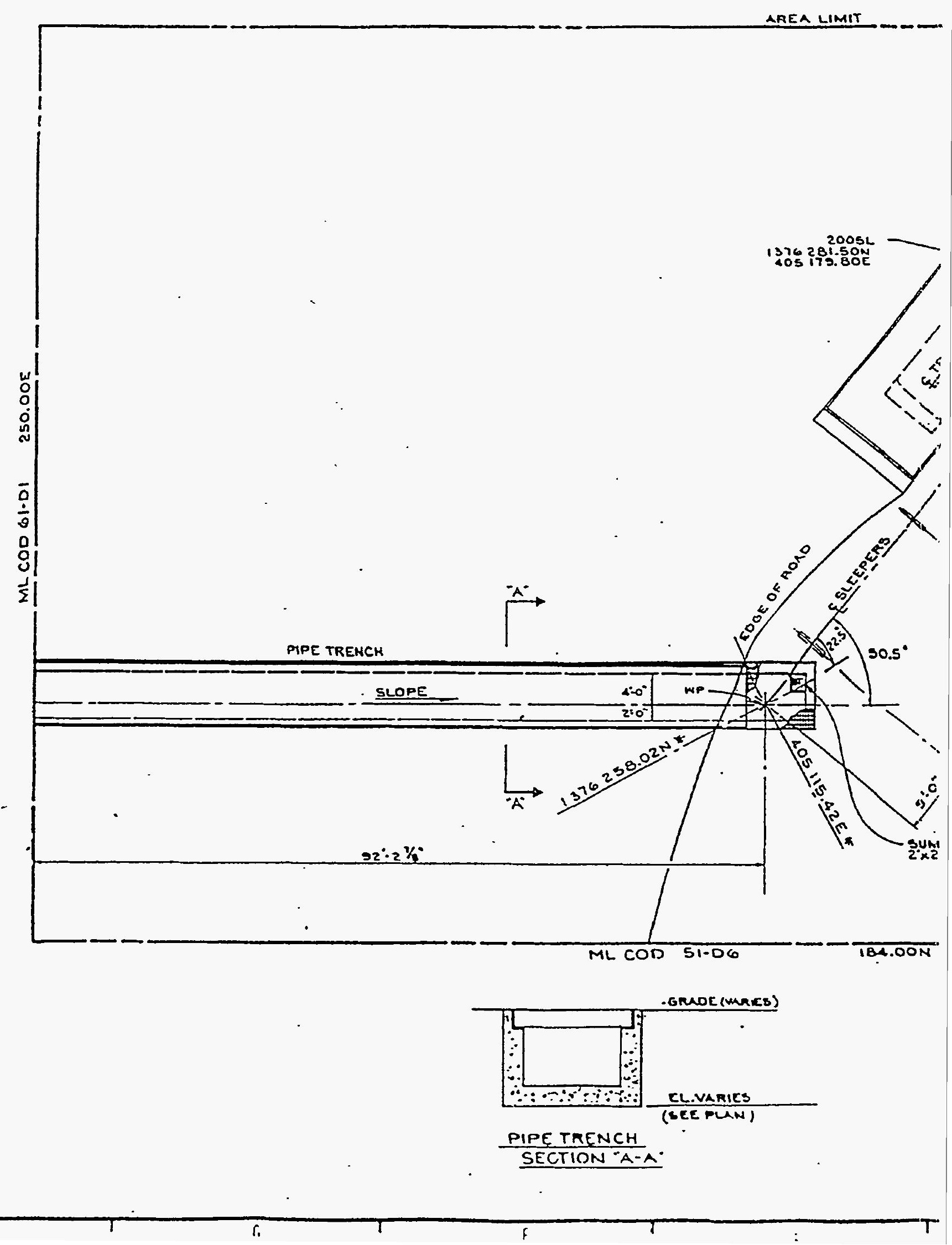




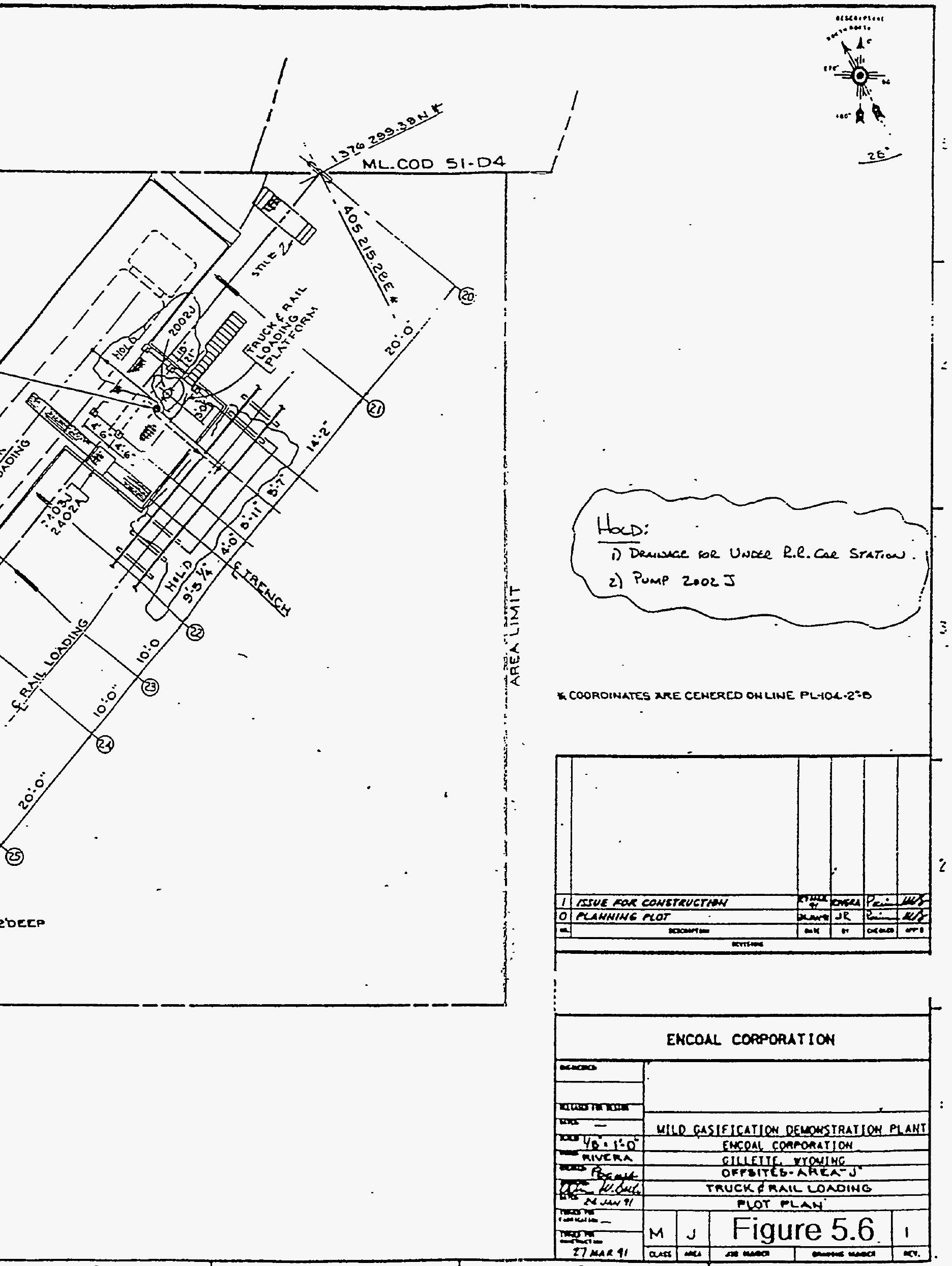




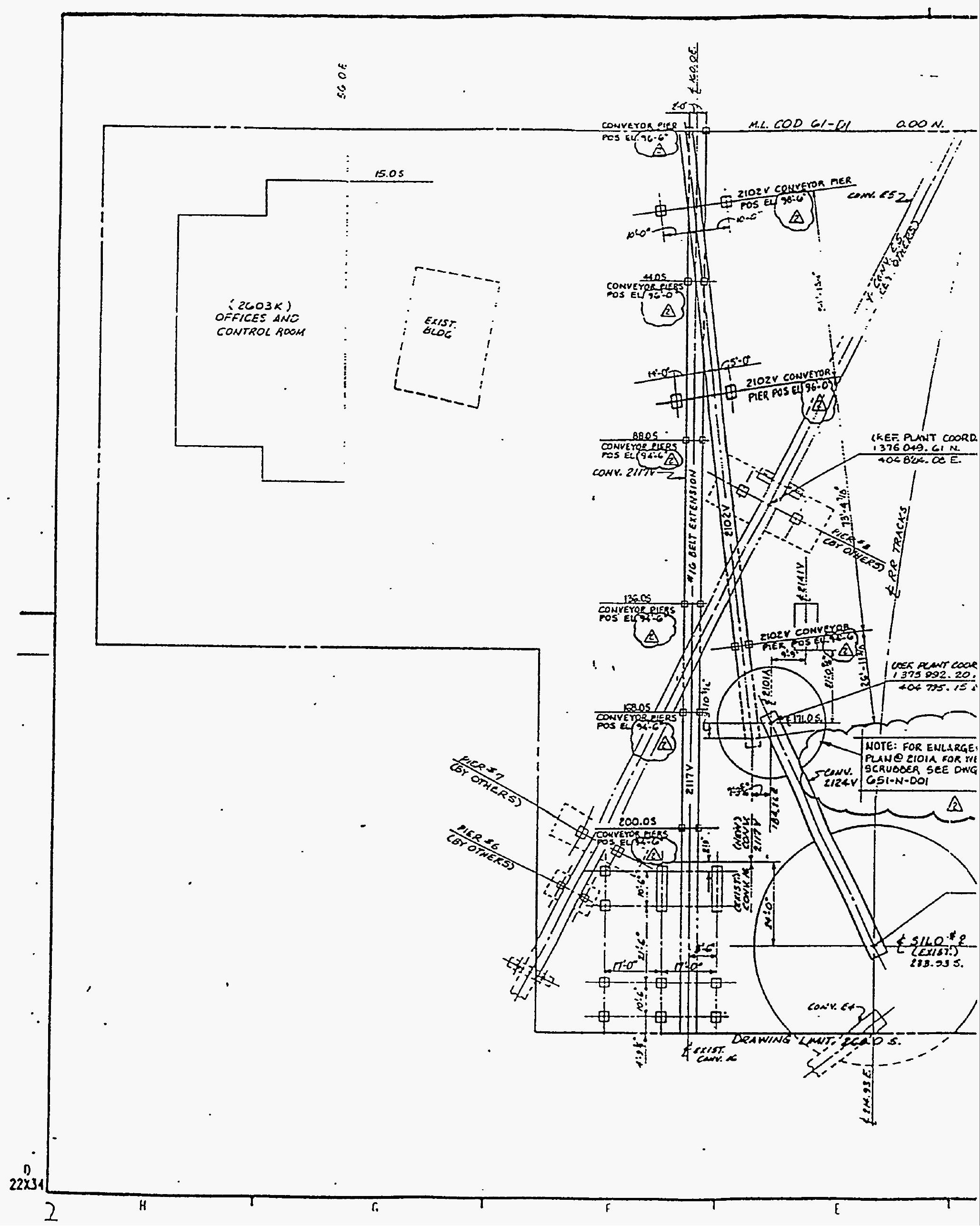




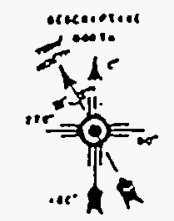

I

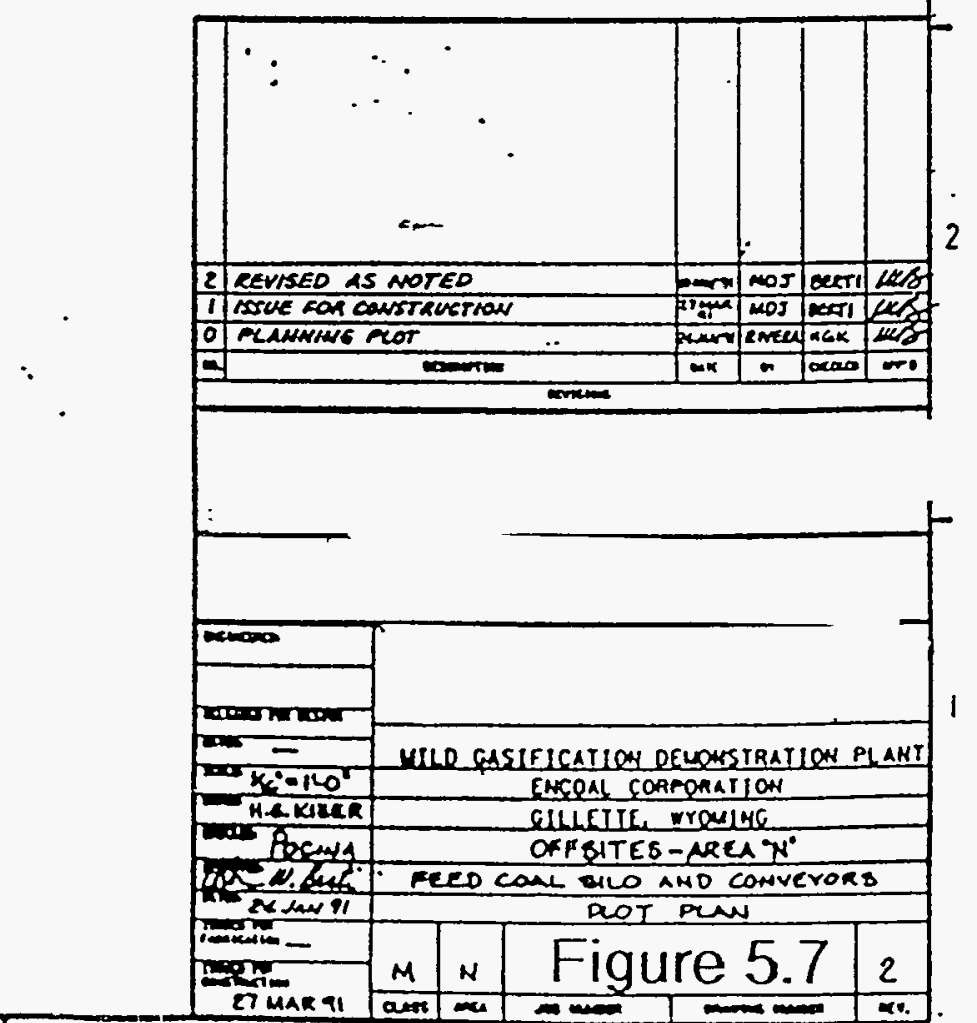


(6) Design all drainage structures for the 100 year, 24 hour event.

(7) Use bolted connections for all field erected joints with specially designed torque limiting bolts.

During the 1988 preliminary design studies by Kellogg, a conceptual layout of the PDF plant structure was developed. One of the first tasks for the Civil Engineering group after reactivating the project in 1990, was to re-evaluate and finalize the PDF plant structure. This was essential for design of the foundation, an early item on the Project Master Schedule for construction. Being an engineered structure, the steel had to be detailed and ordered early in the schedule also. The review of the PDF structure was completed expediently and resulted in significant reductions of floor space and steel. The revised planning drawings of the structures for the PDF building and screening building elevation views are shown in Figures 5.8 through 5.12. Figures 5.13 through 5.17 show the final floor plans for the PDF structure and screening building.

MSHA requires that a coal dryer be separated from other coal handling facilities by 100 feet or more or, if enclosed in a common building, the dryer must be separated by walls that will prevent a deflagration from entering other parts of the building. Special venting requirements also affect the dryer off-gas ductwork and cyclone inlet and outlet ductwork. Here, explosion doors are required for pressure relief and a process gas relief valve is required for both pressure relief and over-temperature of the dryer loop. ENCOAL chose to keep all PDF facilities in one building and thus zoned the building to meet the MSHA requirements. Zone 1 was unclassified and included the plant building up to the underside of the $6^{\text {th }}$ floor. Zone 2 was the designation for the $6^{\text {th }}$ through $9^{\text {th }}$ floors which contained the dryer. The headhouse at the top of the plant where coal enters was classified electrically and so became Zone 3 , which had to be pressurized and sealed mechanically from both Zones 1 and 2. The previous figures show the floor layouts in each of these zones.

\subsection{MECHANICAL DESIGN}

Pressure vessels, valves, piping, tanks and rotating equipment fall under the category of mechanical design. For the ENCOAL facility, with its near atmospheric conditions, pressure was not a major problem. Other than utilities and fluid pumping systems, all pressures in the LFC process are measured in inches of water, both positive and negative. The main process vessels were specified for two pounds of pressure and one pound vacuum. Consequently, none of the process vessels were specified to be ASME Code stamped since this does not apply at these low pressures. However, it was specified that all vessels would be built in accordance with ASME code requirements. The exceptions to this standard were the utility boiler and the liquid nitrogen storage equipment which required full ASME Code certification.

It was recognized from the outset that the PDF plant would go through a lot of start-up and shutdown cycles. Elevated temperatures dictated that provisions be made for expansion and contraction, so spring cans and expansion joints were incorporated into support for vessels, large diameter piping (ductwork) and certain equipment. Piping larger than $30^{\prime \prime}$ was isometrically detailed by Kellogg's design group and furnished prefabricated to the field erection contractor. All of this large diameter pipe and ductwork was custom built from plate. Smaller diameter piping was specified to American Petroleum Institute (API) or American National Steel Institute 


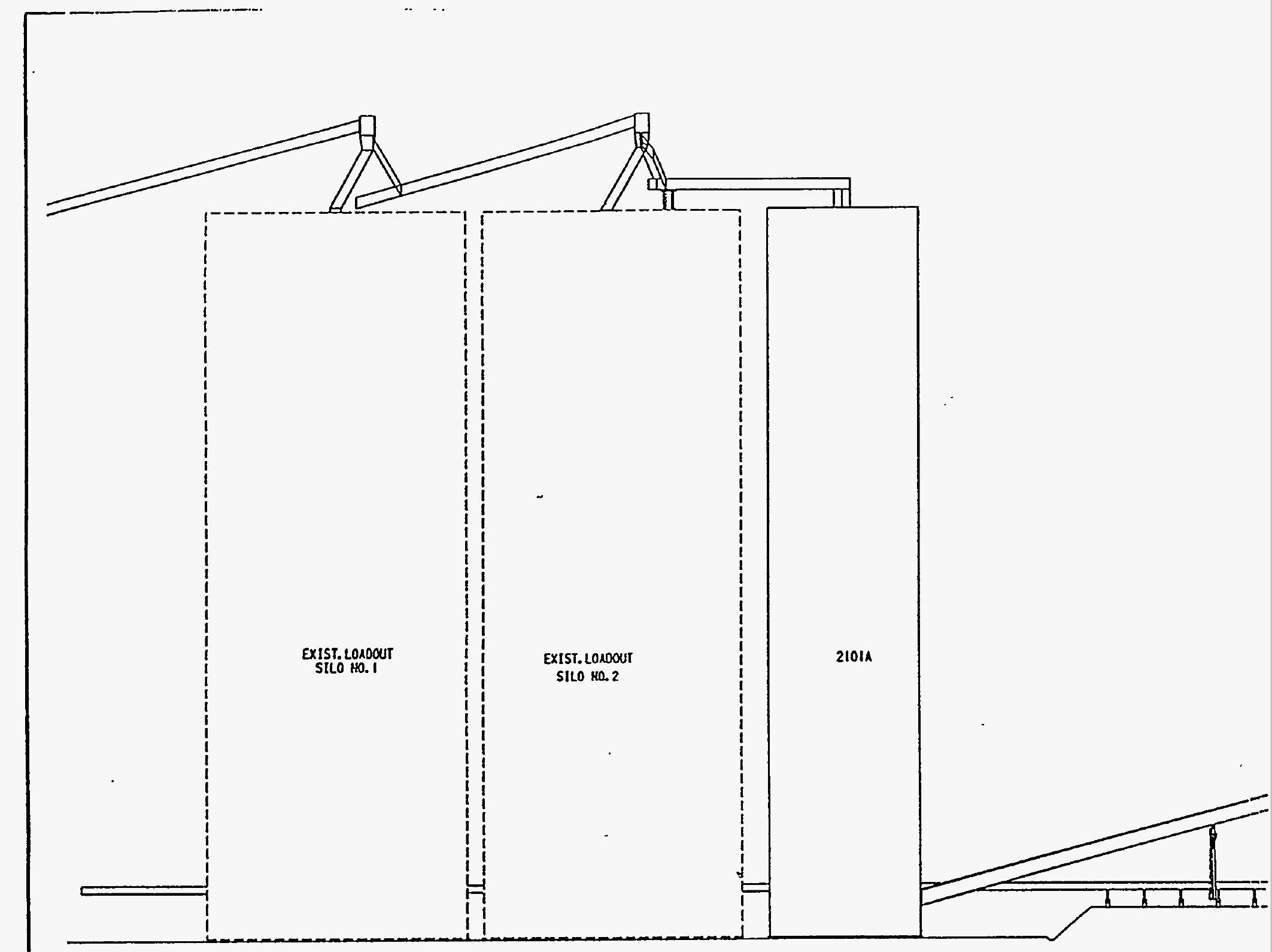




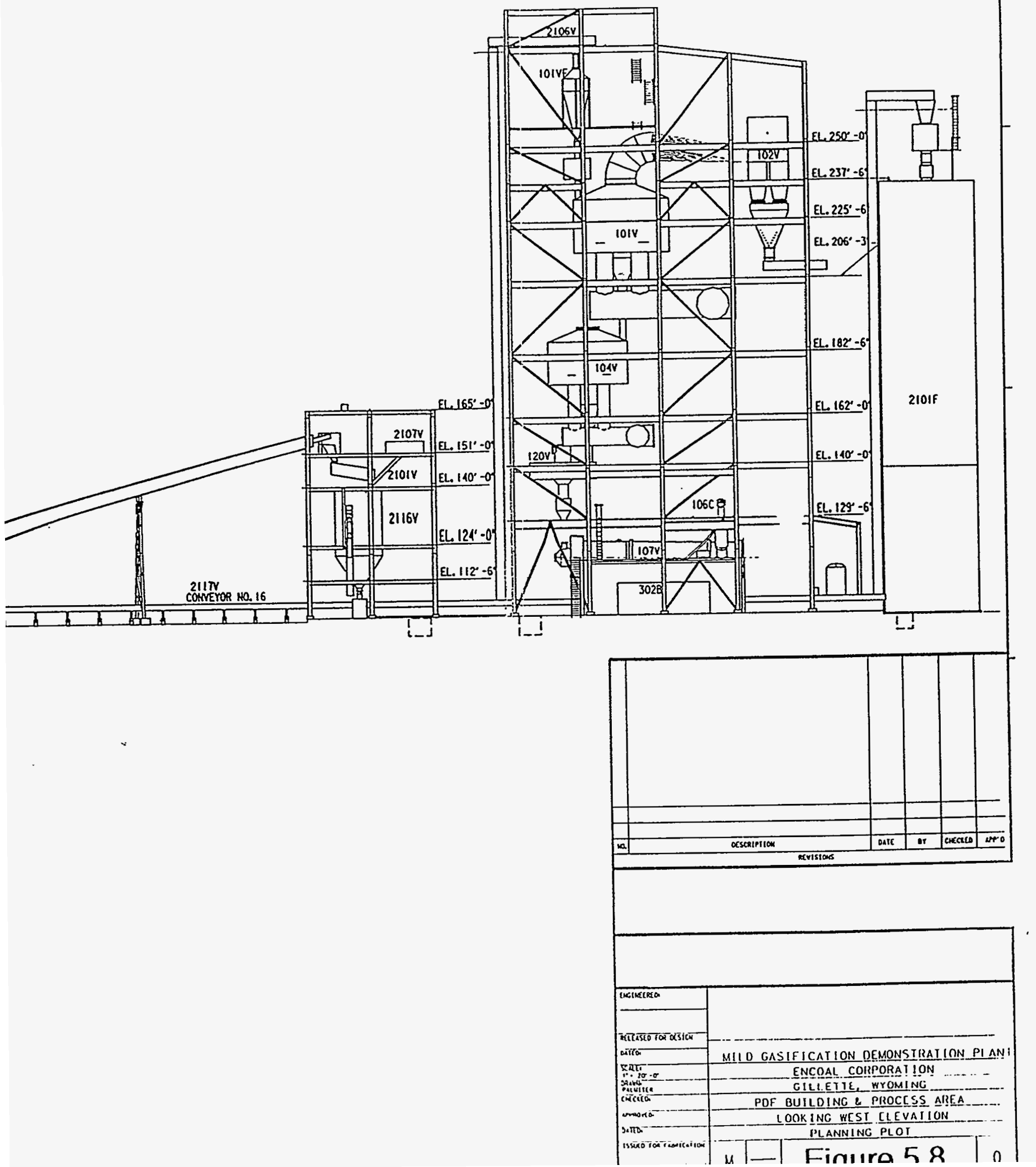




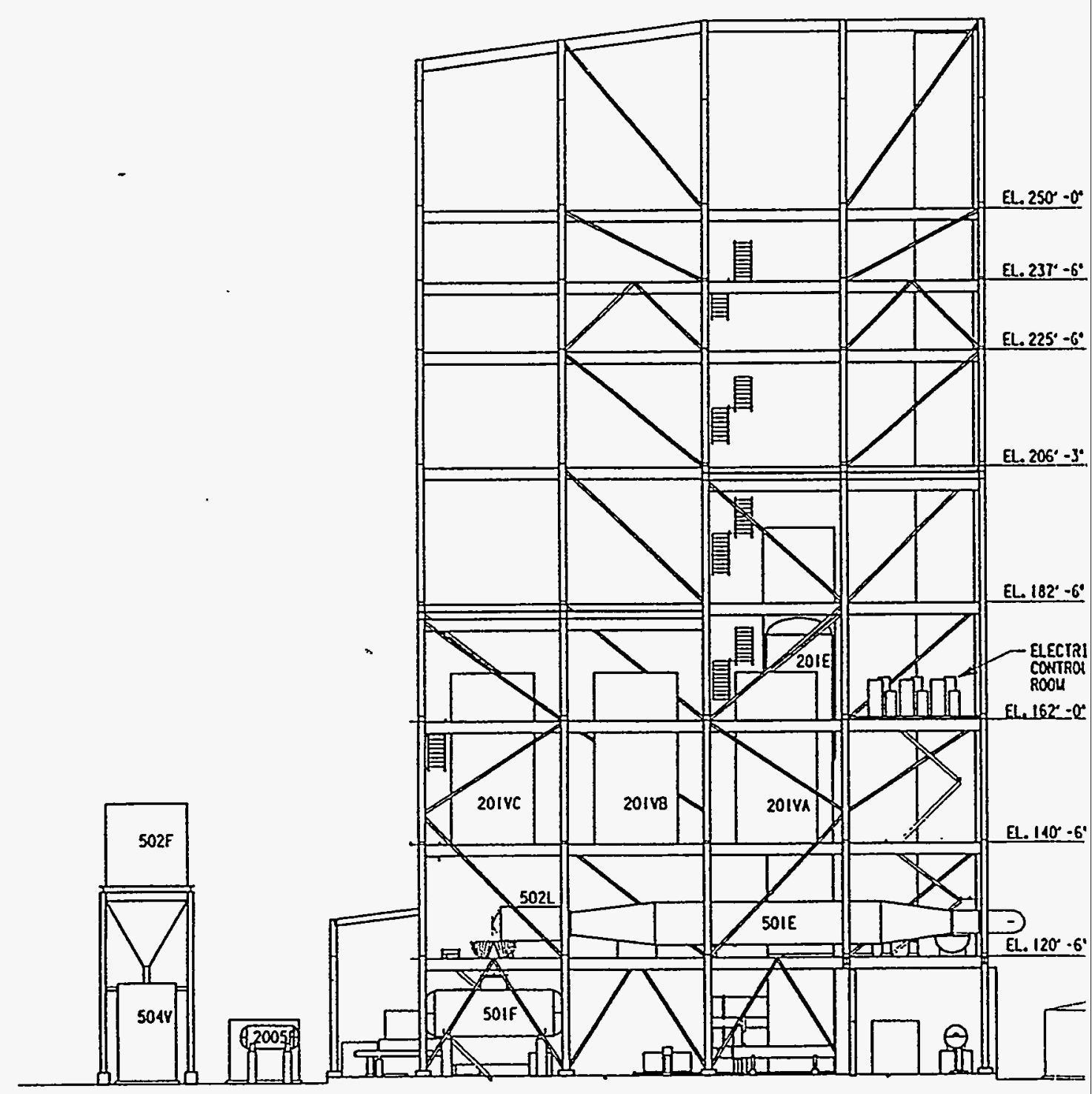



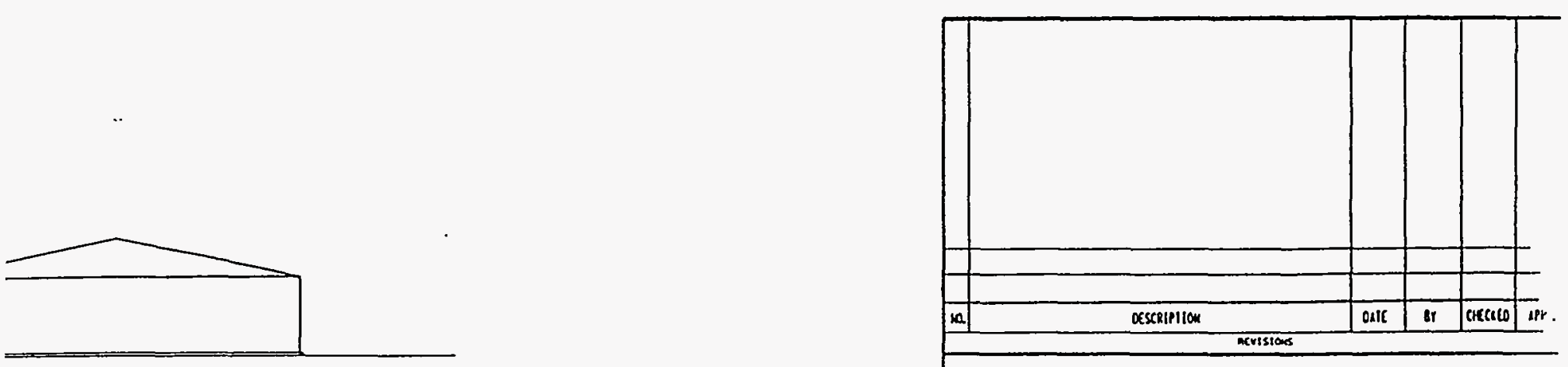

U

ENCOAL CORPORATION

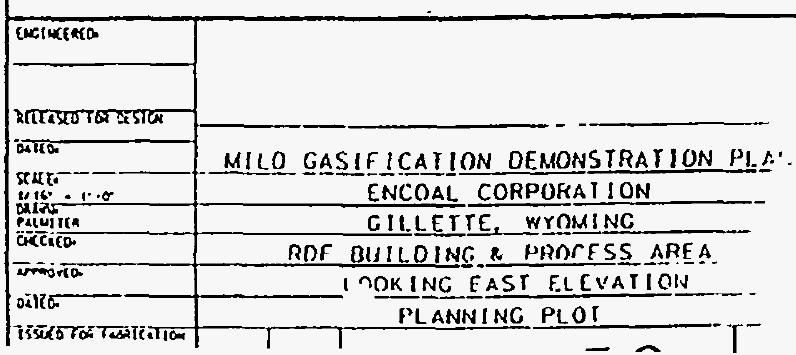




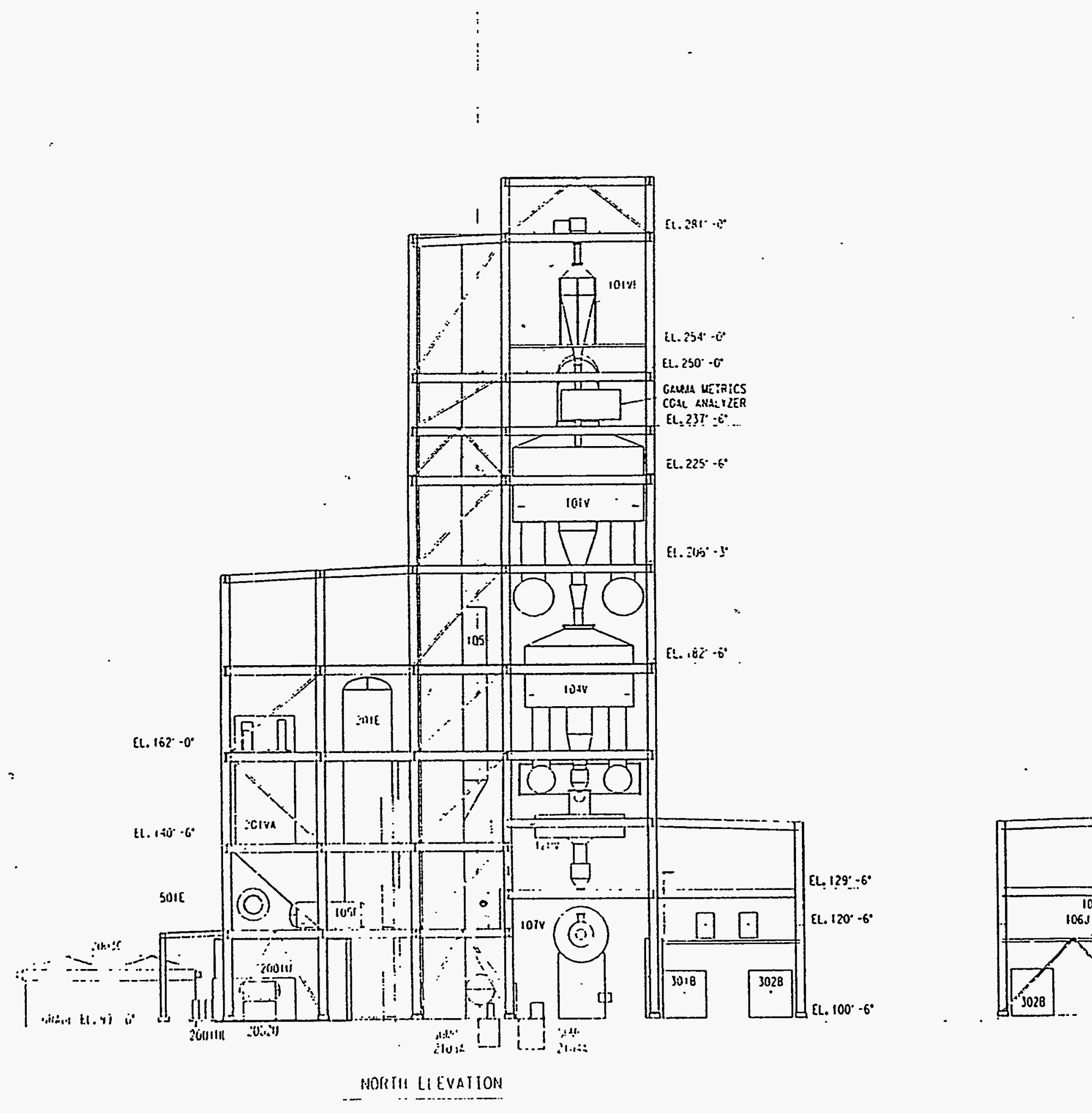




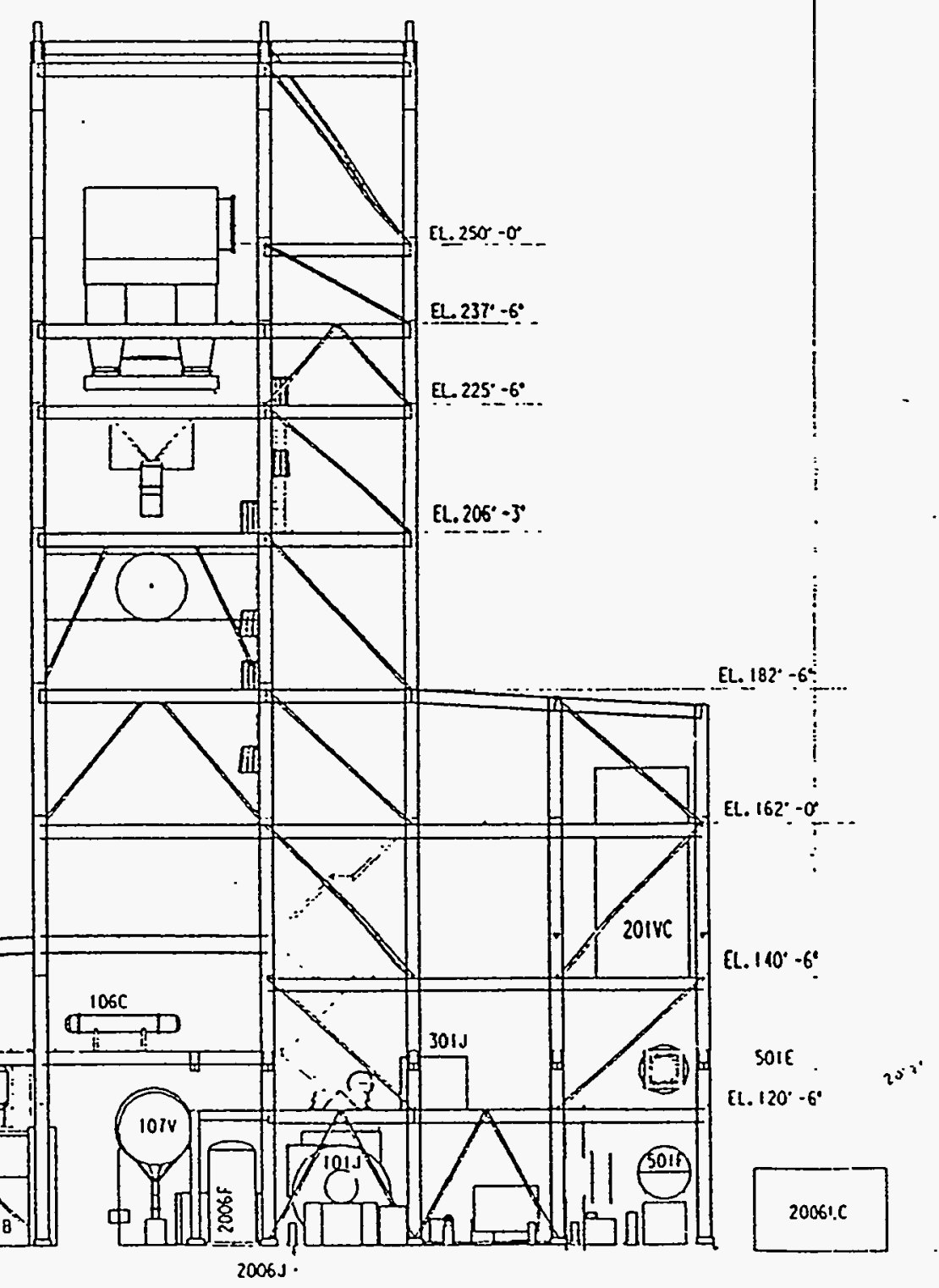

PAGE $20 \& 21$

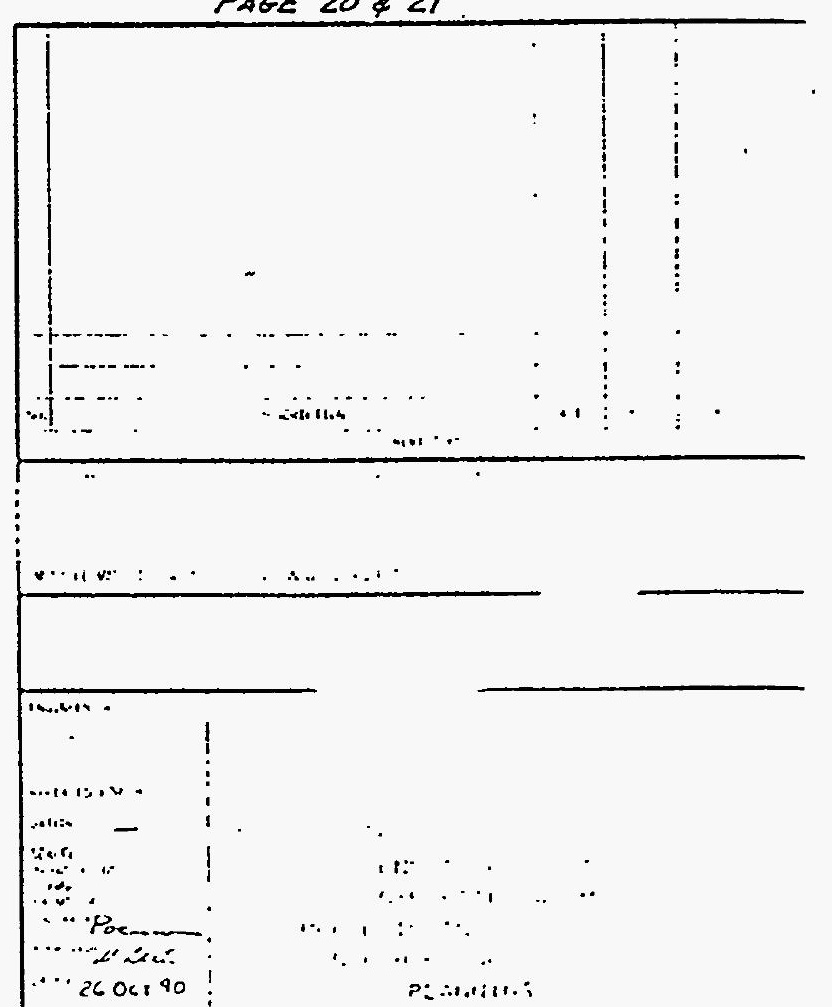




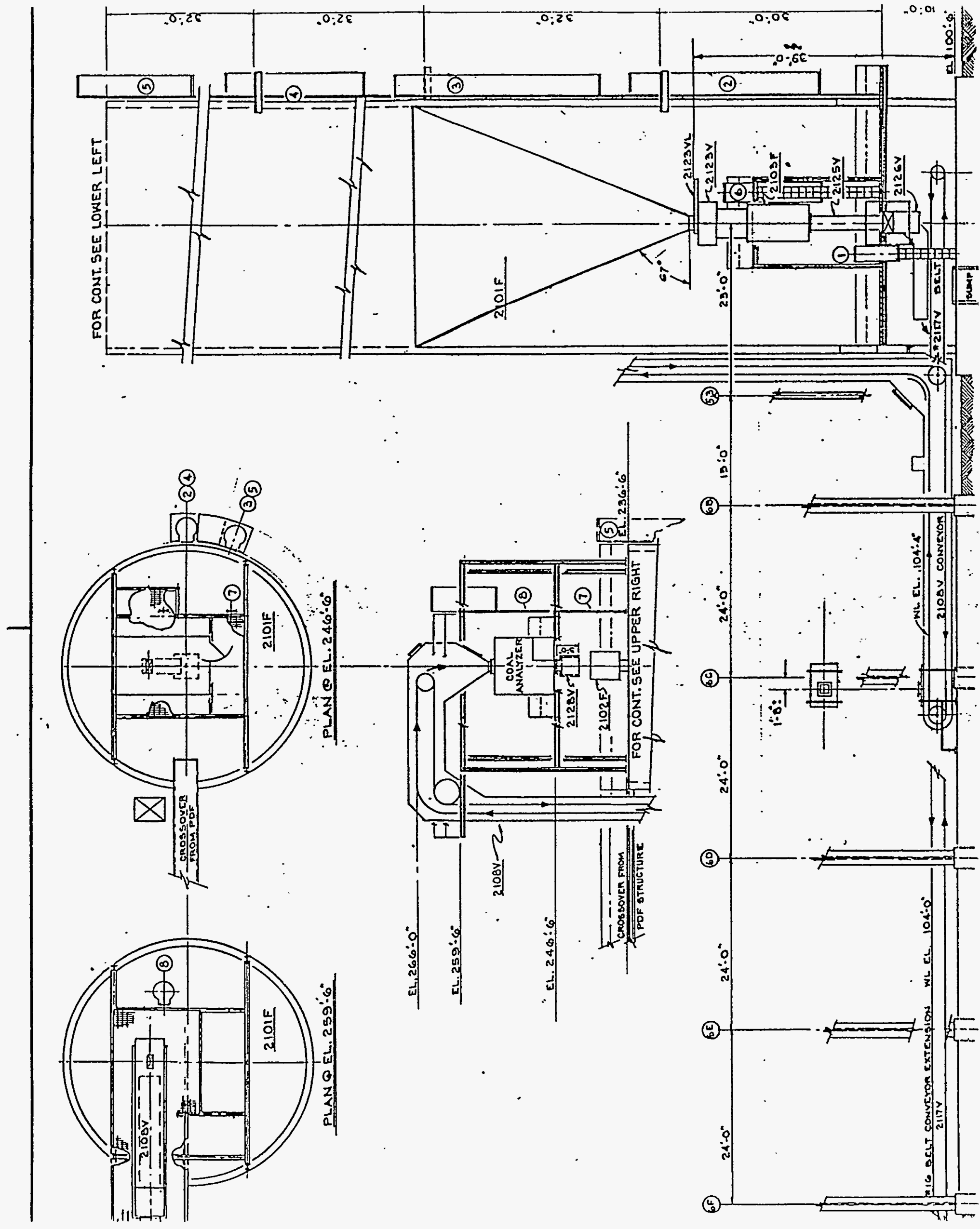




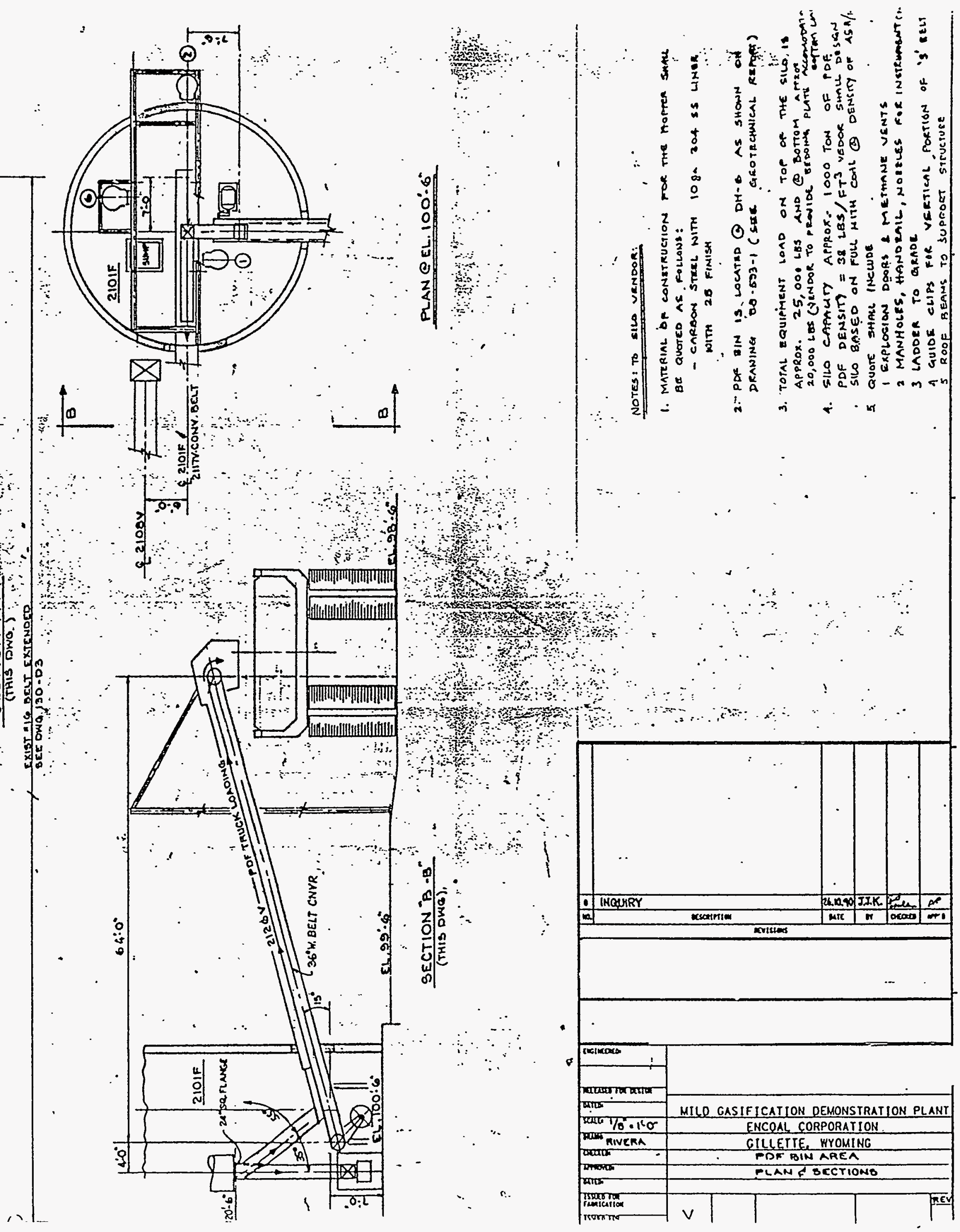




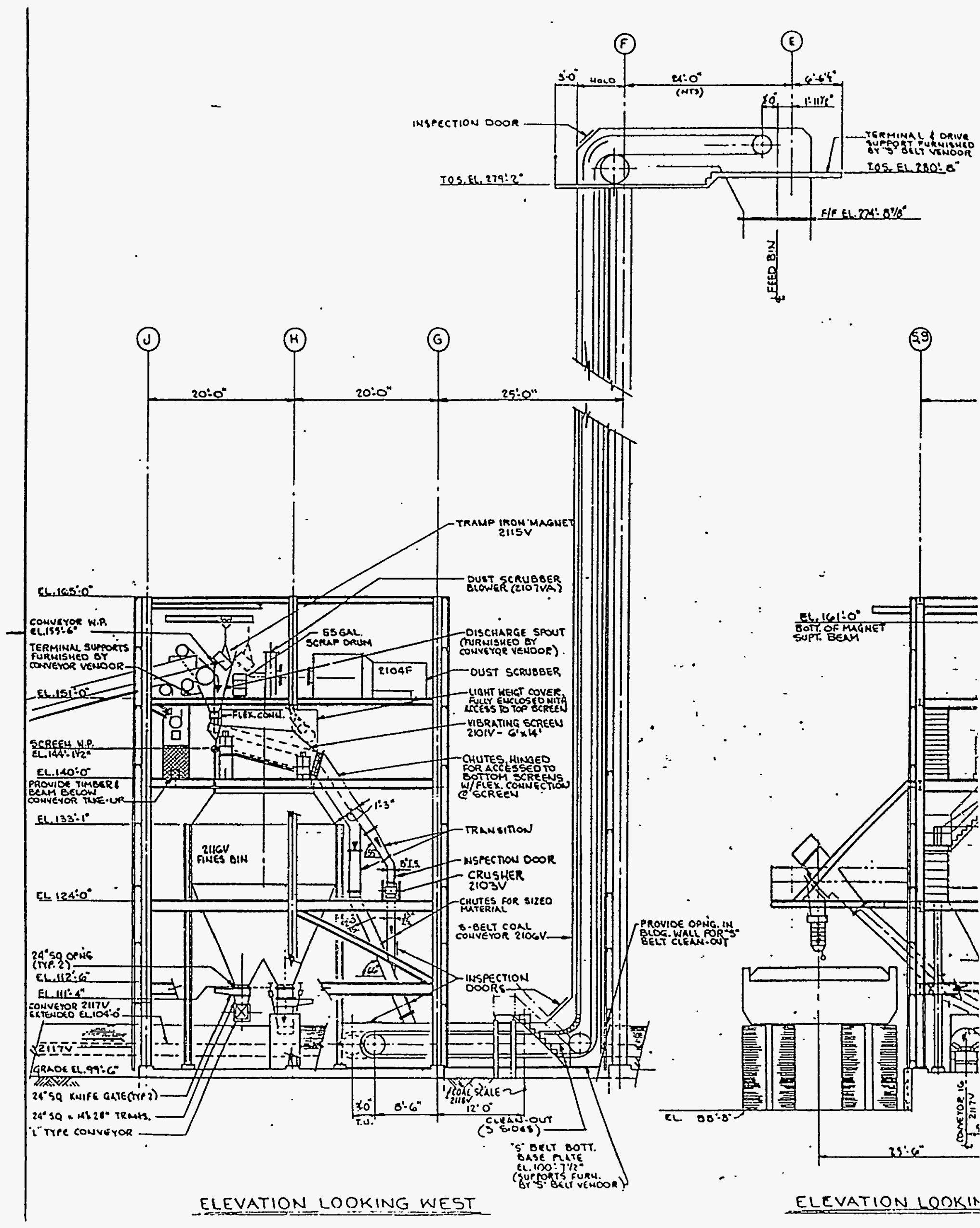




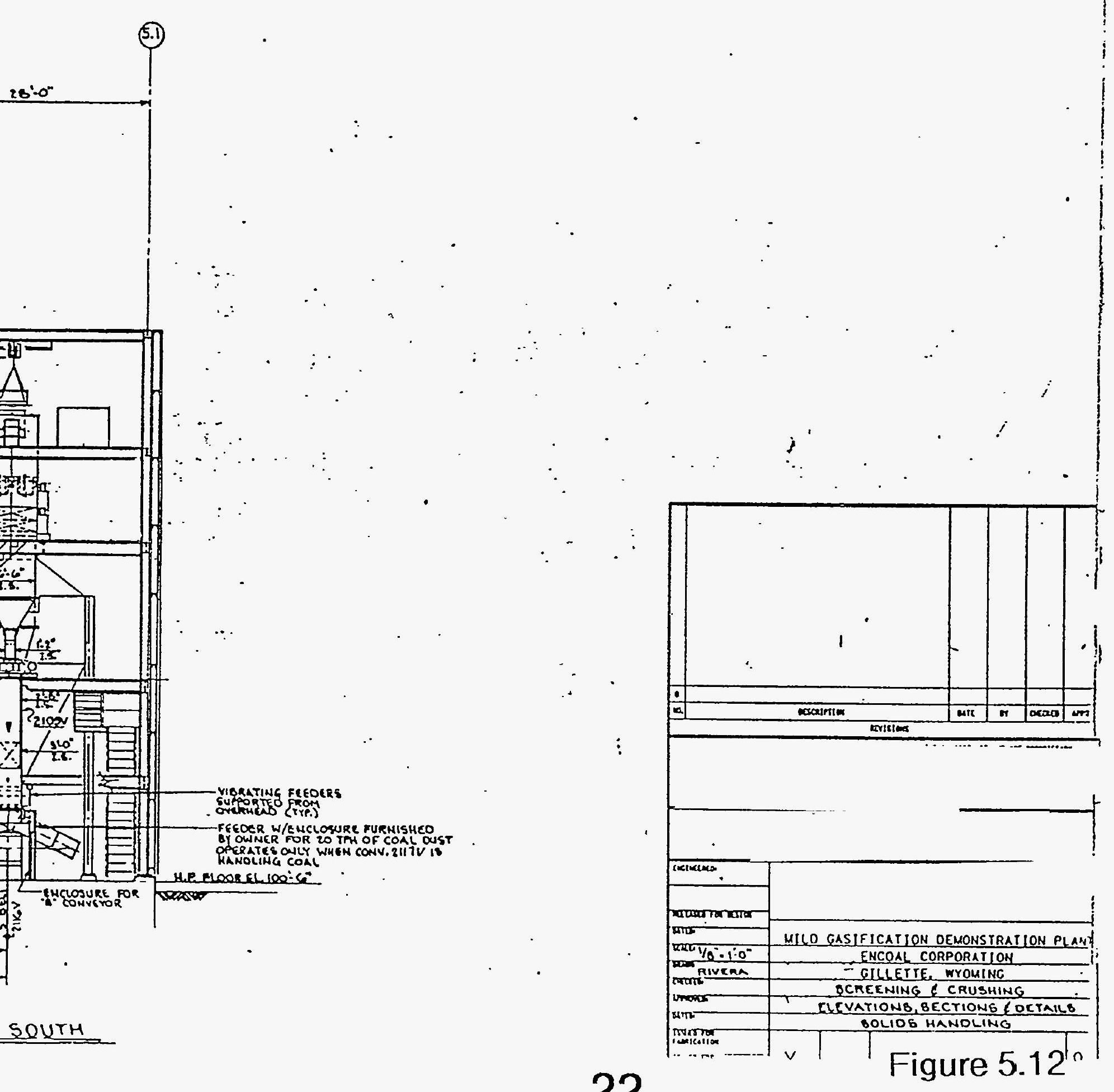


Sising

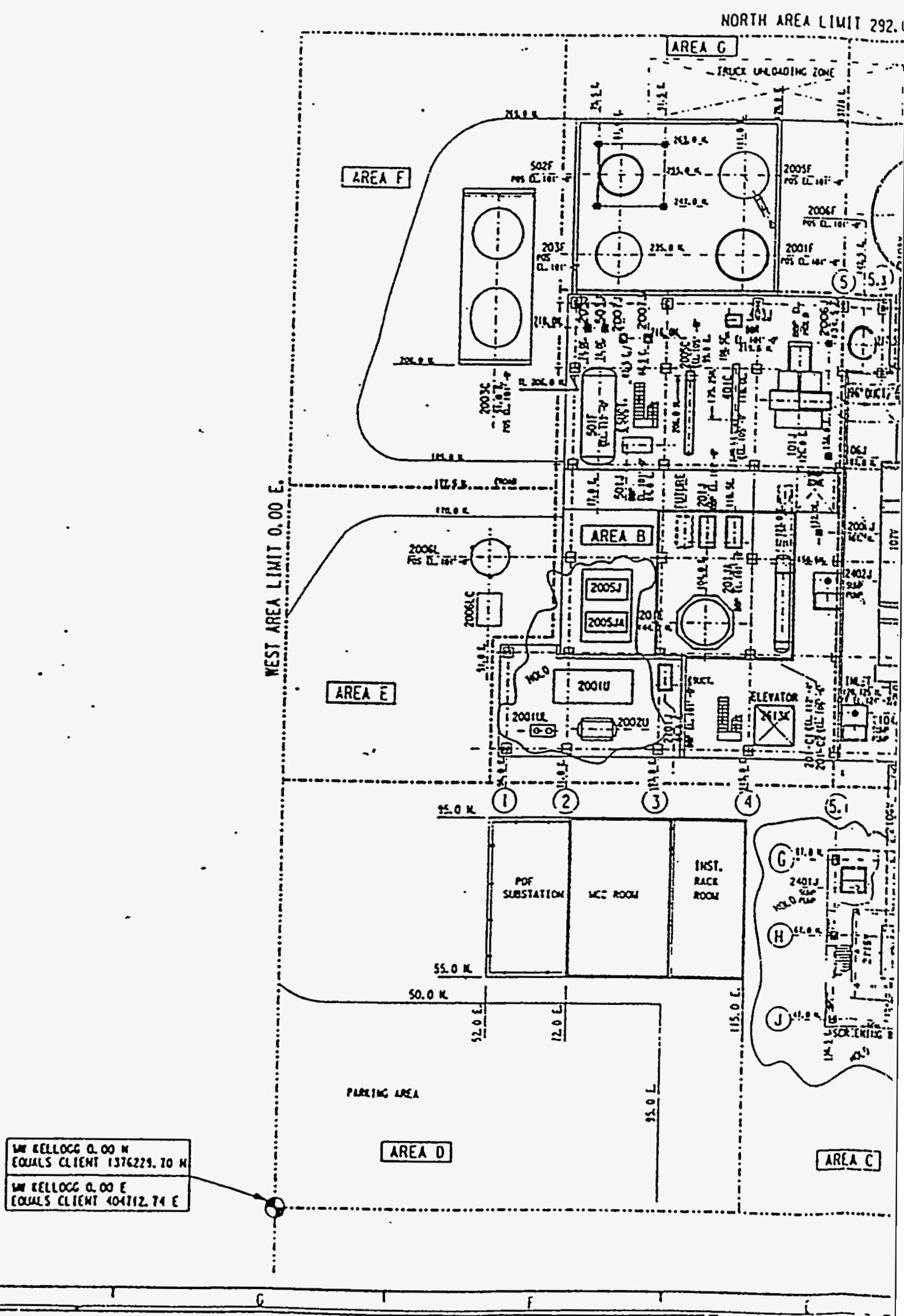




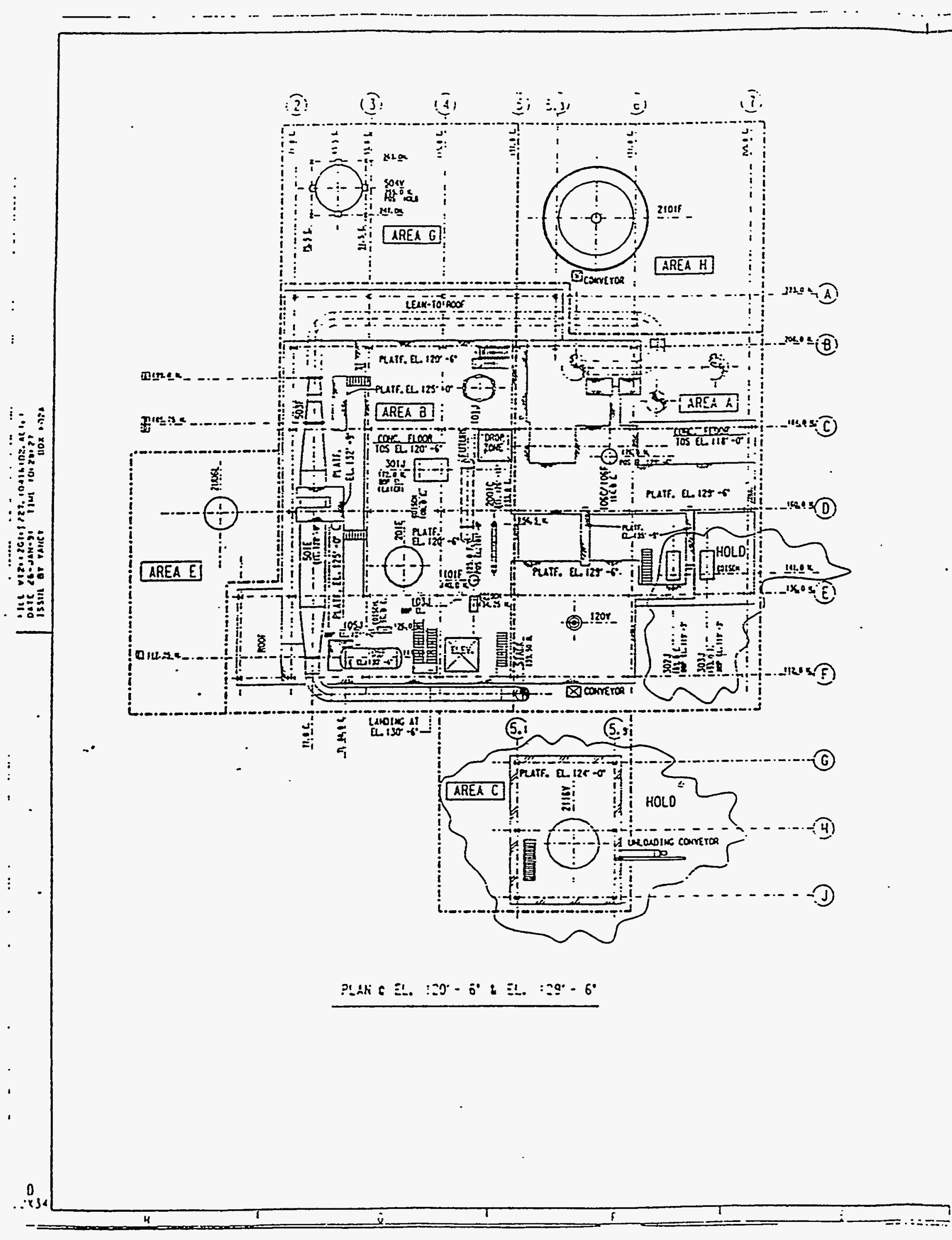




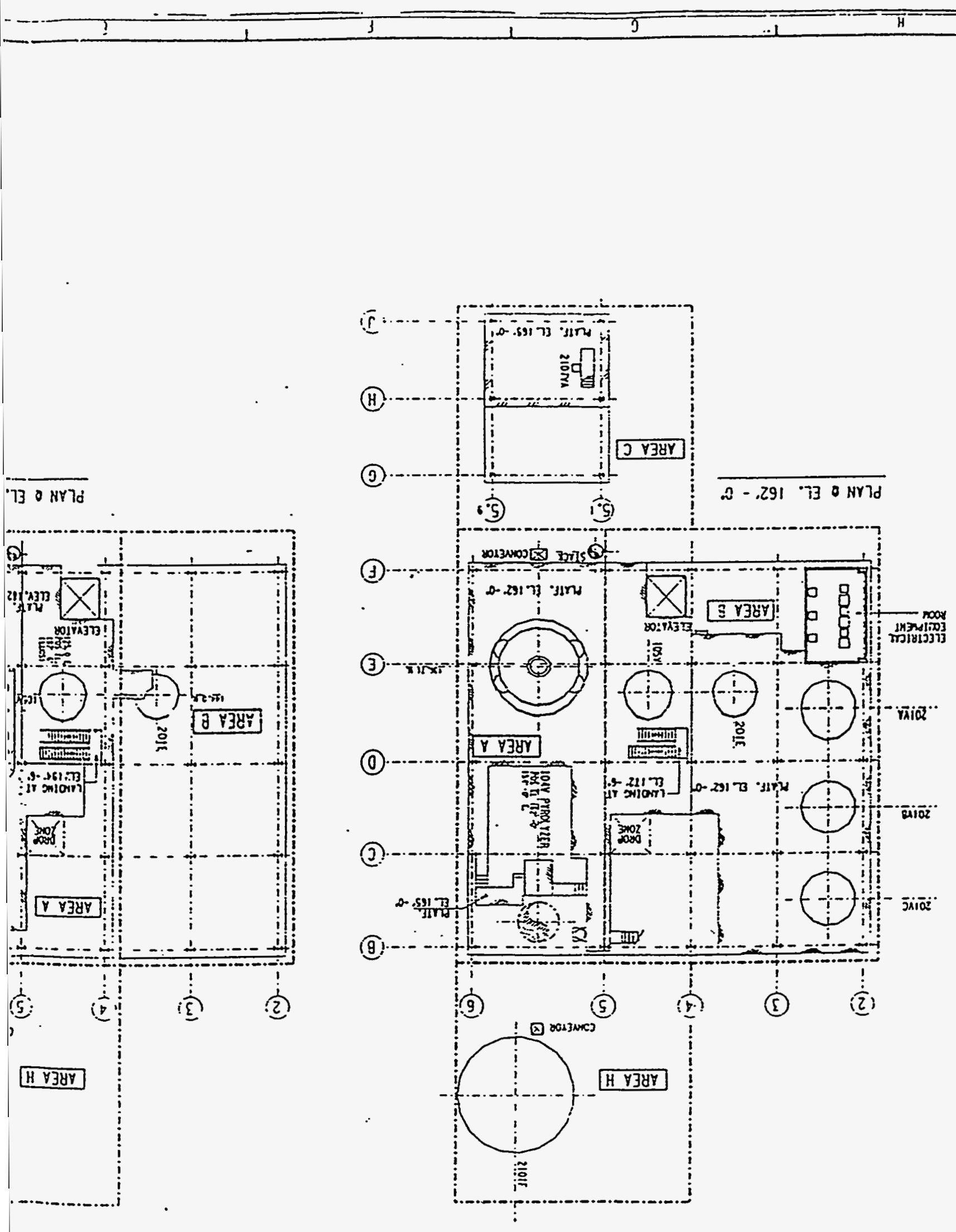



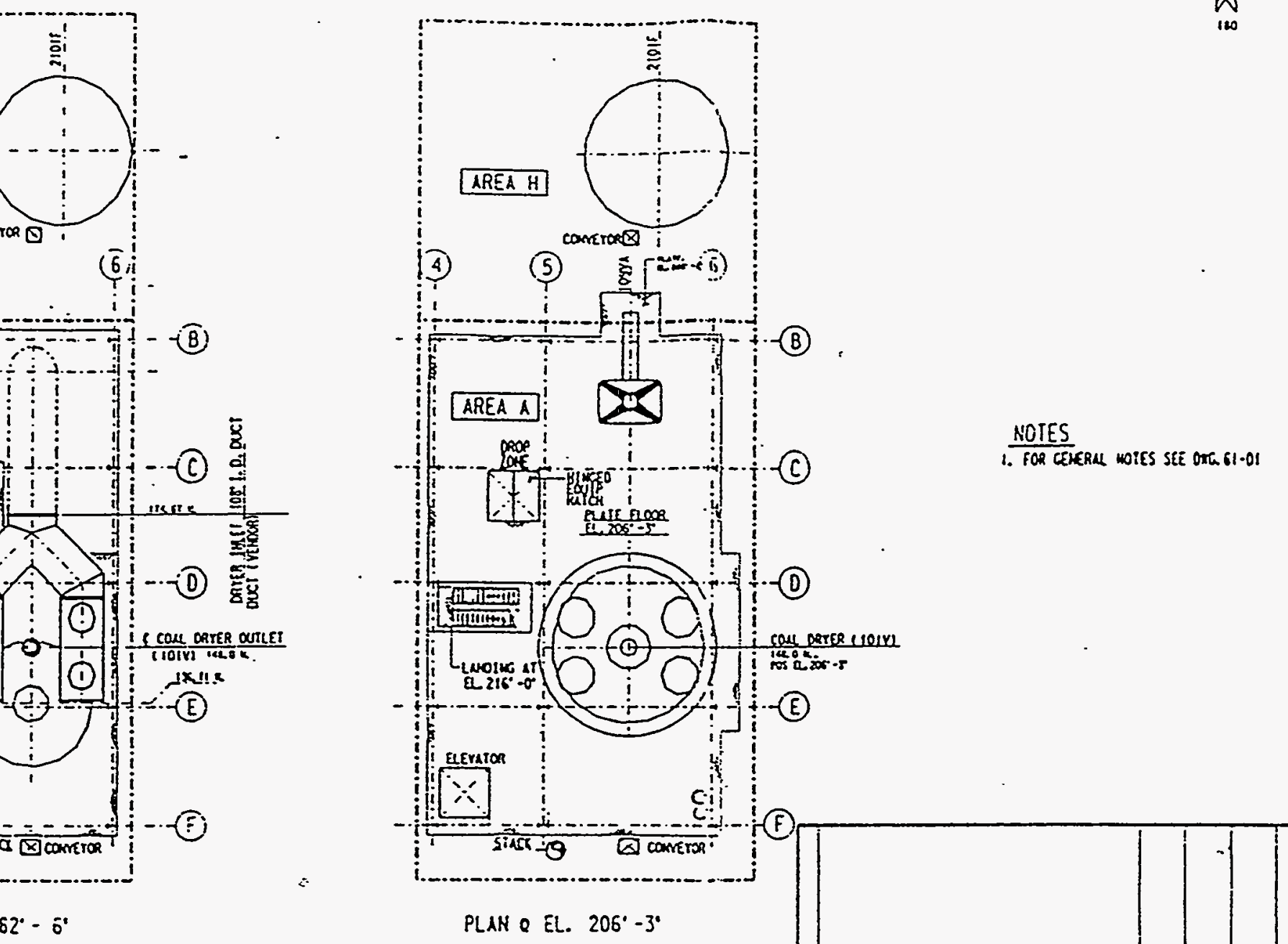

osscatplive

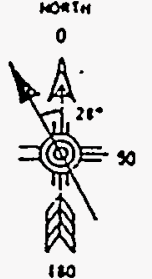

AREA H

(4)

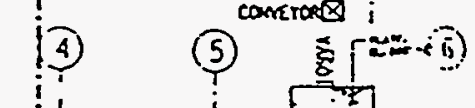

i.

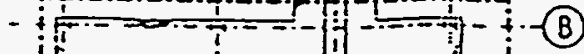

B).

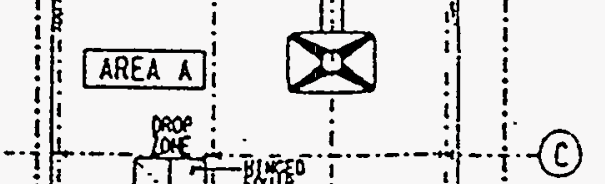

NOTES

(C)

1. FOR CEHERLL WOTES SEE OTLE1-OI

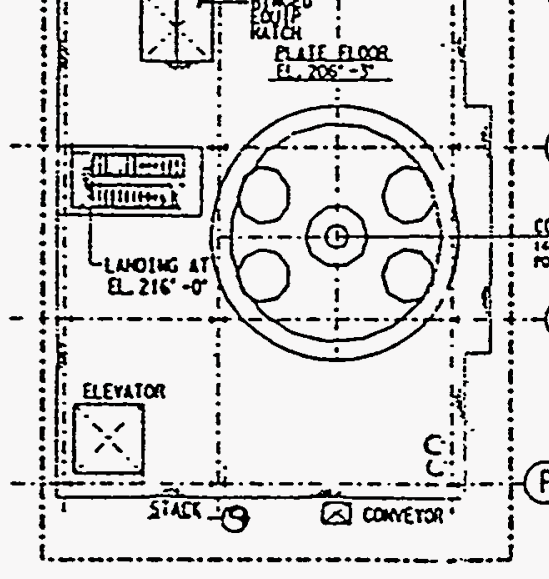

PLAN Q El. $206^{\circ}-3^{\circ}$

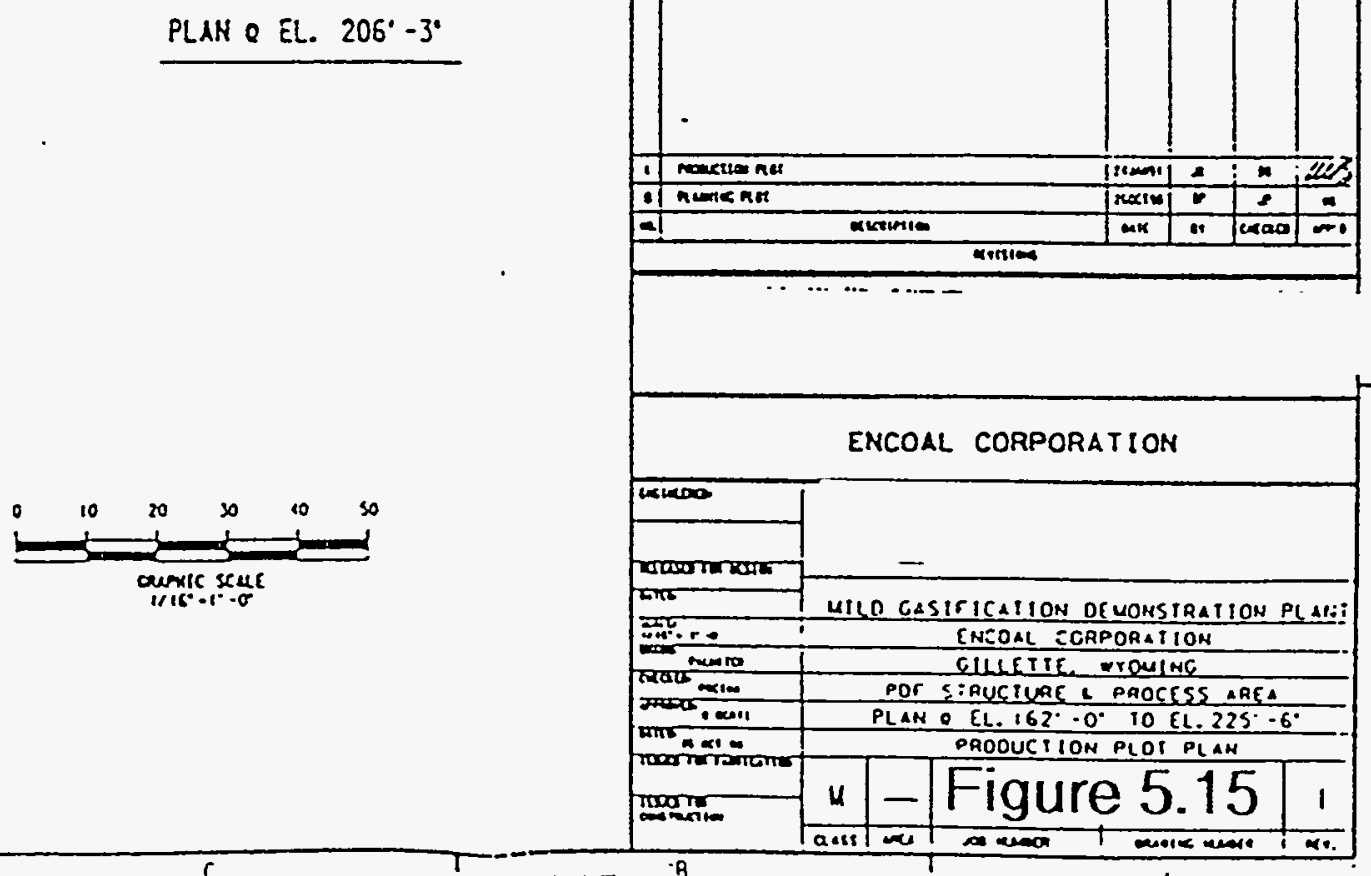




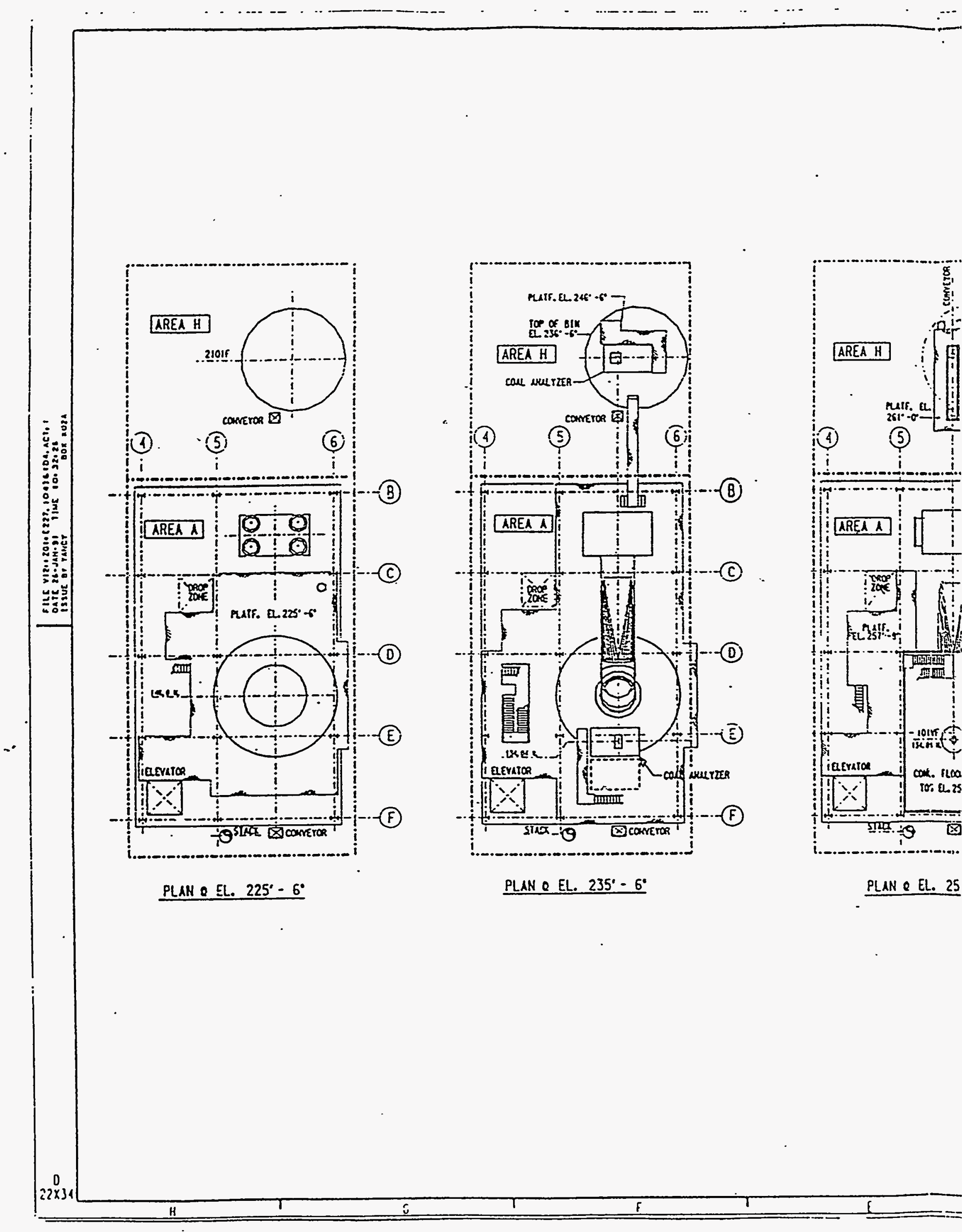




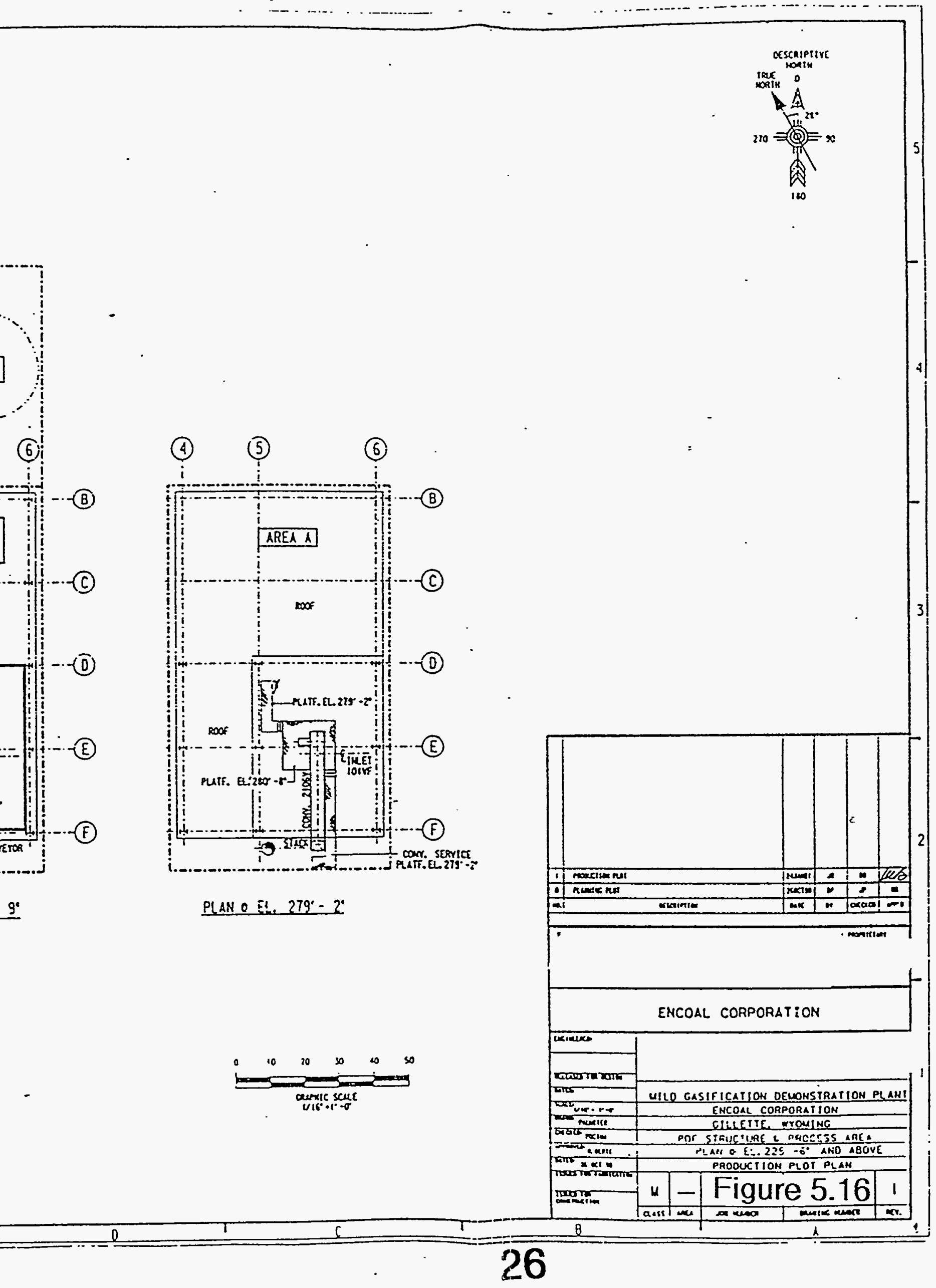




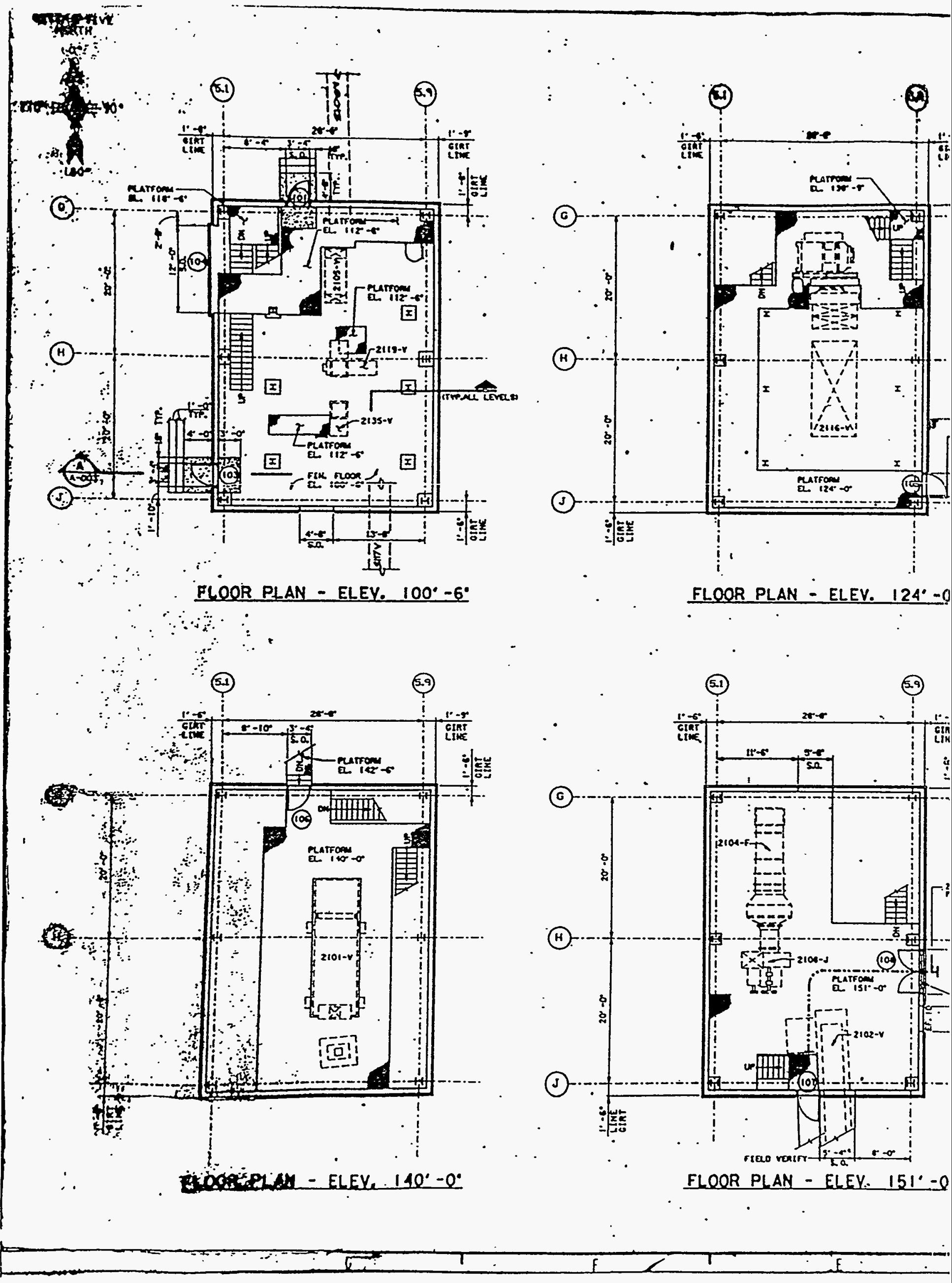


GENERAL NOTES:

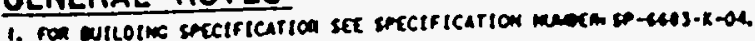

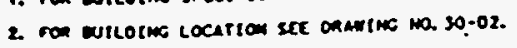

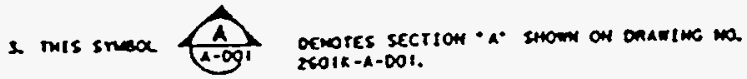

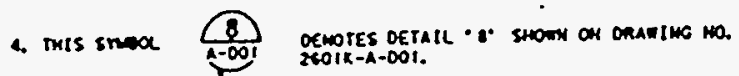

5. $\infty$ wor seace trefe oradiucs. initren otwors lows are to ee rolomed.

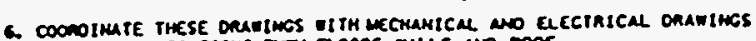
for unt renethations thind rioons, walls wo moor.

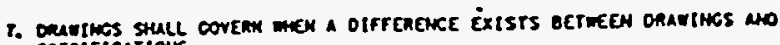
sectiftcations.

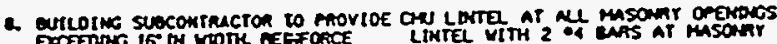

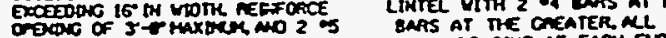

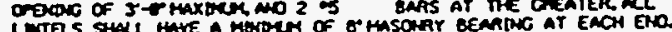

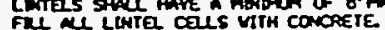

2LEDo uberevititions

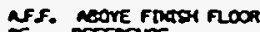

nei norgence

Mo. EOAL

OU CONORETE MASONAT UNTS

HU. HOCON HETK

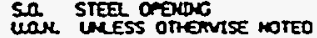

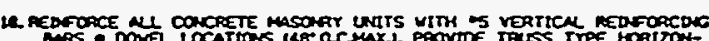

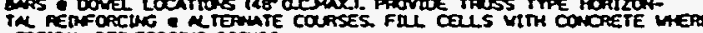
FETPCA REDFORC ON DOARS.

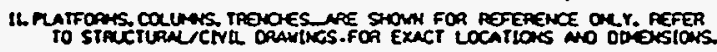

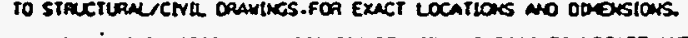

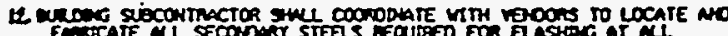

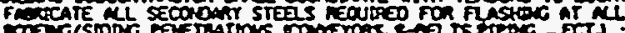

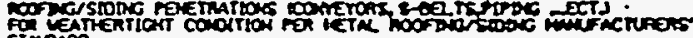
stmonen.
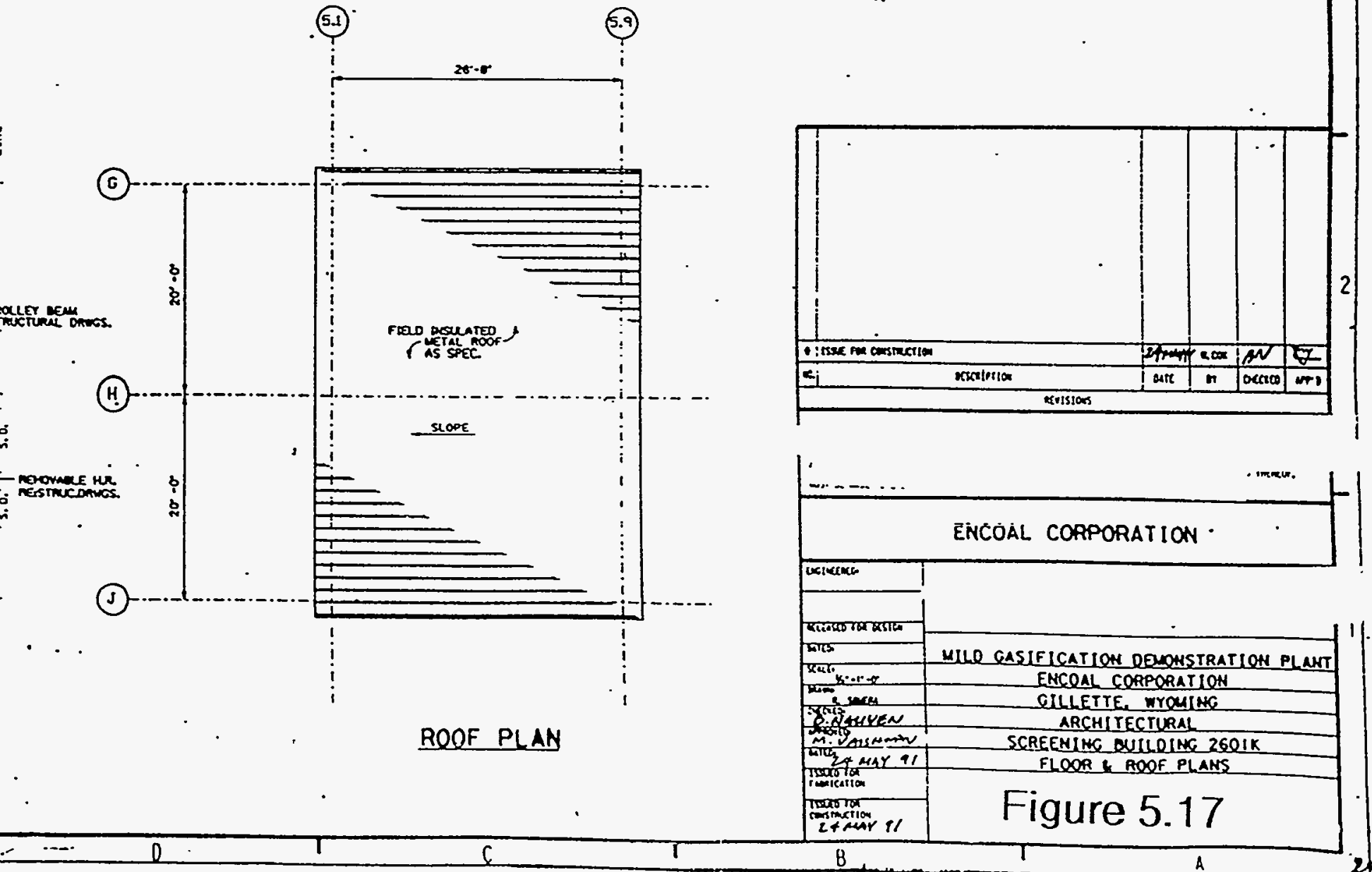
(ANSI) standards. Piping smaller than $3^{\text {n }}$ was furnished by the erection contractor and was field routed. All valves were supplied by Kellogg using their Vendor Quality Management approach where the design is done jointly with the vendor representatives in Kellogg's engineering office.

The presence of high temperatures and dusty, corrosive fluids in much of the gas and liquid piping was a given. Carbon steel was selected as the base material for all piping systems, with refractory lining systems for temperatures over $600^{\circ} \mathrm{F}$. A protective coating between the refractory and steel was applied. Over $1000^{\circ} \mathrm{F}$, a dual refractory liner consisting of formed panels and then gunned refractory was used. Otherwise, a single layer of gunned refractory was specified, this layer being hardened where high dust loading was predicted for erosion protection and modified for acid resistance where corrosion was also predicted.

Control of corrosion and erosion where refractory was not specified was also a concern. Vessels and piping where acid condensation could take place were lined with Hasteloy C-22 or fabricated from Incoloy alloys. This included all of the dryer off gas ductwork, cyclones and blower housing. High corrosion rates were not expected in other areas of the plant. Prior to the cyclones in the dryer and pyrolyzer loops, high dust loadings were expected, but these areas were protected by hardened refractory. Therefore the balance of the plant piping and vessels were simply given a $1 / 8$ " corrosion/erosion allowance. Most of the time the actual wall thickness was governed by structural requirements, which made the wall thickness $3 / 8$ " plus the corrosion allowance.

In many industrial plants where availability is essential, the major equipment is spared by installation of redundant parallel units, each of which can handle full plant throughput. In the ENCOAL Project, being a demonstration plant, it was decided to spare only equipment in streams essential for process control. This minimized the capital cost and reduced the risks on the Project. As a result, only three critical pumps were spared with in-line, ready to run standby units. Based on the high reliability of the major equipment, this decision was not expected to have a significant impact on future plant availability.

All rotating equipment was specified to comply with current MSHA standards for 8 hour noise exposure and to be gas tight. Not every manufacturer was able to meet the noise standard, but collectively, the PDF building was held within acceptable limits. Even though gas tight equipment was specified, an ambient air monitoring system was added to the PDF building to detect $\mathrm{SO}_{2}, \mathrm{H}_{2} \mathrm{~S}, \mathrm{CH}_{4}$ and $\mathrm{CO}$. The monitoring system was interlocked with the building ventilation system and a plant evacuation alarm.

\subsection{ELECTRICAL AND INSTRUMENTATION DESIGN}

Classification of the various plant facilities for the electrical design was one of the first engineering activities. Review of the National Electrical Code (NEC) and MSHA regulations resulted in the following area classifications:

Class 1, Division 1, Group D and F:

PDF building headhouse; enclosed area under coal and PDF silos; enclosed trenches 
Class 2, Division 2, Group D and F:

Screening building; within 10 feet of conveyors, silo openings and trench covers Unclassified:

Remainder of PDF building; remote buildings; electrical rooms

These classifications along with the zoning of the PDF building as described in Section 5.1 for pressure containment of the coal dryer, were reviewed with the MSHA Division office in Denver to get their input and concurrence. Following these discussions, the classifications were disseminated to all design groups. Also issued were the 4160 volt and 480 volt one-line diagrams (Figures $5.18-5.21$ ) for all of the demonstration facilities based on the equipment listed in the process release. Spare conduit, wiring, switchgear locations, and junction box capacity were built into the design to allow for future additions and deletions.

Also early in the design phase, standards were defined for the motors, switchgear, variable frequency drives and the control system. All motors greater than 5 horsepower were furnished by Kellogg rather than equipment vendors, and were specified to be mill and chemical duty and energy efficient with a service factor of 1.15. Switchgear was specified to meet MSHA's requirement for bypassing and testing on line on a monthly basis. Solid state variable frequency drives were specified where required with local/remote control and programmable ramping. For the control system, it was decided to use an Allen Bradley Programmable Logic Controller (PLC) based system with the Control View operator interface rather than a main frame based distributive control system. This decision saved a considerable amount of money in hardware and programming time and did not sacrifice anything in quality, flexibility or data gathering capability.

Being a first-of-its-kind demonstration plant, a lot of extra instrumentation and sample stations were included in the facilities design. One of the key elements of the LFC Technology as developed by SGI is closed loop control and optimization of the plant operation via sophisticated computer programs. Called Level 0 , this ultimate control system requires reliable, accurate information from field instruments. State of the art sensors for pressure, temperature, flow rates, density, $\mathrm{pH}$ and level were used throughout the plant. Two areas of concern were gas flow measurement in the dirty, hot, corrosive process gas streams and the reliable detection of critical levels. Hot wire anemometers were selected for the severe gas flow applications. Mechanical level detectors were installed on the dryer and pyrolyzer outlets and nuclear devices were specified for all other critical level measurement applications. Feed coal composition and product qualities are also required by the Level 0 control system. The only proven instrument that could provide the instantaneous analyses needed for closed loop control was the GAMMA-METRICS nuclear coal analyzer. Two of these analyzers were installed in the plant, one on the raw coal inlet and one on the PDF outlet.

The Level 0 control system was designed to reside on a remote VAX computer and gather information through a modem. It was a given that the demonstration plant would not start up using Level 0 . Instead Level 0 would be put on line to "learn" by gathering data from the 132 field monitoring points, making predictions for plant operating parameters and comparing its predictions to the actual operating conditions. The Level 0 system would then be calibrated during the first two years plant operation and eventually be put into on-line plant control service once it had demonstrated reliability and accuracy. 


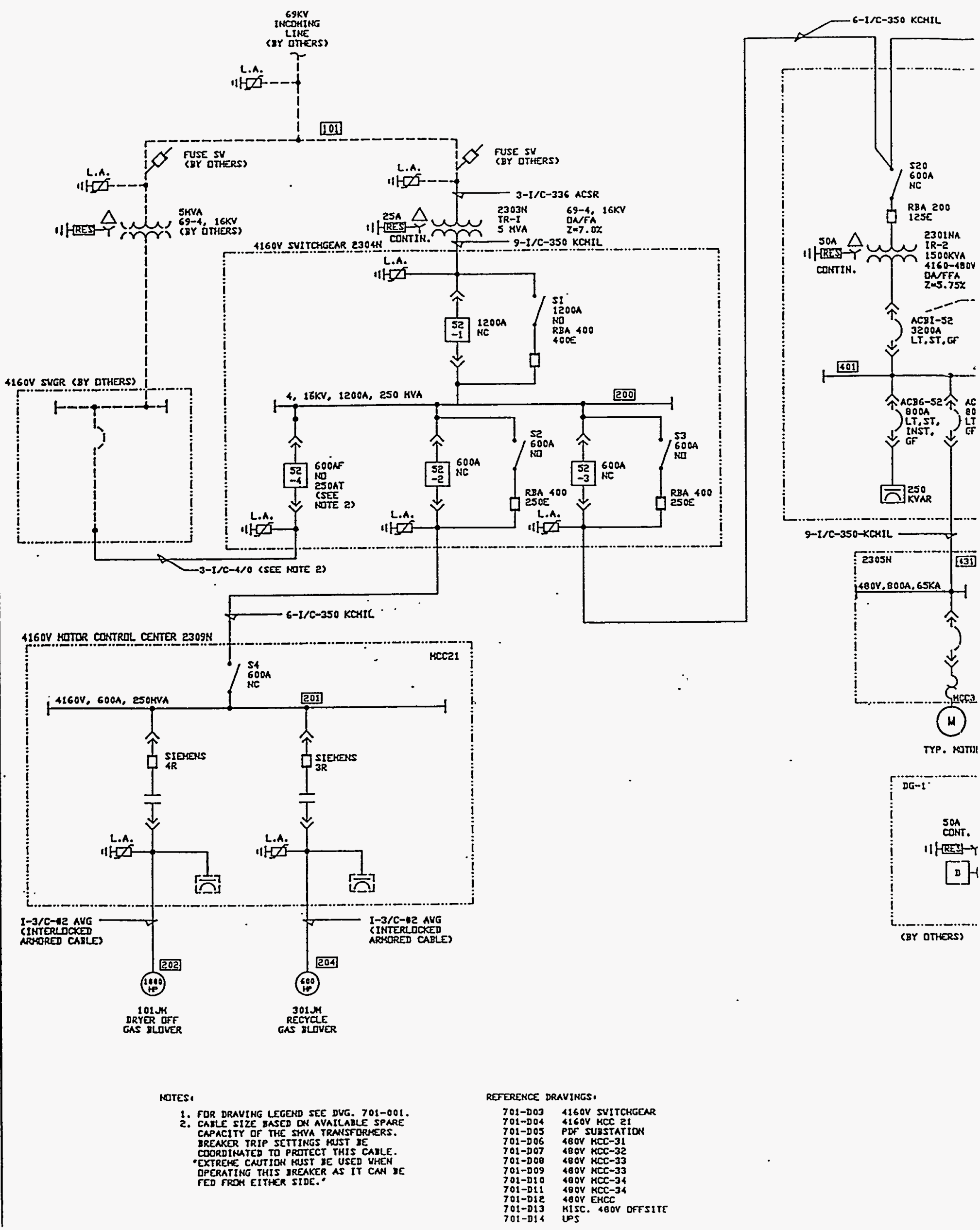




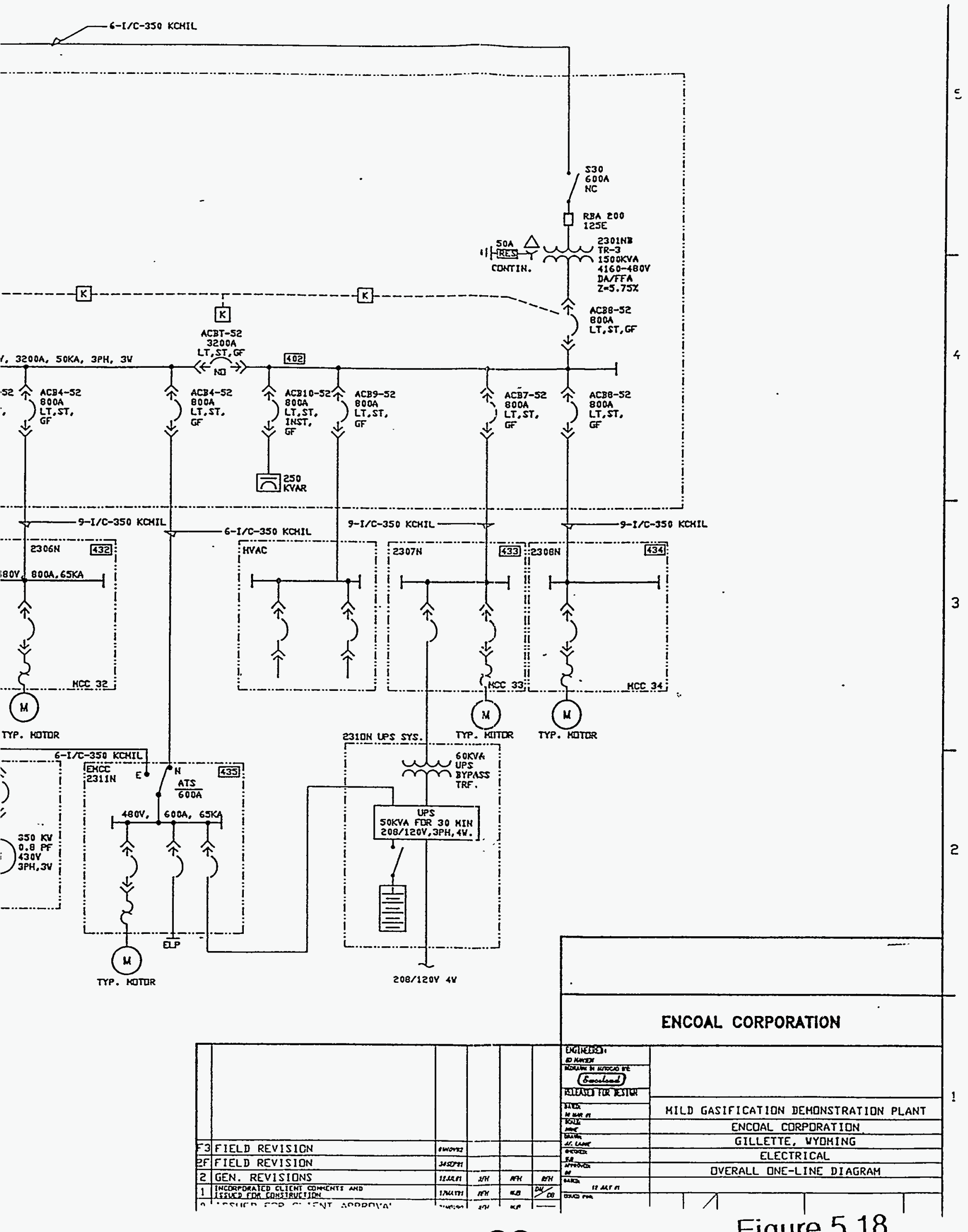




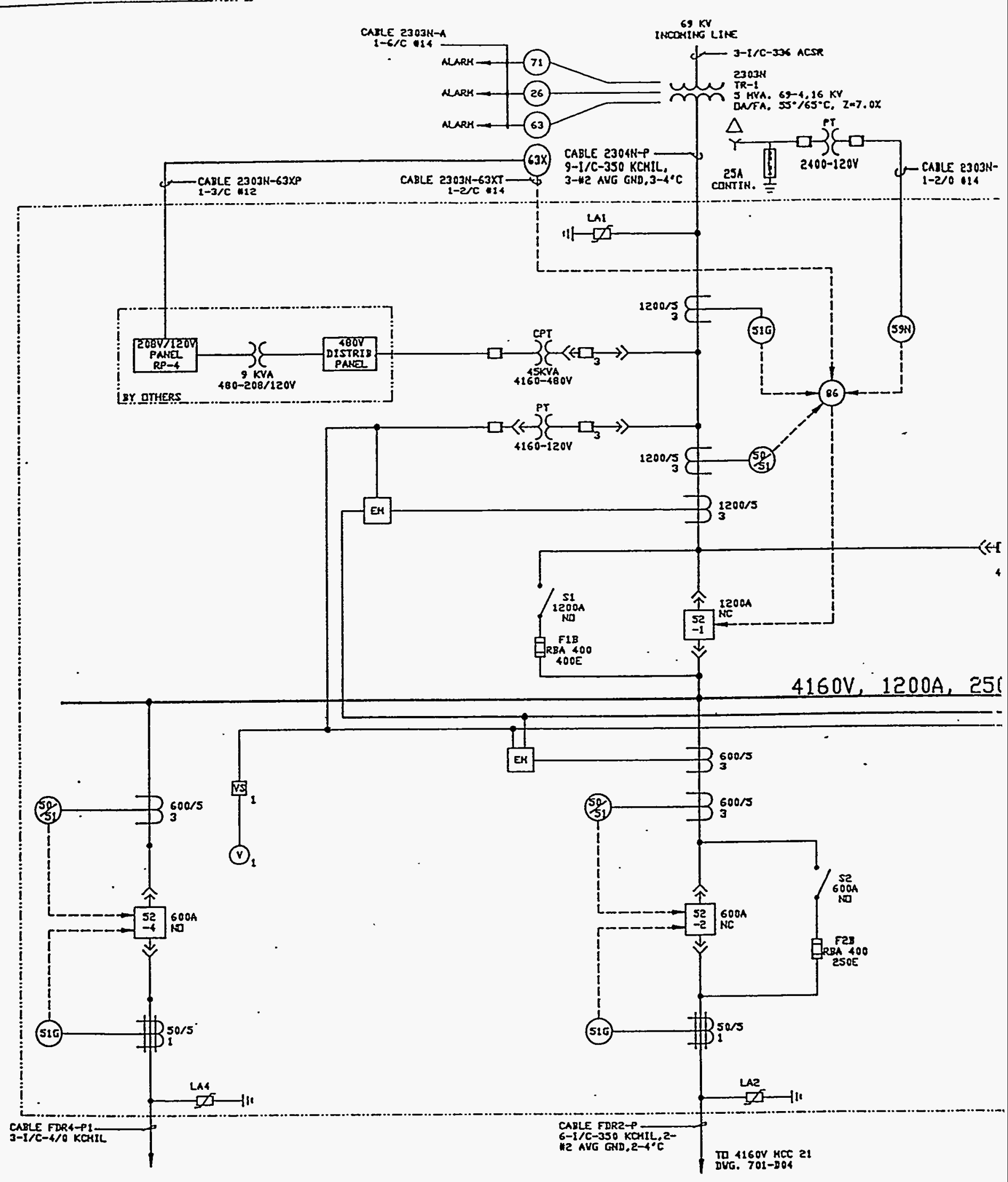




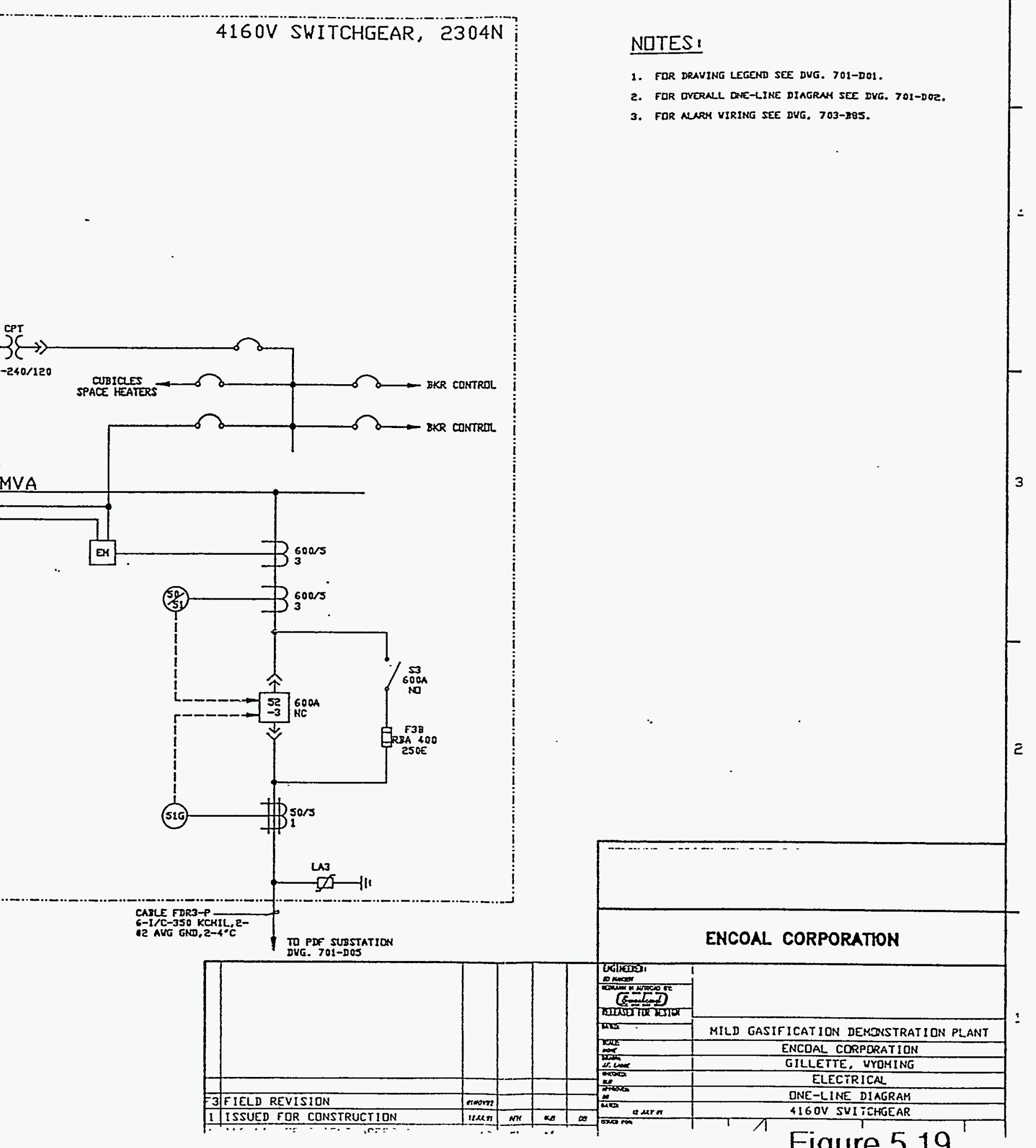




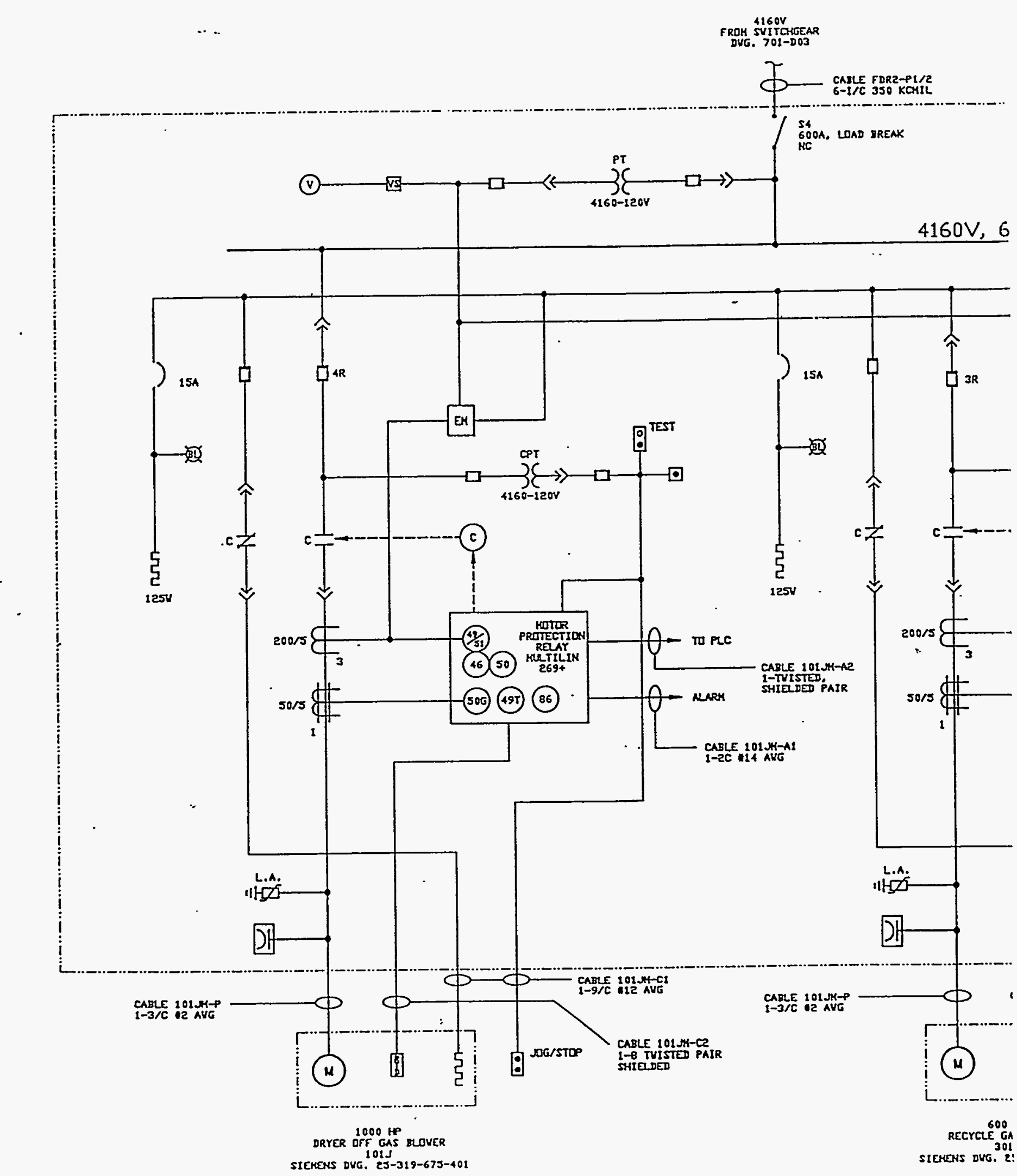




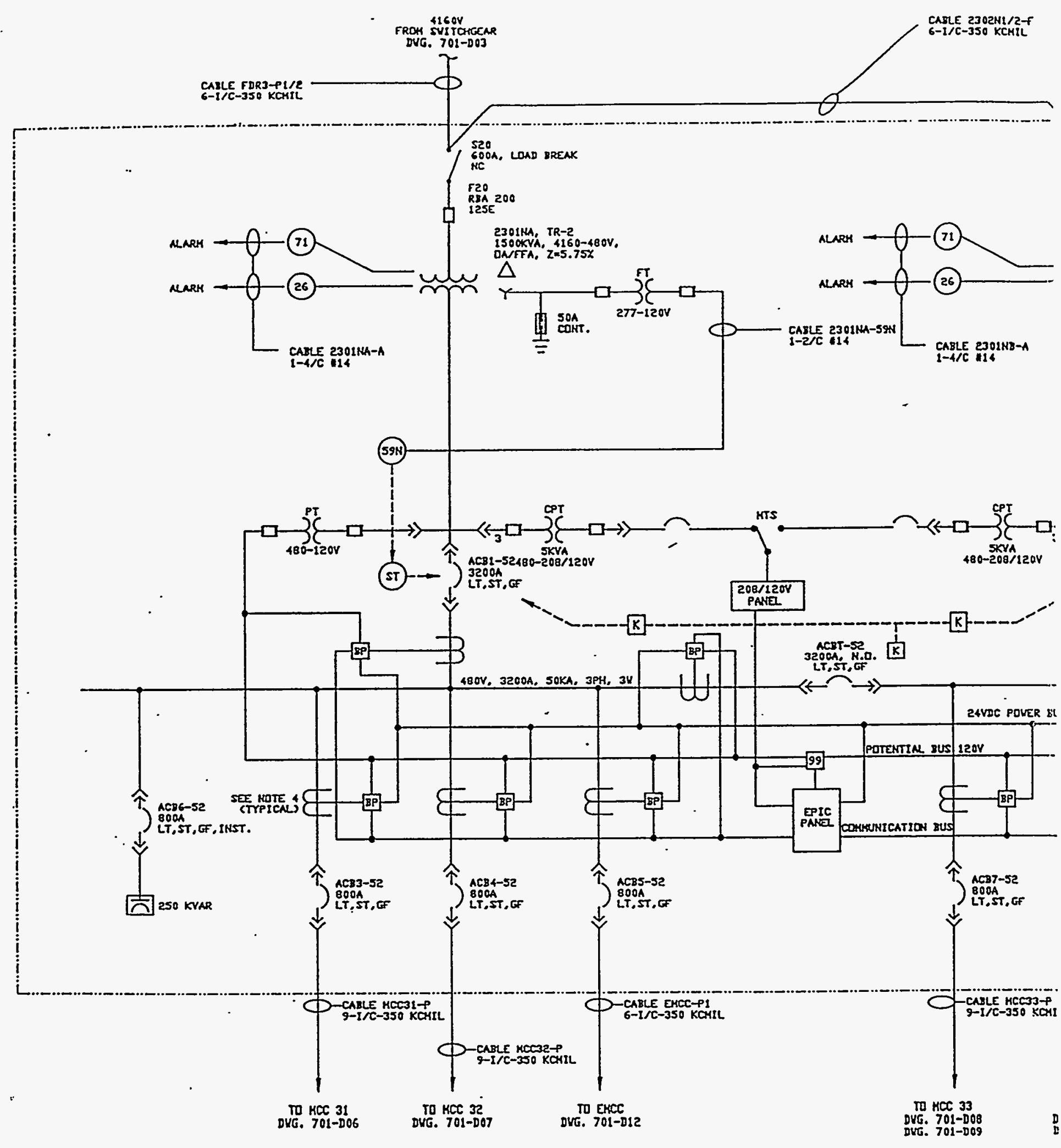


One of the recommendations of the HazOps study group was to develop emergency shut-down (ESD) procedures. This was done as part of the initial electrical and instrumentation design. Safe, ordenty ESD being paramount, the requirements for instrument air capacity, nitrogen capacity and standby power were determined. A battery operated uninterruptable power supply (UPS) was installed to provide backup power to the control computers and certain other electrically operated safety devices. In addition, for longer term outages, a standby generator was installed to maintain power to the UPS system, nitrogen vaporizer, emergency lighting, standby glycol circulation pump and control room.

\subsection{MAJOR EQUIPMENT FUNCTIONS AND DESCRIPTIONS}

The following sections discuss each of the major equipment items or groups according to function in the overall process. For a more complete major equipment list, refer to Appendix A, Table A.1, which contains a cross reference of the equipment names and the number designation.

\subsection{FEED COAL SYSTEM}

Coal is conveyed from the Buckskin Mine into a 3000 ton storage silo (Figure 6.1). A variable speed vibrating feeder (Figure 6.2) loads coal automatically from the silo onto a conveyor which continuously transfers the coal to a triple deck coal screen (Figure 6.3). The triple deck screen divides the feed coal into undersized (less than $1 / 8 ")$, sized (1/8 in. to 2 in.), and oversized (greater than 2 in.) materials. Undersized coal is returned to Triton via truck or conveyor. Coal greater than 2 in. is fed into a crusher (Figure 6.4) to reduce its size. Outfall from the crusher is combined with the sized coal from the screen and is transferred to a 7 ton dryer coal feed hopper by an "S" belt, a flexible wall, ribbed vertical lifting conveyor. A general arrangement drawing for the coal handling equipment in the next three sections is shown in Figure 6.5.

\subsection{COAL DRYER AND CYCLONE}

The coal dryer (Figures 6.6 and 6.7) is a Salem Furnace Company shallow bed rotary grate type dryer with a grate diameter of $30 \mathrm{ft} .9 \mathrm{in}$. The grate is perforated for gas flow and has a circular opening in the center for discharging coal. Several types of dryers were considered in the early stages of equipment selection; the choice was highly influenced by the desire to minimize particle size degradation during coal handling. The coal enters the dryer at the outer edge of the grate through the inlet chute. The distance between the discharge of the inlet chute and the grate establishes the coal bed depth. As the grate rotates, stationary rabbles (Figure 6.8), which act like plows, move the coal toward the center of the grate. The coal then falls through the center opening into a duct (soaking pit) which deposits the coal on the pyrolyzer grate situated below the dryer. 


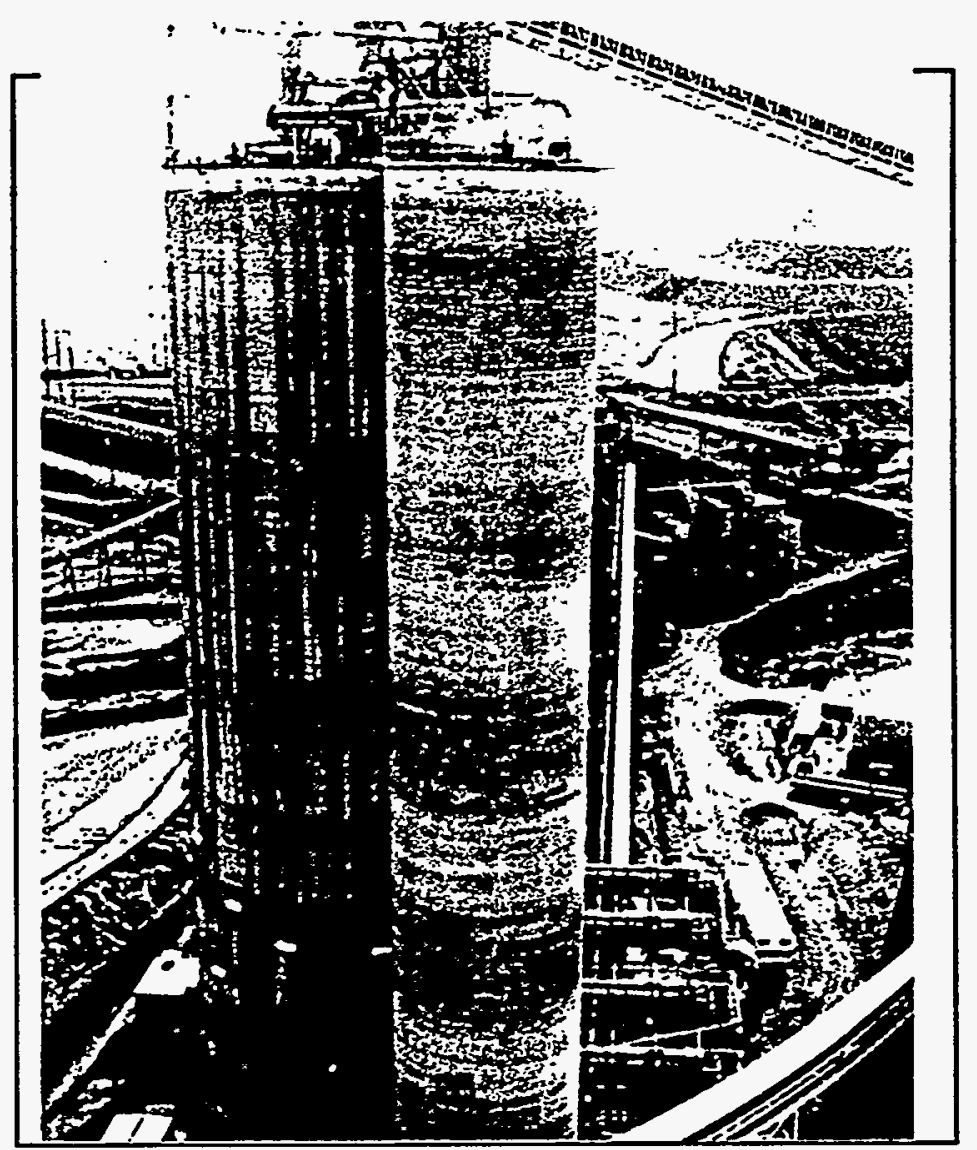

Figure 6.1 Coal Feed Storage Silo

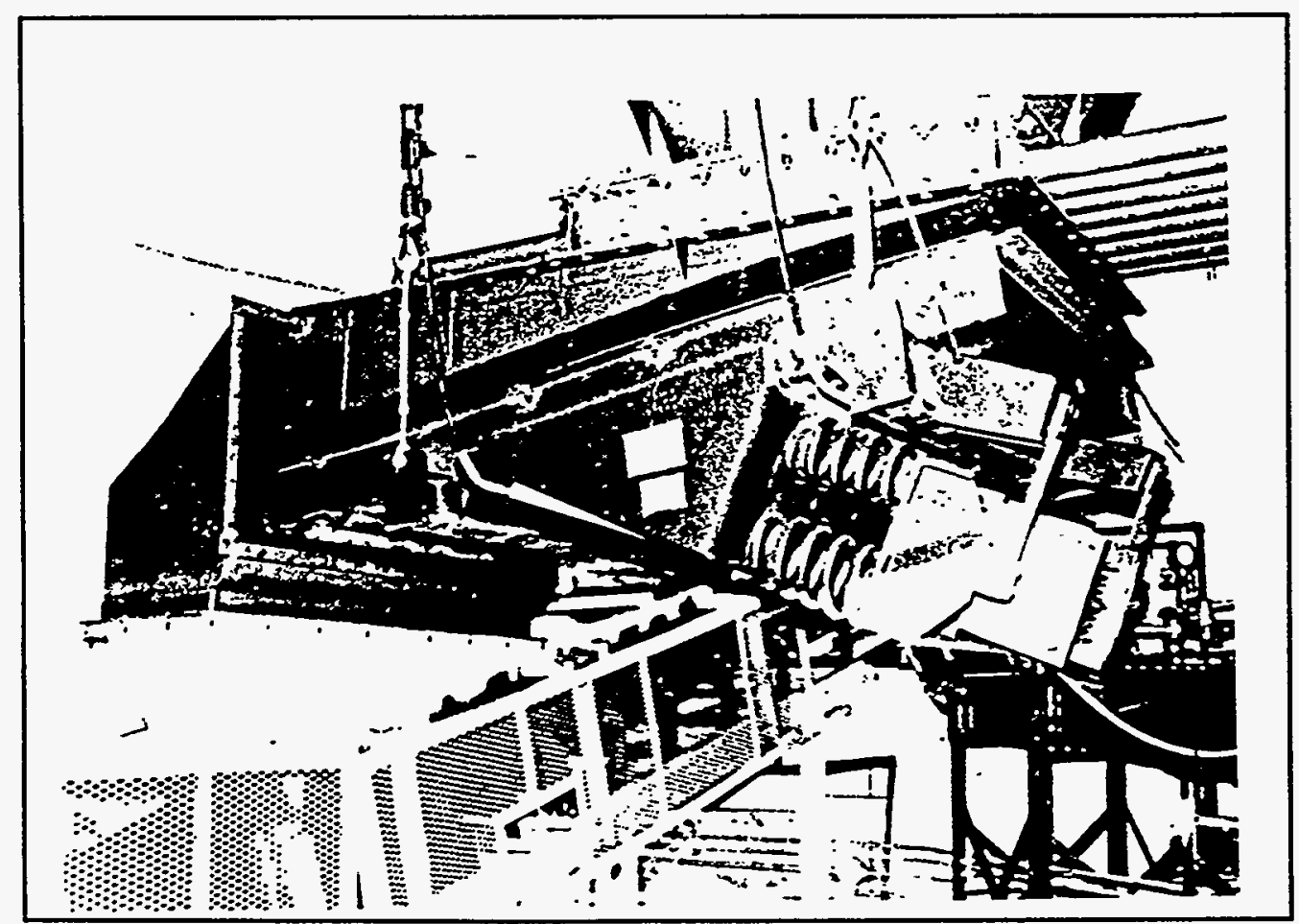

Figure 6.2 Vibrating Feeder 


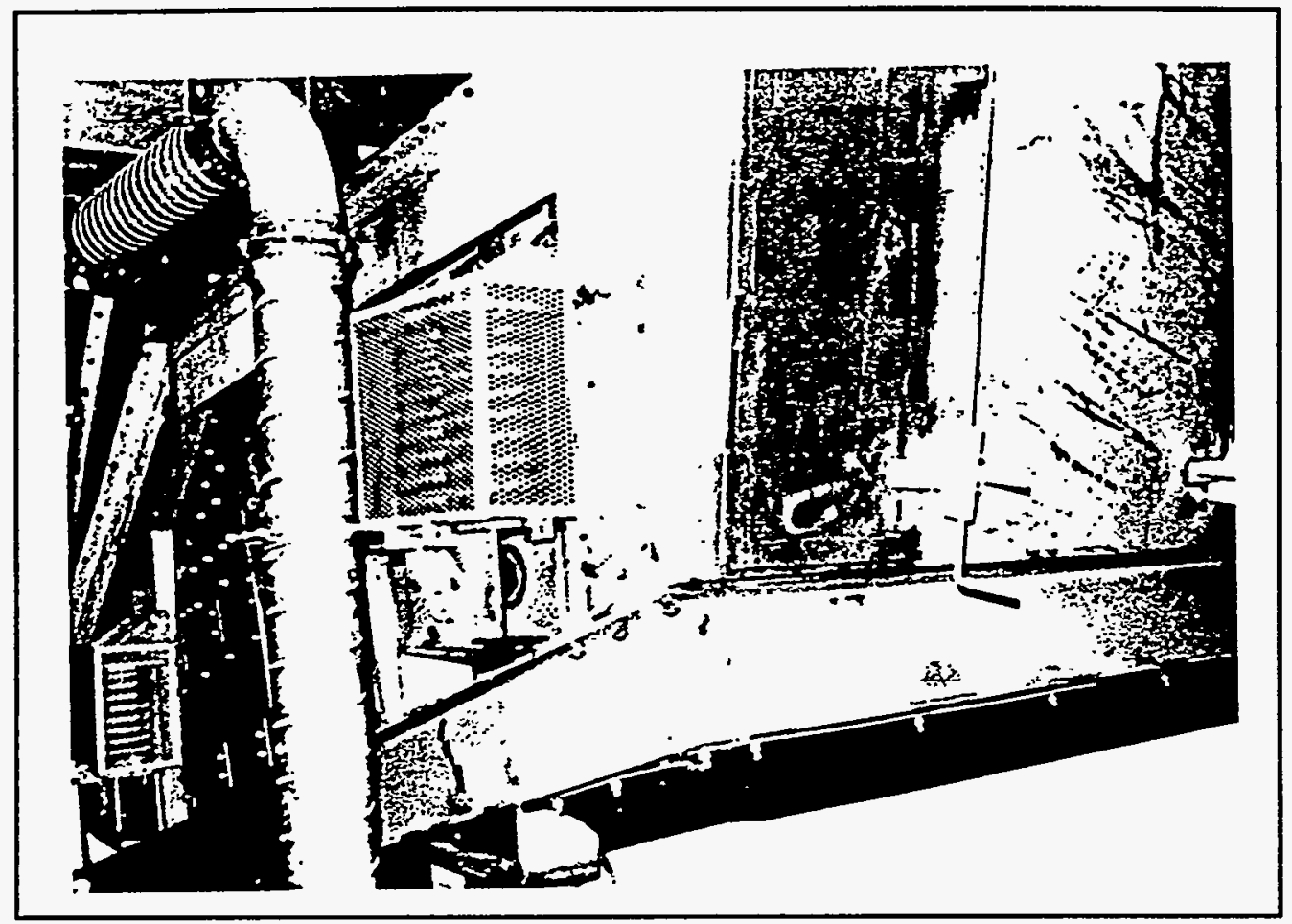

Figure 6.3 Triple Deck Coal Screen

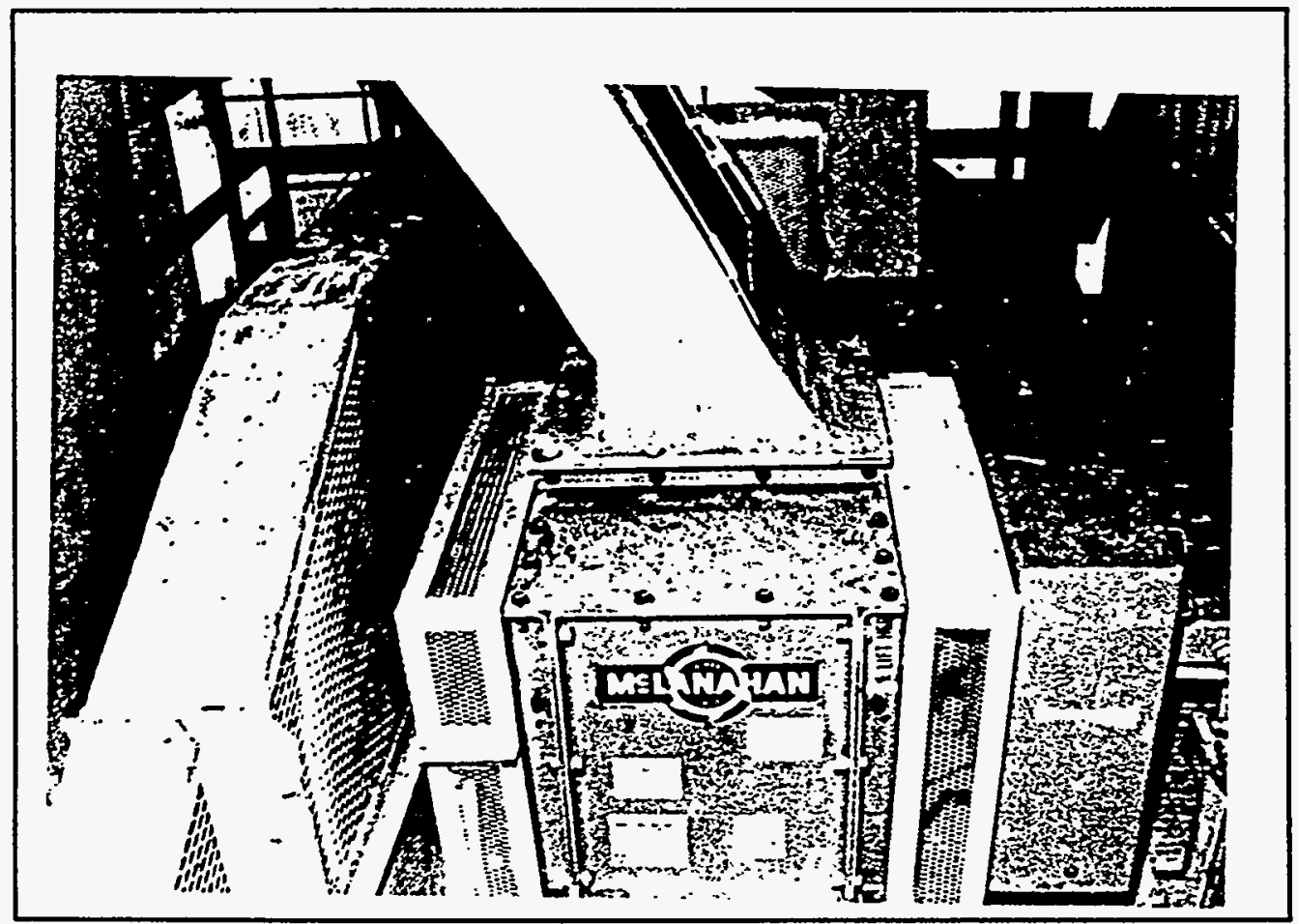

Figure 6.4 Coal Crusher 


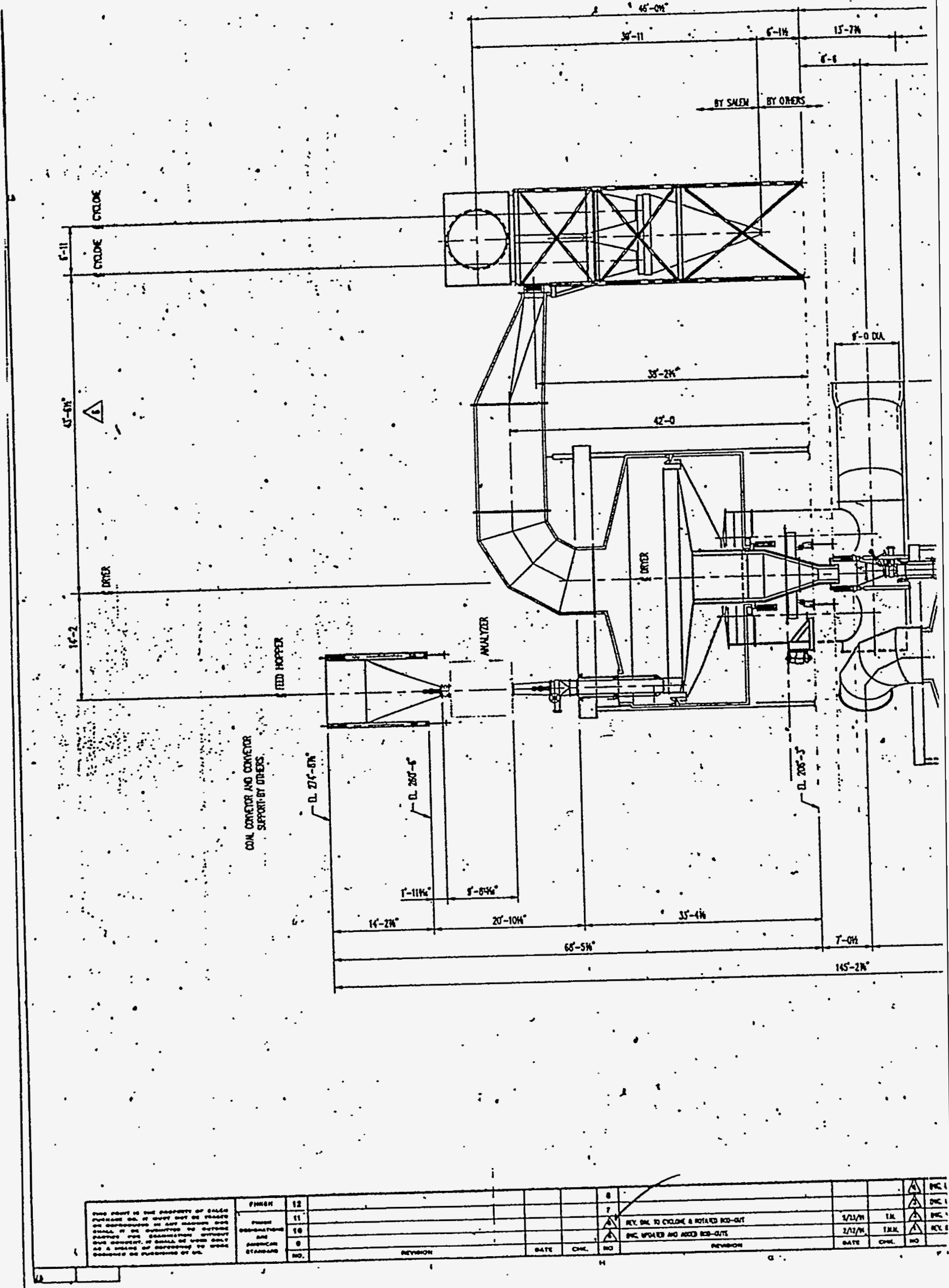




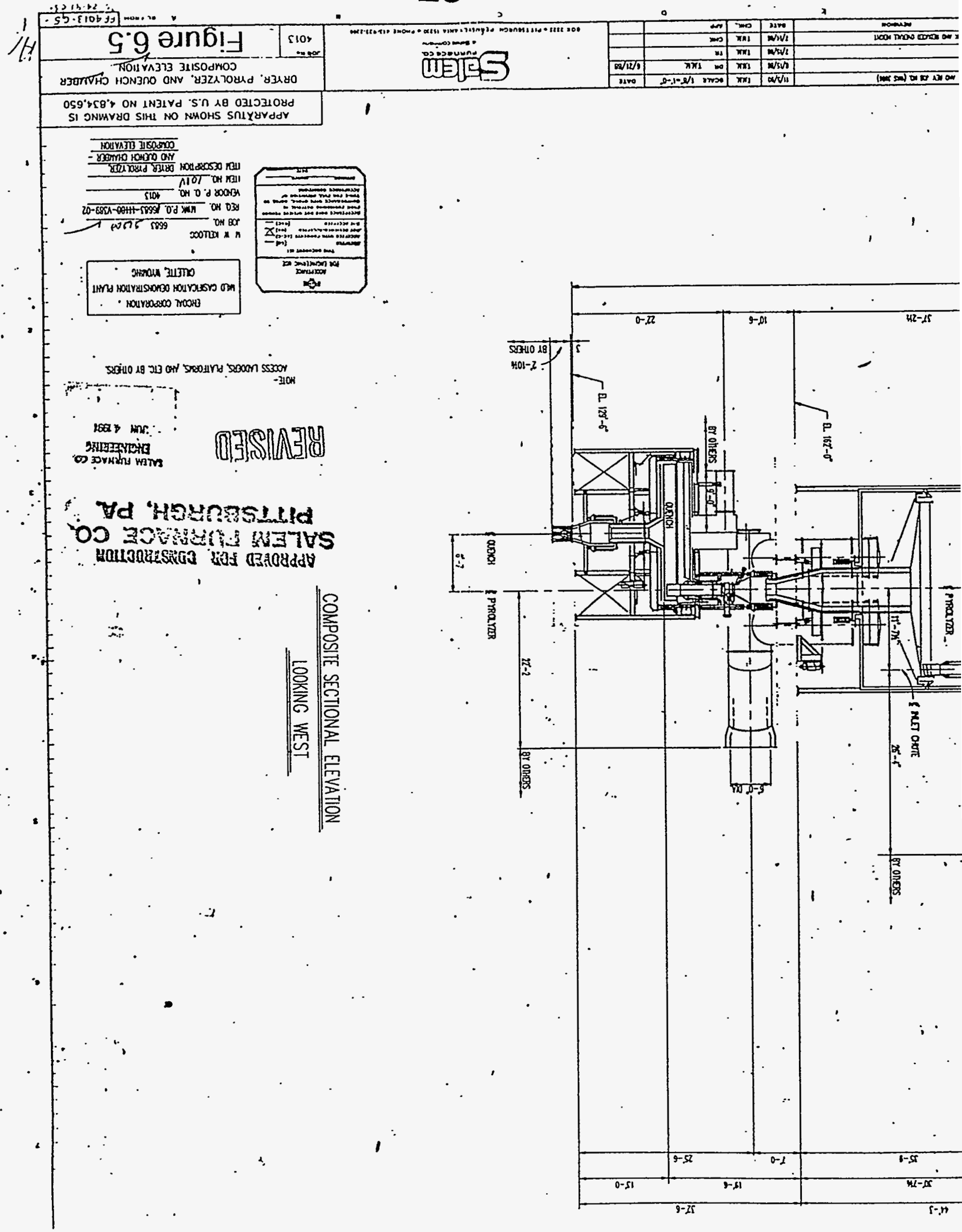




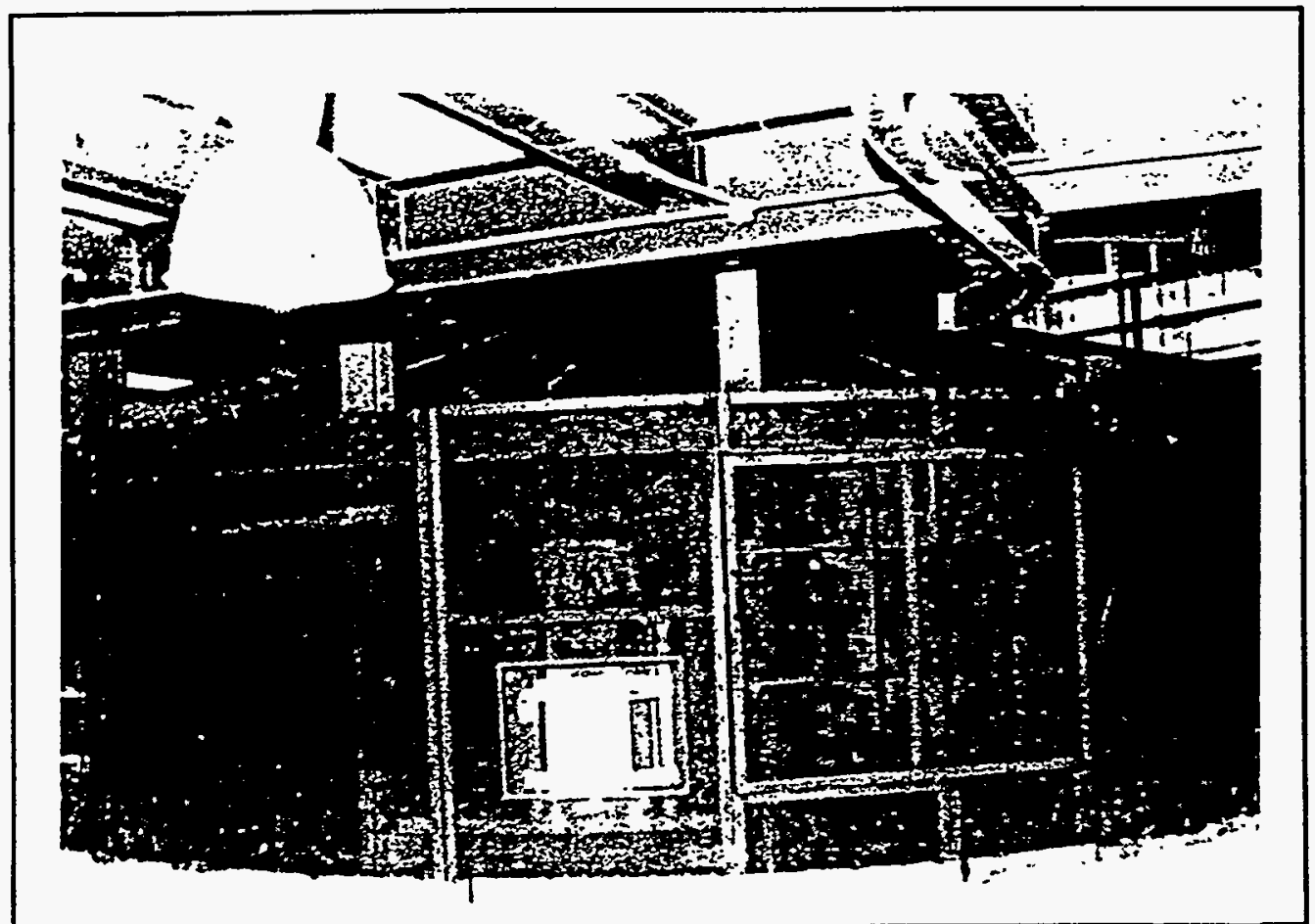

Figure 6.6 Salem Coal Dryer

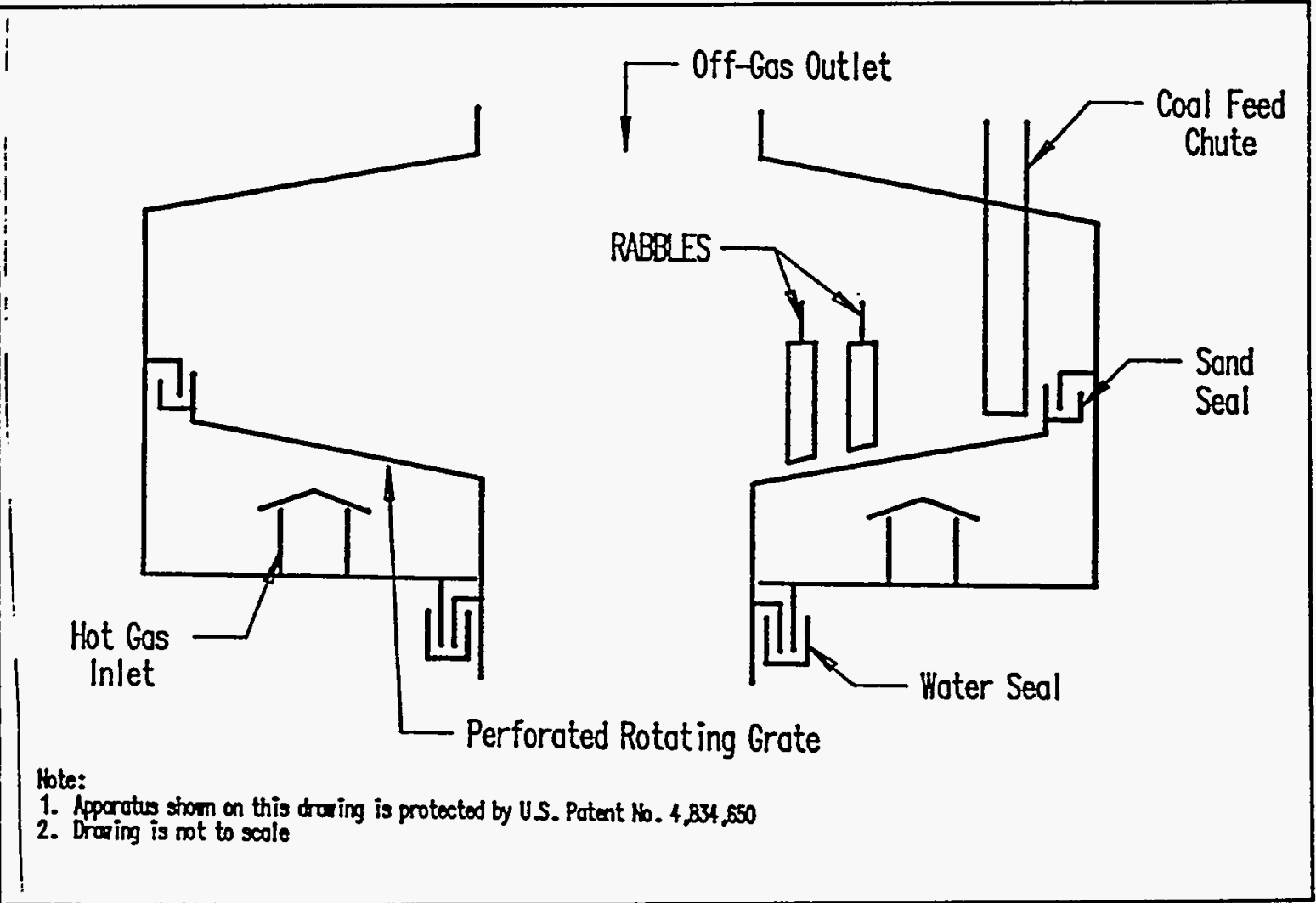

Figure 6.7 Sketch of the Dryer Internals 


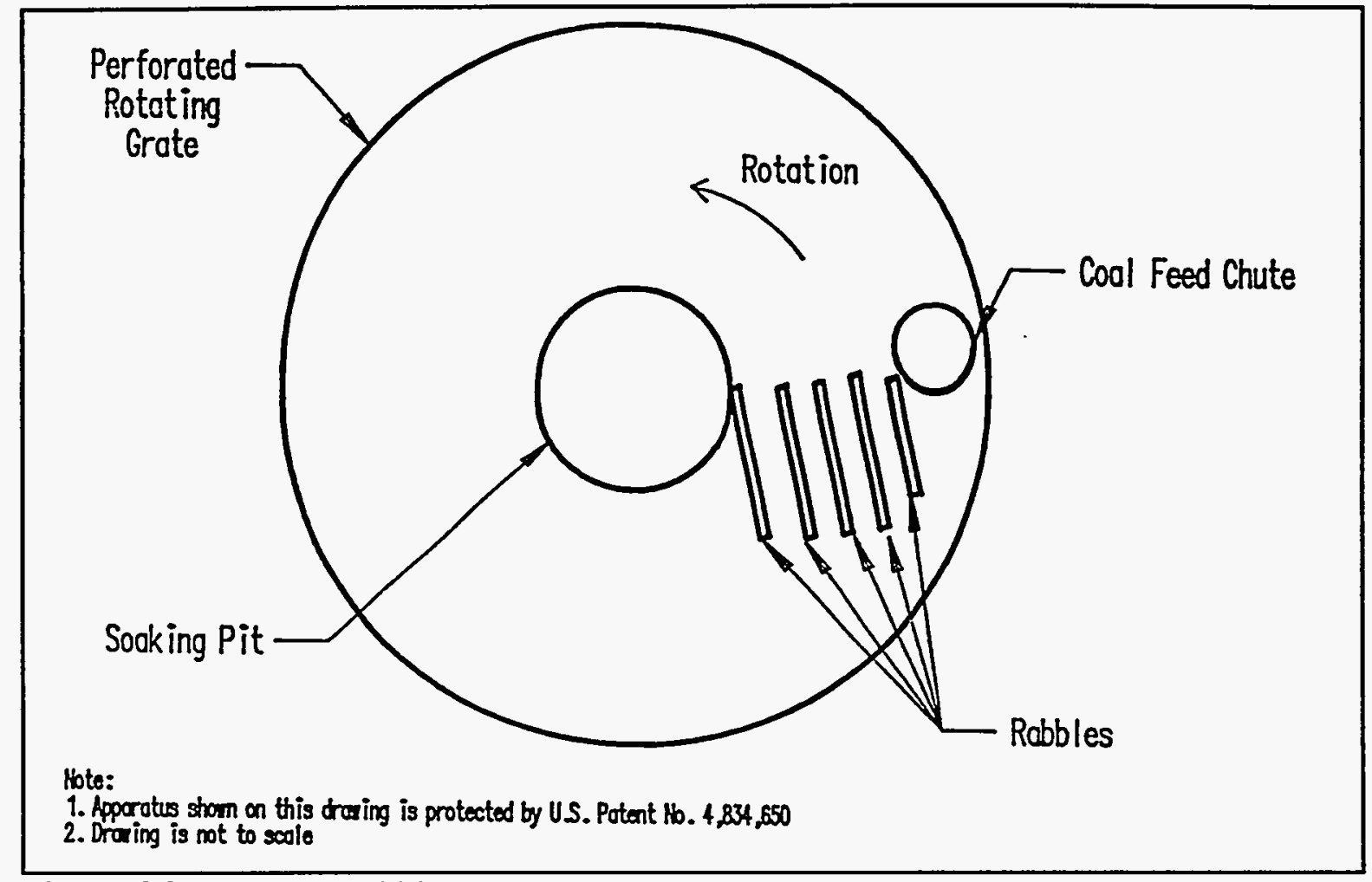

Figure $6.8 \quad$ Dryer Rabbles Arrangement

As the coal particles move across the grate in a spiral path, they are in direct contact with a hot gas stream that flows upward through the perforated rotating grate. The hot gas stream is a mixture of hot flue gas from the dryer combustor and recycled gas from the dryer. The inlet gas flow rate and temperature to the dryer are the two major control variables which affect the drying process.

Since the perforated grate of the dryer is rotating while the shell of the dryer is stationary, a sand seal was installed between the outer edge of the grate and the shell of the dryer to prevent the hot gas from bypassing the grate through the clearance between the grate and shell. Furthermore, since the rotating structure of the grate extends outside the enclosure vessel, water seals are installed between the external moving and stationary members to contain the gas within the dryer.

The hot gas that flows through the perforated grate removes the moisture from the coal through convective heat transfer. The gas flow rate through the coal bed is not sufficiently high to fluidize the coal. However, some coal fines are entrained. The vapor stream leaving the dryer flows through a cyclone to remove most of the entrained particulates. In the cyclone (Figures 6.9 and 6.10), the dust-laden gas enters a cylindrical chamber tangentially and leaves the vessel through a central opening. The coal fine particles tend to move toward the wall of the cyclone by the virtue of their inertia. Coal particles from the cyclone are collected into a hopper. The collected fines are dropped from the hopper into a screw conveyor/cooler (Figure 6.11) where they are cooled to ambient temperature by indirect heat-exchange with cooling water. The cooled fines are then mixed with water and transferred to the PDF cooler sump. 


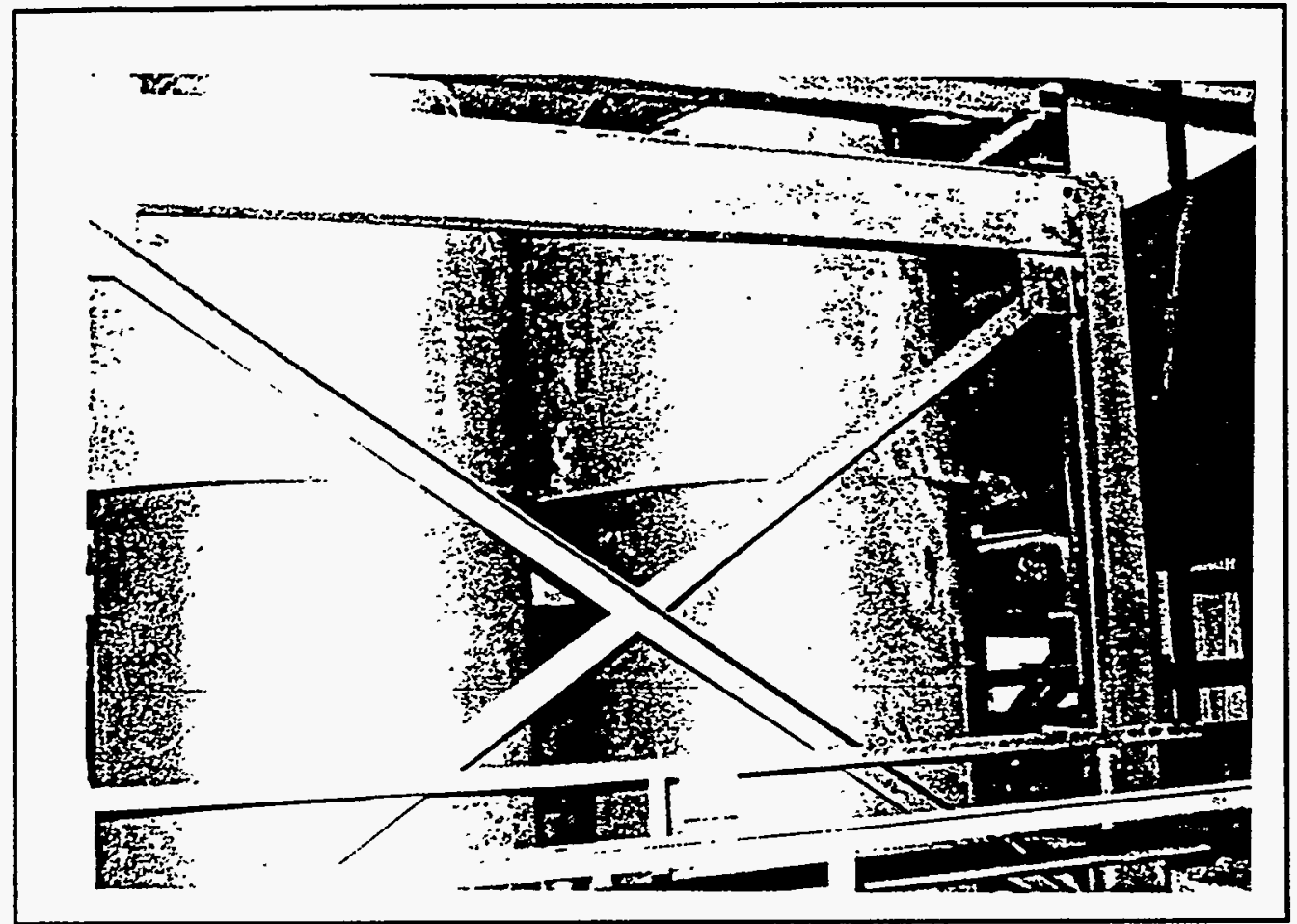

Figure 6.9 Dryer Cyclone

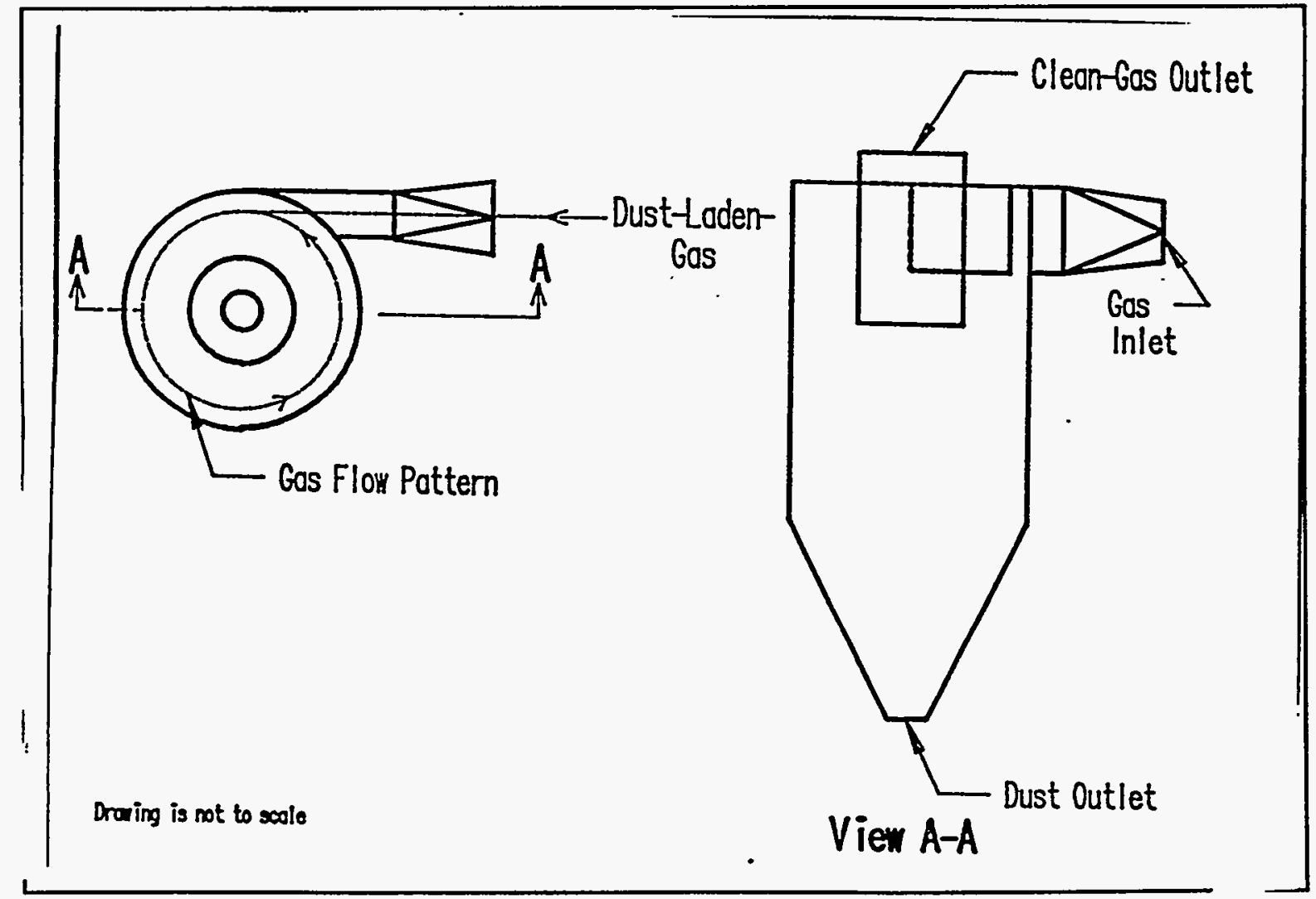

Figure, 6.10 Typical Cyclone Design 


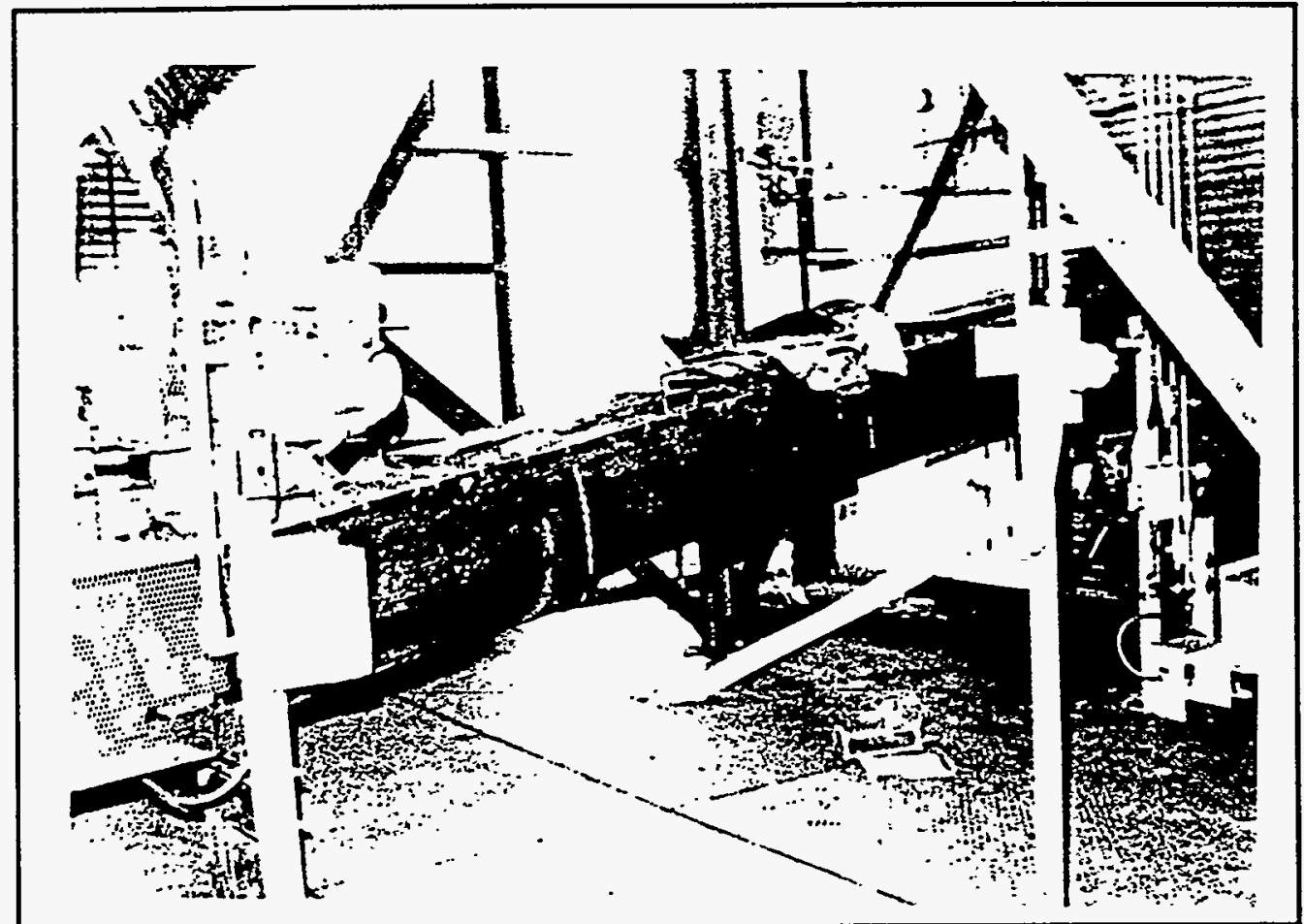

Figure 6.11 Coal Fine Screw Conveyor/Cooler

A motor operated valve is located in the soaking pit which allows dried coal to drop from the dryer into the pyrolyzer. This valve can be closed to isolate one vessel from the other. When operating, a standing leg of solids provides a vapor seal between the two vessels.

\subsection{COAL PYROLYZER AND CYCLONE}

The pyrolyzer (Figure 6.12) is also manufactured by Salem Furnace Company. Dried coal drops from the dryer into the pyrolyzer through the soaking pit. The design of the pyrolyzer is similar to the dryer. The mechanisms by which coal is moved through the pyrolyzer and heated by a stream of hot gas are essentially the same as those described for the dryer in section 6.2 . The grate is perforated for gas flow and has a diameter of $25 \mathrm{ft}$. 5 in. Solids are discharged from the pyrolyzer through a circular opening in the center of the grate into a quench table situated below the pyrolyzer.

The gas leaving the top of the pyrolyzer flows through the pyrolyzer cyclone to remove entrained coal particulates. The pyrolyzer cyclone operates by the same principle as the dryer cyclone. The coal particulates that are captured by the cyclone are collected into a surge bin where they are mixed with water to form a slurry. The slurry is pumped to a floor sump for treatment as described in section 9.2.

A motor operated valve is located in the soaking pit which allows coal to drop from the pyrolyzer into the quench table. The valve can be closed to isolate one vessel from the other. A standing leg of solids provides the vapor seal between the pyrolyzer and the quench table when this valve is opened. 


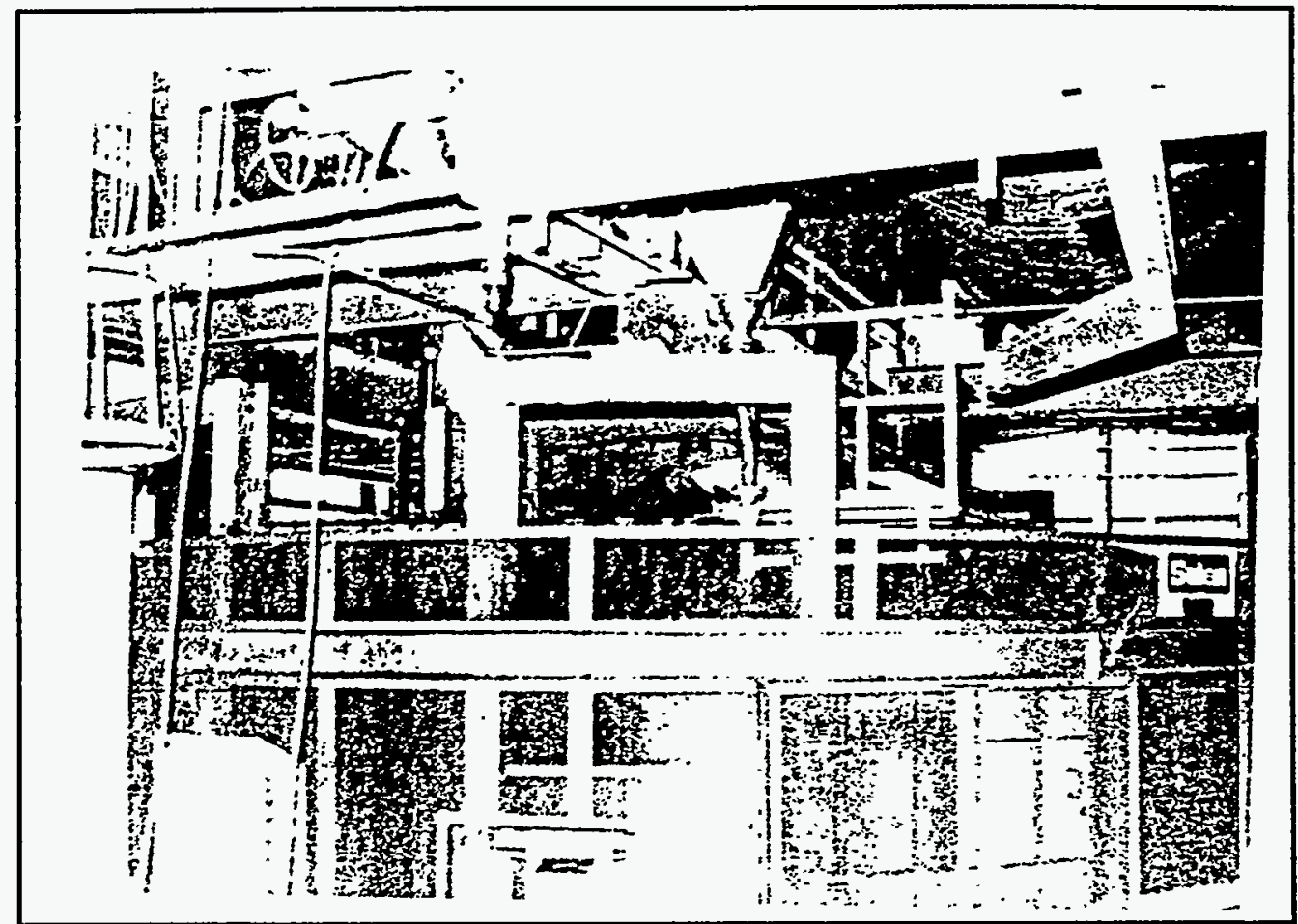

Figure 6.12 Salem Coal Pyrolyzer

\subsection{QUENCH TABLE}

Hot pyrolyzed coal particles drop from the pyrolyzer central discharge chute onto the outer edge of the rotating deck of the Salem quench table (Figure 6.13). The rotating deck is lined with refractory and has a circular opening in the center for discharging solids. This rotating deck is not perforated, thus being-different from those in the dryer and pyrolyzer. As the table rotates, stationary rabbles transfer the pyrolyzed coal from the perimeter to a central outlet chute. As the pyrolyzed coal particles move across the table in a serial path, they are quickly quenched by spraying water on them to stop the pyrolysis reaction. The steam that is generated by quenching the solids is sent to a condenser (Figure 6.14) where it is condensed by cold glycol/water solution. The condensed water is recycled back to the quench table.

\subsection{PDF COOLER}

The quenched pyrolyzed coal is dropped from the quench table discharge chute through a rotary valve into the PDF cooler where it is cooled to ambient temperature. The cooler (Figure 6.15) is a rotating cylindrical vessel which measures $11 \mathrm{ft}$. in diameter and $50 \mathrm{ft}$. in length and is manufactured by the Rennenberg Division of Heyl and Patterson. A general arrangement drawing for this vessel is shown in Figure 6.16. The vessel is oriented horizontally with a slight incline angle. Internally, the vessel contains 120 cooling coils which run the length of the vessel. The coils are $31 / 2$ in. in diameter with cooling water flowing through them. Thus, the pyrolyzed coal is cooled indirectly in this vessel. The solids enter the end of the cooler, which has a slight vertical lift, tumble over the cooling tubes, and flow out the opposite end. 


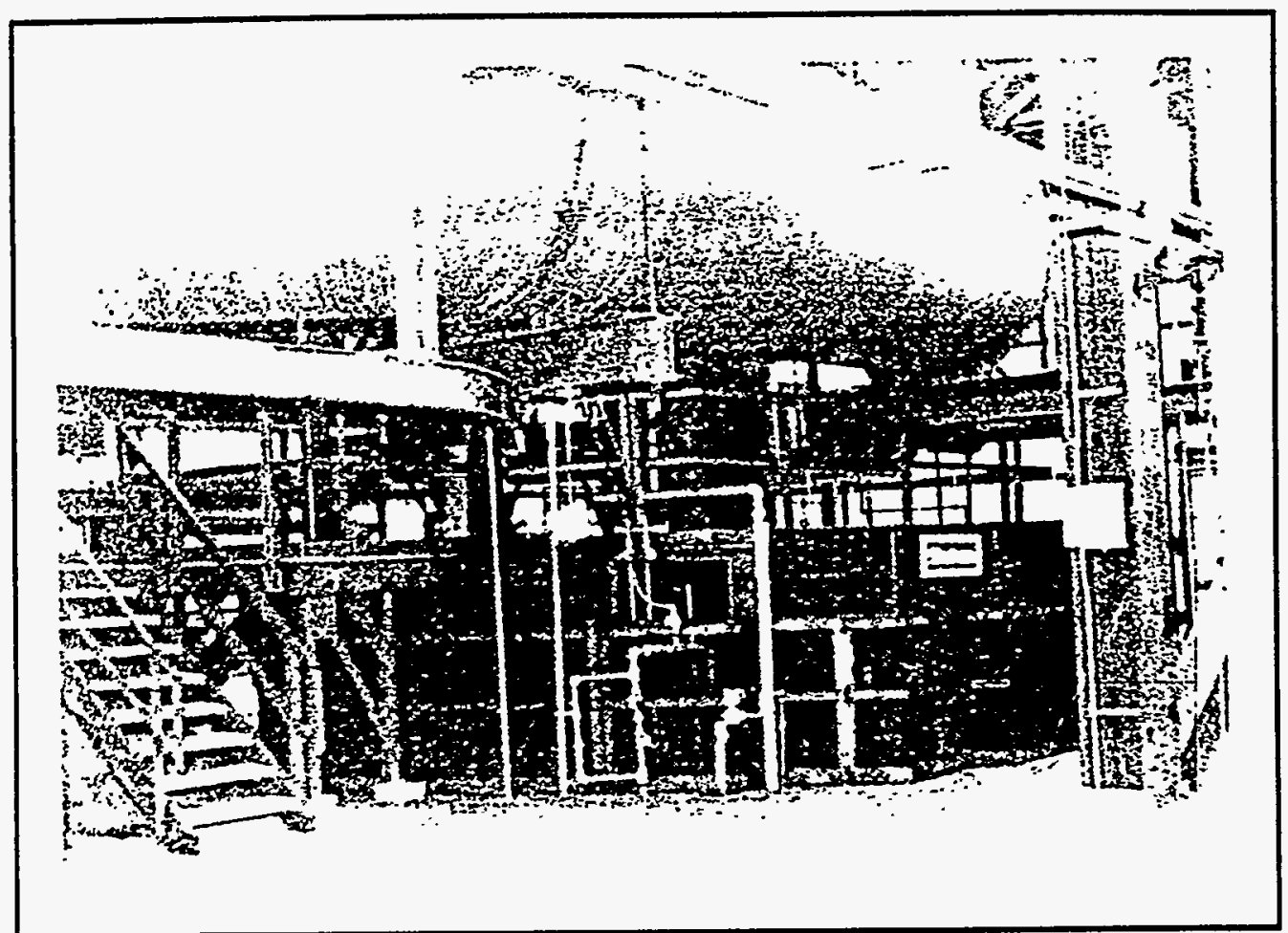

Figure 6.13 Salem Quench Table

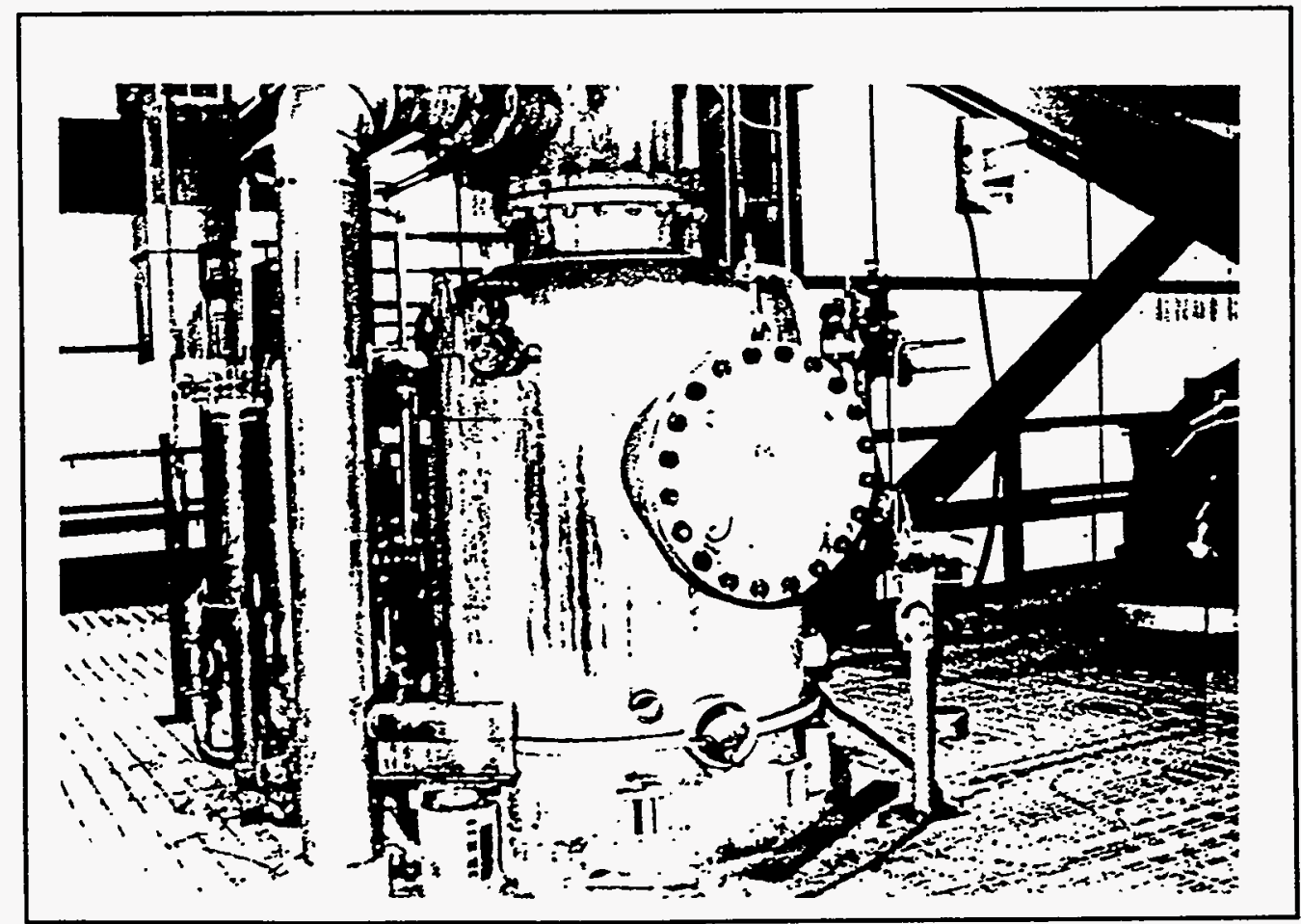

.Figure 6.14 Quench Steam Condenser 


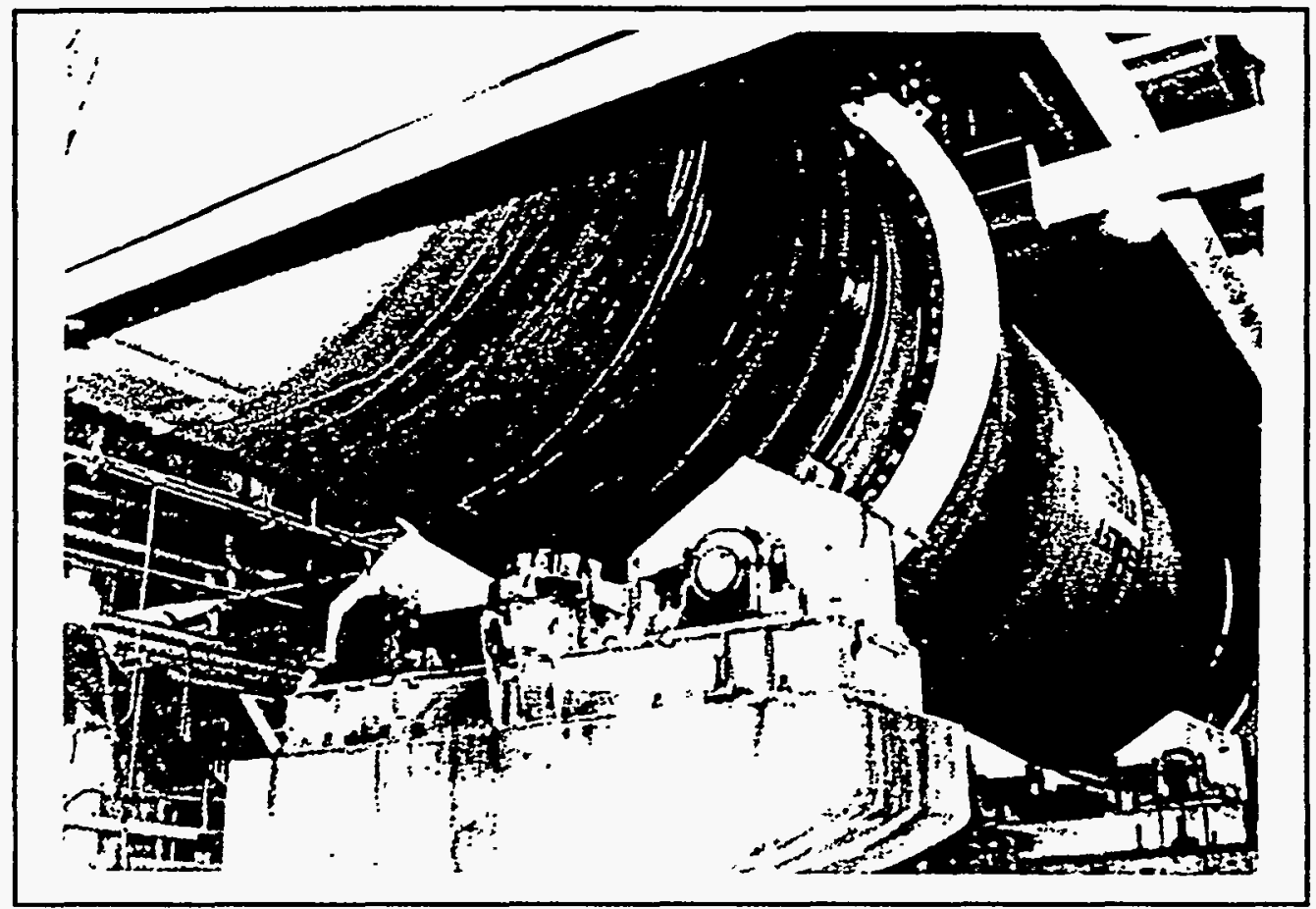

Figure 6.15 PDF Cooler

\subsection{PDF PRODUCT SYSTEM}

The cooled solids, now PDF, drop from the PDF cooler onto an "S" belt which is a flexible wall, ribbed vertical lifting conveyor and has the same design as the coal feed "S" belt. The PDF is conveyed to a GAMMA-METRIC coal analyzer (Figure 6.17) which measures its moisture, ash, carbon, hydrogen, nitrogen, sulfur and Btu contents. After the PDF passes through the analyzer, it is dropped into the PDF storage silo. When the PDF storage silo is to be emptied, a mass flow feeder transfers the PDF from the silo into a dust suppressant applicator in which a dust suppressant known as MK is applied to the surface of the PDF.

\subsection{QUENCH TOWER}

The quench tower (Figures 6.18 and 6.19) is a typical packed-bed column which condenses the organics in the off-gas from the pyrolyzer cyclone by bringing the gas into direct countercurrent contact with a liquid (CDL) stream. A general arrangement drawing of the quench tower is shown in Figure 6.20. The vessel is $12.5 \mathrm{ft}$. in diameter and $80.5 \mathrm{ft}$. in height. Internal vapor and liquid reflux distributors are provided to achieve cross-sectionally uniform vapor and liquid flows. The column contains a bed of Glitsch Grid packing which provides ample surface area for vapor/liquid contact. Cooled condensed organic liquid (CDL) is circulated by a pump to the top of the column while the off-gas enters the column from the bottom. By direct contact, heat is removed from the off-gas by the CDL and desirable organics condense in liquid form. The hot CDL is then pumped from the bottom of the column through a shell and tube heat-exchanger where it is cooled by a 50/50 glycol water solution as described in Section 7.4. Most of the cooled CDL is recirculated to the top of the quench tower as reflux; a small portion is sent to storage. The temperature and flow rate of the reflux are controlled to give the desired exit temperature for the gas stream leaving the top of the tower. 

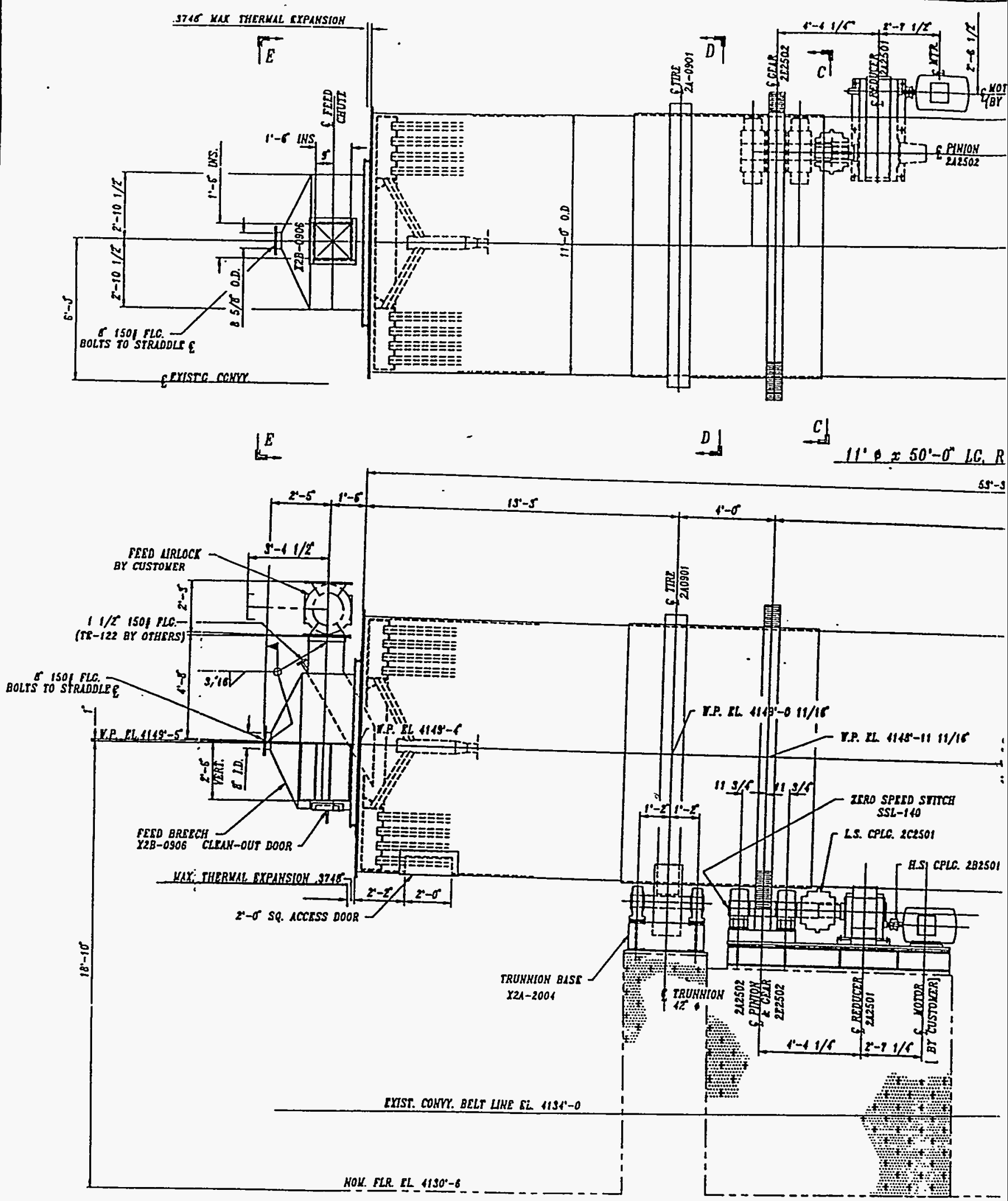

ELEVATION OF $11^{\prime} \emptyset \times 50^{\prime} \quad$ LG. I

MOTLS: 1.) INLST AND OUTLST YATSR CHMARR OISICH PRISS IS

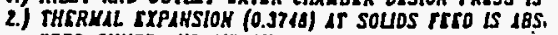

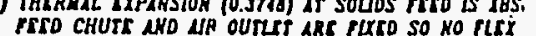




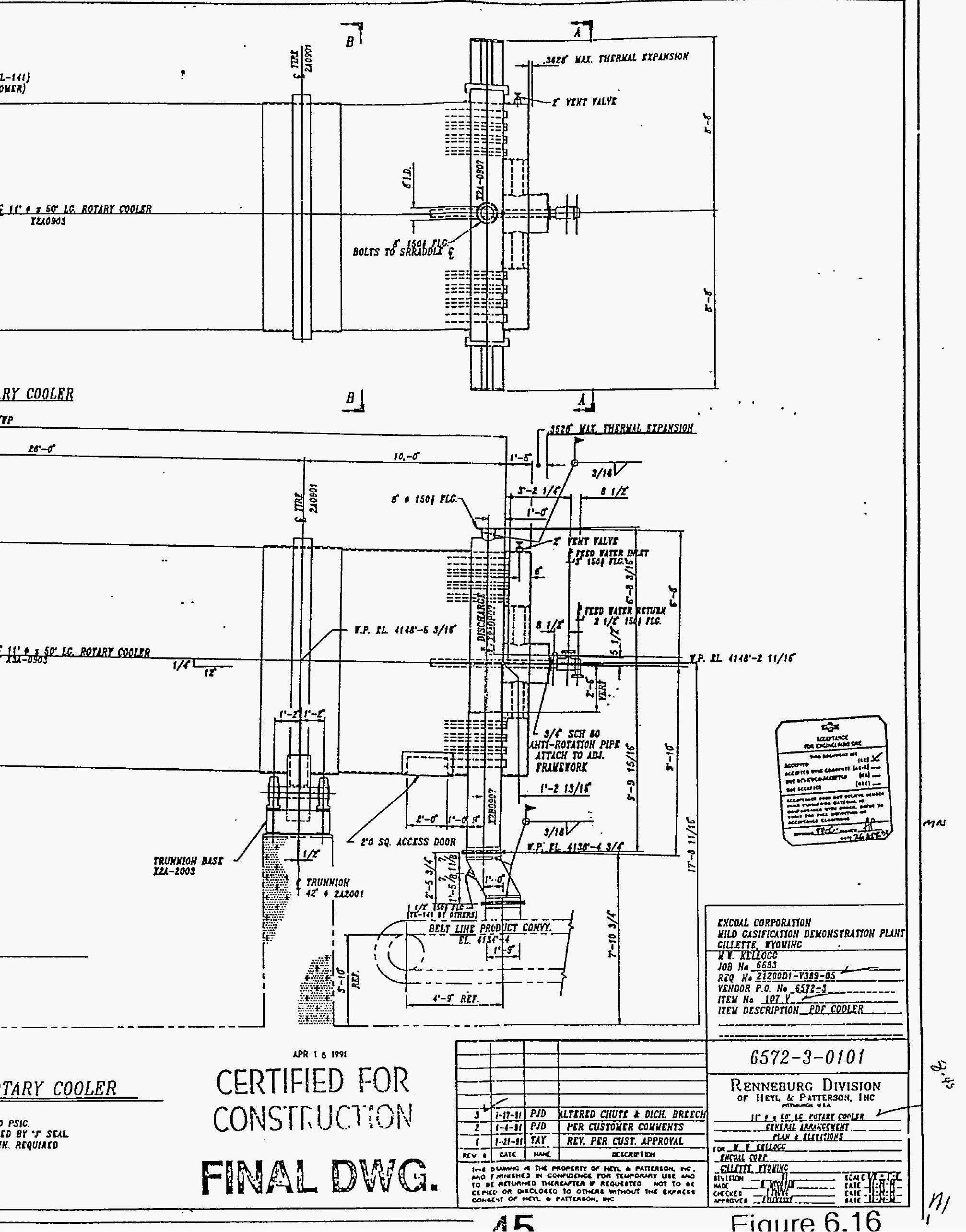




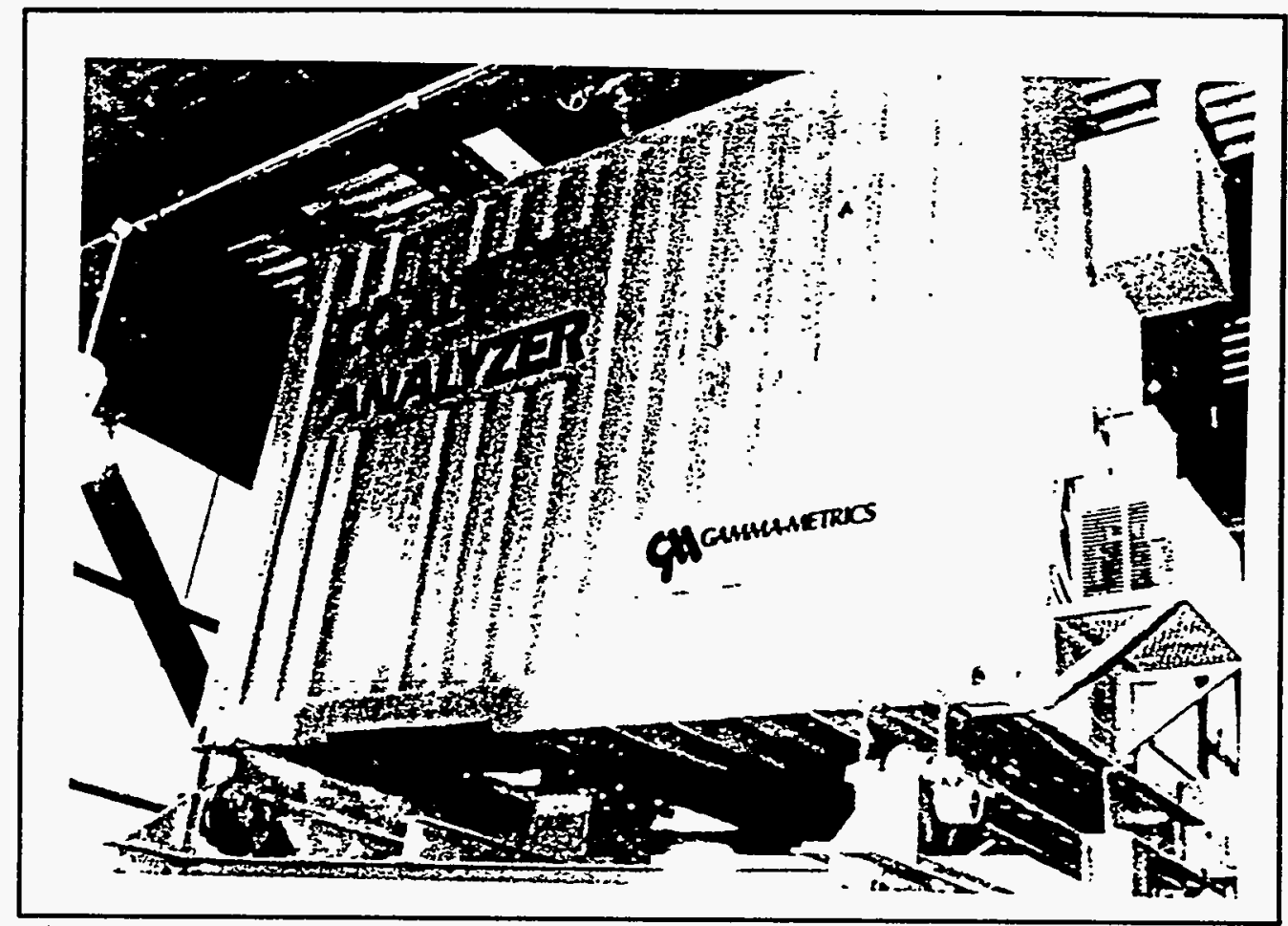

Figure 6.17 Gamma-Metric Coal Analyzer

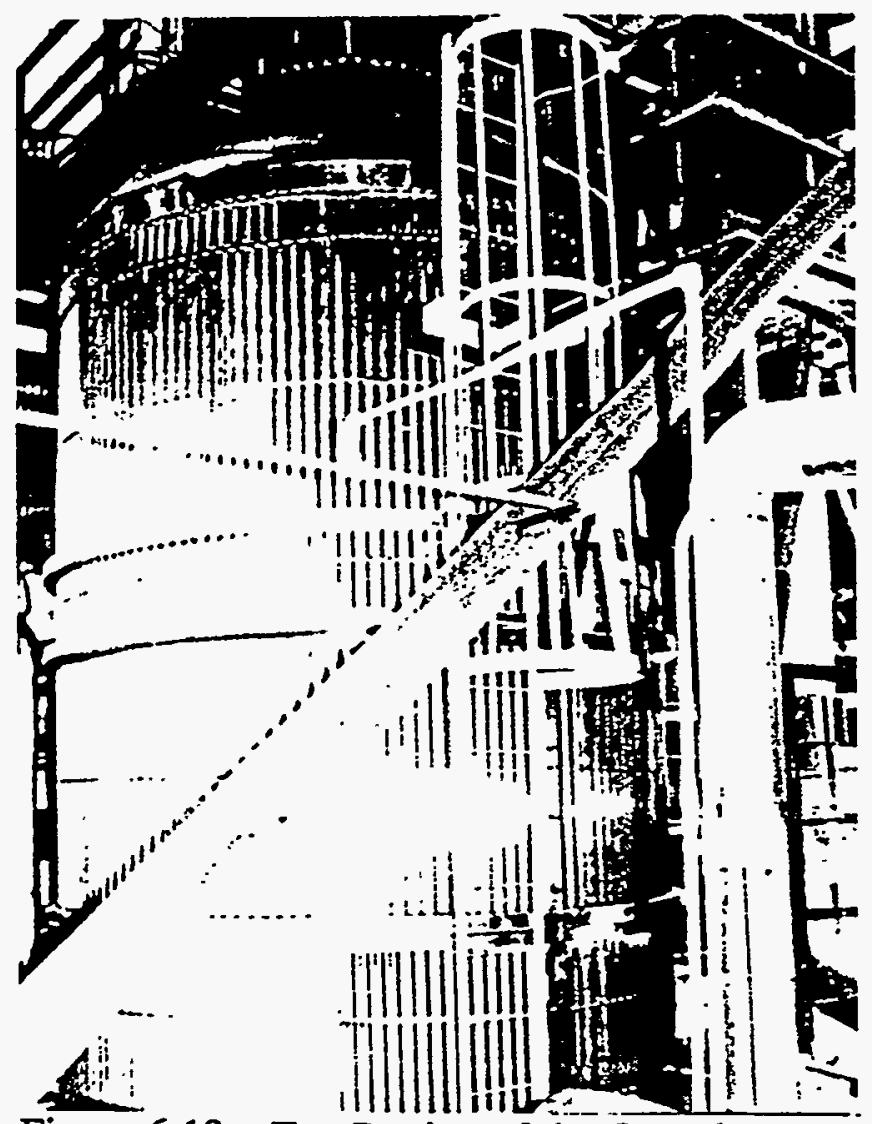

Figure 6.18 Top Portion of the Quench Tower 


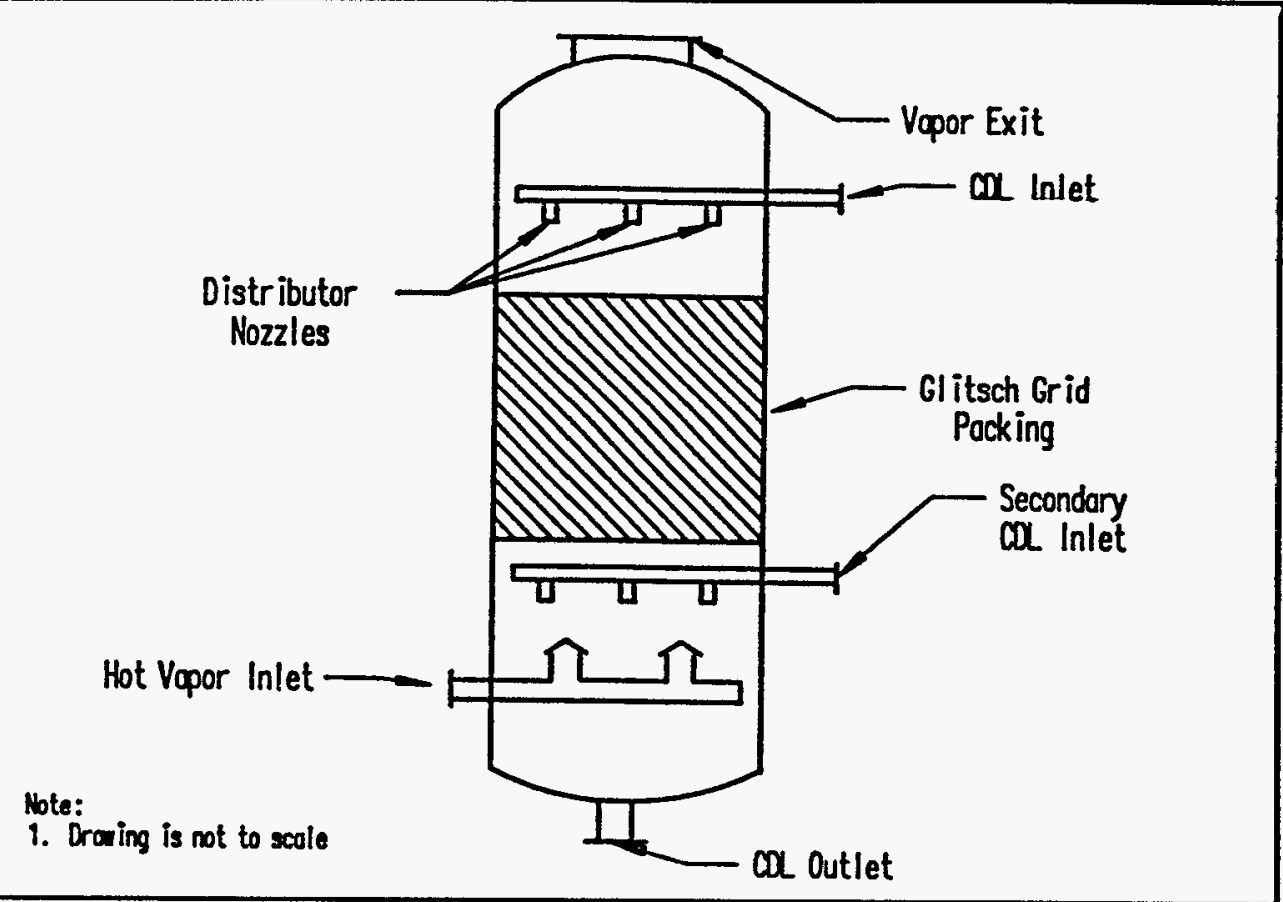

Figure 6.19 Sketch of the Quench Tower Internals

\subsection{ELECTROSTATIC PRECIPITATORS}

The gas stream leaving the quench tower may contain some $\mathrm{CDL}$ in the form of a fine mist. It was predicted that between 25 to $50 \%$ of the CDL condensed in the quench tower could be smaller than 2 microns drop size. In order to recover the mist as liquid, three Lodge Cottrell electrostatic precipitators (ESP) operating in parallel were installed. Figure 6.21 shows a general arrangement of the ESP's. Each vessel is $13.5 \mathrm{ft}$. in diameter, $24 \mathrm{ft} .4 \mathrm{in}$. in height, and contains nearly 300 electrodes (Figure 6.22). In each tube is a wire electrode (Figure 6.23); the liquid particles are charged by an electric field and move to the surface of the tube where they are collected. This is achieved by maintaining a high electrical potential between the electrode and the tube. Liquid collected in the tubes runs down the tube wall and is collected in the open bottom section of the ESP. From each of the 3 ESP's, the liquid flows by gravity into a collection line that transports it to the bottom of the quench tower where it combines with the rest of the CDL.

\subsection{COAL DERIVED LIQUID (CDL) HANDLING SYSTEM}

The net liquid product from the LFC process is taken as a slip stream from the reflux being returned to the top of the quench tower. As the CDL flows to storage (Figure 6.24), it is analyzed for immiscible water content by a BS\&W monitor. If the water content is greater than 1 percent by volume, the CDL is considered to be off-specification (off-spec) and is automatically diverted to an off-spec CDL storage tank. Off-spec CDL can be pumped back to the quench tower for reprocessing. If the CDL meets specification, it flows into the CDL product storage tank.

CDL can be loaded to tank car or tank truck from the storage tank through a CDL loading pump and meter (Figure 6.25). 
$80: 6$ OIA

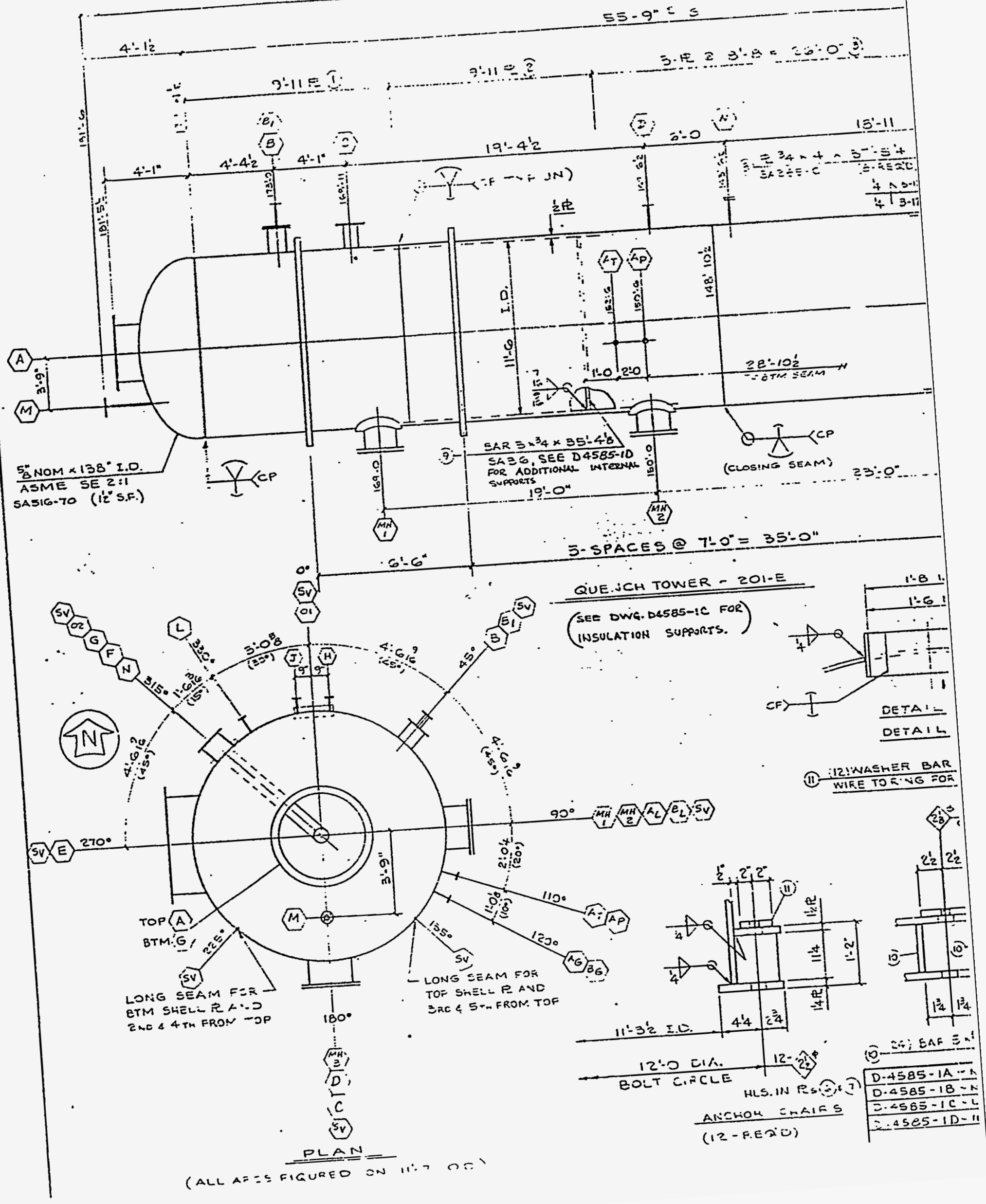




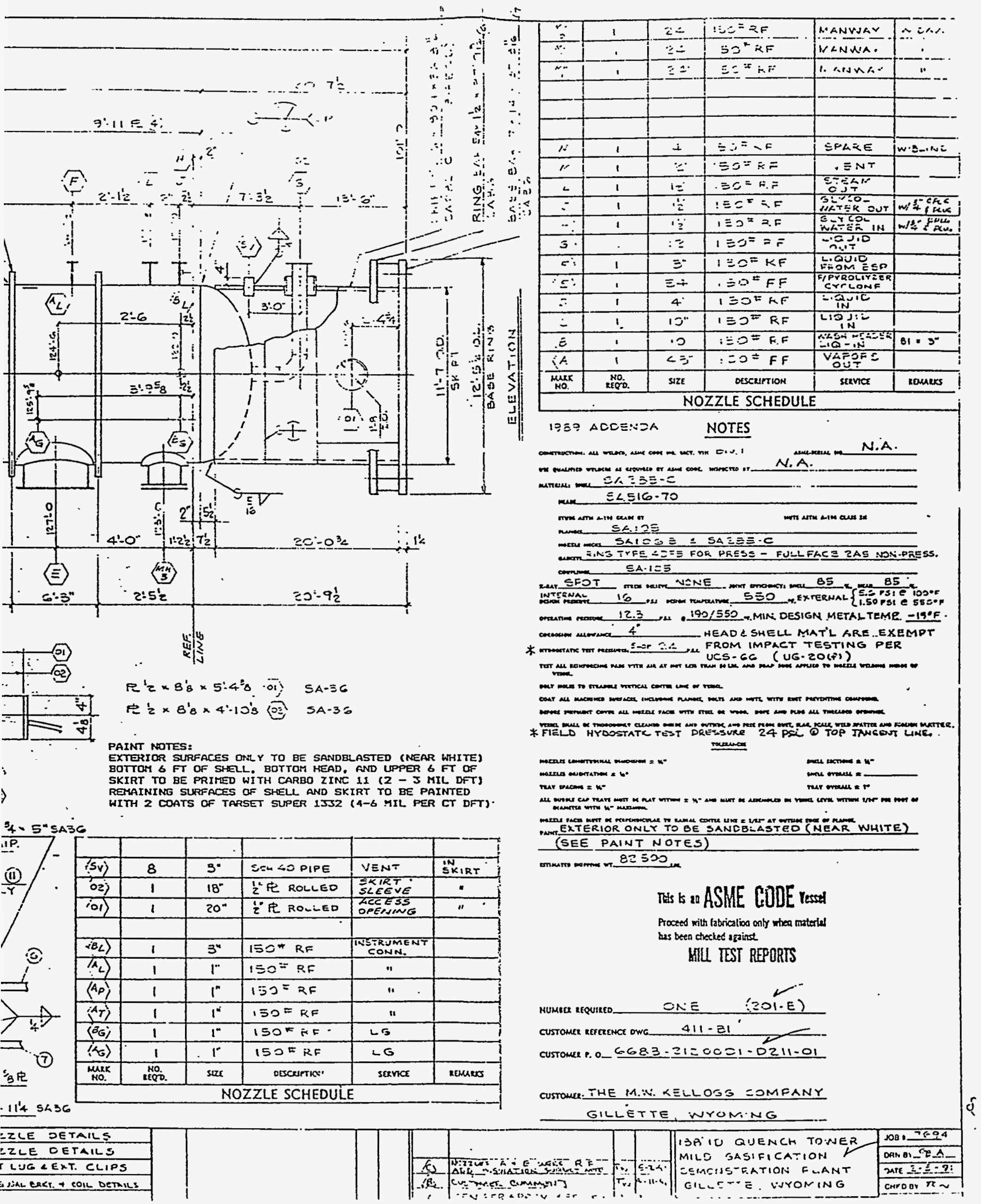




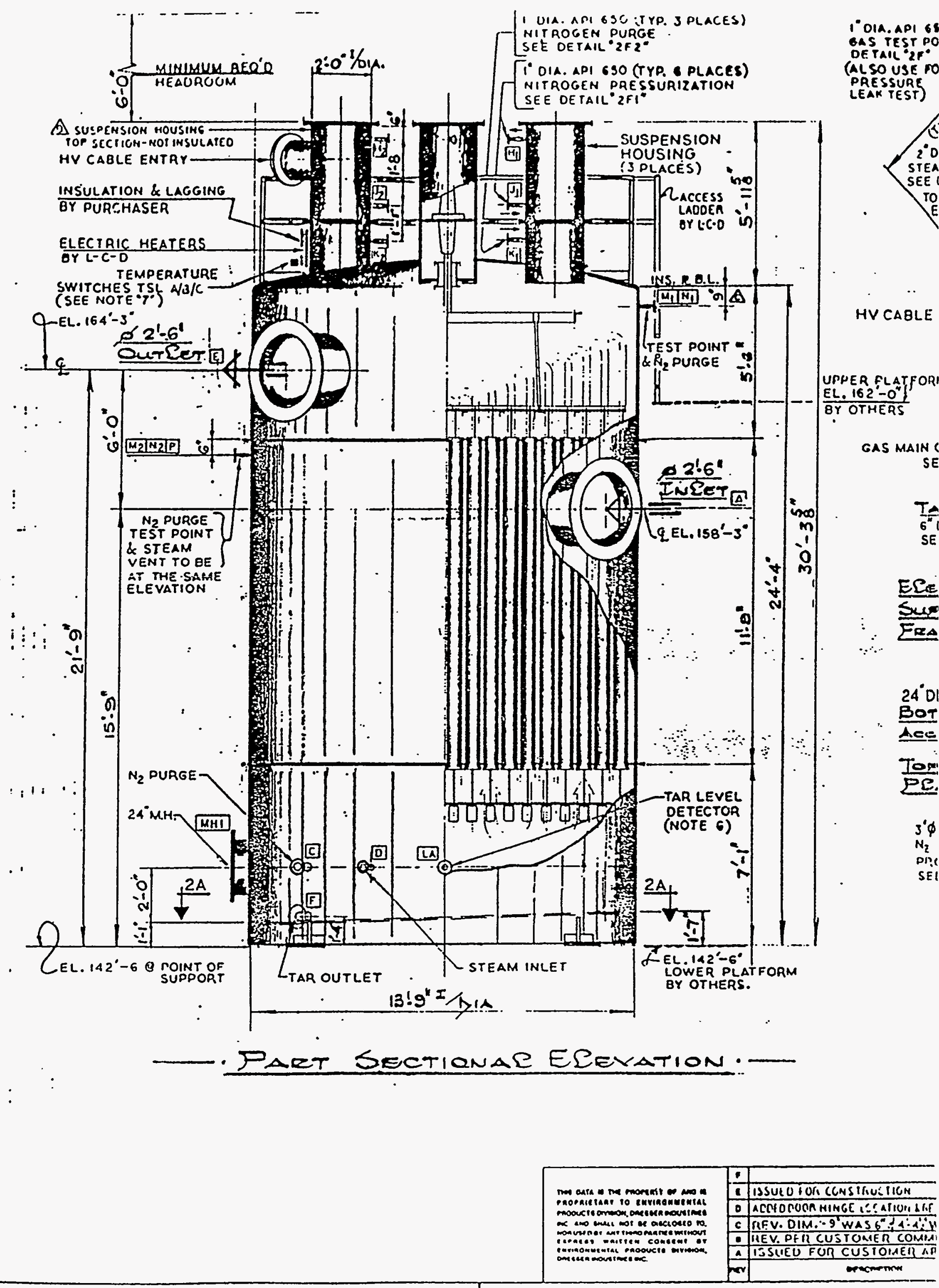




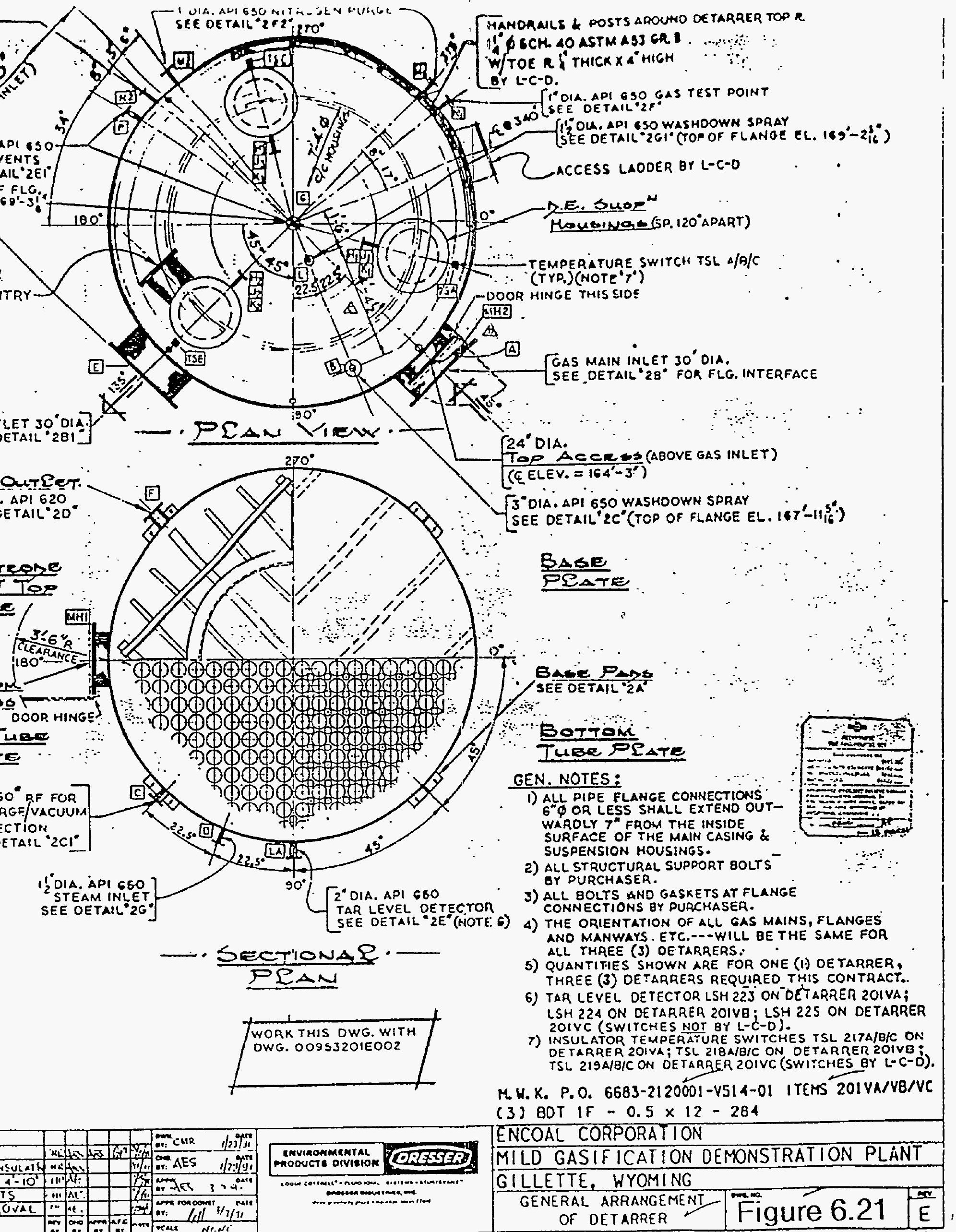




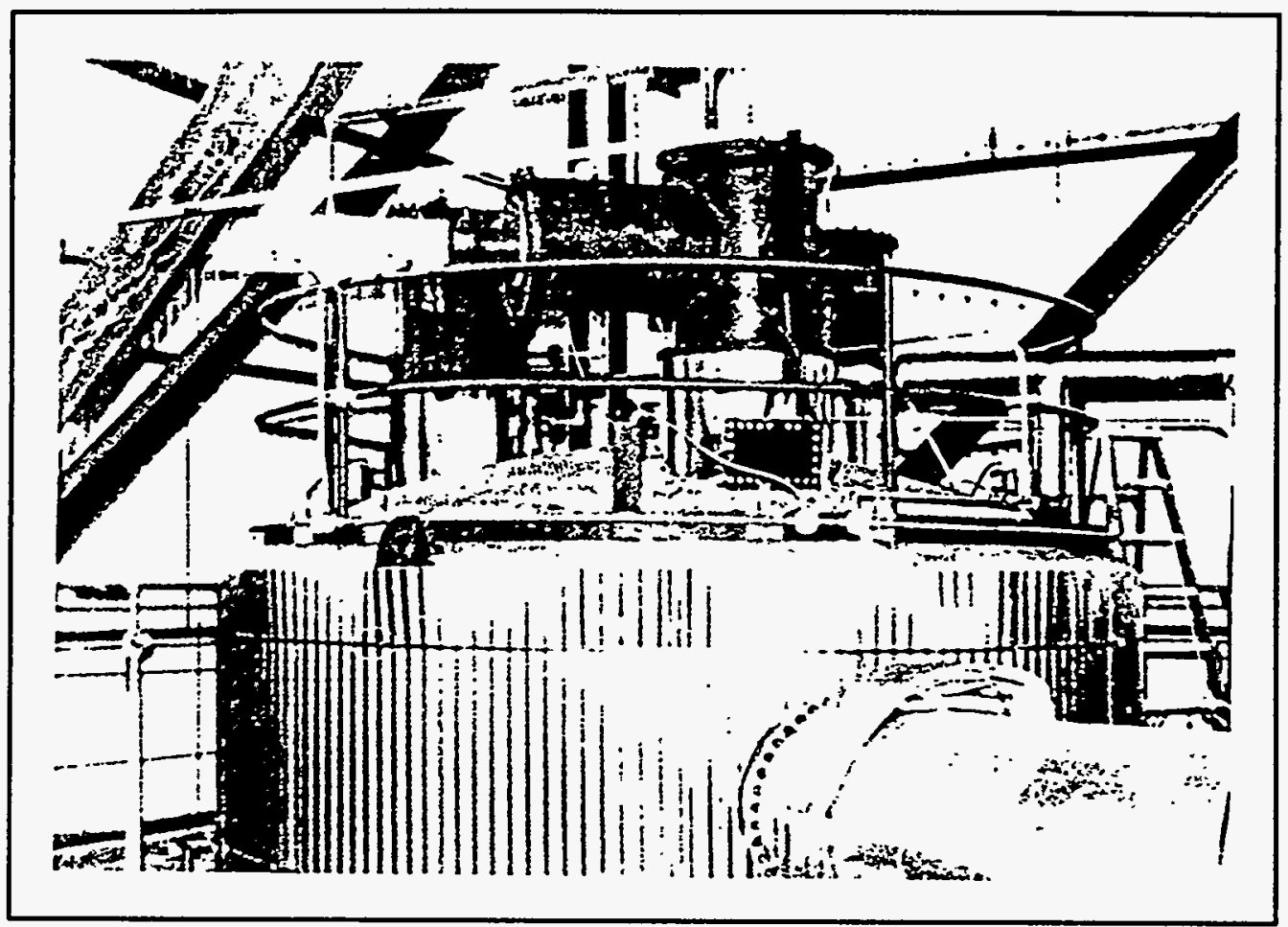

Figure 6.22 Top Portion of the Electrostatic Precipitator

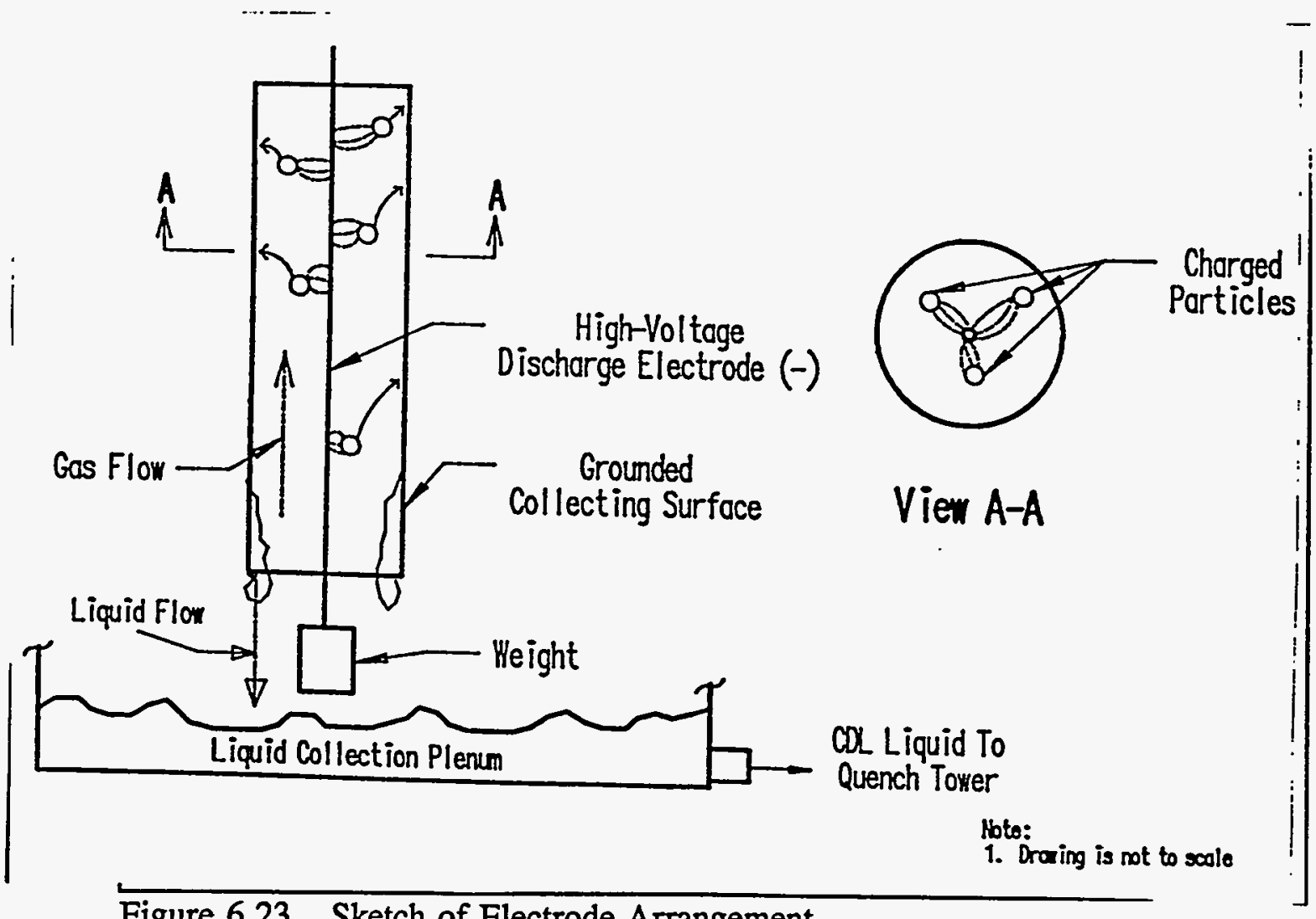

Figure 6.23 Sketch of Electrode Arrangement 


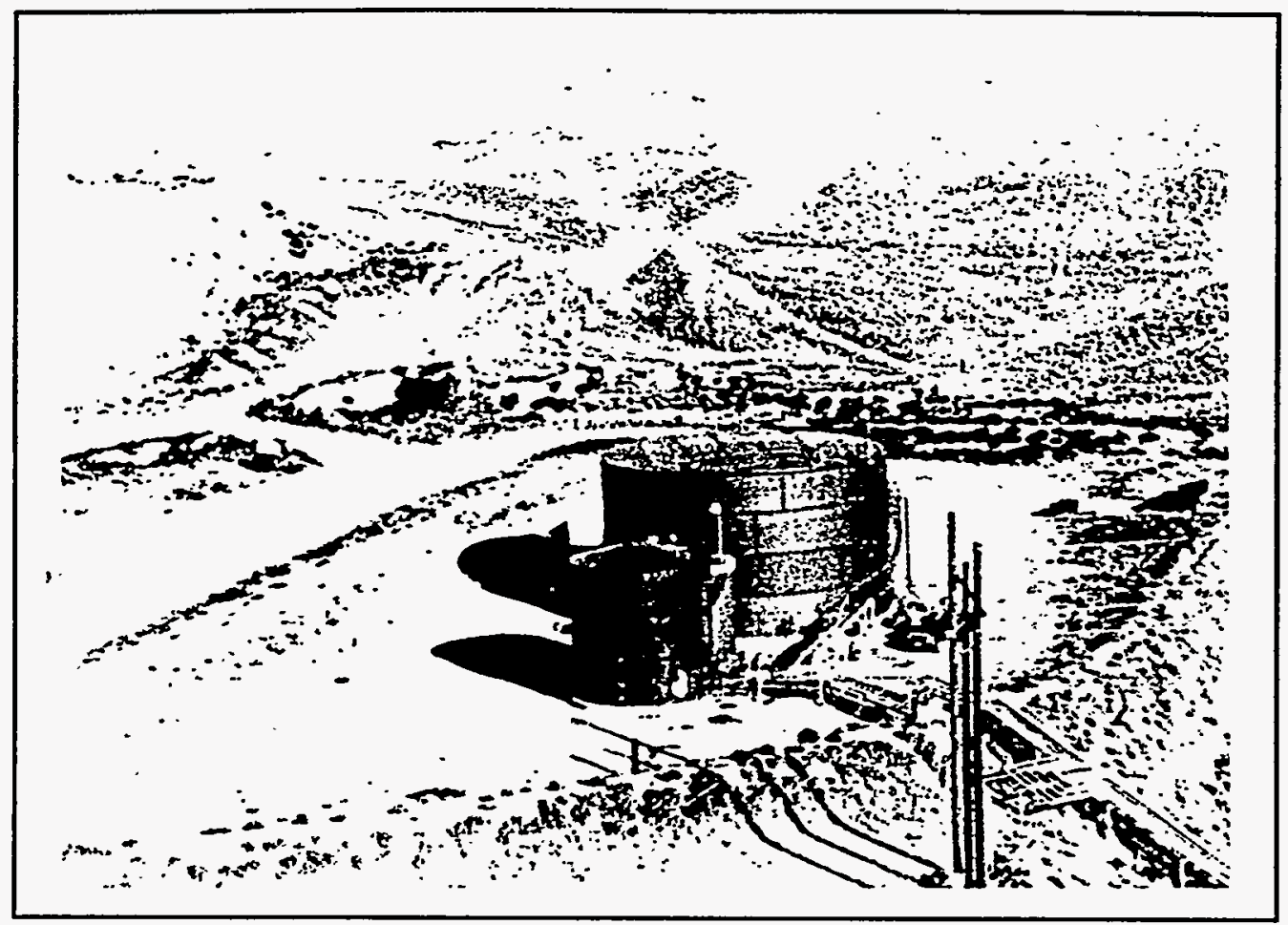

Figure 6.24 CDL Storage Tanks

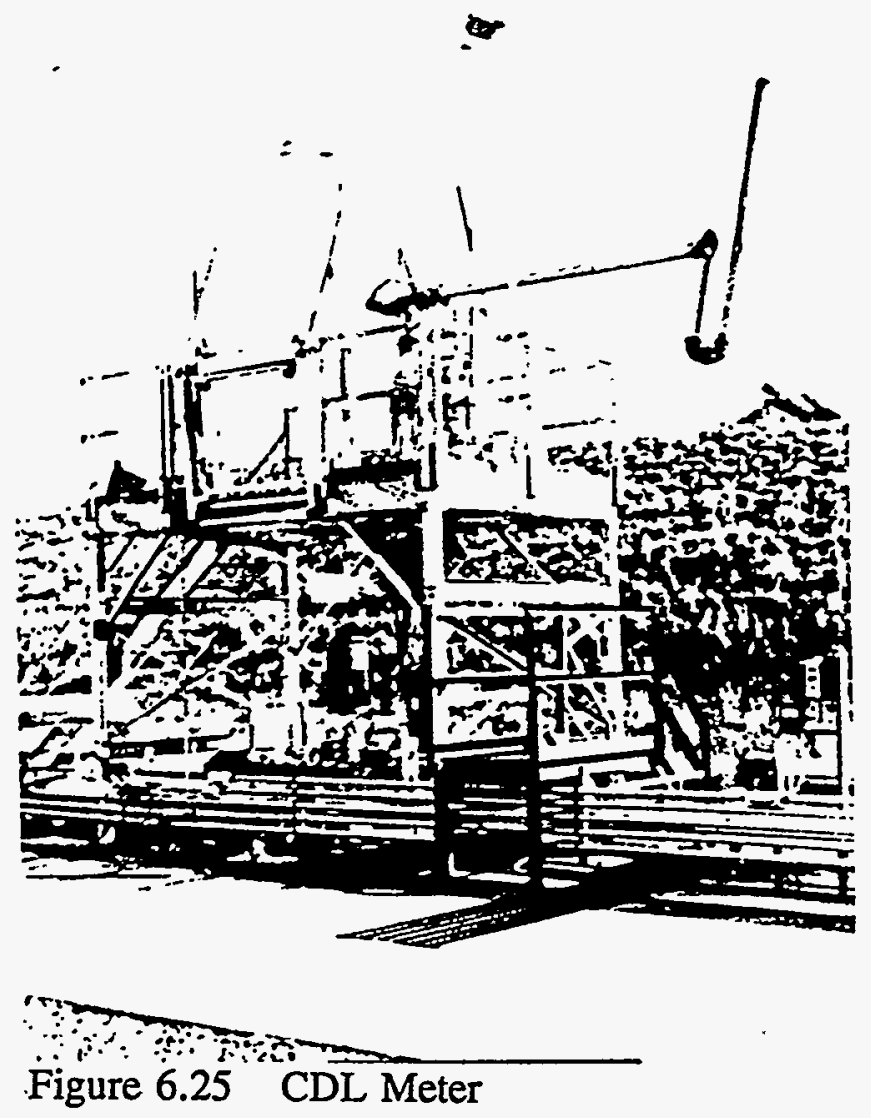




\subsection{DRYER BLOWER}

Recirculation of hot gases in the dryer loop is provided by a large blower (Figure 6.26). Recycled gas flows from the dryer cyclone to the suction of the blower. The gas is then pushed by the blower, mixed with the hot flue gas from the dryer combustor, and moved into the dryer under the grate to provide heat for the drying process. The dryer blower is a high-volume, lowhead fan driven by a $1000 \mathrm{HP}, 1200 \mathrm{RPM}$ electric motor. The motor is connected to the blower through a variable speed fluid-coupling. Gas flow demands are met by adjusting the settings on the variable speed coupling. The maximum head differential that the blower will develop is about 23 in. of $\mathrm{H}_{2} \mathrm{O}$ pressure. The height of the blower shell is $16 \mathrm{ft}$. and the suction and discharge ducts are $8 \mathrm{ft}$. in diameter.

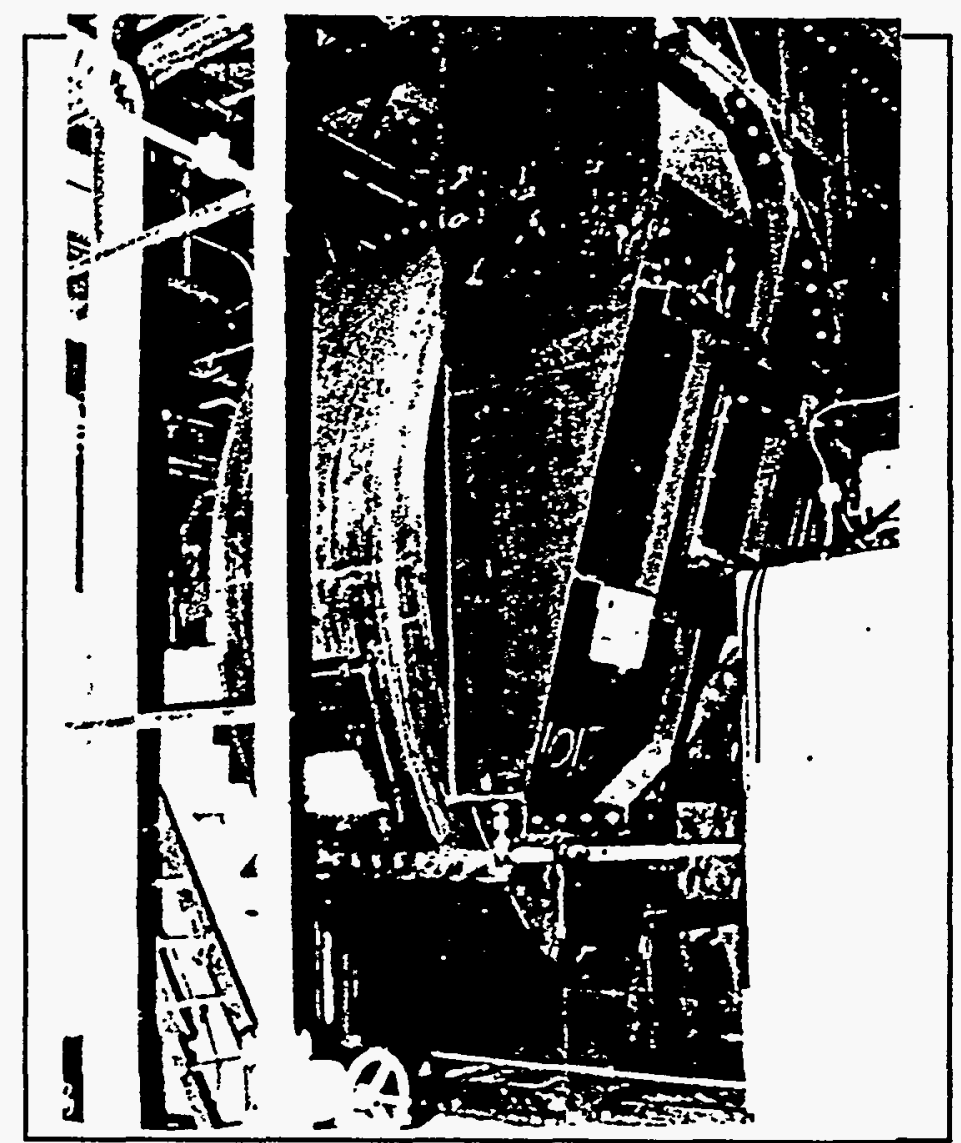

Figure 6.26 Dryer Recirculation Blower

\subsection{PYROLYZER BLOWER}

A $600 \mathrm{HP}$ blower moves the pyrolyzer off-gas from the ESP's to the combustors and to recirculation in the pyrolyzer loop. The shell of the pyrolyzer blower (Figure 6.27) is $12 \mathrm{ft} .3$ in. in height and a 1780 RPM motor drives the blower. Gas flow control is achieved by adjusting an inlet damper located at the blower suction. The maximum differential head that the blower will develop is about 31 in. of $\mathrm{H}_{2} \mathrm{O}$ pressure. The suction and discharge ducts are $4 \mathrm{ft}$. in diameter. 


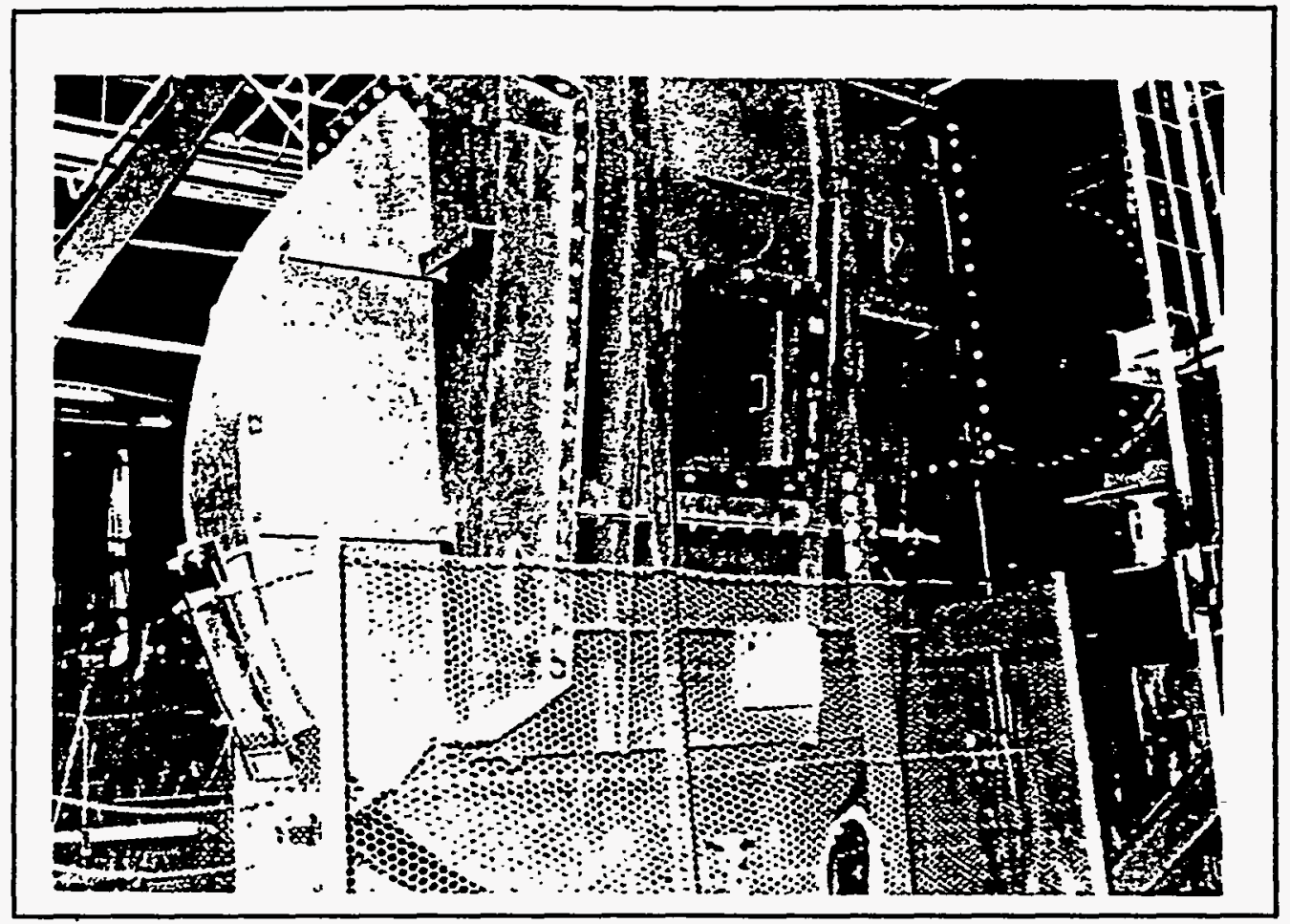

Figure 6.27 Pyrolyzer Recirculation Blower

\subsection{COMBUSTORS}

The dryer and pyrolyzer combustors (Figure 6.28) are gas fired heaters which supply the heat required for drying and pyrolyzing the coal. A general arrangement drawing typical of both combustors is shown in Figure 6.29 and Figure 6.30 shows the internals. Recycled gas from the discharge of the pyrolyzer blower, which contains non-condensible hydrocarbons, is the primary fuel for each combustor. Due to the low Btu value of the recycled gas (50-70 Btu/SCF), natural gas is burned as supplemental fuel. Each combustor is equipped with a forced draft air blower (Figure 6.31) which supplies air for combustion and takes suction from the atmosphere. Each blower is driven directly by a $100 \mathrm{HP}$ motor.

The combustors contain a natural gas fired pilot burner for the ignition of the flame within the combustor. Each combustor is equipped with natural gas burners which can deliver a maximum of $17 \mathrm{MM}$ Btu per hour. The primary fuel burners are ring type which contain clusters of nozzles. The burner management system for each combustor is controlled by individual programmable logic control (PLC) systems. The PLC monitors a number of variables and controls the natural gas and air so that the on-gas temperatures to the dryer and pyrolyzer are maintained.

\subsection{PURGE GAS TREATMENT}

In order to meet environmental standards, the purge gas being discharged to the atmosphere by the LFC process must be treated. The off-gas from the process, containing mostly water vapor, nitrogen, carbon dioxide and small amounts of sulfur oxides, (Table 6.1) is vented to a desulfurization unit (Figure 6.32) which consists of a wet gas scrubber and a horizontal 


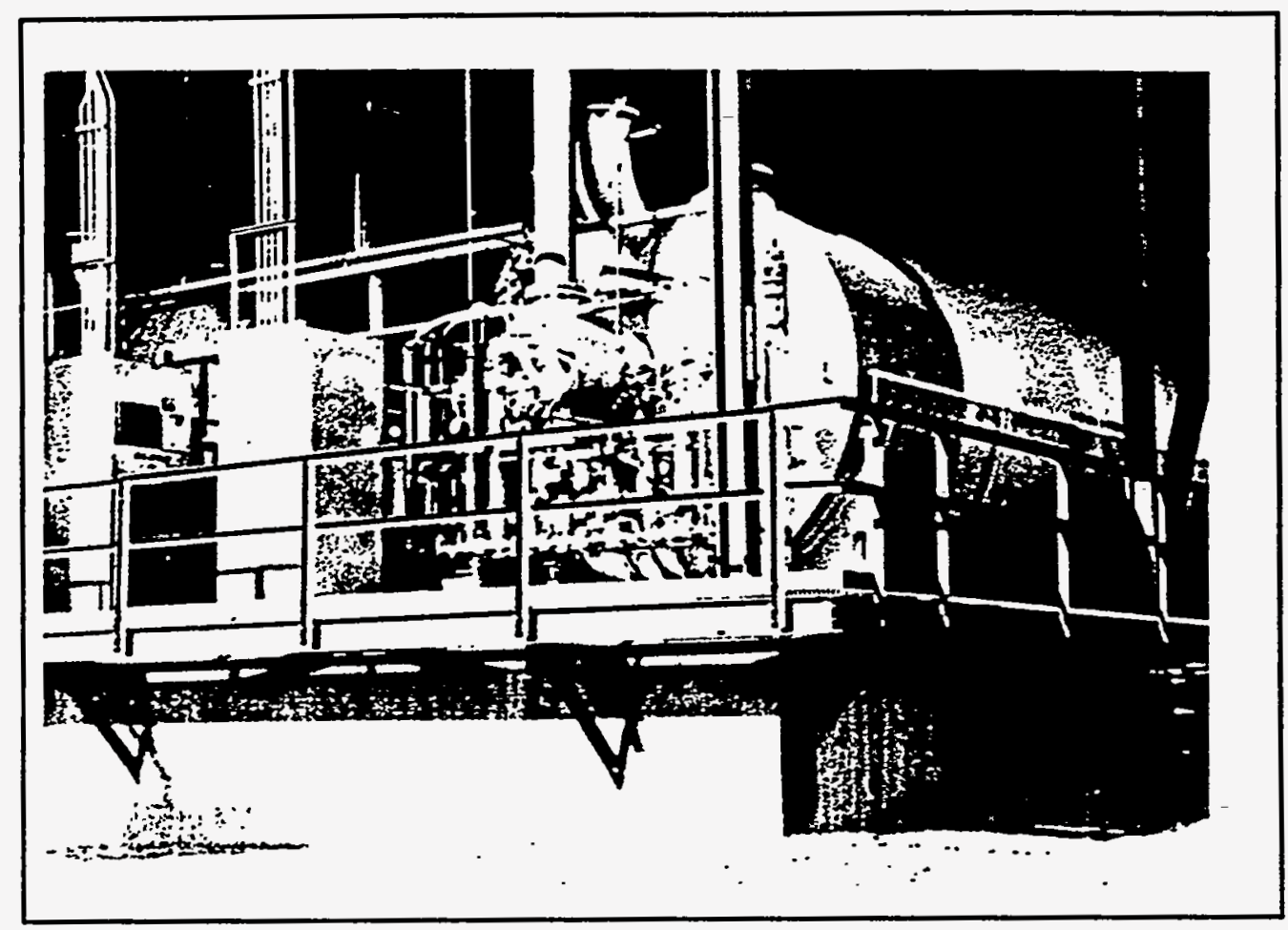

Figure 6.28 Combustors

scrubber. The gas is treated with sodium carbonate solution which converts the sulfur oxides to sodium sulfite. In the wet gas scrubber, dual atomization nozzles disperse the sodium carbonate solution into fine particles with compressed air and spray it into the purge gas stream to reduce the entrained particulates and sulfur oxides. The horizontal scrubber further reduces sulfur oxides in the purge gas as it flows horizontally through spray curtains of sodium carbonate solution. The gas then passes through mist eliminators just prior to leaving the horizontal scrubber to capture any entrained treating solution in the form of fine mist. (Figure 6.33)

Table 6.1 Purge Gas Composition

\begin{tabular}{lcc} 
COMPOSITION & WT. \% UNTREATED & WT. \% TREATED \\
\cline { 2 - 2 } & 0.03 & \\
$\mathrm{CO}_{2}$ & 14.10 & \\
$\mathrm{~N}_{2}$ & 46.74 & 14.01 \\
$\mathrm{H}_{2} \mathrm{O}$ & 37.93 & 46.60 \\
$\mathrm{SO}_{x}$ & 0.50 & 38.64 \\
$\mathrm{NO}_{x}$ & 0.02 & 0.02 \\
$\mathrm{O}_{2}$ & 0.41 & 0.02 \\
Solids & 0.27 & 0.68 \\
& & -0.00
\end{tabular}

The spent treating solution is discharged to an evaporation pond (Figure 6.34) where the sodium sulfite will oxidize into sodium sulfate. At the end of the Project life, the sodium sulfate, dried by evaporation, is encapsulated in a clay lined pod, covered with top soil and reclaimed. 


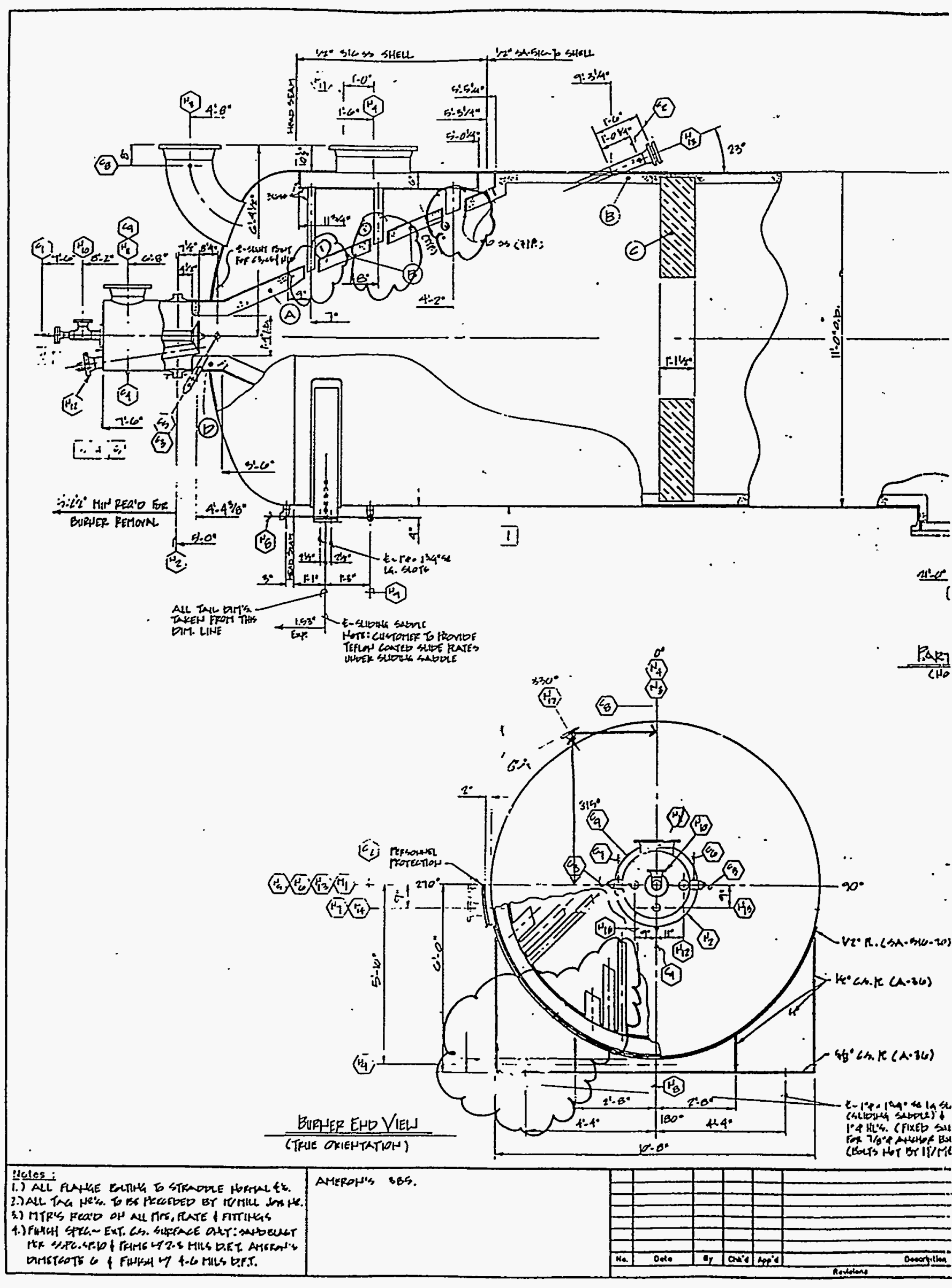




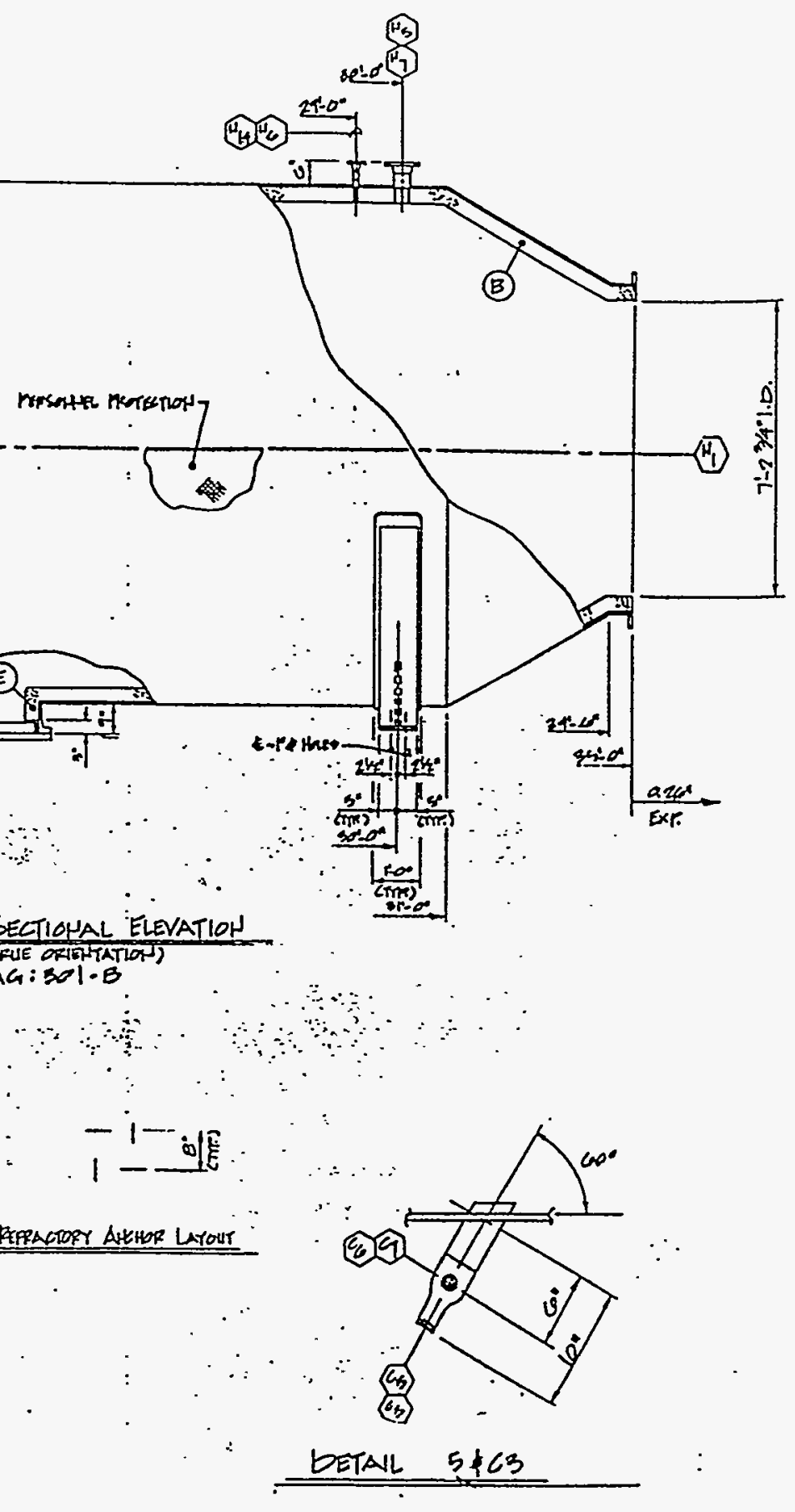

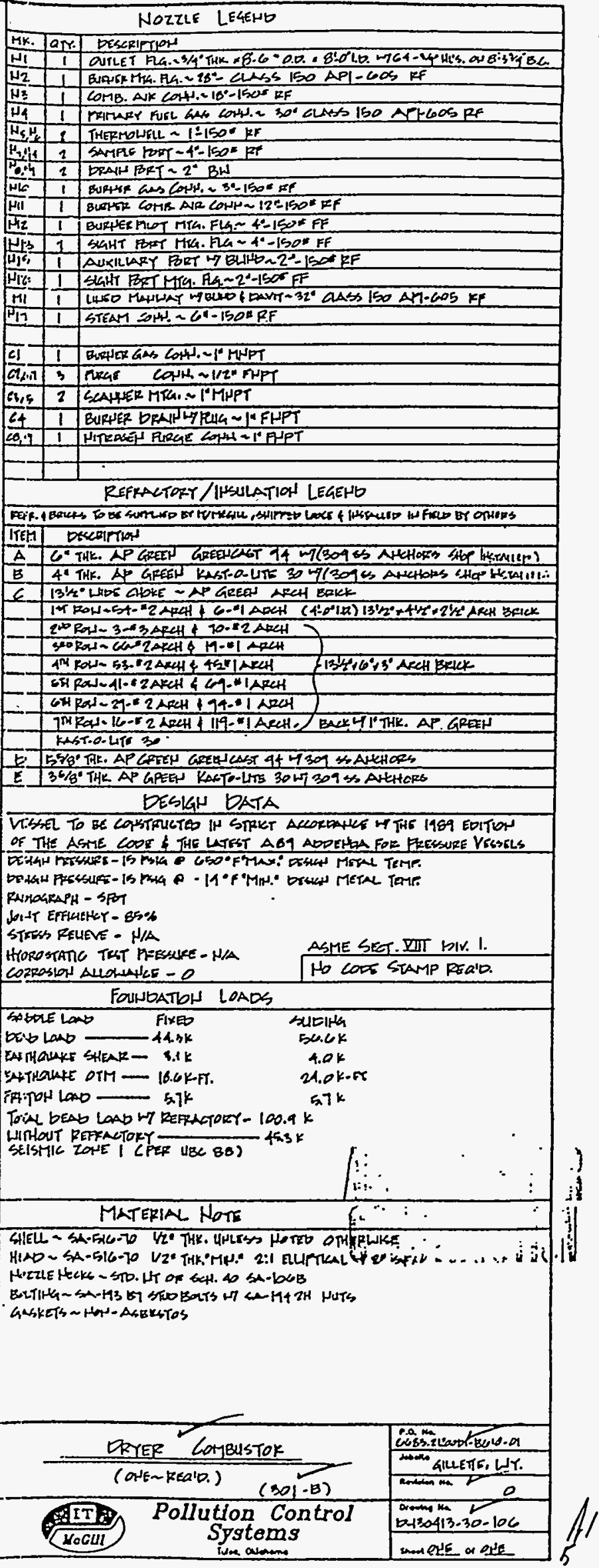

$55 \quad$ Figure 6.29 


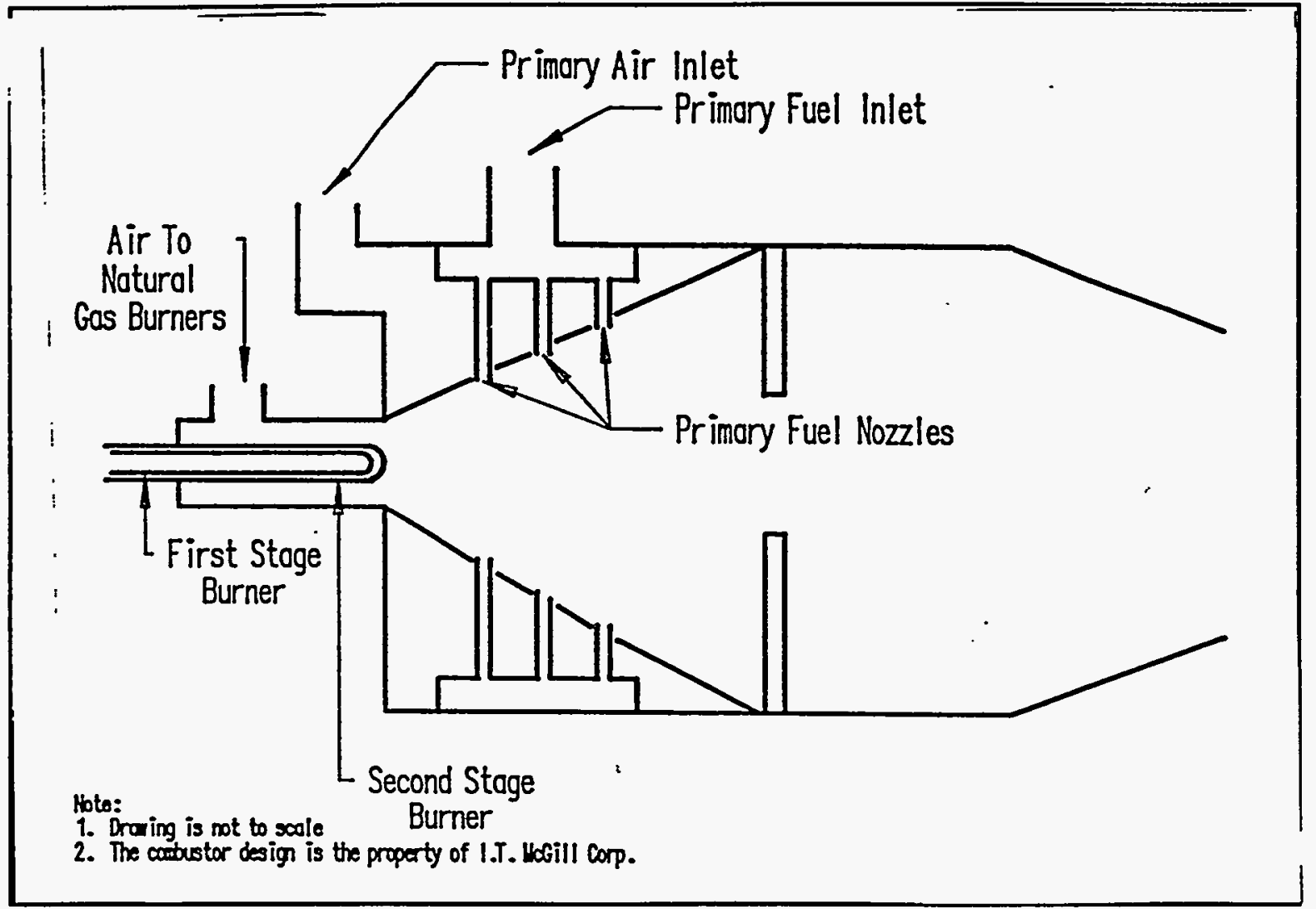

Figure 6.30 Sketch of the Combustor Internals

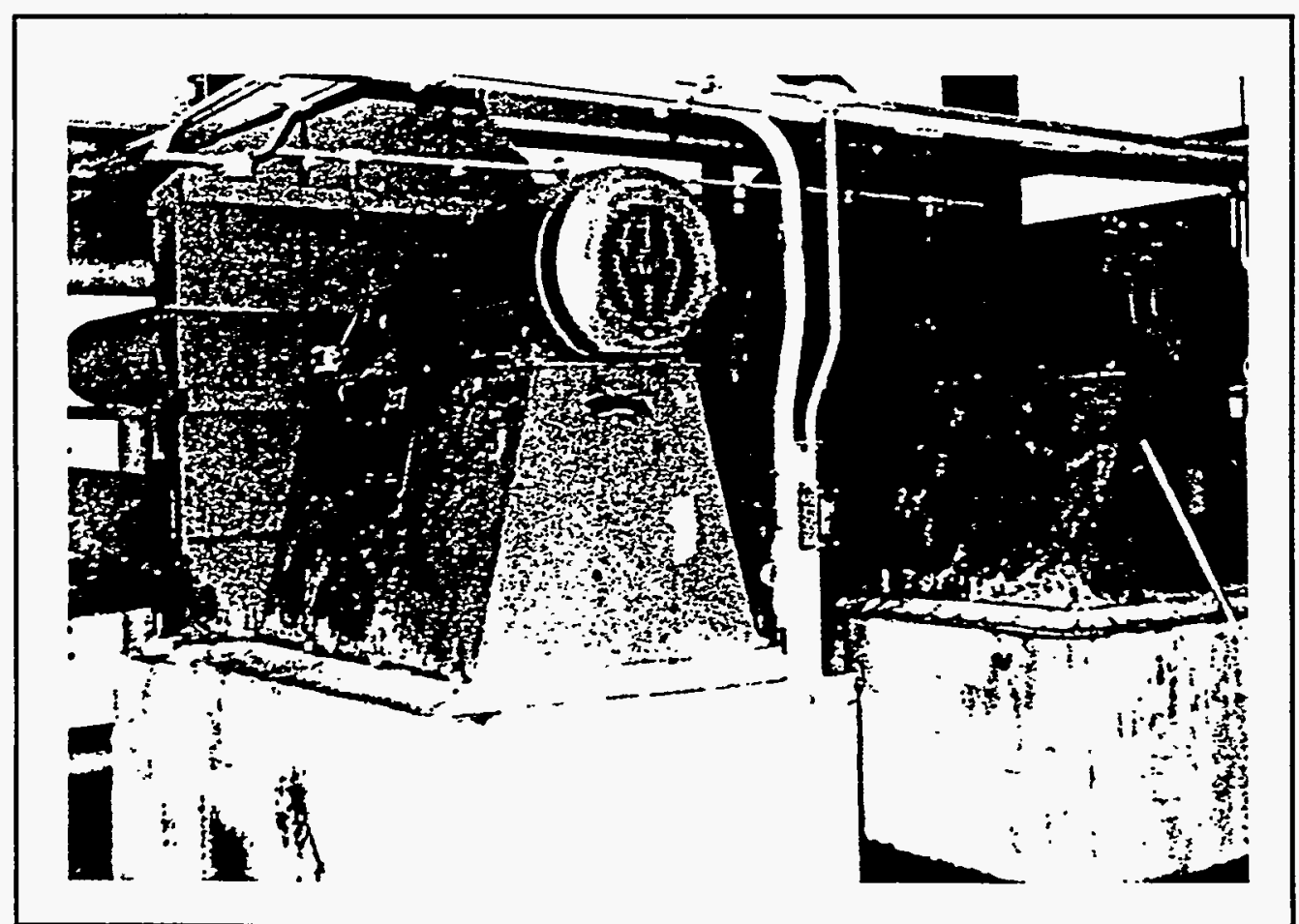

Figure 6.31 Combustion Air Blowers 
Page 57 Omitted 


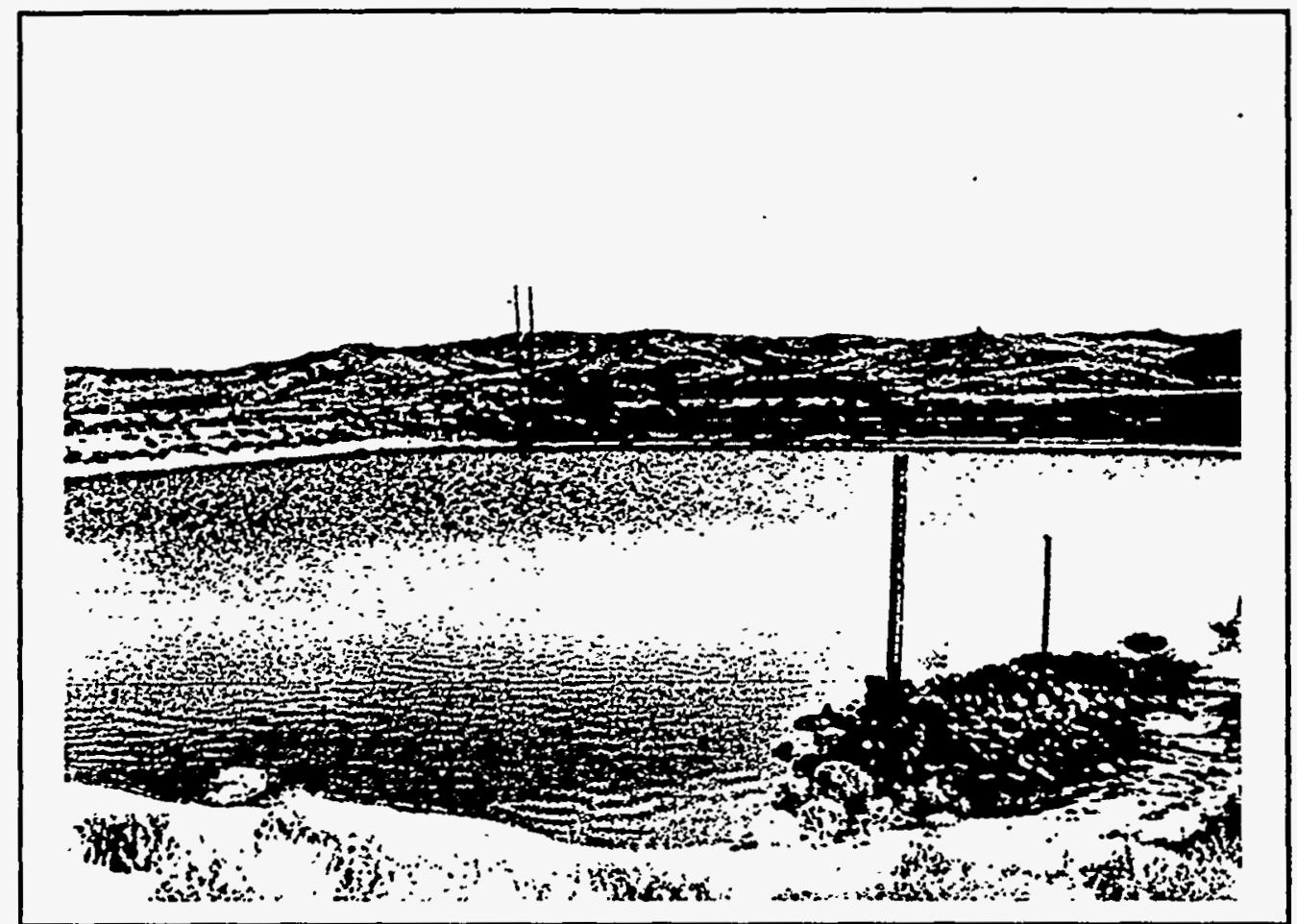

Figure 6.34 Temporary Evaporation Pond

\subsection{DUST SCRUBBERS}

When raw coal is conveyed from the feed coal silo, through the screening facilities, to the dryer feed hopper, coal dust is generated as the coal is loaded onto or discharged from a conveyor. In order to control the emission of dust, two dust scrubbers (Figures 6.35 and 6.36), one at the bottom of the feed coal silo and the other at the screening building, were installed. The dust scrubbers are used to collect coal fines at various transfer points i.e., the discharge of coal from or onto a conveyor. The dust scrubber, with the aid of a blower, pulls a suction at each transfer point. As the dust laden air stream passes through the scrubber, dual atomization nozzles disperse water into a fine mist with compressed air and spray it into the air stream. The air stream then flows through chevron separators to remove the coal dust and water, and the clean air is discharged to the atmosphere.

During startup and shutdown conditions, there are times when the facilities are not operating at design conditions, and dried, underpyrolyzed coal (off-spec PDF) is produced. The transfer of off-spec PDF to the PDF storage silo can be dusty. Therefore, two additional dust scrubbers were installed. They are used to collect coal fines at various transfer points where PDF is conveyed, e.g. from the PDF cooler to the PDF storage silo, and from the storage silo to conveyors. 


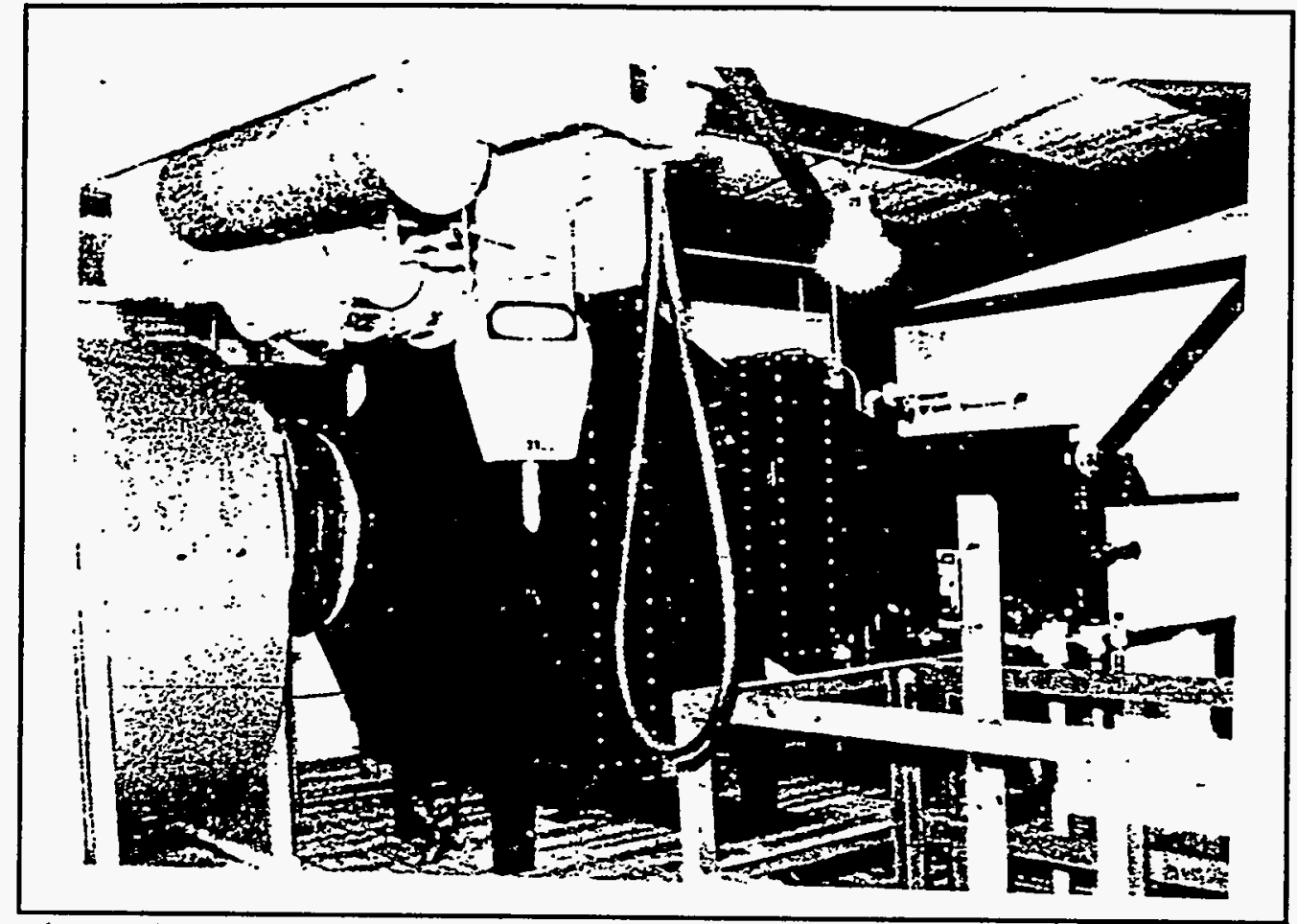

Figure 6.35 Dust Scrubber at Screening Facilities

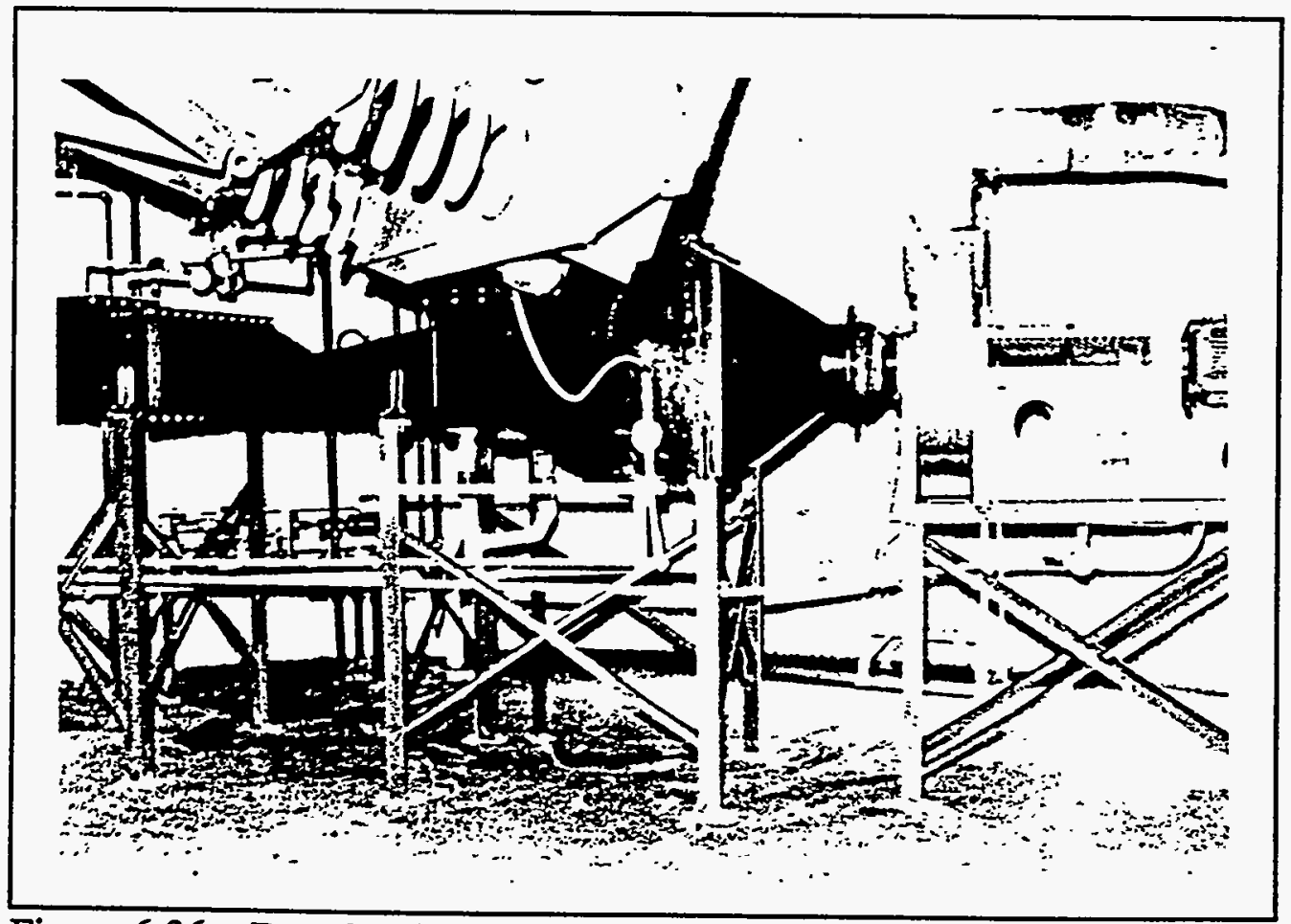

Figure 6.36 Dust Scrubber at Coal Feed silo 


\subsection{UTILITIES}

\subsection{STEAM SYSTEM}

A package steam boiler from York Shipley is used to supply 150 psia steam at a design capacity of $10,000 \mathrm{lb}$ per $\mathrm{hr}$. The package includes a water softener, deaerator, chemical injection system, steam boiler, and a vendor supplied control package. The water softener is used to remove dissolved minerals from the feed water to prevent fouling in the equipment. The deaerator removes dissolved oxygen from the water to prevent corrosion. Chemicals are injected into the feed water before it enters the steam boiler to ensure clean water with no dissolved oxygen is used. The steam boiler burns natural gas as the source of heat to vaporize the feed water into steam.

Steam is used at various utility stations located in the PDF building. In the analyzer house where gas-chromatographs are used to determine the composition of various process streams, steam is used to provide heat for sample lines. Steam is also used to maintain the glycol/water system (described in section 7.4) temperature during plant startup and shutdown.

\subsection{INSTRUMENT AND PLANT AIR}

Compressed air demands in the facilities are met by two electrically driven air compressors; each delivers 750 SCFM of air at 125 psig discharge pressure. The compressed air used to operate various pneumatic instruments and valves is dried to $-40^{\circ} \mathrm{F}$ dew point of water before its application. Since the pneumatic instruments and valves are deemed to be crucial to the operation of the facilities, miscellaneous plant air consumers will be automatically shut off from air supply if the system pressure starts to fall, thus giving preference to instrument air.

Compressed air is used at various utility stations located in the PDF building. Other major compressed air users are the dust scrubbers, the wet gas scrubber in the desulfurization unit, and the MK dust suppressor. It is expected that one compressor will supply the total air requirements except when MK is being applied to the PDF.

\subsection{COOLING WATER}

Triton Coal Company has an 8-acre pond called Sedimentation Pond No. 1. It is used for settling suspended particles from the mine water before discharge. Cooling water circulation pumps take suction from this pond. The cooling water then flows through filters and into the cooling water system. The major users of cooling water are the PDF cooler, glycol/water trim cooler (described in section 7.4), dust scrubbers, dryer fines screw cooler, and dryer blower fluid coupling. All the water which is used solely for indirect contact heat-exchange operations is returned back to the pond. The heat that is added to the pond by heat-exchange operations is small, and natural evaporation of water from the pond will maintain a satisfactory pond temperature. The largest heat loads on the system are the PDF cooler and the glycol/water trim cooler. 


\title{
7.4 GLYCOL/WATER CIRCULATING SYSTEM
}

The glycol/water system is a closed circulation heating and cooling system. During normal operation, process heat is first absorbed in the system and then given up to heat consumers or released to the atmosphere and/or cooling water. During startup and shutdown situations, when process heat is not available, the system is heated with steam to maintain the necessary user temperature.

A cold 50/50 glycol/water solution is stored in a 150-barrel storage tank. A circulation pump or its spare takes suction from the storage tank and discharges parallel streams through the following:

\author{
Pyrolyzer Quench Steam Condenser \\ Quench Oil (CDL) Coolers \\ Glycol/Water Steam Heater
}

During normal operation, glycol/water is used to condense steam in the pyrolyzer quench steam condenser. The steam is generated in the quench table by quenching pyrolyzed coal with water. In the CDL cooler (Figure 7.1), glycol/water extracts heat from the CDL so that the CDL can be recirculated to the top of the quench tower as reflux. During start-up and shutdown, the glycol/water is heated by steam in the glycol/water steam heater. The three heat absorbing streams rejoin, forming a hot glycol/water header to supply approximately $185^{\circ} \mathrm{F}$ glycol/water to heat consumers (i.e., tank heaters, heat tracings, and MK application heater).

The cool glycol/water streams returning from the heat consumers recombine into a header, and flow through a fin fan air/glycol heat exchanger (Figure 7.2) which cools the glycol/water to $95^{\circ} \mathrm{F}$ by forced convective air. If the ambient temperature is too high and the glycol/water cannot be cooled to the design temperature by the fin fan cooler alone, the glycol/water will be cooled further by heat-exchange with cooling water in the glycol/water trim cooler, which operates in series with the fin fan cooler. The glycol/water then returns to the storage vessel. The temperature of glycol/water to storage is controlled by a bypass across the two exchangers.

Since both of the glycol/water circulating pumps are driven by electric motors, in case of emergency, a small gear pump is used to supply glycol/water to critical heat traced lines. The electric motor for the smaller pump is connected to the emergency electric power supply.

\subsection{POTABLE WATER}

Potable water originates from the Buckskin Mine's water system and supplies the PDF area and administration building via an underground main. In the PDF area, potable water services the emergency eyewash and safety showers, and is the feedwater for steam generation. It is also the source of water for preparing the glycol/water solution in the storage tank. 


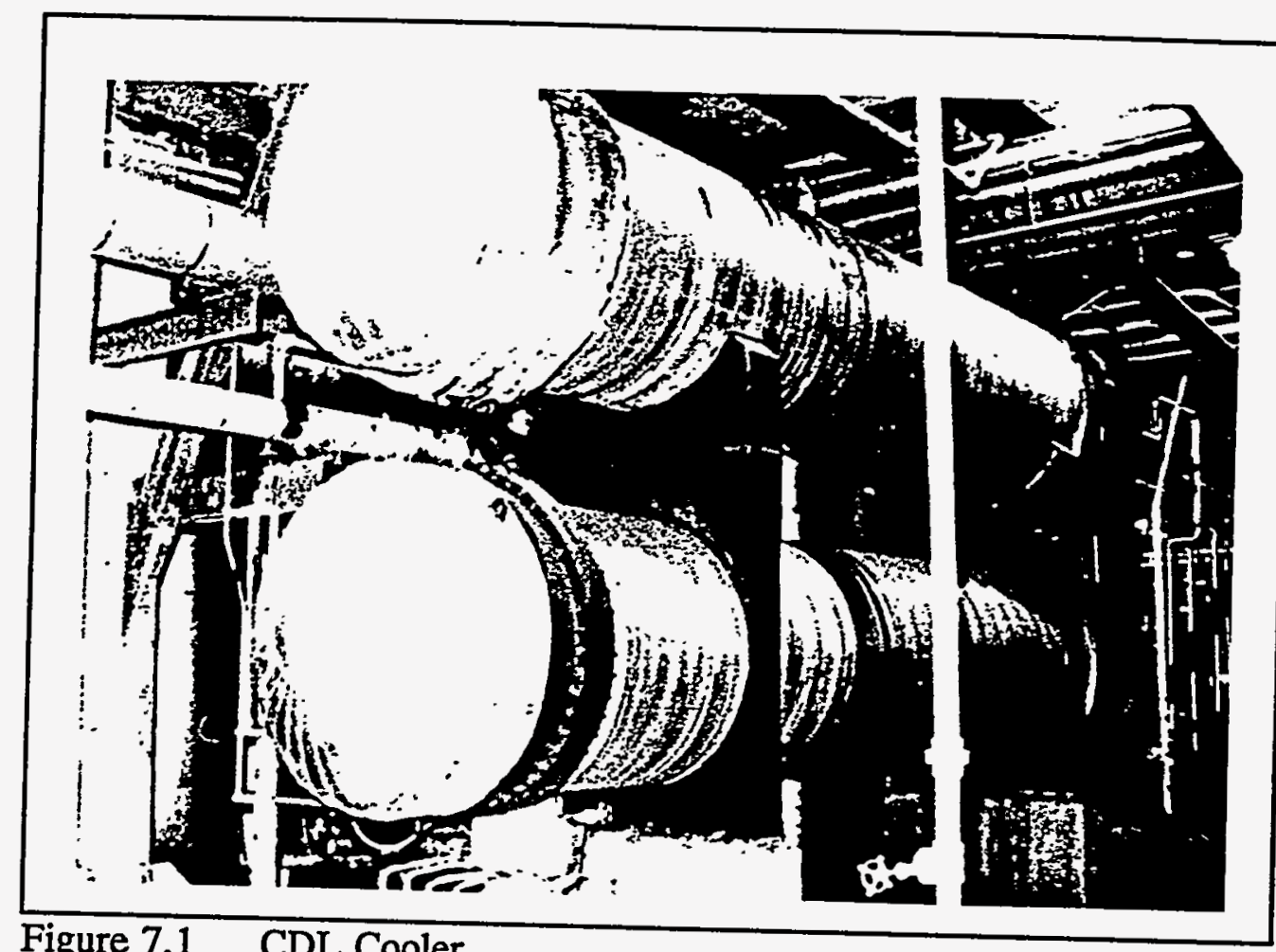

Figure 7.1 CDL Cooler

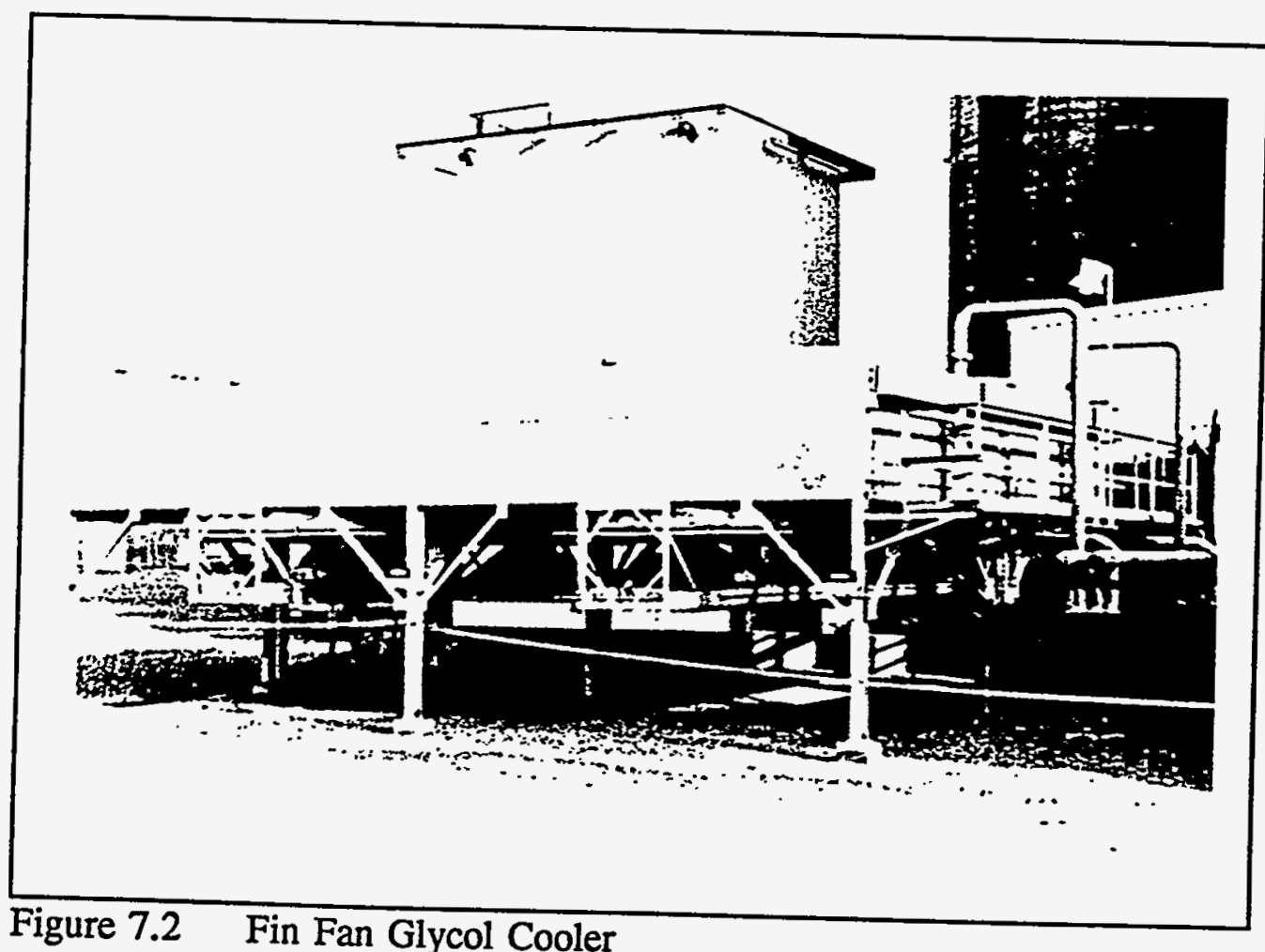

Figure 7.2 Fin Fan Glycol Cooler 


\title{
7.6 FIREWATER
}

Firewater for the PDF area is supplied from the existing Triton underground firewater main. The new extension from the Triton system splits into three branches. One branch partially rings the unit area, supplying water to fire hydrants located outside the PDF structure. The second branch supplies firewater to hose stations located on each level of the screening structure. The third branch supplies firewater to hose stations on each level of the PDF building. There are ten levels in the PDF building. Each level contains, as a minimum, one firehose station. The water supply to each of the lower five levels contains a restriction orifice to prevent excessive flow from decreasing the available water to the upper five levels.

A firewater booster pump was installed to increase the head pressure of the firewater system within the PDF building, thus ensuring ample water is available to the upper levels. The pump takes suction from the underground firewater main and discharges through a vertical header supplying water to each level. The pump is not spared but does contain a full line size bypass. Normally, the bypass line is open and the pump is aligned for automatic starting. The building firewater pressure is maintained from the existing system through the pump bypass. If the water pressure within the building decreases due to heavy demand, a pressure instrument will sense the situation and automatically start the booster pump.

On the lowest level, the firewater header extends approximately five feet outside the PDF building and terminates with a block valve and two fire hydrant type nozzles. The intent is to connect a fire truck (pumping type) to the nozzles to supply the firewater when the firewater booster pump is out of service for maintenance. The fire truck pump will take suction from the underground firewater main through a fire hydrant nozzle.

\subsection{NITROGEN}

Liquid nitrogen is transported to the plant by truck and off-loaded into an 11,000 gallon cryogenic storage vessel. Pressure on the liquid nitrogen storage vessel is maintained at 100 psig. The liquid nitrogen is vaporized to supply gaseous nitrogen to the facilities at $100 \mathrm{psig}$ and $40^{\circ} \mathrm{F}$. The vaporizing coils are contained in a static water/glycol mixture bath that is direct fired by a natural gas burner.

Nitrogen is distributed to utility (hose) stations in the PDF and screening buildings. Additionally, it is hard piped with pressure regulators and trip valves to prevent vacuum conditions from occurring in the following vessels:

\author{
Coal Dryer \\ Dryer Cyclone \\ Pyrolyzer \\ Pyrolyzer Cyclone \\ Pyrolyzer Quench Chamber \\ ESP's
}


In case of a process upset where the above equipment maybe subjected to vacuum conditions, nitrogen will be introduced into these vessels to maintain a preset minimum internal pressure. In addition, before each startup, nitrogen is used to inert the drying and pyrolyzing loops to reduce the oxygen content. It is supplied to the combustors as purge gas to inert the combustor before it is lighted. It is also used as the purge gas for various instruments. Moreover, the ESP vessels require nitrogen to continually purge and pressurize the electrical connection dome chamber.

\subsection{NATURAL GAS}

Natural gas is the main source of fuel for all the building heating equipment in the facilities. It is supplied to the unit area from Western Gas Processors Pipeline. Natural gas is used to fire the space heaters, nitrogen vaporizer, feed coal silo heater, PDF silo heater, package steam boiler, and both dryer and pyrolyzer combustors.

\subsection{CONSTRUCTION}

\subsection{CONTRACTING METHODOLOGY}

Construction of the ENCOAL LFC plant was done by Kellogg Construction Inc. (KCI) as part of the EPC contract with The MW Kellogg Company. Due to the short time allowed by the original Construction Schedule shown in Figure 8.1, a fast track approach was used, that is the field construction overlapped the engineering phase for all but the first two months. $\mathrm{KCI}$, as the project manager, chose to implement the project by hiring subcontractors rather than use their own labor due to the remoteness of the location compared to their normal work area. KCI was able to find an adequate number of qualified local contractors to bid and perform the work. All work was done on a merit shop basis.

Shortly after the ENCOAL Project was approved and went into design, Triton Coal Company, the site host started construction on a project to expand the Buckskin Mine coal handling facilities. A number of interferences between the two projects resulted in some design changes, but for the most part, there were advantages to both projects being in construction at the same time. Having contractors available on site reduced mobilization costs and being able to offer more work made contractors more competitive. In the case of the earthwork and the concrete silos, ENCOAL being a sister company to Triton, was able to "tag on" to existing competitively bid contracts and start field construction as soon as the design work was done in those areas. As a result, ENCOAL subcontracted directly for the earthwork and silos and $\mathrm{KCI}$ managed the work in the field. 


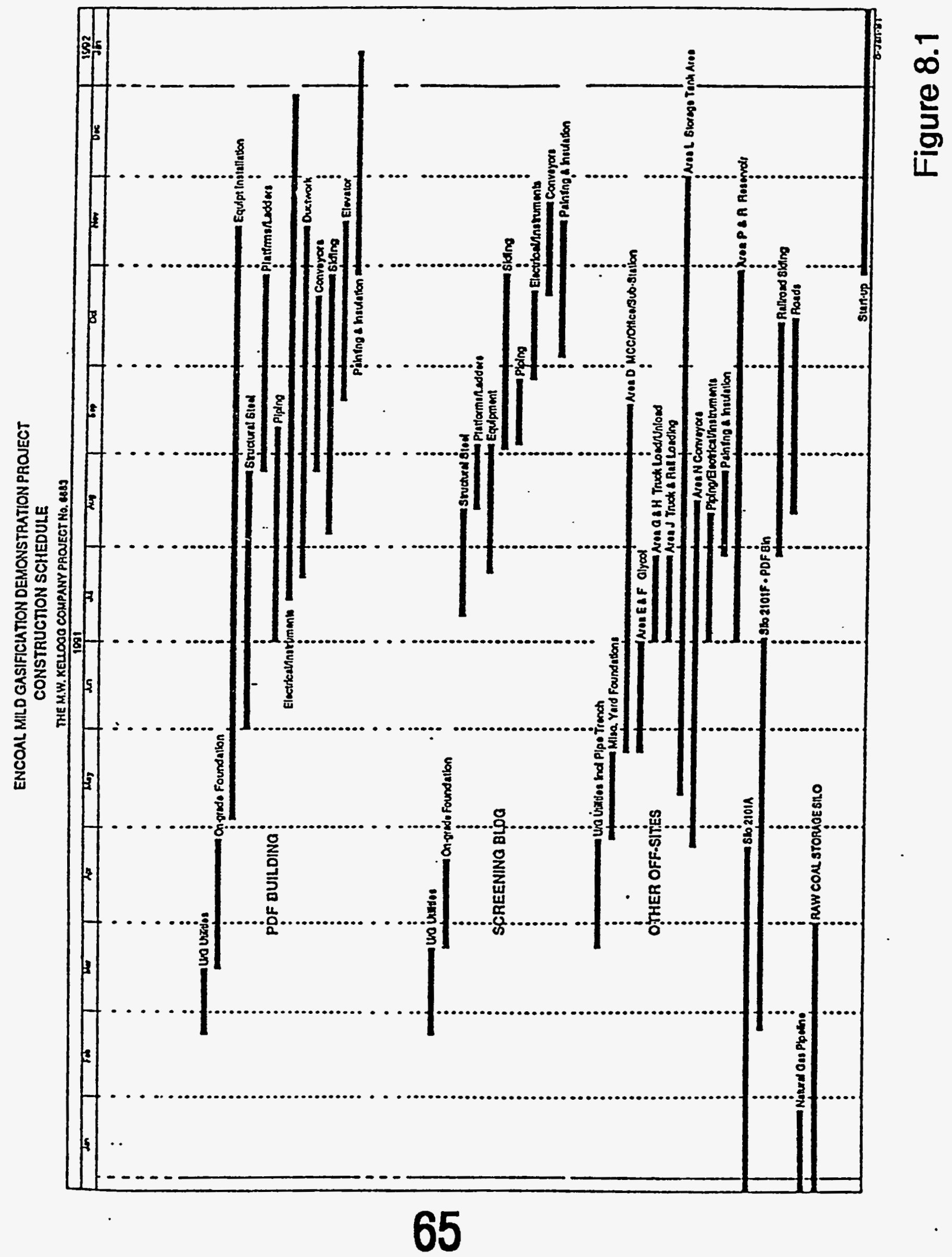




\subsection{CONTRACT PACKAGES}

As discussed above, $\mathrm{KCI}$ elected to perform the construction phase by using subcontractors for all field work. The result was 17 major subcontract "packages" for specialty work as outlined in Table 8.1. The advantages of this method were:

(1) improved ability to do work in parallel and save time

(2) allowed better match of subcontractor skills with the specialty work to be done and saved the mark-up that a general contractor would charge,

(3) allowed more small and small disadvantaged businesses to compete for the work, and

(4) enabled $\mathrm{KCI}$ to use more local contractors.

The disadvantages of the subcontractor approach were:

(1) more effort was required to coordinate the on-site work and

(2) there were more interface points between subcontractors that had to be worked out.

The advantages far outweighed the disadvantages on the project and many qualified local firms were successfully employed.

\subsection{EARTHWORK, SURVEYING AND TESTING}

The initial rough excavation for the PDF plant and screening building was done by Triton using a large mining shovel and trucks. Several thousand yards of material had to be moved and this was the most efficient and expedient method. Completed in September, 1990, the work only took two days. For the fine grading at the plant site and overall site preparation, a contract was awarded to the low bidder on the Triton expansion project. Early surveying work was also done by extending one of Triton's contracts since they were on site and had all the ground control points established. This initial work was managed by ENCOAL and Triton prior to mobilization of $\mathrm{KCI}$ in the field.

By October, 1990, Kellogg had completed enough engineering to define the scope of work for a total site preparation package, complete with drainage, roads, ponds, plant buildings and tank farms as described in Section 5.1. KCI then mobilized at the plant site and developed an office for the construction team that would follow. They bid the earthwork, surveying and materials testing and awarded new subcontracts for each. Site preparation began in earnest at this point.

As a matter of practice, all engineered backfill was tested for compaction and all structural concrete was tested for proper mix qualities. Test cylinders were taken from each major concrete pour and tested for seven day and 28 day strengths. Spot checking of welding was done for general piping and plate work. Natural gas piping was inspected by $\mathrm{x}$-ray techniques on $100 \%$ of the welds. A materials testing contractor performed all of these services. 
Table 8.1 Subcontractors for ENCOAL Project

\begin{tabular}{||l|l|c|c|c||}
\hline \multicolumn{1}{|c|}{ PACKAGE } & SUBCONTRACTOR & $\begin{array}{c}\text { SMALL } \\
\text { BUS. } \\
\text { (Y/N) }\end{array}$ & $\begin{array}{l}\text { PEAK } \\
\text { STAFF }\end{array}$ & $\begin{array}{l}\text { AMOUNT } \\
\text { (M\$) }\end{array}$ \\
\hline \hline Mechanical Erection & Summit Construction & N & 125 & 6,564 \\
\hline Electrical \& Instr. & West Electric & N & 35 & 2,072 \\
\hline Architectural Bldgs. & Hladky Construction & Y & 20 & 440 \\
\hline Above Ground Piping & Hladky Construction & Y & 8 & 283 \\
\hline Earthwork & AGE Construction & Y & 7 & 546 \\
\hline Foundations & Hladky Construction & Y & 22 & 773 \\
\hline Concrete Silos & Hoffman Inc. & Y & 20 & 3,000 \\
\hline Surveying & Eagle Surveys & Y & 3 & 64 \\
\hline Materials Testing & C.E. \& M.T. & Y & 2 & 71 \\
\hline Underground Piping & Larry's Inc. & Y & 12 & 869 \\
\hline Insulation & Hladky Construction & Y & 6 & 245 \\
\hline Ceramic Lining & Coors Inc. & N & 5 & 135 \\
\hline Rail Siding & Midwest Railroad & Y & 9 & 127 \\
\hline Large Storage Tanks & Rocky Mountain Fab. & N & 10 & 264 \\
\hline Firewalls & Caspar Builders & Y & 4 & 31 \\
\hline Tank Lining & Western States & Y & 4 & 46 \\
\hline Equip. Foundations & Larry's Inc. & Y & 12 & 541 \\
\hline
\end{tabular}

\subsection{STORAGE SILOS}

The design for the demonstration facilities called for three days of raw coal storage ahead of the PDF plant, two days of PDF storage after the plant and 12,000 tons of long term PDF storage for unit trains. To accomplish the latter, a swap was worked out with Triton to add 12,000 tons of raw coal storage in the new expansion facilities (a more useful arrangement for them) and take ownership of two existing 6000 ton storage silos that were much easier for ENCOAL to use. Included was the use of some existing conveyors, sampling systems, additional storage silos and rail loading facilities. This saved ENCOAL a great deal of additional capital and construction work that would have been required to meet the needs for long term PDF storage with its own new silo. 
Hoffman Inc. was the successful bidder on Triton's two planned 12,000 ton silos for their expansion project. Consequentially, ENCOAL negotiated a contract with Hoffman for a third identical silo. Construction of this silo was managed by Triton and was well underway when KCI moved to the site. The Project Master Schedule reflected that ENCOAL's raw coal silo would have to be constructed very early in the job, because it would be very difficult if not impossible to build after Triton's expansion conveyors were installed. The active rail loop on one side and the conveyors on the other would prevent access. Therefore, the design, specifications, bid and award of this silo was expedited by Kellogg. Construction of the 3000 ton feed coal silo beginning with the caissons and pile cap was started in November, 1990 as a result of these efforts. The slip-formed, continuous concrete pour was completed in early February, 1991 during a fortunate break in the weather. Figures 8.2 and 8.3 show the slip form just prior to starting and the completed silo respectively. The silo internals and roof were completed in April, 1991.

The remaining 1000 ton PDF product silo also needed to be completed fairly early in the schedule to avoid conflict for access with the mechanical erection contractor. Being very similar in design to the raw coal silo, the contract for the PDF silo was negotiated with the low bidder of all the other silos. Caissons and a pile cap were also required for this silo, but the depth was much less, being on the order of 20 feet. The PDF silo slip was completed in May, 1991 and the internals and roof in July, 1991. Both the raw coal and PDF silos were equipped with a stainless steel hopper liner to improve material flowability.

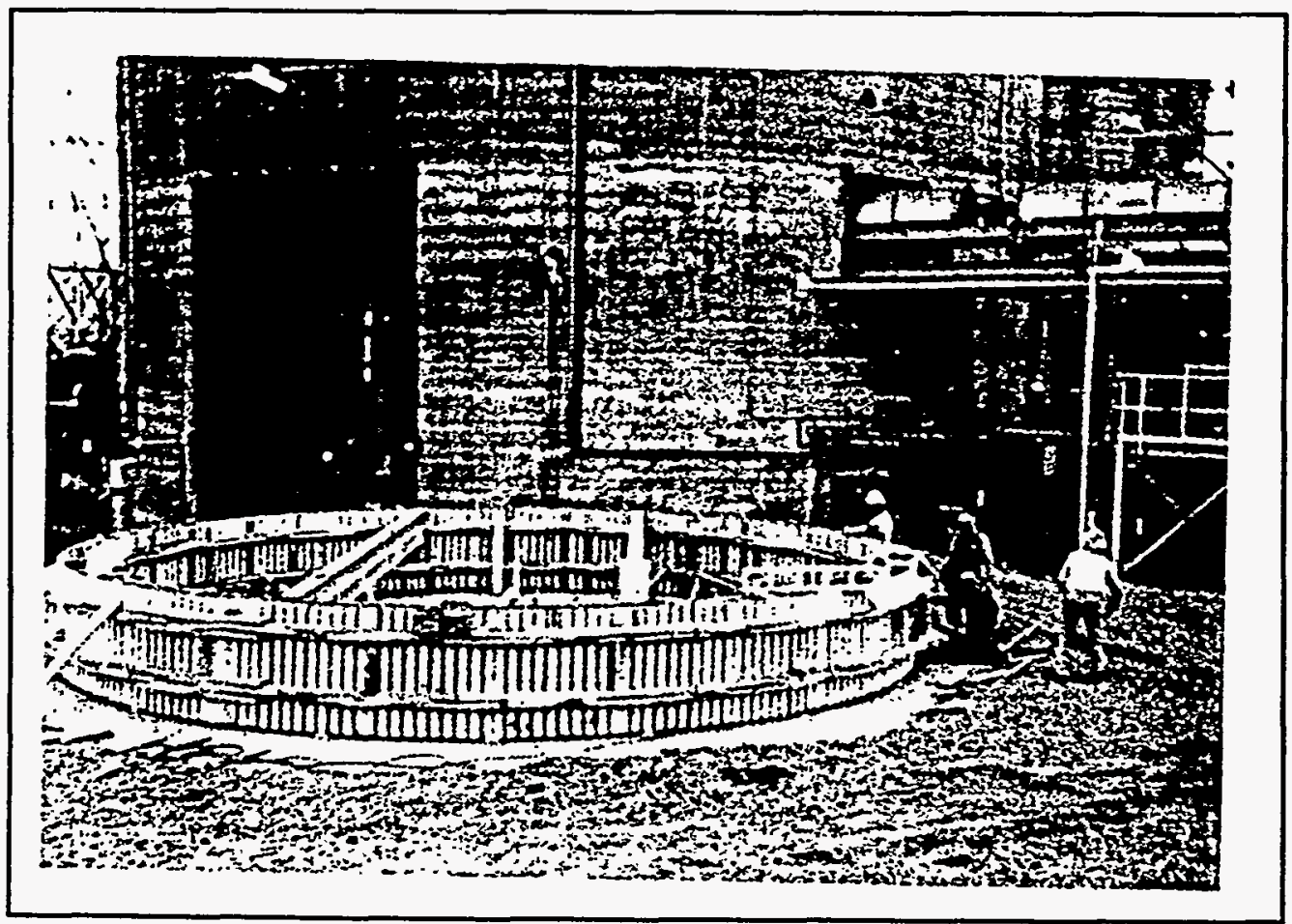

Figure 8.2 Raw Coal Silo Slip Form 


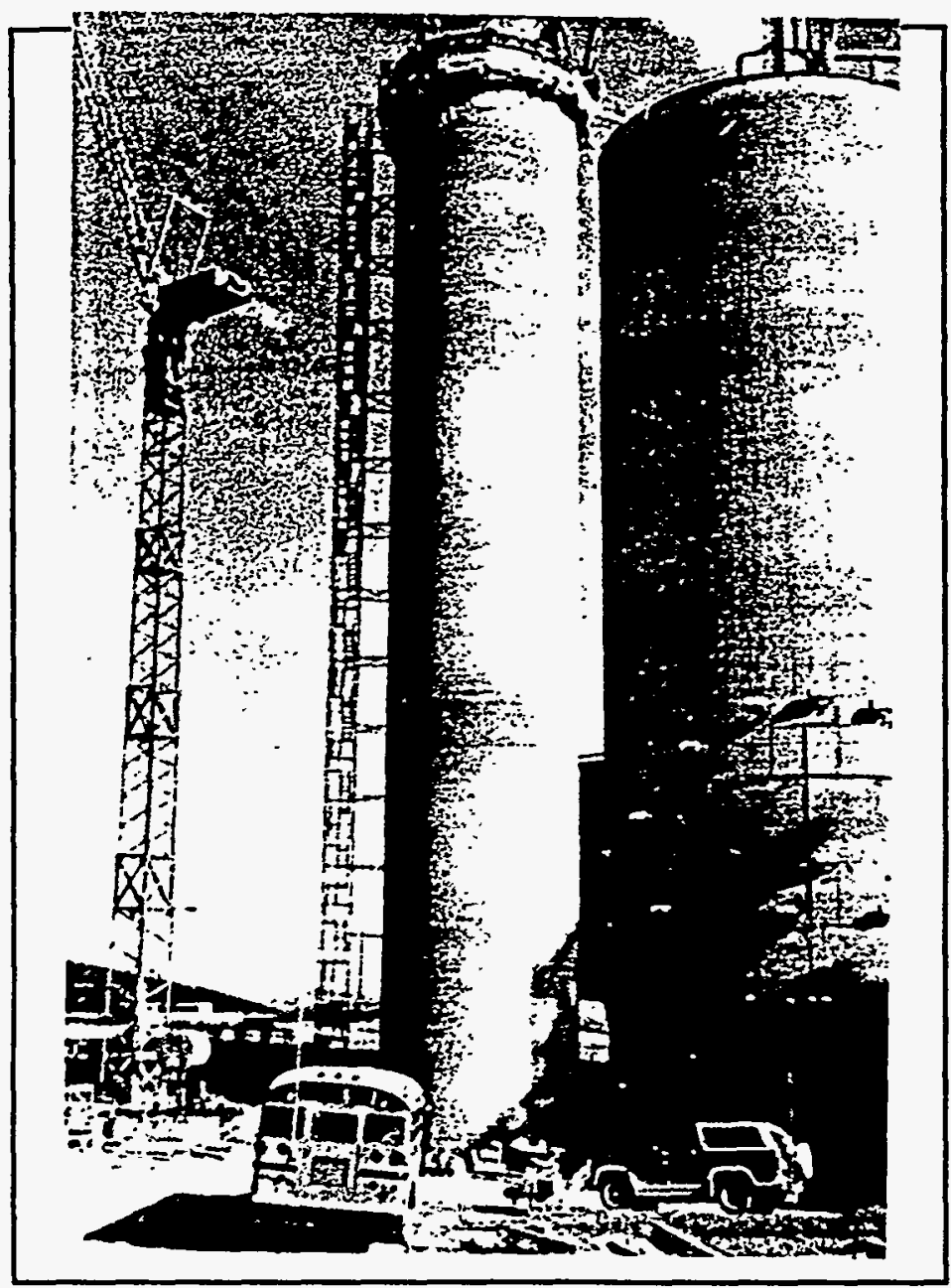

Figure 8.3 Completed Raw Coal Silo

\subsection{PDF PLANT}

The construction sequence for the PDF building began with the installation of a large spread footer type foundation with integral column supports for the building structure. This was followed by the underground and underfloor piping and foundations that mounted on the spread footer. Then the concrete frost walls, trenches and floor sections were poured. Next, the main erection of the structural steel and concurrent equipment installation was done. Delivery of several large pieces of equipment were critical to the erection sequence. The expediting schedule shown in Figure 8.4 was developed to track these major items and make appropriate adjustments in the construction sequence as needed. A detailed construction schedule was developed based on these expected deliveries of major equipment as shown in Figure 8.5. This schedule had to be adjusted several times due to late arrival of equipment. Finally, as the PDF building was topped out, installation of the steel siding commenced. The screening building, off-site buildings and piping were done essentially in parallel with the main plant erection. Electrical and instrumentation work trailed all mechanical/civil work and was completed last. 


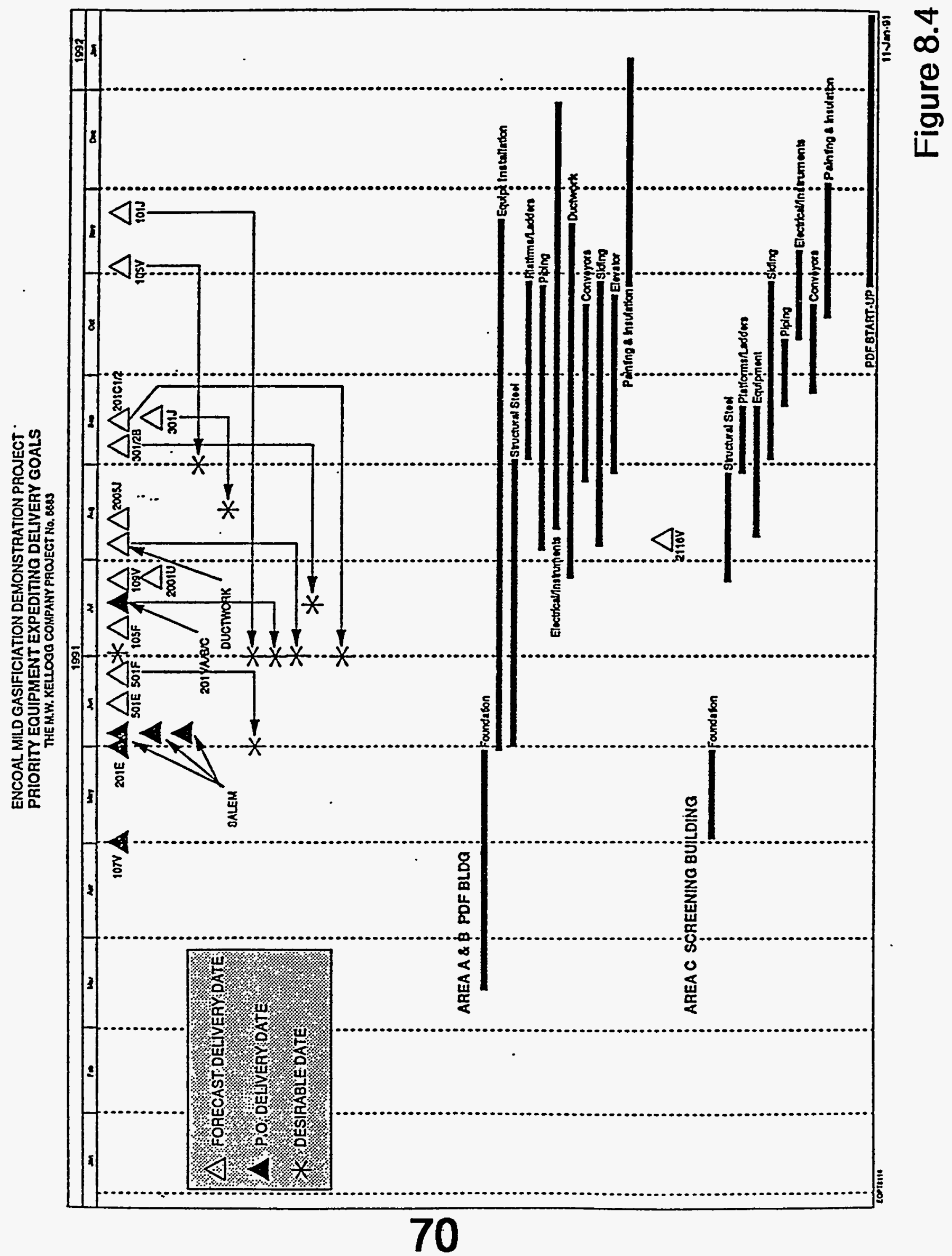




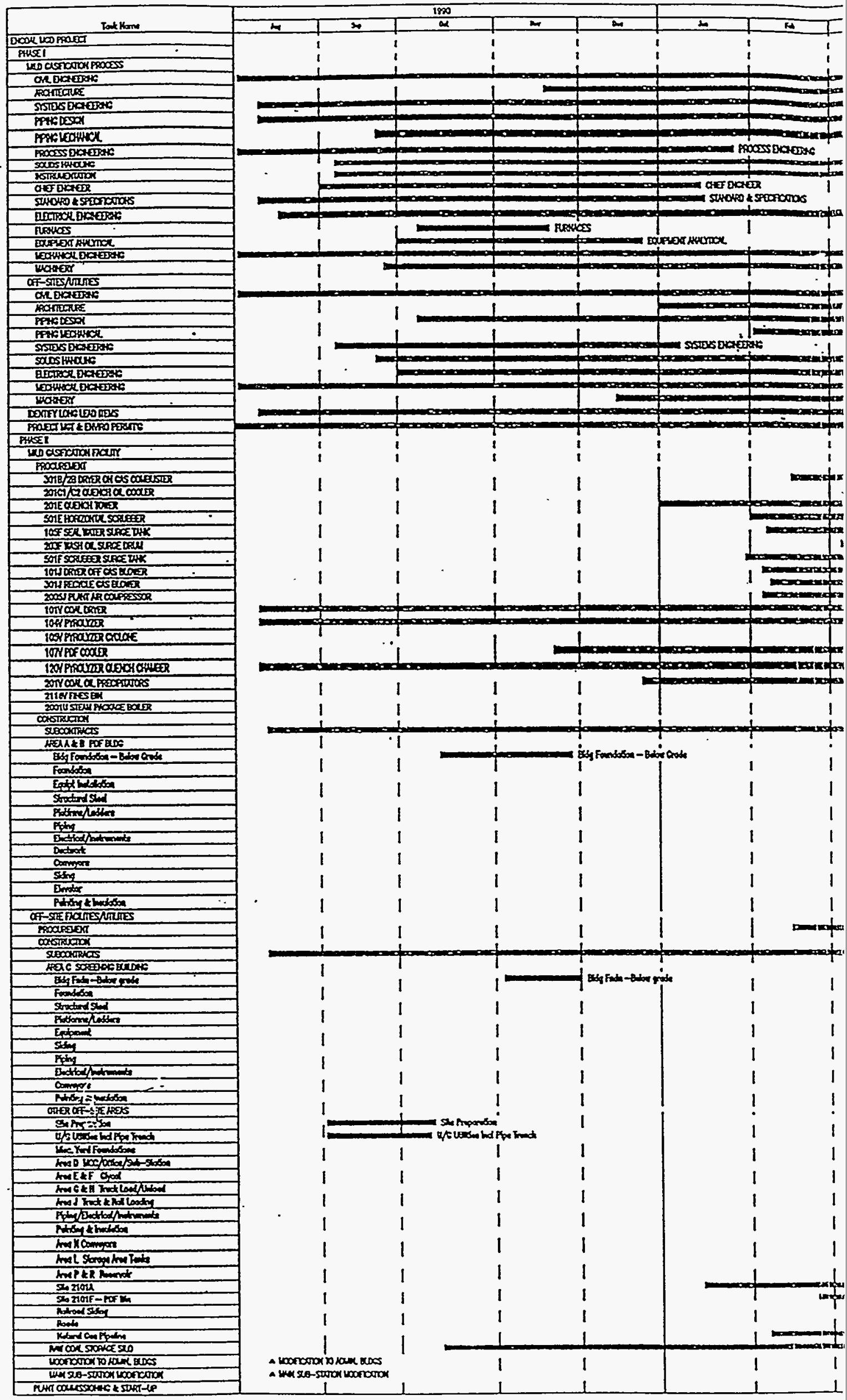




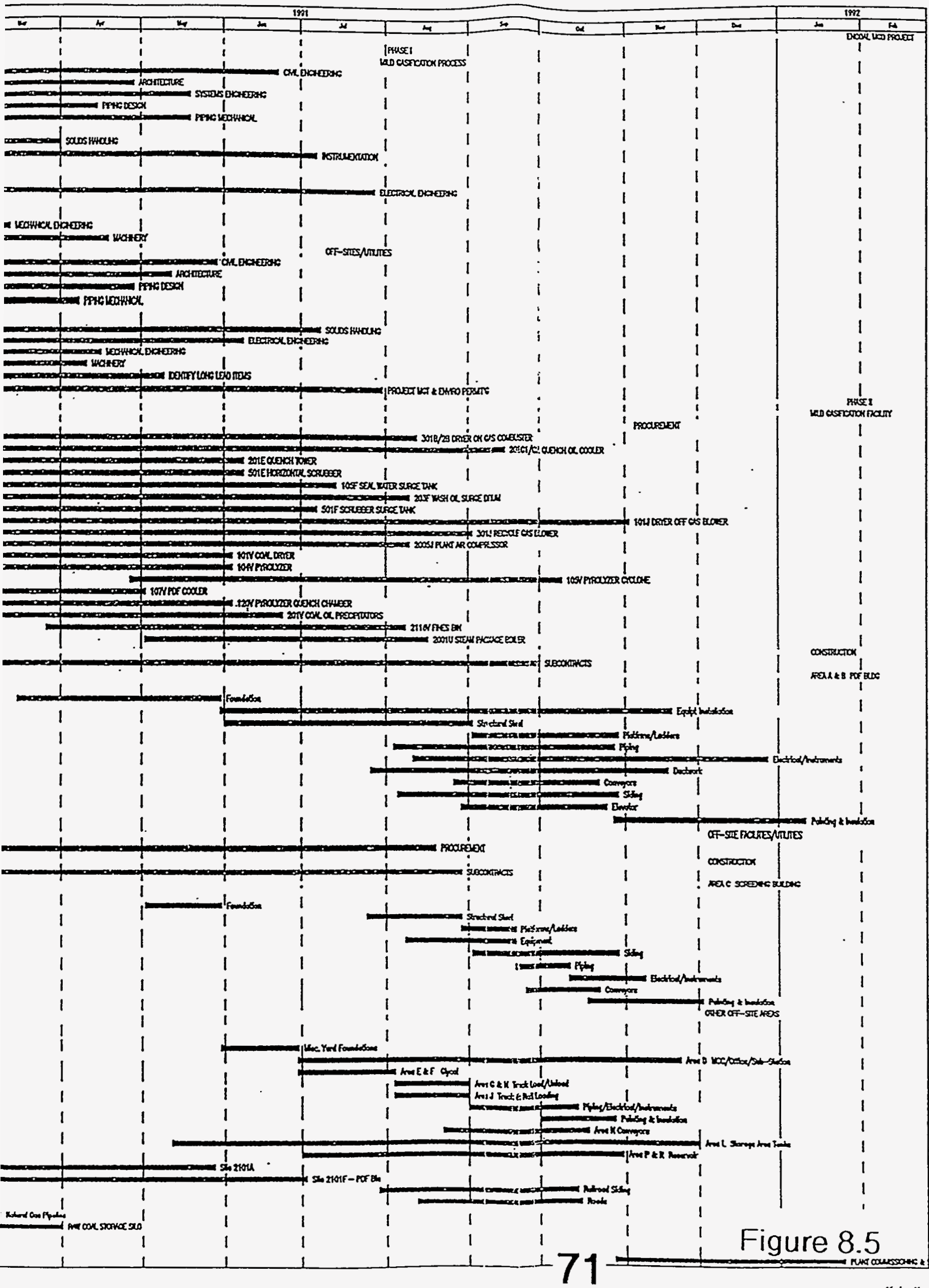




\subsubsection{Foundations}

Geotechnical surveys on the site showed that soil conditions were poor near the surface, but that with slightly more excavation, a suitable bearing zone could be reached in the area of the PDF building. This was not true for the silos because of the small diameter and high loading, thus caissons and pile caps were required. A spread footer for the PDF building had an additional advantage from a timing point of view; the foundation could be placed before winter weather arrived and it would take less engineering time to complete the design than for individual foundations for each piece of equipment, many of which were not even selected yet. Specifications and bid documents for the foundations package were prepared in Houston prior to $\mathrm{KCl}$ 's mobilization. The bid was awarded and construction started in early October, 1990.

A ground breaking ceremony was held during mid-October in the initial stages of foundation installation. By the end of November, the largest monolithic pour in the state of Wyoming, a 3000 cubic yard base, was made (Figures 8.6-8.9). By the end of 1990, the columns were in place and the spread footings for both the PDF building and screening were backfilled with compacted material. Closely following the completion of the major plant foundations, a subcontract was awarded for the conveyor and tank foundations remote to the plant area. The same subcontractor was the successful bidder and they continued to work through the winter as the weather allowed, completing the additional foundations by May, 1991.

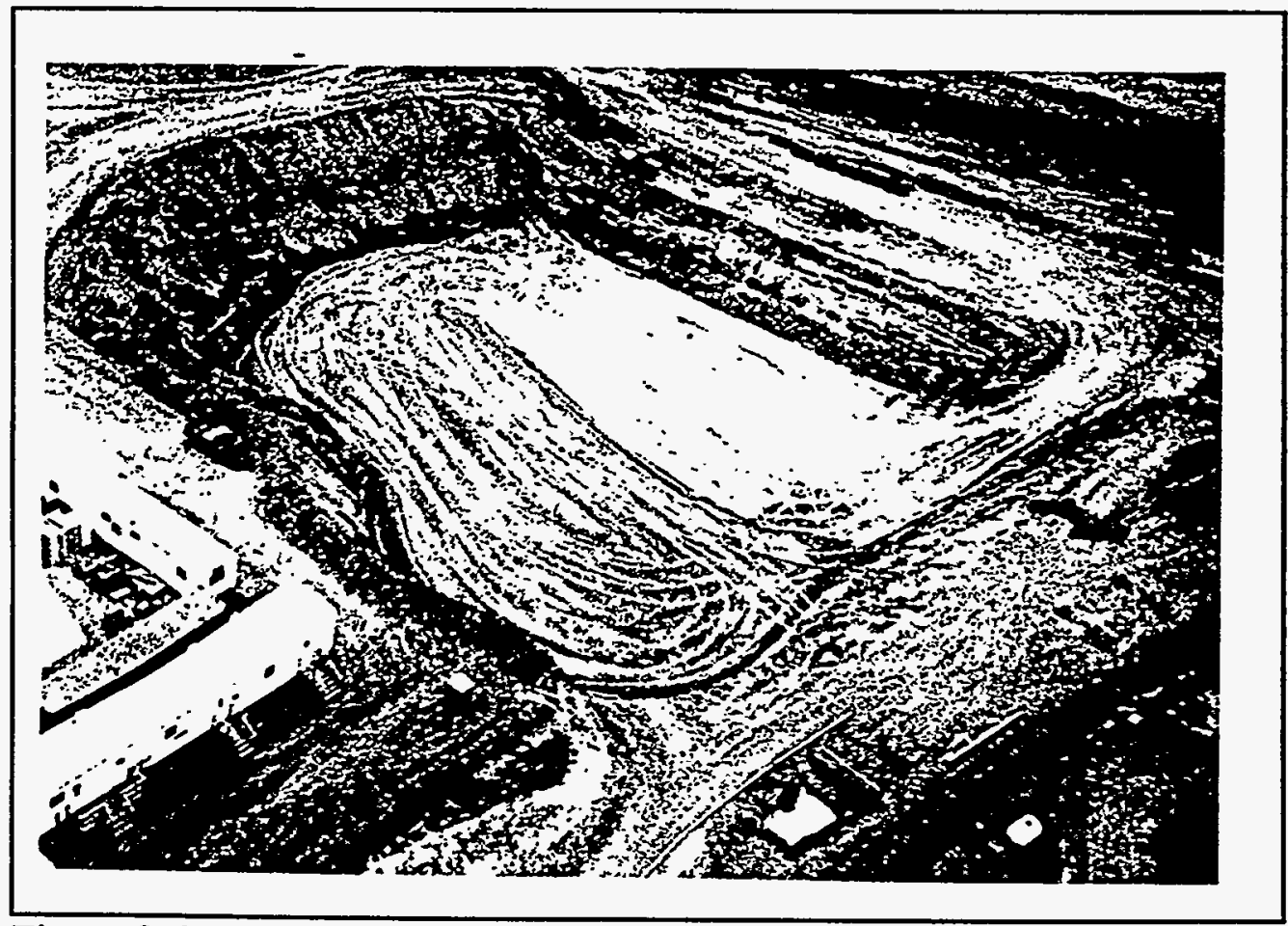

Figure 8.6 PDF Building Excavation 

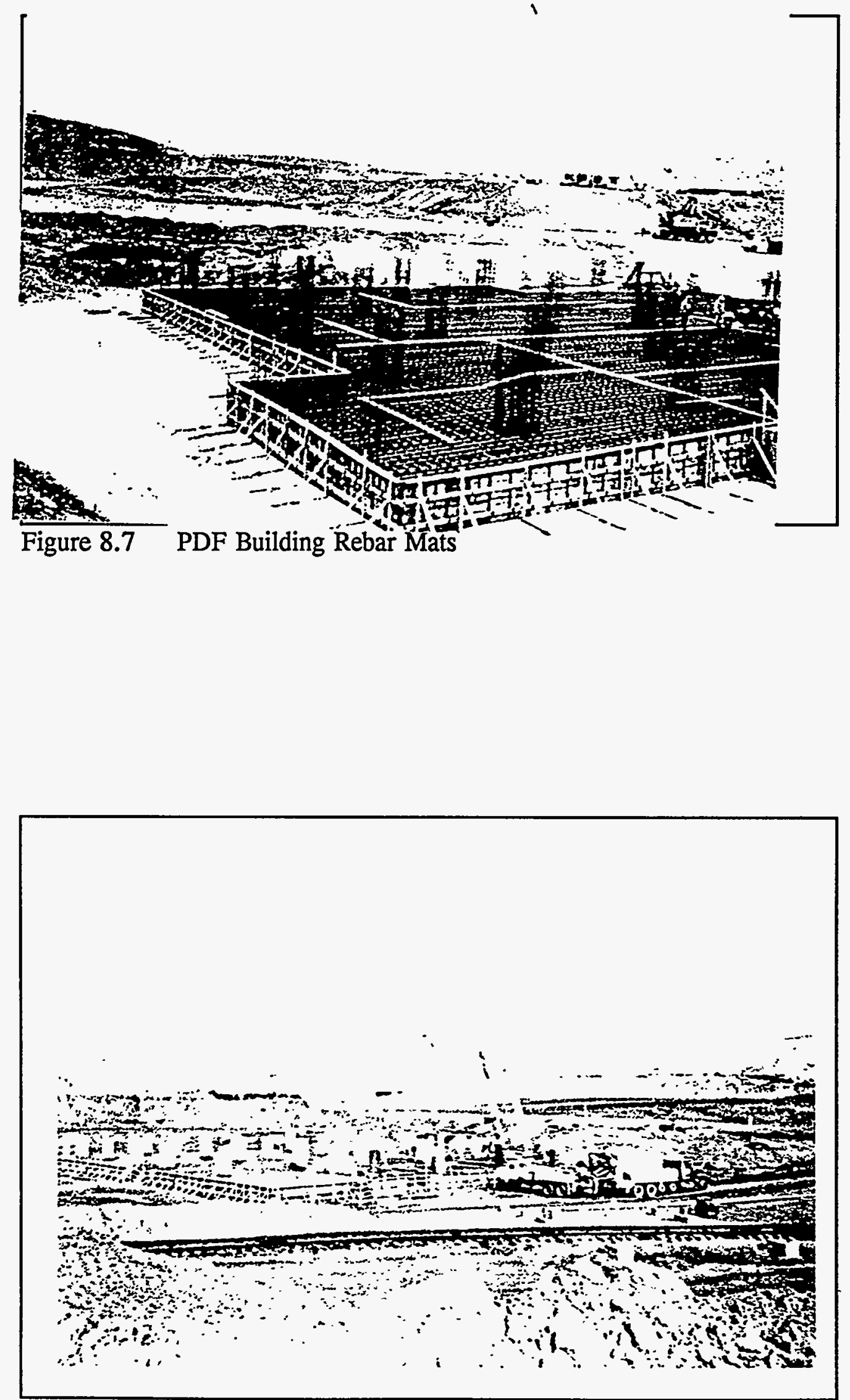

Figure 8.8 PDF Building Foundation Pour 


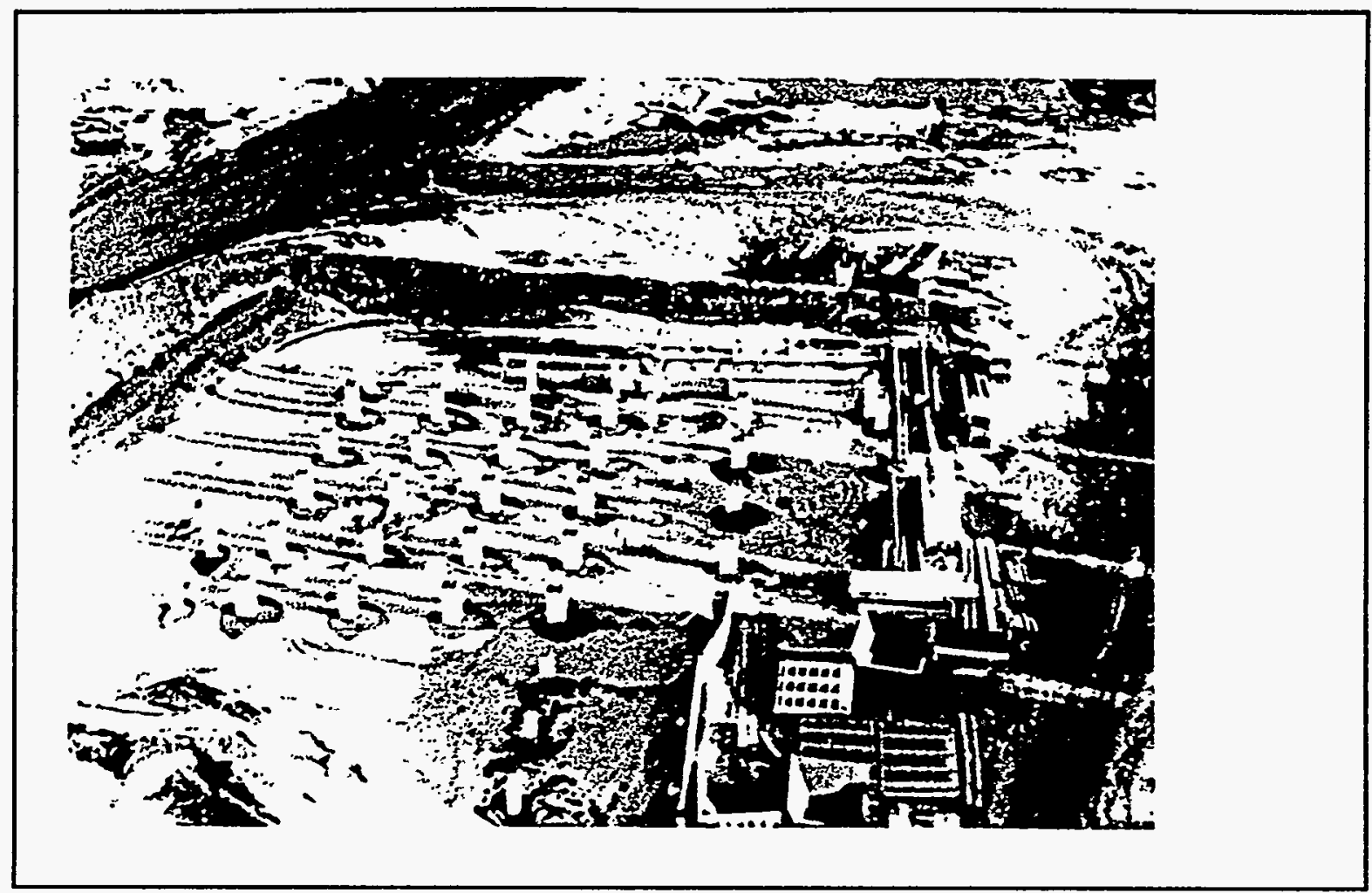

Figure 8.9 PDF and Screening Building Foundations

\subsubsection{Underground Piping, Conduit and Equipment Foundations}

Completion of the spread footer for the PDF building opened the way for the piping and equipment foundations that were located on top of it. Requiring different skills, these subcontracts were awarded separately. Most of the underground piping was specified as high density polybutylene plastic. Underground conduit was standard weight PVC covered with red dyed concrete outside of the plant area. The natural gas piping was polyethylene coated steel and the flue gas system discharge line which was 304 stainless steel. The subcontract for underground piping included all of the buried piping and conduit in the PDF/screening building area, natural gas piping to the property line at the gas supplier's metering station, firewater system with valves and hydrants, stainless line and the cooling water lines to and from the sedimentation pond. Work began as soon as the weather allowed in March 1991 and was completed by July.

In parallel with the underground piping, a subcontract was awarded for the installation of the concrete piers, foundations, trenches and floors in the PDF and screening buildings. This work also began right after the winter weather cleared in March, 1991 and continued through June. Each individual concrete pier or foundation was excavated through the compacted backfill to the spread footer and attached to pre-installed rebar or dowelled into the foundation concrete. The pier was then formed, poured and backfilled. Figures 8.10 and 8.11 show the backfilled spread footer prior to starting piping and equipment foundations and Figure 8.12 shows these subcontracts completed. 


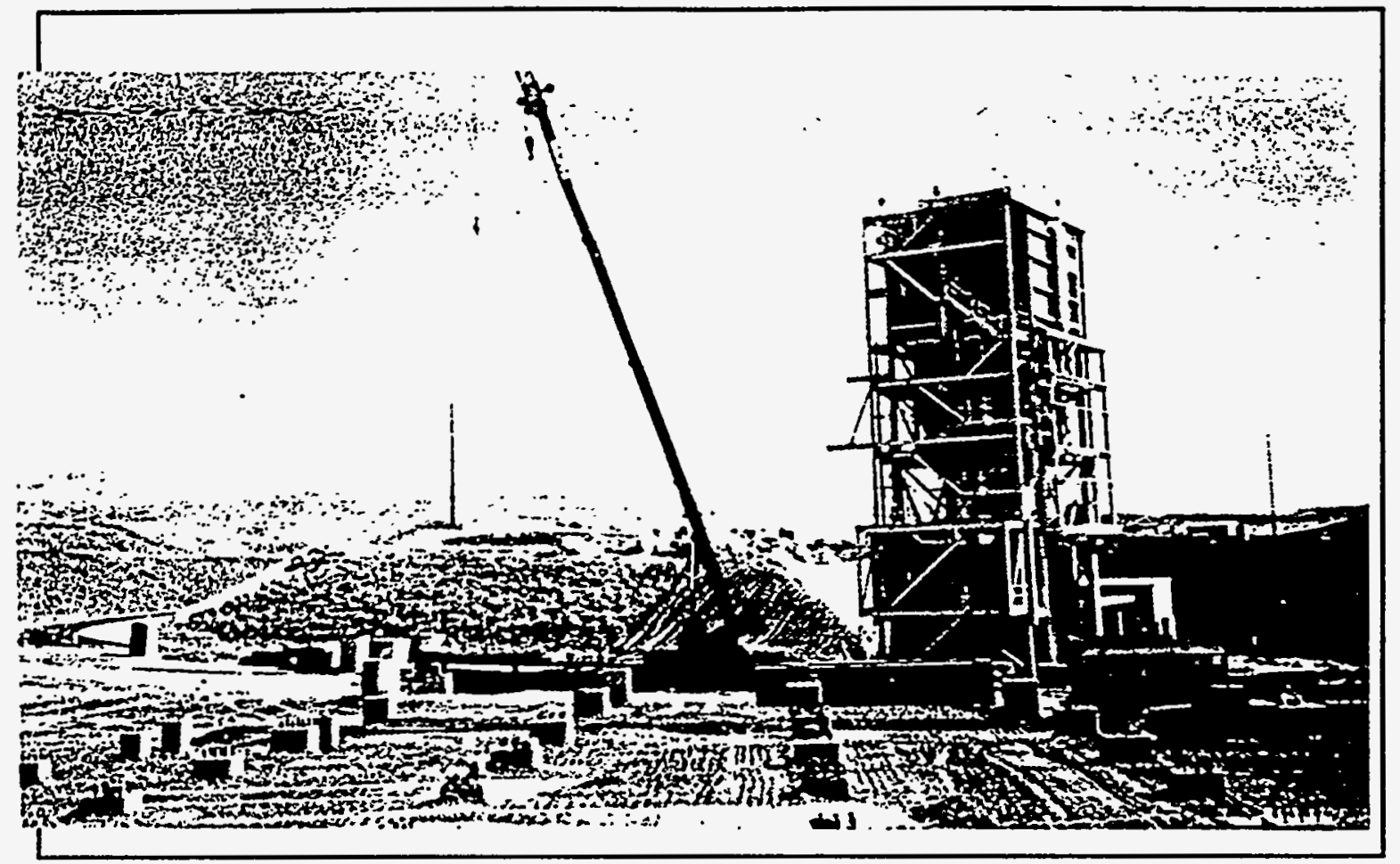

Figure 8.10 Backfilled PDF Building Foundation

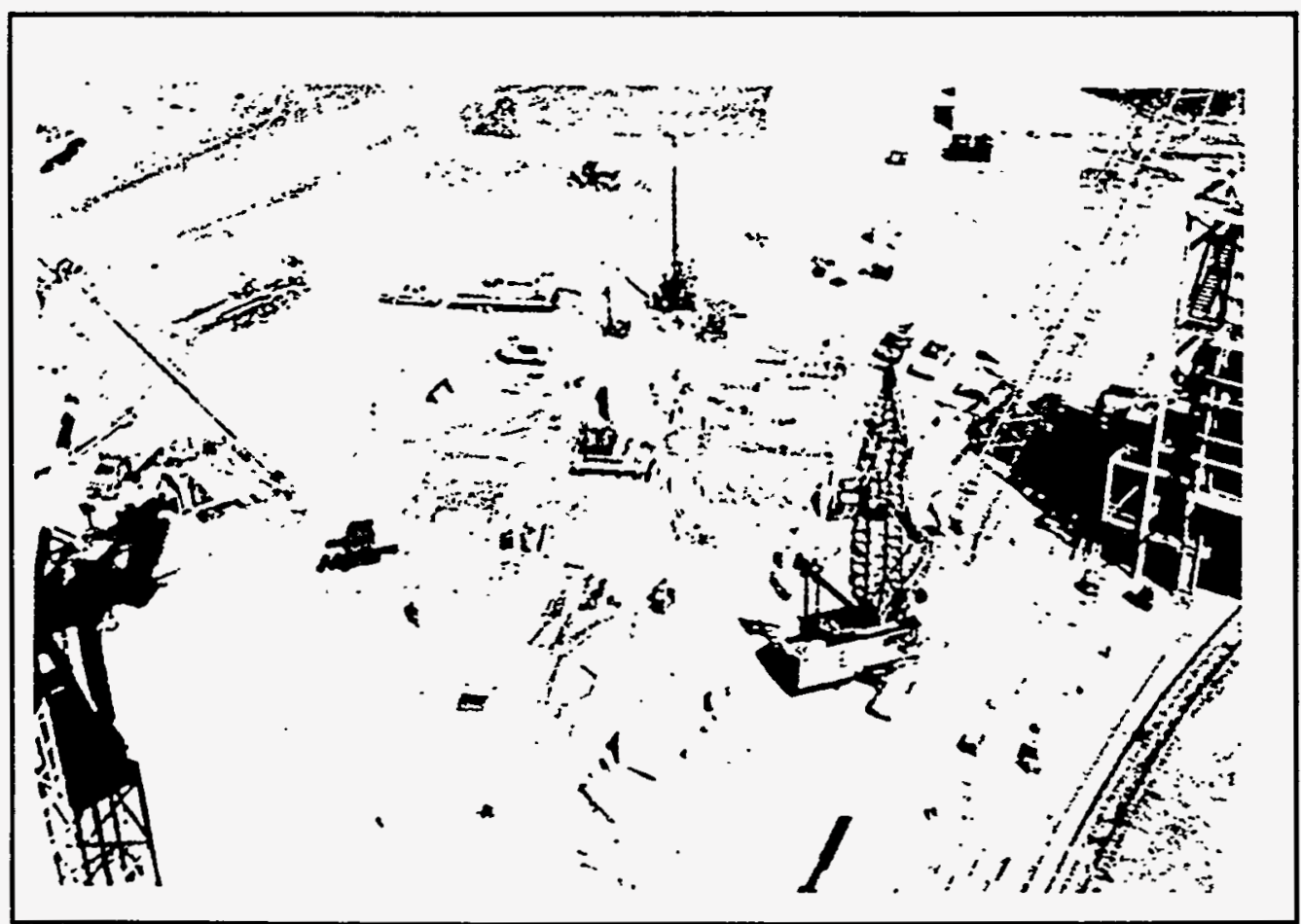

Figure 8.11 Underground Piping and Equipment Foundations in Progress 


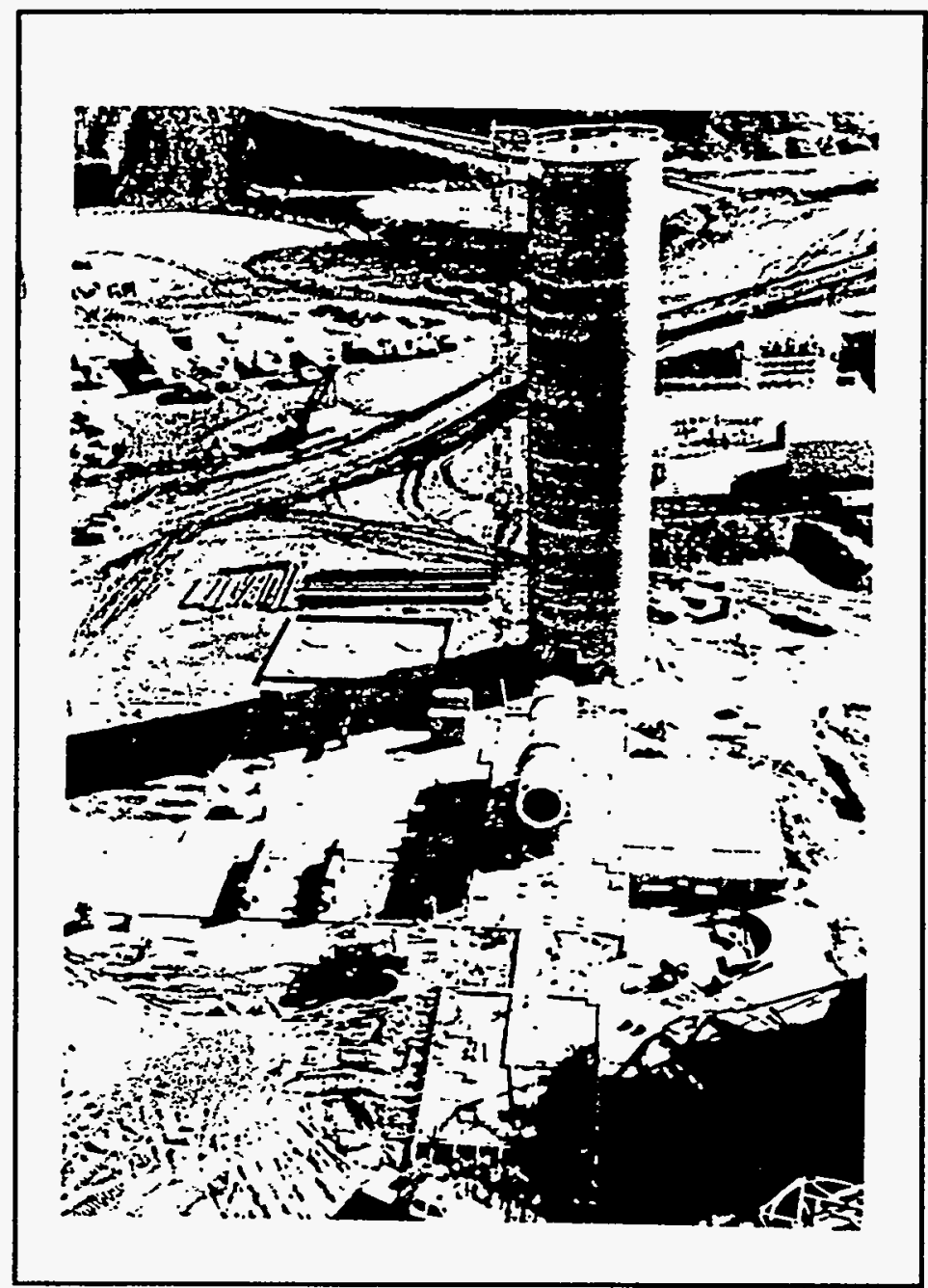

$\begin{array}{ll}\text { Figure 8.12 } & \text { Completed Equipment Foundations and } \\ & \text { Floor Slabs }\end{array}$

\subsubsection{Mechanical Erection}

A subcontract for the mechanical erection of the facilities was bid in February 1991 and awarded in April. It was planned to mobilize the subcontractor in May. However, about this time engineering delays and ensuing equipment delivery delays started to catch up with the Project. Structural steel and the first of the major equipment, scheduled to start arriving in May had slipped by more than a month. The mechanical subcontractor did mobilize by the end of May, but slowly so they did not run out of available work. As a reference for the discussions that follow, Appendix A contains a complete floor by floor description of the plant and screening buildings.

By the end of June, the Project worked through the delay problems and material delivery was in full swing. The PDF cooler, so large that it had to be delivered by rail, had arrived and was set as soon as the foundations were ready (Figure 8.12). The quench column was delivered in mid June and was set in place straight from the truck. Both of these pieces of equipment had to be set before work could begin on the structural steel. 
The steel fabricator did an excellent job of keeping ahead of the erection contractor after they started receiving engineering drawings from Kellogg. The erection plan called for assembly of the PDF quench table, pyrolyzer and dryer on the ground one by one and lifting them into place as the structural steel was going up. The other major equipment that had to be set on elevated floors as the structure was going up were the purge gas scrubbers, ESP's, recycle blower, pyrolyzer cyclone, dryer cyclone and large diameter prefabricated ductwork. Figure 8.13 shows the quench column in place and the first of the structural steel in progress. In the lower right corner of the picture, the quench table assembly is in progress. Figure 8.14 shows the quench table in place.

The erection plan worked very well and provided the flexibility to deal with the delayed delivery of some pieces of equipment. Both of the large process gas blowers arrived more than a month late but posed no real problem in the erection sequence. The horizontal scrubber and ESP's arrived close to the required dates and were set in July. Figures 8.15 and 8.16 show the progress at this point. Placement of the structural steel on the $4^{\text {th }}$ floor opened the way for the installation of the pyrolyzer vessel. The assembled pyrolyzer is shown on the ground in Figure 8.17 and in place in Figure 8.18. The roof of the pyrolyzer appears in the lower right corner of the picture. Erection of the PDF structure was at about 106' at this juncture where the floor area reduced to less than half of the ground floor area. Figure 8.18 also shows the installed combustors, motor control building and fines bin.

One of the longest delayed pieces of equipment was the pyrolyzer cyclone. Structural steel was temporarily omitted in the area just to the left of the pyrolyzer to accommodate installation of this large vessel when it finally arrived. Originally designed as a single unit, the manufacturer shipped the vessel in two pieces to save shop fabrication time and it had to be assembled in place. In Figure 8.18, the lower half of the pyrolyzer cyclone appears at the bottom of the picture on the delivery truck. Figure 8.19 shows the complete cyclone installed in the structure. (Center) This procedure delayed steel erection for two weeks.

The $6^{\text {th }}$ floor was designed to support the dryer and is the bottom of zone 2, the specially designed dryer containment zone described in Section 5.1. This floor was covered with checker plate instead of grating like the rest of the floors in the plant. Figure 8.20 shows the start of the structural steel and $6^{\text {th }}$ floor decking above the pyrolyzer. The plastic cover around the combustors is for weather protection for the refractory lining work in progress.

Like the pyrolyzer, the dryer shell was assembled on the ground as a unit and lifted into place after all supporting structural steel was in place. It did not fit together well and a lot of trimming and grinding was necessary to assemble it. Portions of the both the dryer and pyrolyzer grates and substructure were preassembled by the fabricators' shop. These structures were bolted in place loosely before installation of the roof of each vessel. After completion of the vessel, the grate assembly was rotated and all bolts were torqued and the nuts spot welded as required by the manufacturer. Figure 8.21 shows the completed dryer assembly and the inlet and outlet ductwork (120" OD). 


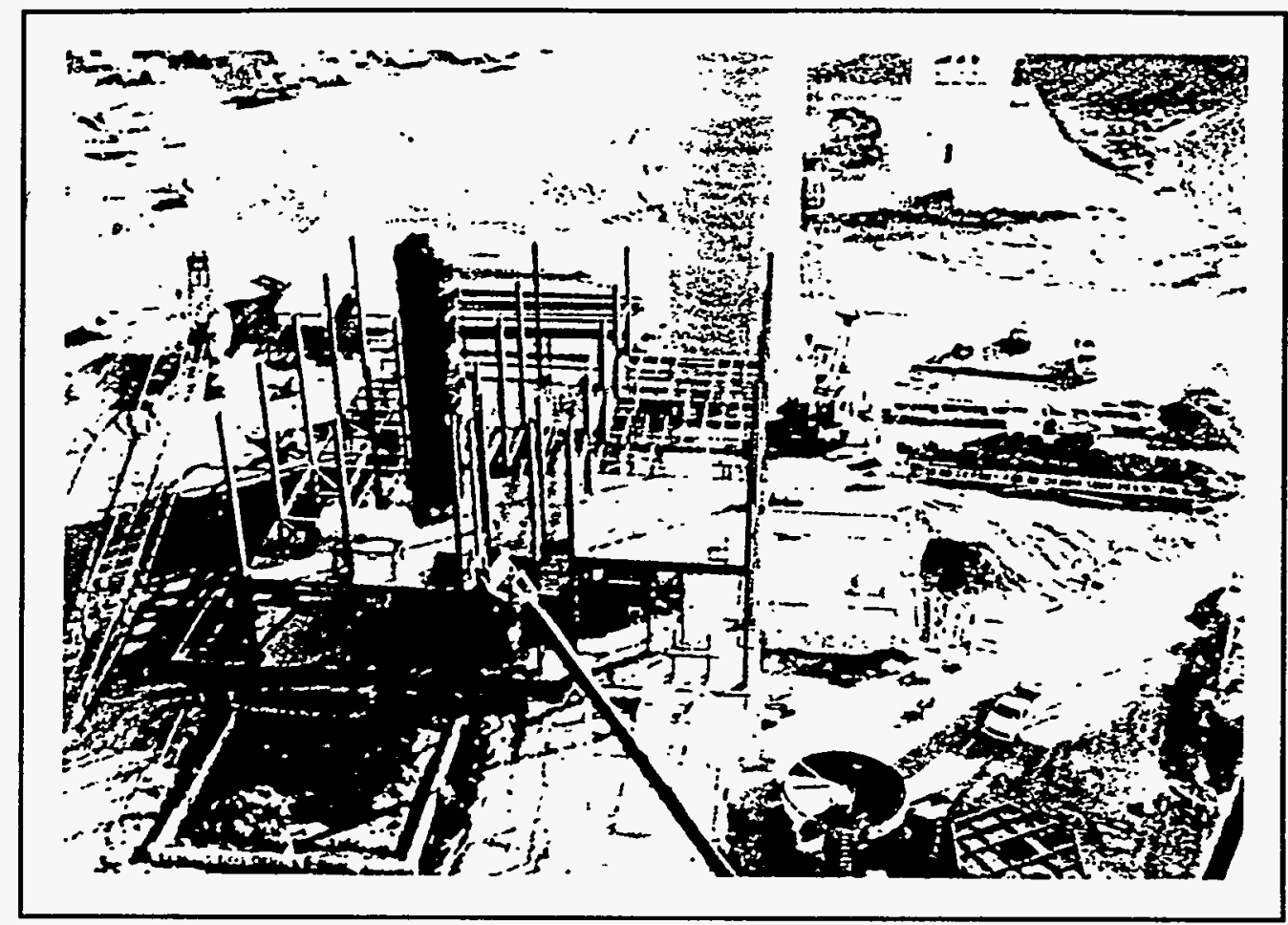

Figure 8.13 Quench Column and PDF Quench Table

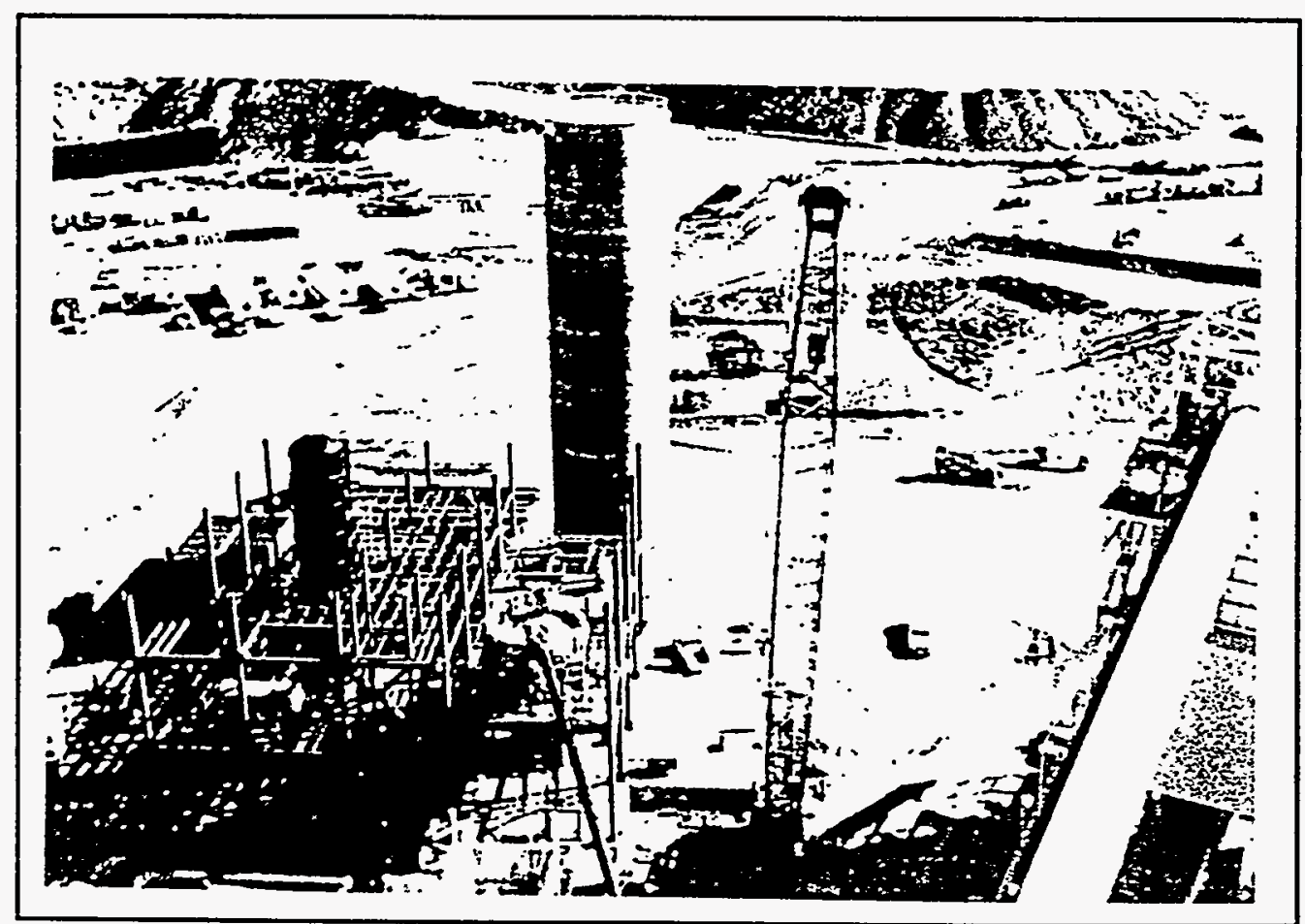

Figure 8.14 PDF Quench Table and 3rd Floor In Place 

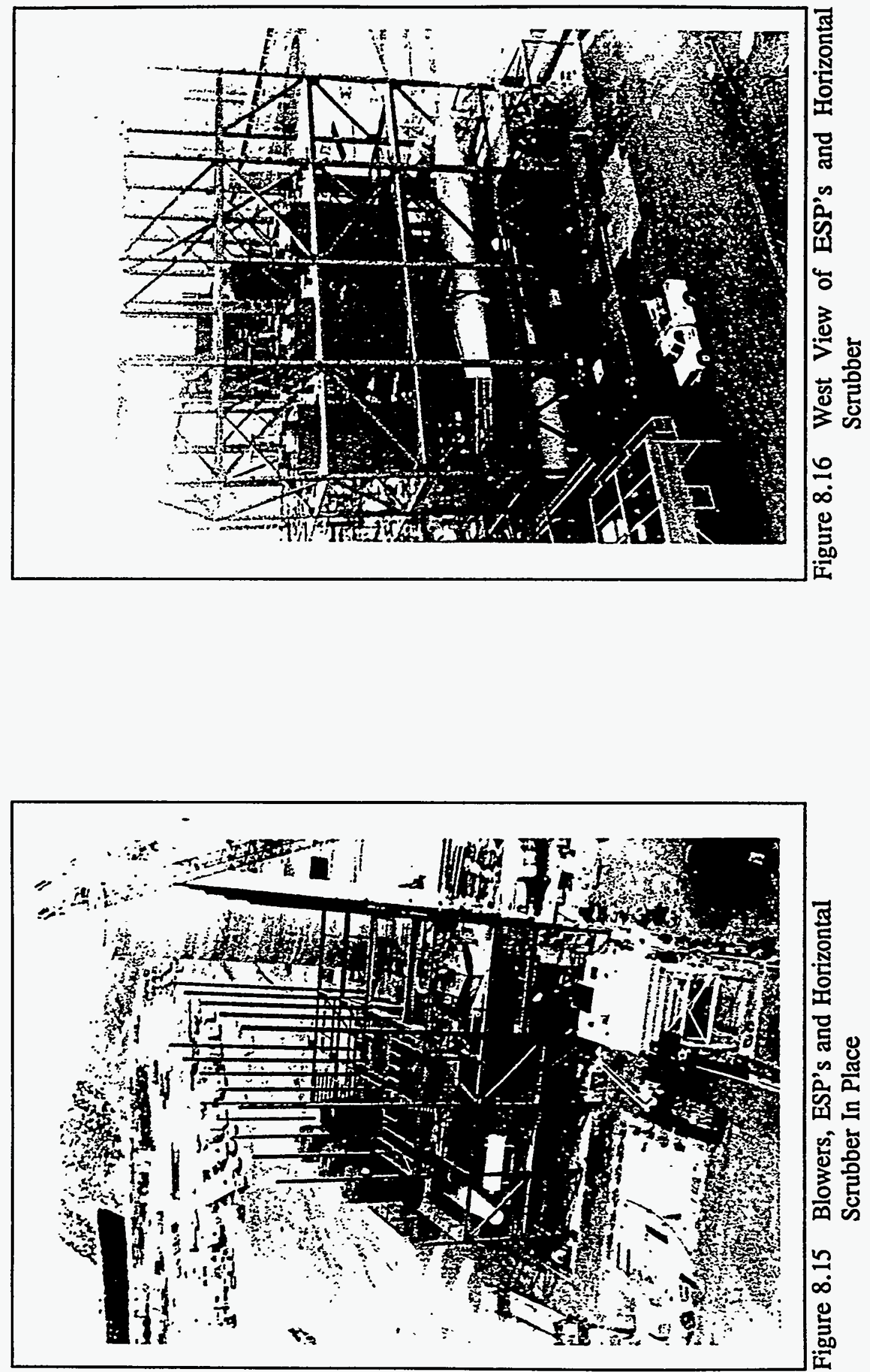
The last large piece of equipment to arrive on site, two months behind schedule, was the dryer cyclone. Welded into three large pieces on the ground, each piece had to be lifted in through the open roof of the plant. As shown in Figure 8.22, structural steel installation continued as long as possible around the open area while waiting on delivery of the dryer cyclone. During this time, crews were reduced and shifted to the screening building, raw coal conveyor and product conveyors. The dryer cyclone arrived in late February 1992 and the final sections of structural steel were placed as shown in Figure 8.23 .

The girts and metal siding on the PDF structure began to be installed in November, 1991 at the lower levels of the building. The single layer, uninsulated panels went up fairly slowly due to wind and weather problems. A number of the openings on the upper floors changed during the building erection, thus requiring improvising by the siding subcontractor which slowed progress. Work on the siding was well underway in Figures 8.22 and 8.23.

After the dryer cyclone was set, the way was cleared for installation of the PDF S-Belt, GAMMA-METRICS analyzer and structural steel on top of the PDF silo. Figure 8.24 shows this work completed as well as the rest of the equipment, piping and ductwork in the top sections of the PDF building. On the south side of the building, the raw coal SBelt was installed and the picture in Figure 8.25 was taken just before installation of the fiberglass stack. Final completion of PDF structure occurred in March, 1992 as illustrated in the aerial view in Figure 8.26.

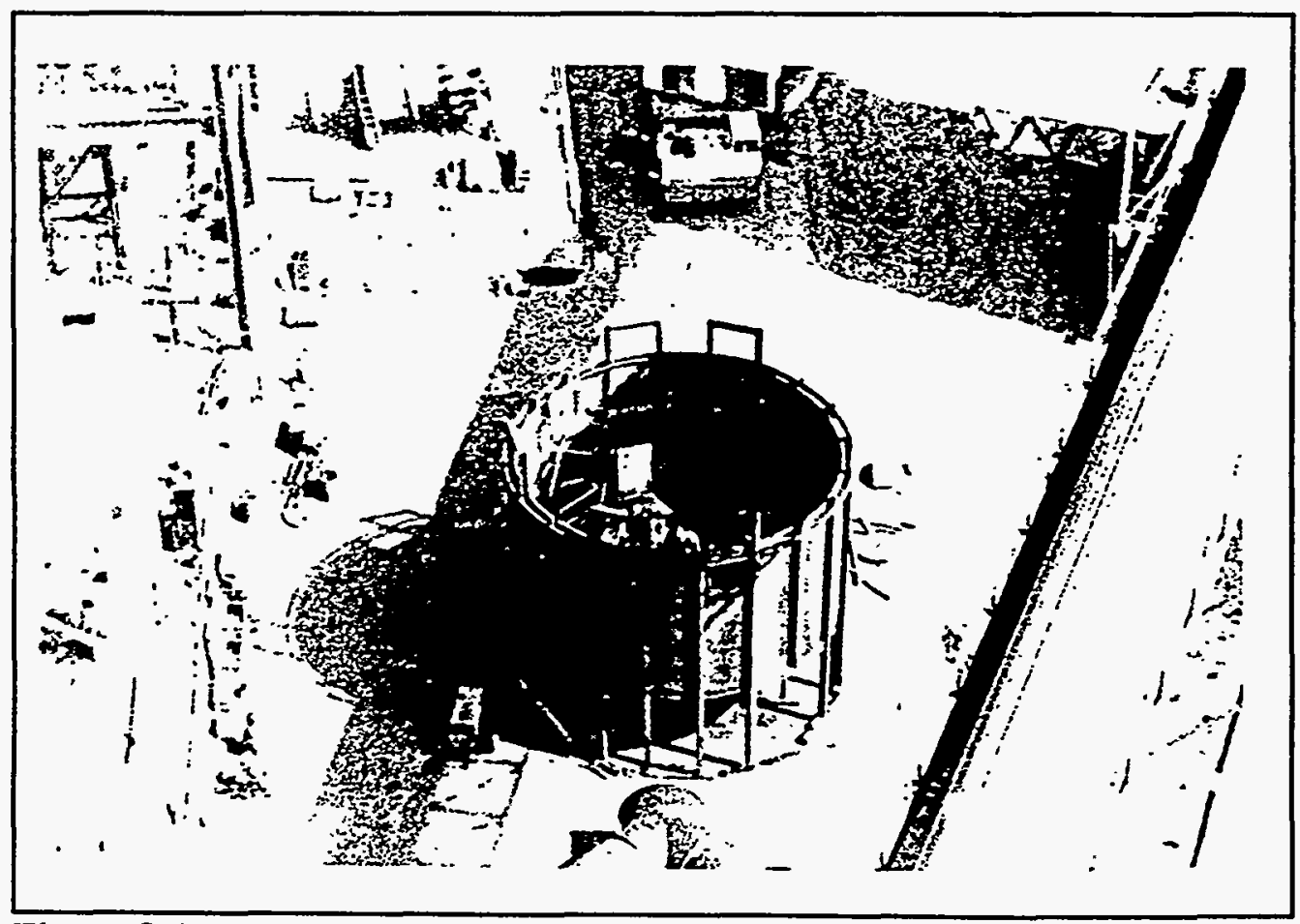

Figure 8.17 Pyrolyzer Assembly 

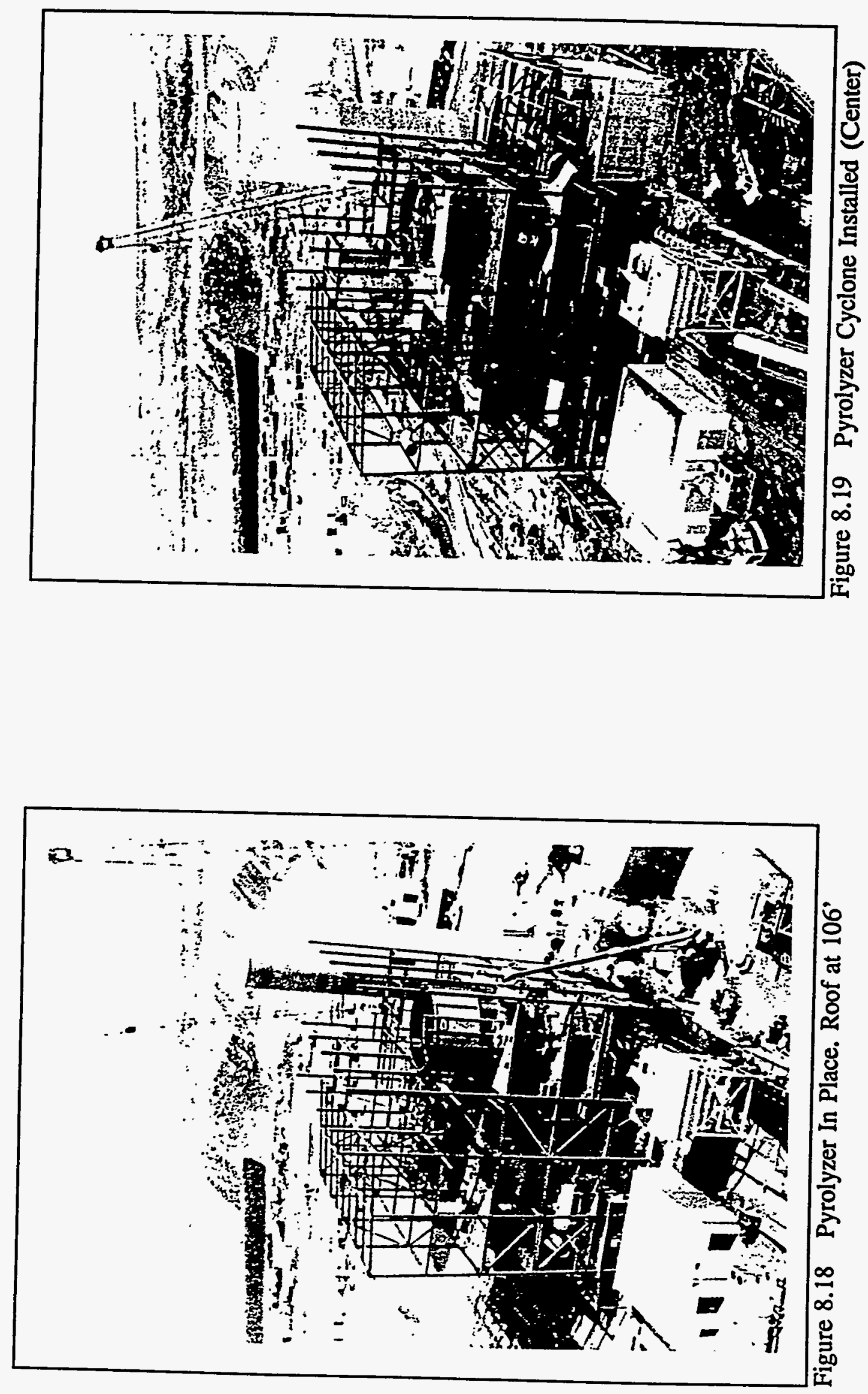


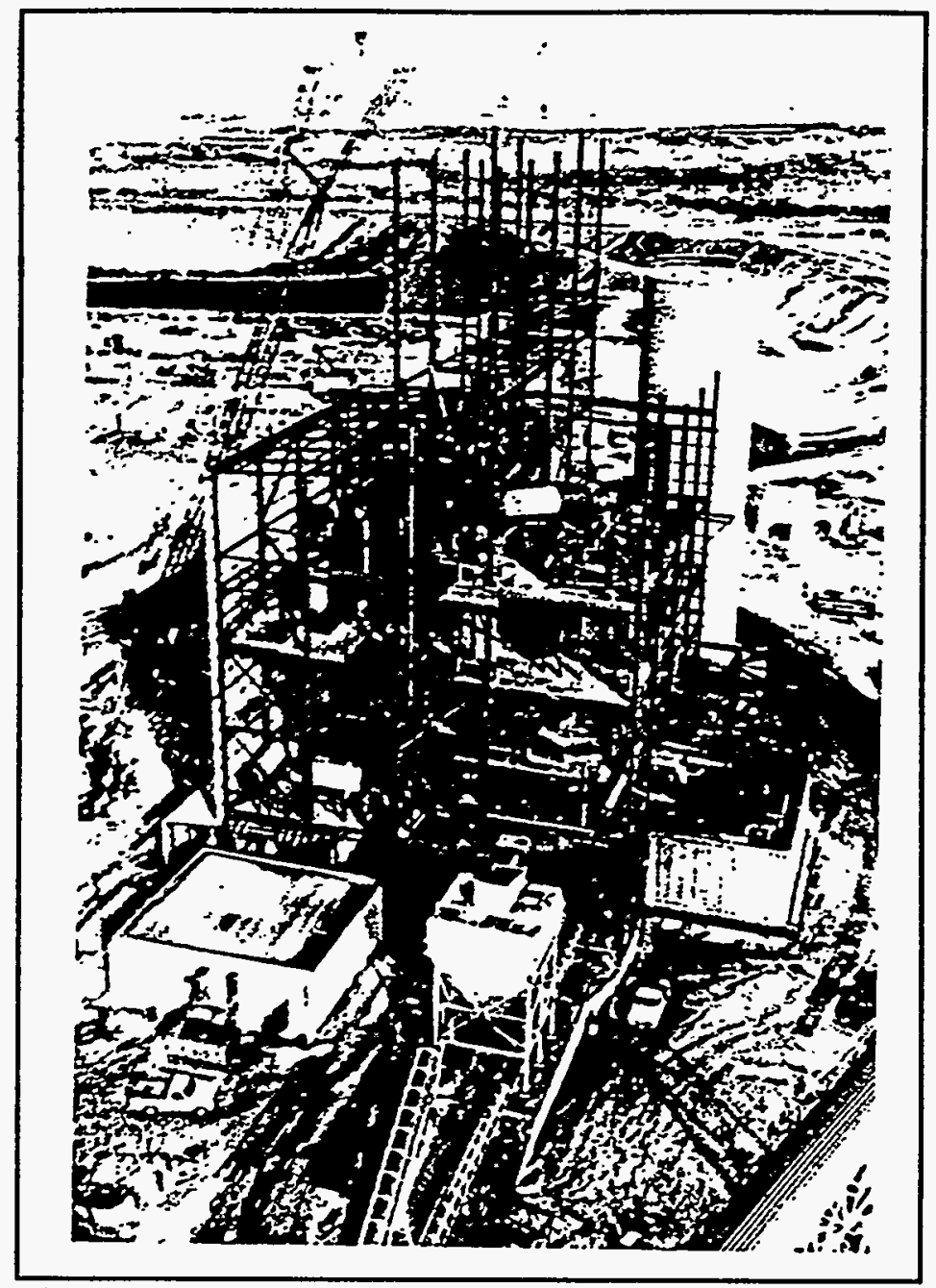

Figure 8.20 Start of 6th Floor Deck and Steel

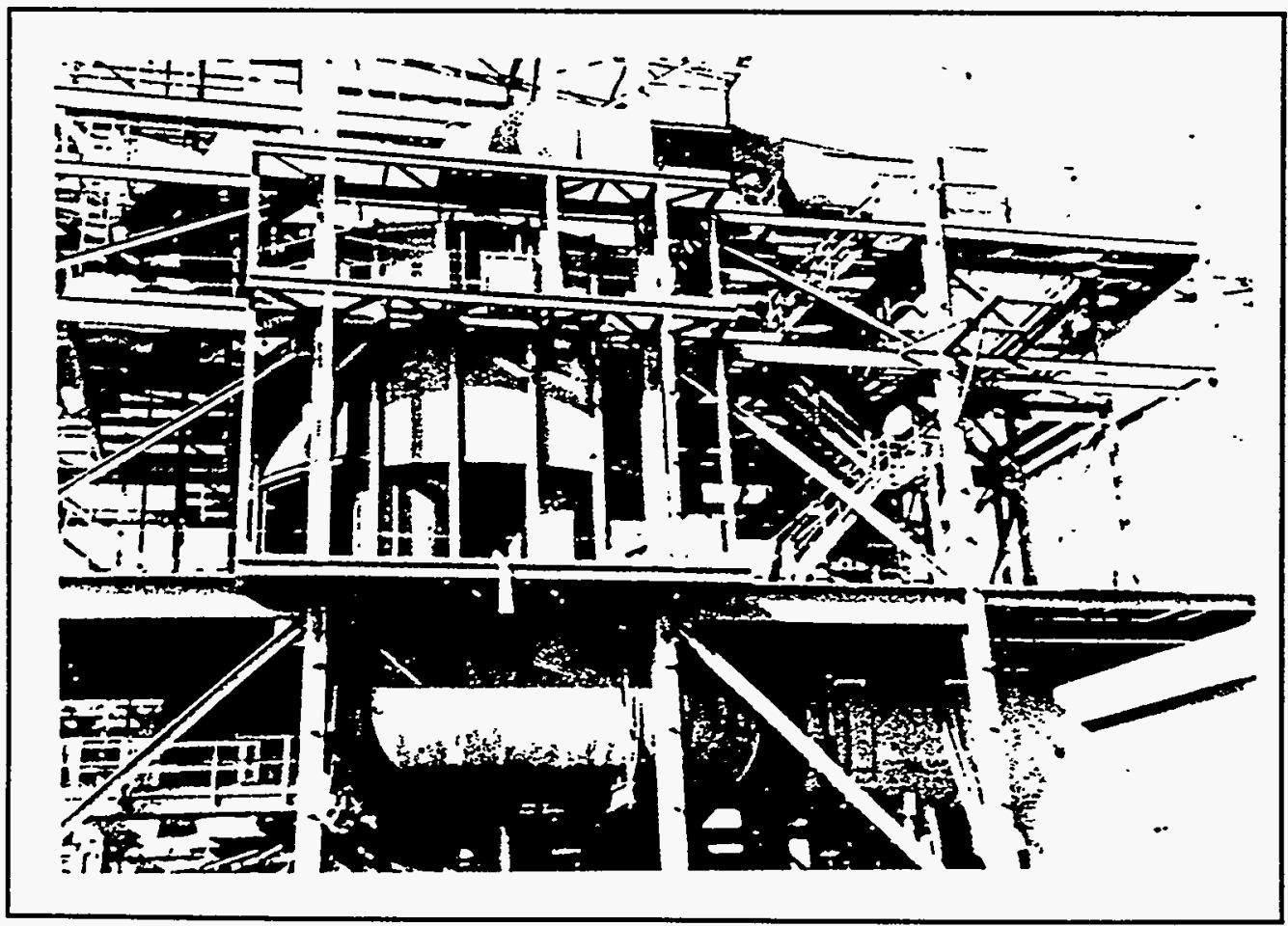

Figure 8.21 Dryer, Inlet Duct and Outlet Duct 


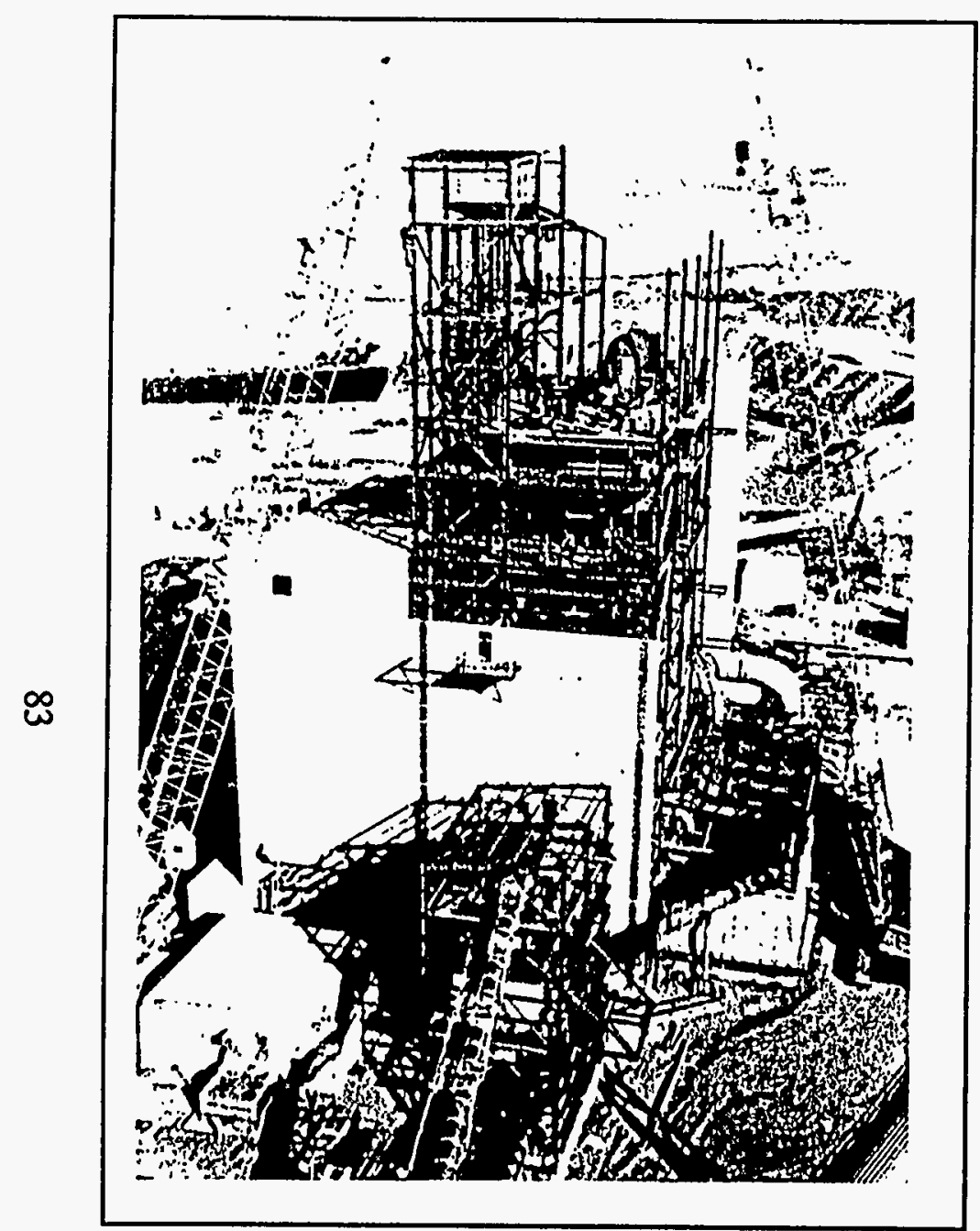

Figure 8.22 Dryer In Place Awaiting Cyclone

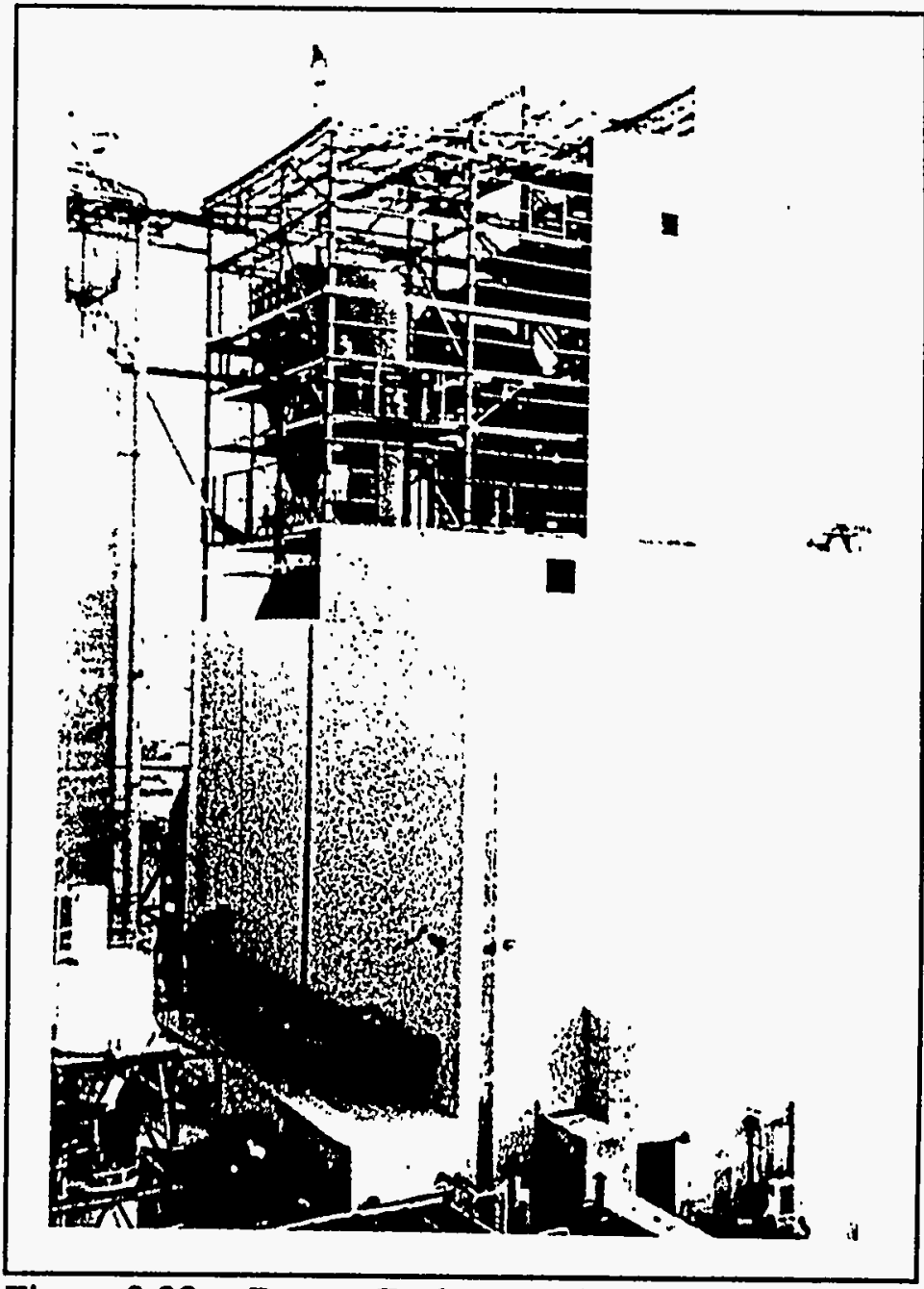

Figure 8.23 Dryer Cyclone and Structural Steel in Place 


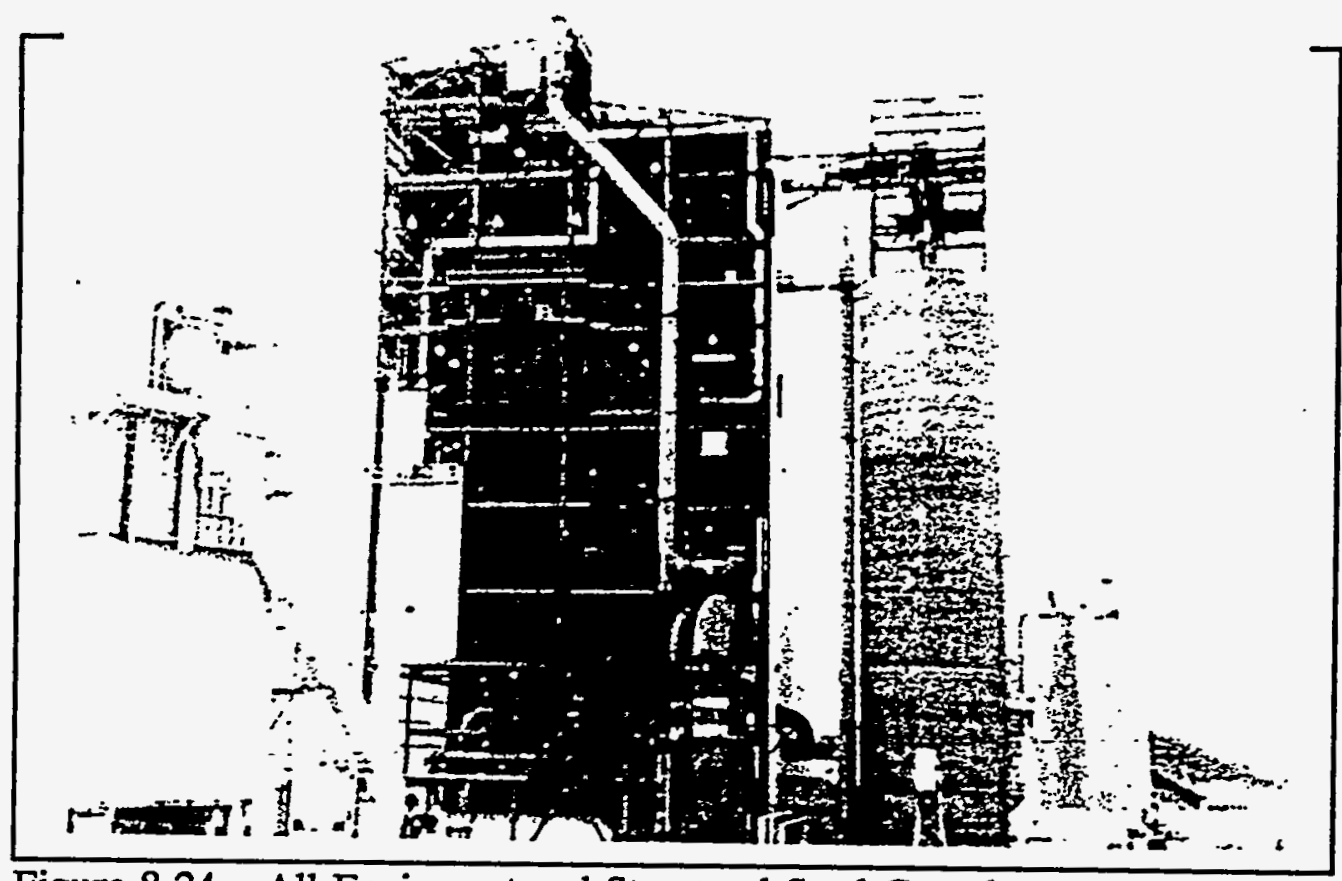

Figure 8.24 All Equipment and Structural Steel Complete

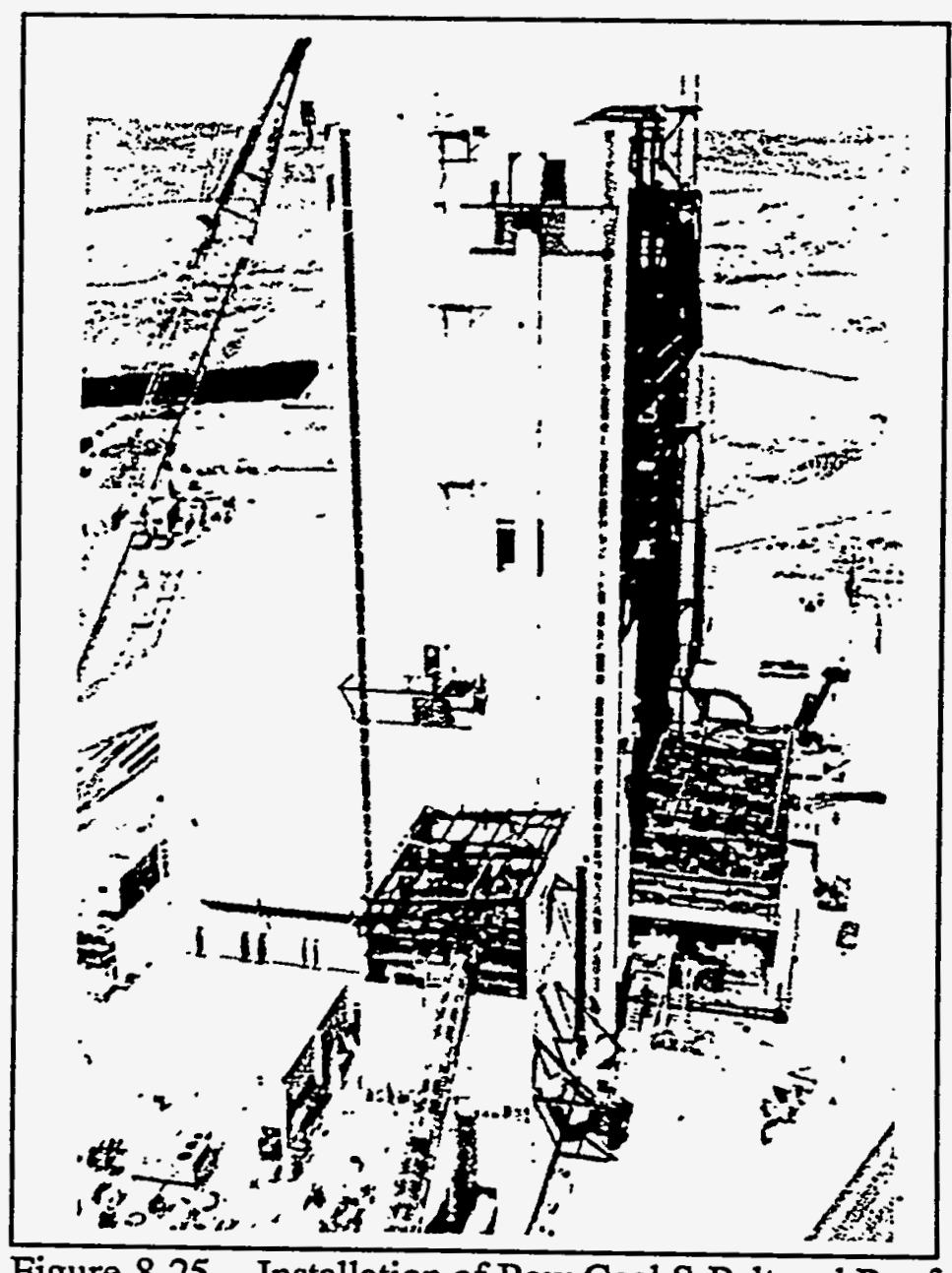

Figure 8.25 Installation of Raw Coal S-Belt and Roof 


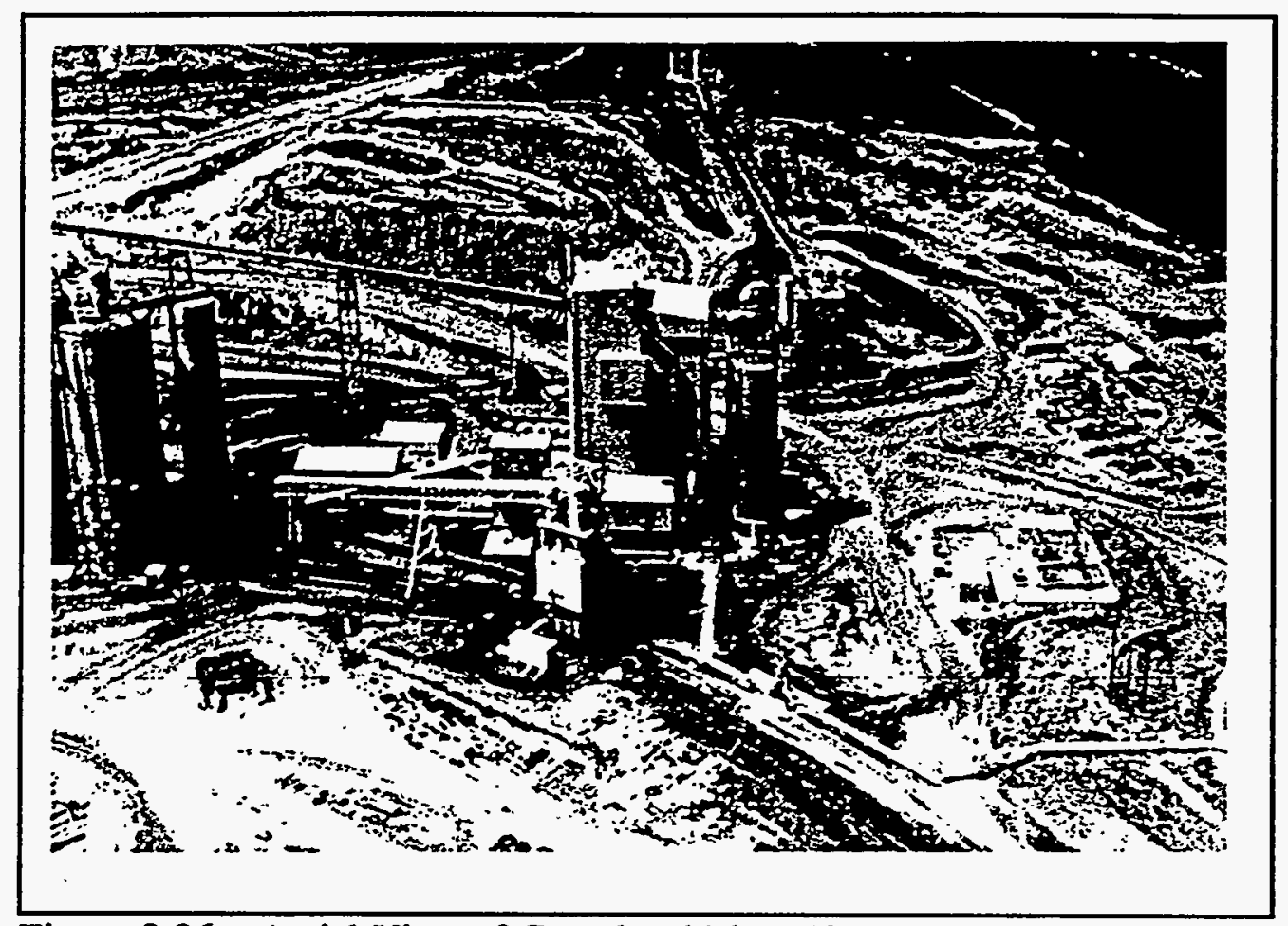

Figure 8.26 Aerial View of Completed Plant (Center)

\subsection{SCREENING BUILDING}

Separated from the main PDF structure by 20 feet, the raw coal screening building contains a large dust collector, a screen, crusher, 100 ton storage bin and loadout conveyor. This equipment was located remote from the plant due to electrical classification, noise and vibration. A spread footer foundation was also used for this 90 foot high structure and was installed under the same contract as the main plant. As mentioned above, whenever work slowed on the erection work on the PDF building, part of the construction crew moved to the assembly of the screening building.

First, the prefabricated, field erected storage bin was assembled and welded together. Then the building was erected around the bin, setting the equipment on each floor on the way up. The design of this building was completed by the KCI/ENCOAL engineering team in the field. Numerous misfits between the conveyors, mechanical equipment and building structure had to be corrected. The cost and schedule impacts of these changes were minor, however, since the building is small. The siding contractor moved over to the screening building after completing the PDF building and completed installation of the triple wall insulated panels in March, 1992.

A heating unit was installed on a small pad outside the building. Figure 8.27 shows the mechanically complete screening building just before starting the siding. The completed screening building structure is shown in Figure 8.28. 


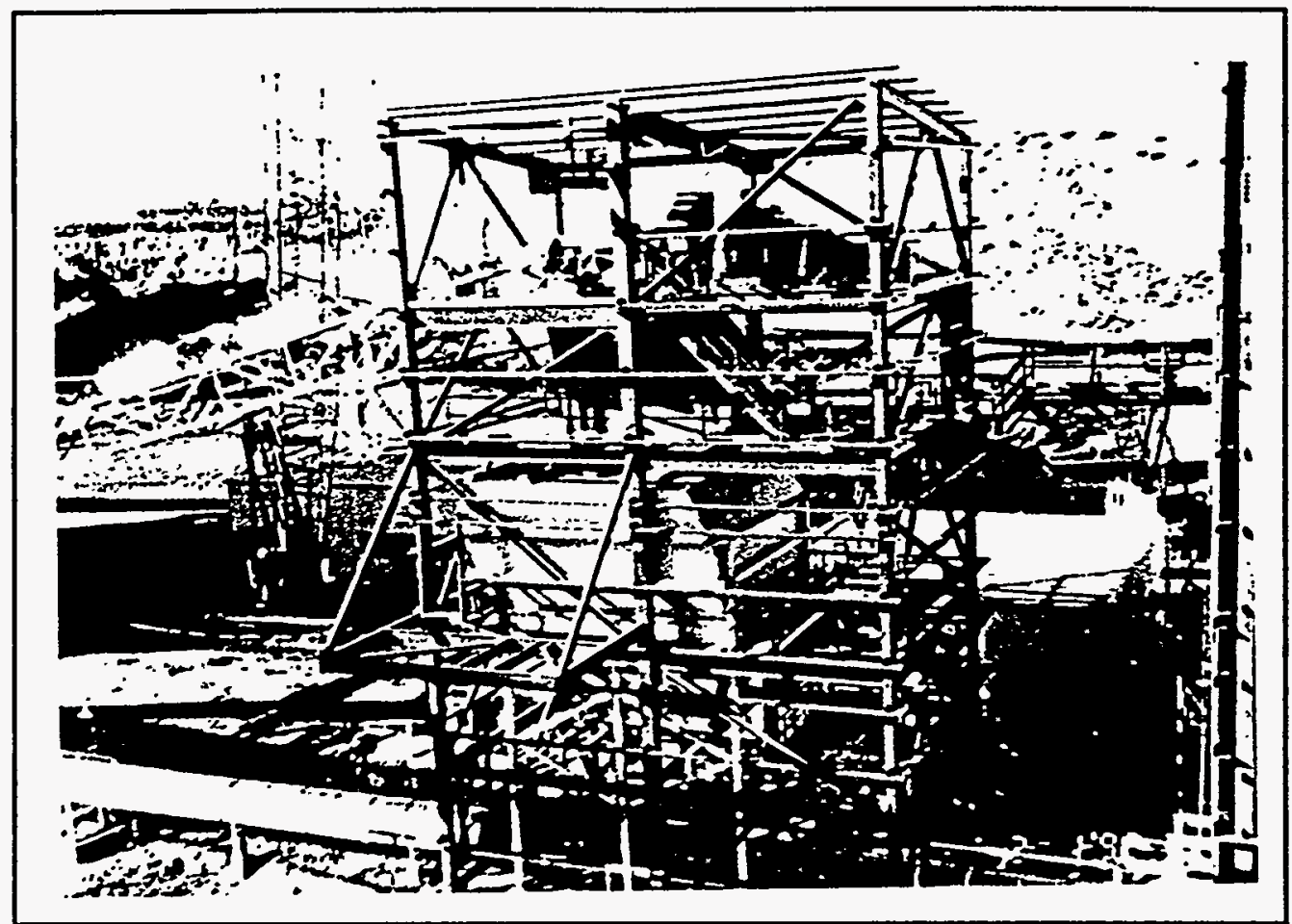

Figure 8.27 Screening Building Prior to Siding

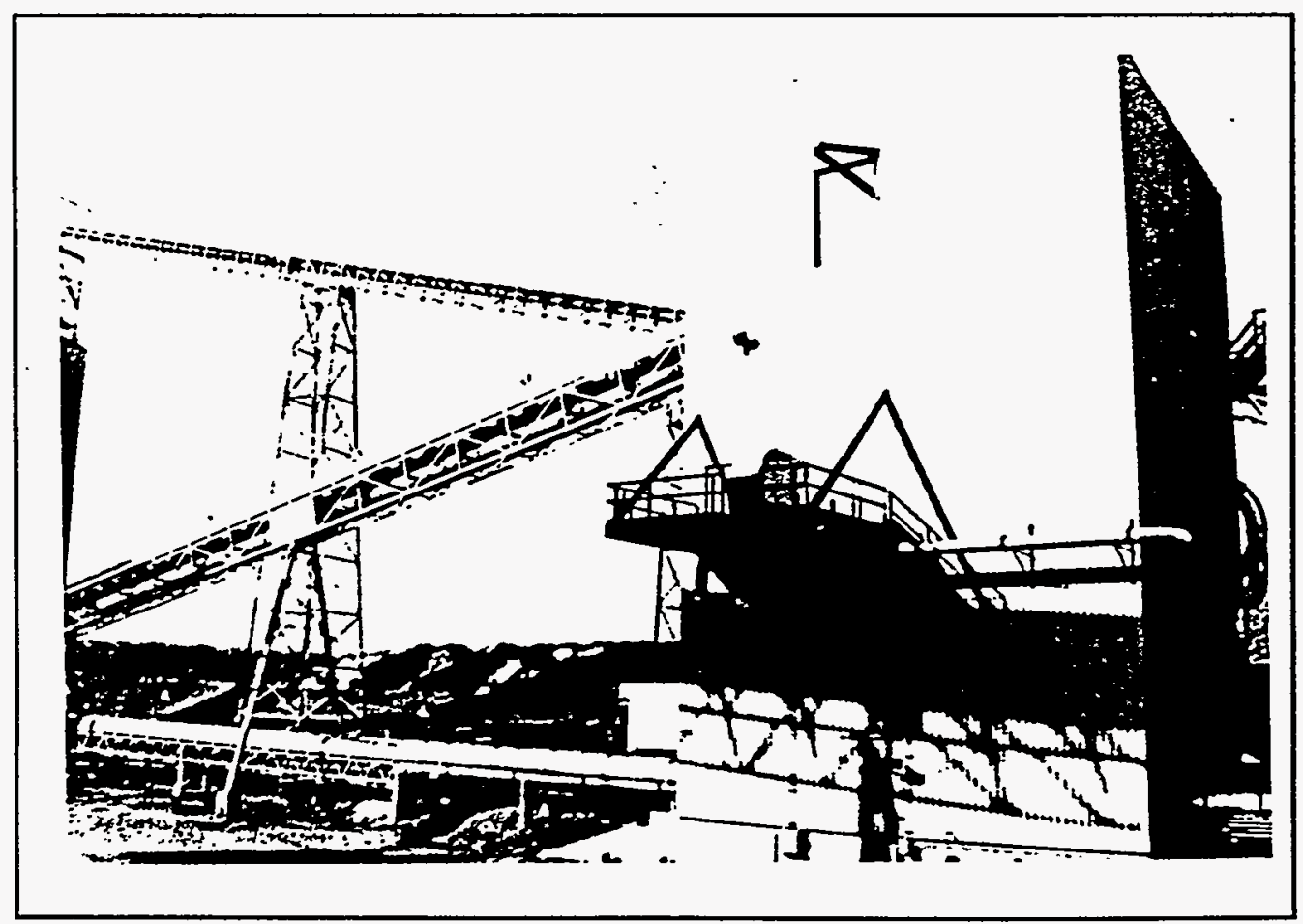

Figure 8.28 Completed Screening Building 


\subsection{ABOVE GROUND PIPING}

The above ground piping contract consisted of 5 oil lines, glycol/water heat tracing lines and the CDL loadout rack. The piping was installed on pipe racks between the PDF plant and the CDL tank farm (Figure 8.29). A large trench was included where the piping crossed a haul road for mine trucks. The work also included all of the piping inside the tank farm between the off-spec CDL tank and the 15,000 barrel storage tank, setting the pumps for CDL circulation and furnishing and installing the CDL truck/train loadout platform (Figures 8.30 and 8.31). This subcontract was bid and awarded in the fall of 1991 and most of the work was complete by December. However, late delivery of the 8" CDL loadout pump and especially the positive displacement meter delayed the final completion of the above ground piping package until April 1992.

\subsection{ARCHITECTURAL BUILDINGS}

Four buildings remote from the main PDF plant and screening building area were required for the ENCOAL Project. Two were pre-engineered metal buildings, the control room and the main electrical substation. The other two were concrete block, namely the motor control center (MCC) and the cooling water pump house. The four buildings were bid as a package under one subcontract and awarded in June 1991. Priority was placed on the MCC building to clear the way for the electrical and instrumentation subcontractor, since that is where the majority of the power and instrumentation wiring and switchgear had to be located. There were no major problems with the MCC building and it was completed in August (Figure 8.32). The next building in order of priority was the pump house, but it could not be started until a permit modification for the existing sedimentation pond changes was received. Therefore the subcontractor moved on to the substation building next.

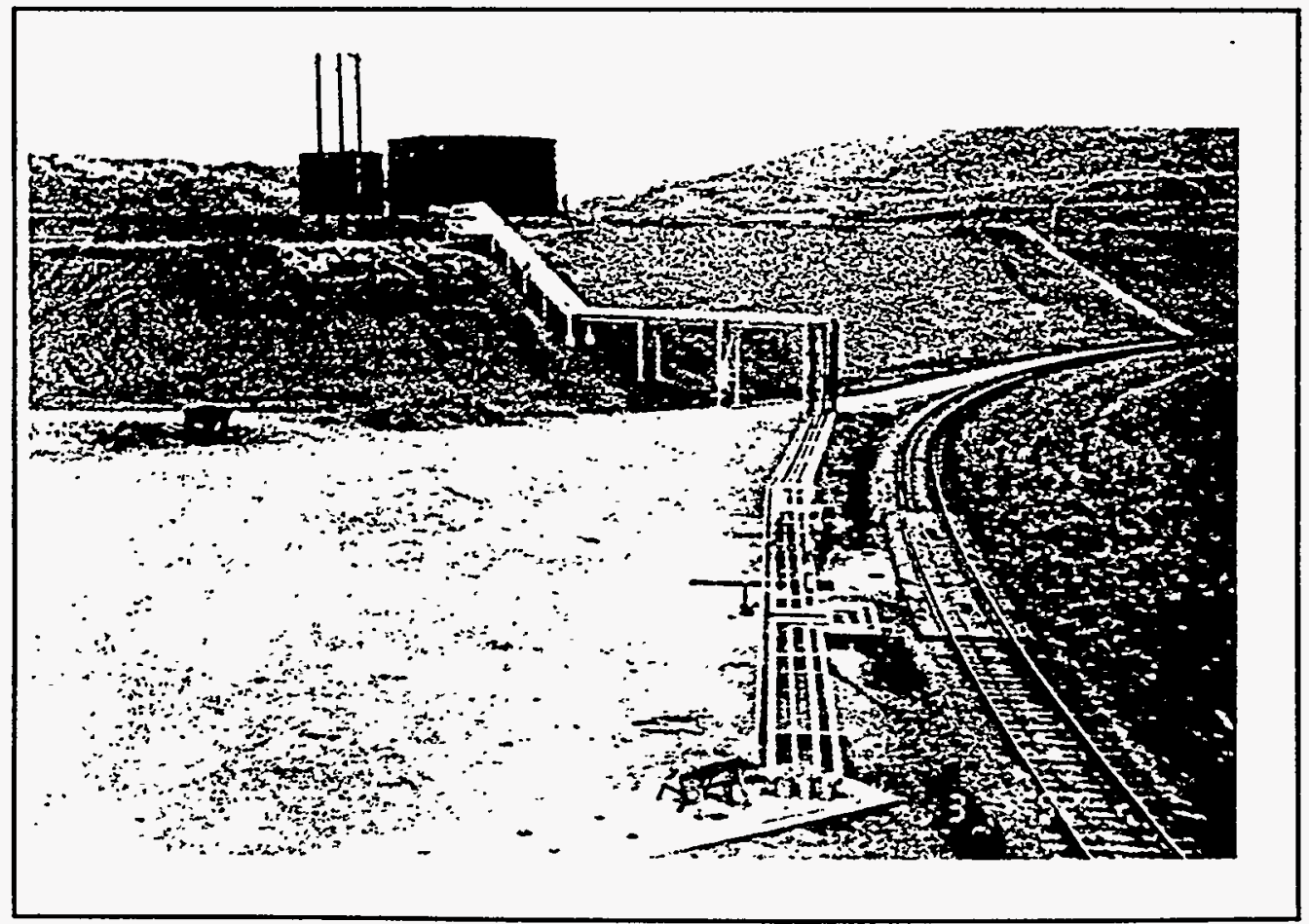

Figure 8.29 Above Ground Piping 


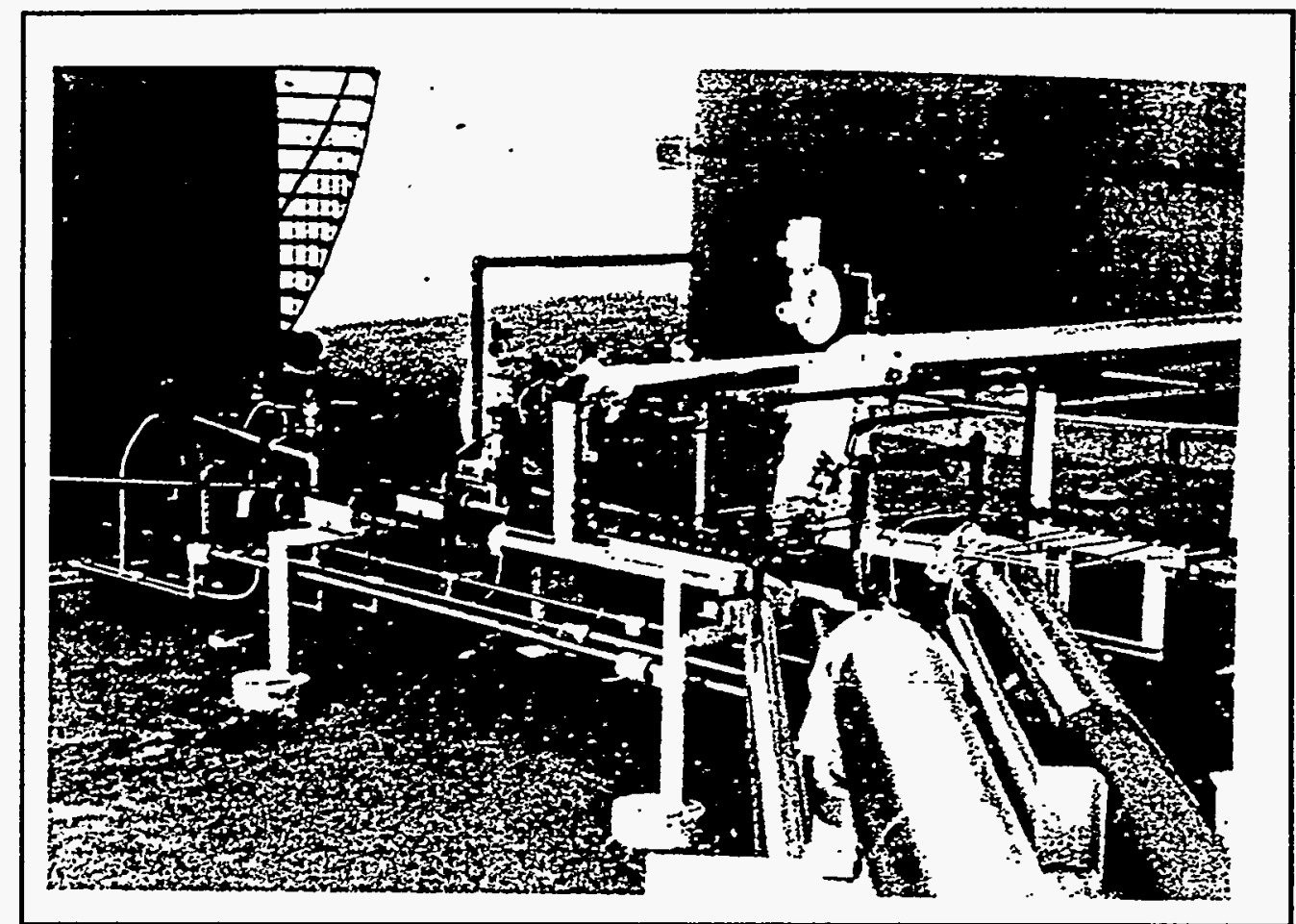

Figure 8.30 Tank Farm Piping

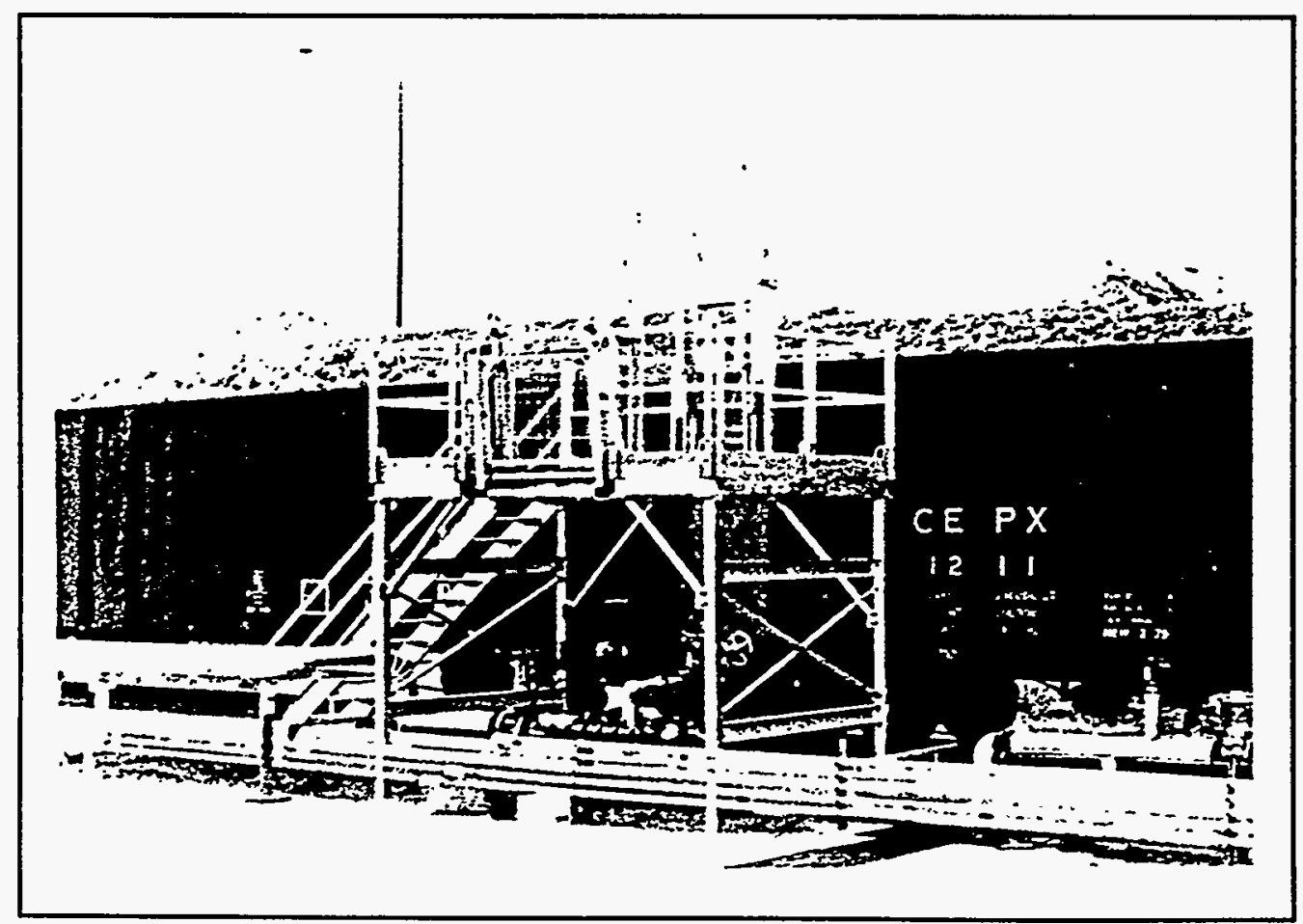

Figure 8.31 CDL Truck/Train Loadout Rack 


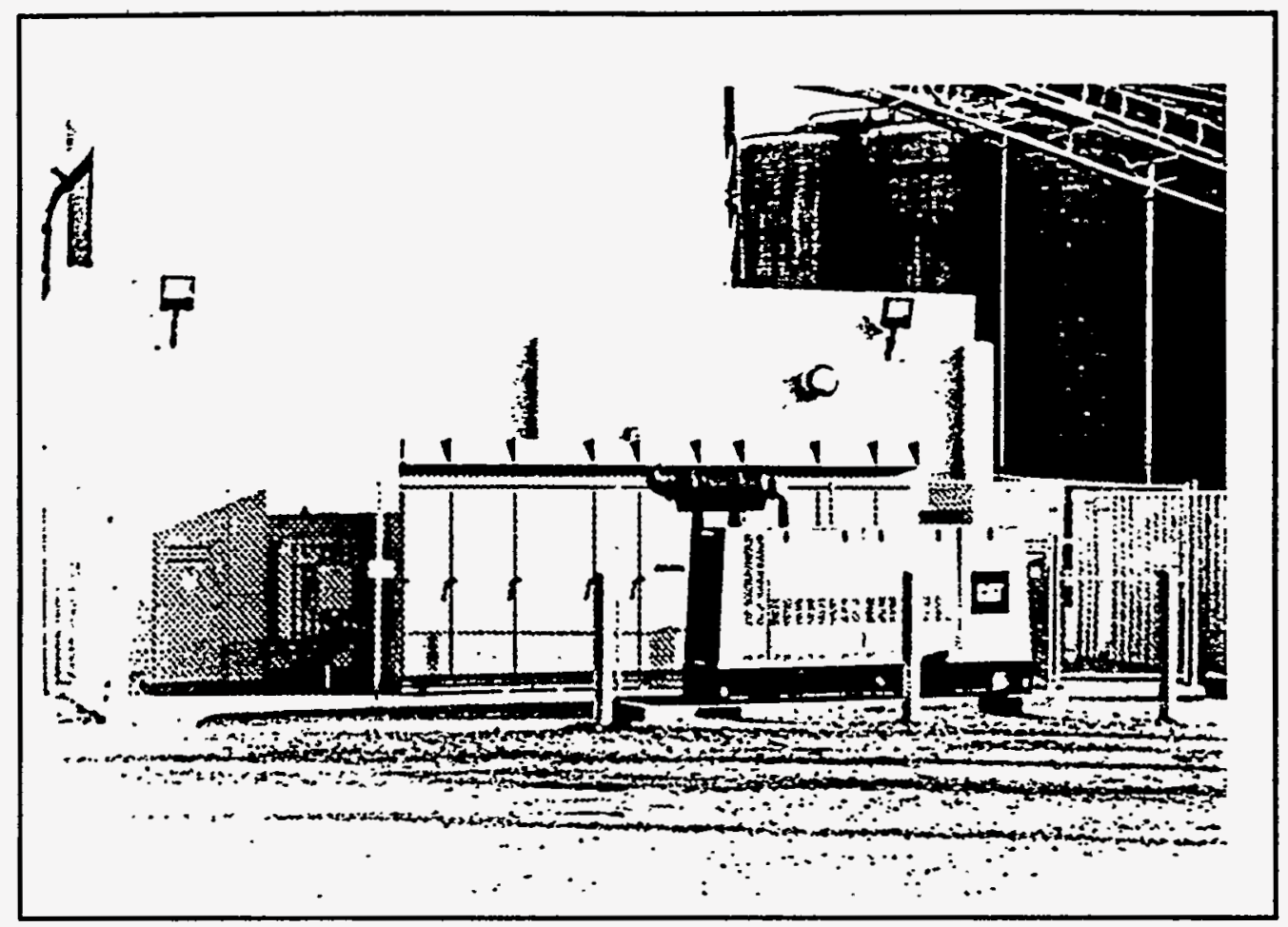

Figure 8.32 MCC Building and 480V Substation

The substation building was completed in September, 1991, opening the way for permanent power to be supplied to the construction site. Up to this point, construction power was supplied by a temporary tie-in to Triton's distribution system. ENCOAL's control building was last on the priority list. The foundations for the control building were placed at the same time as the MCC building in July while awaiting delivery of materials. The control building was framed in by the end of September and ENCOAL was able to move into its new offices in late November (Figures 8.33 and 8.34). Permit approval for construction of the pump house was finally received in September, 1991 and work was well underway by the end of the month. Completion of the pump house, including the setting of the pumps and piping was completed by the end of November, 1991 (Figures 8.35 and 8.36).

\subsection{ELECTRICAL AND INSTRUMENTATION}

Engineering and procurement of the electrical and instrumentation systems was the last home office work to be completed at Kellogg, as would be expected. The subcontract for the electrical and instrumentation field installation was bid in April, 1991 and awarded by mid-June. The subcontractor, mobilized in July as soon as enough materials were on hand to keep the crews efficiently working. The instrumentation portion of the work was in turn subcontracted to a specialist. Both of these subcontractors struggled for places to work at times throughout the project due to delays in equipment deliveries and slow progress on the mechanical erection of the PDF plant equipment. These problems were minimized by controlling staff levels to match the amount of work areas available. Use of cable trays in the PDF plant instead of individual conduit and the preplacement of conduit with the underground piping package significantly improved the productivity of the electrical installation crews. Together, these two items resulted in a lower peak workforce for the electrical and instrumentation subcontract than originally projected. 


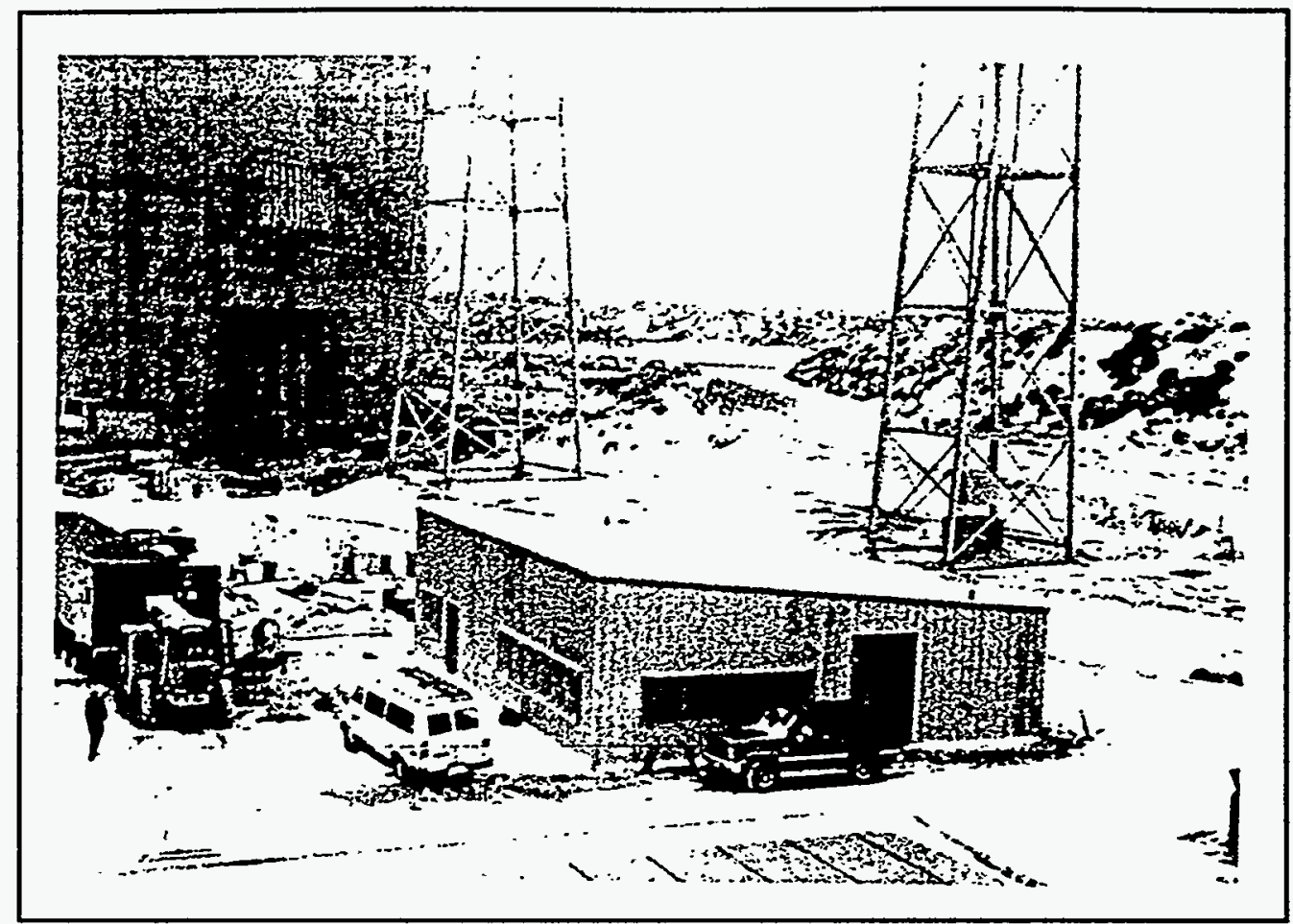

Figure 8.33 Control Building Near Completion

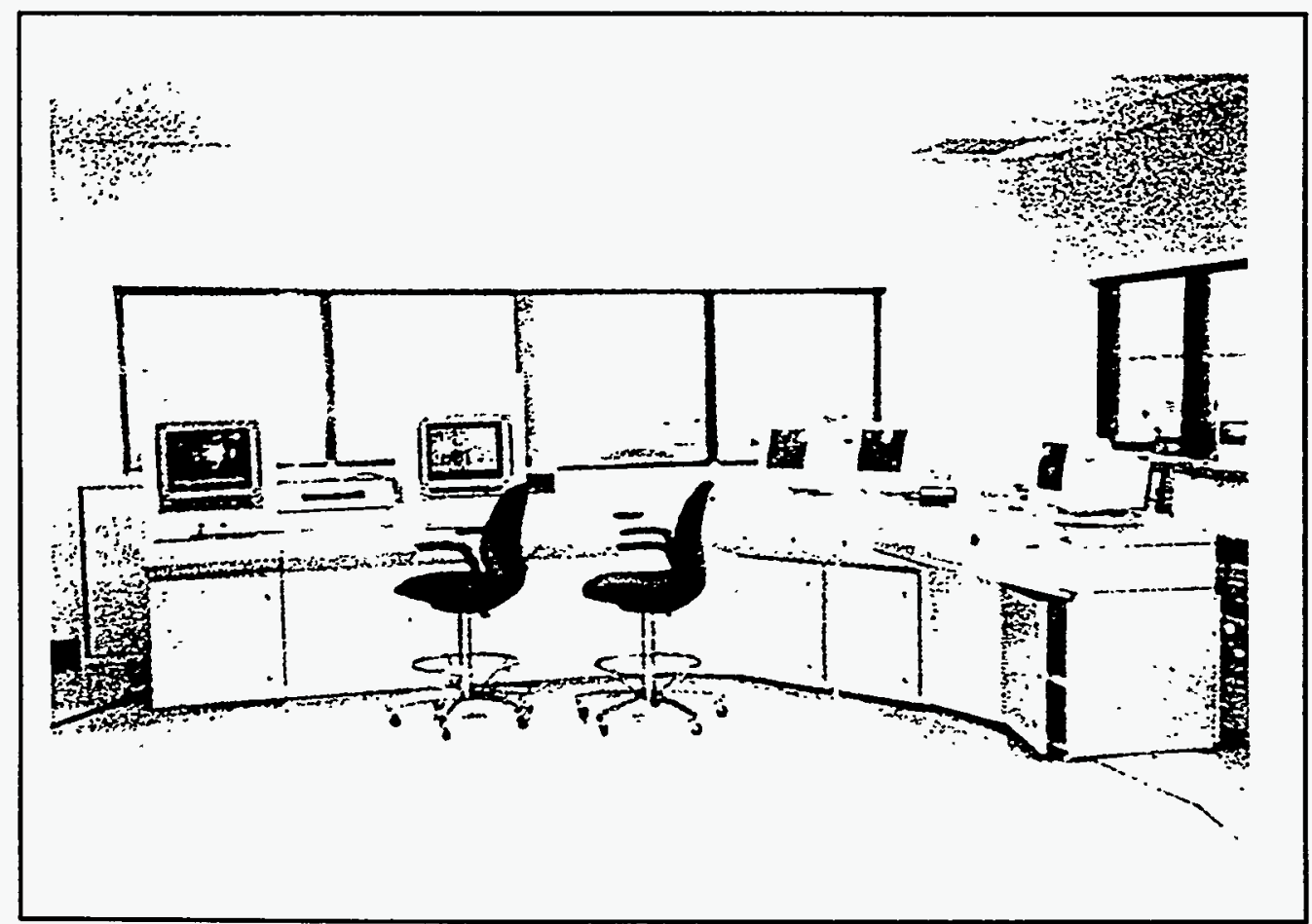

Figure 8.34 Original Control Room Layout 


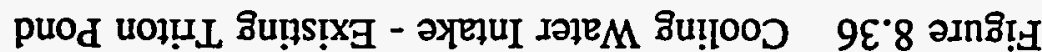

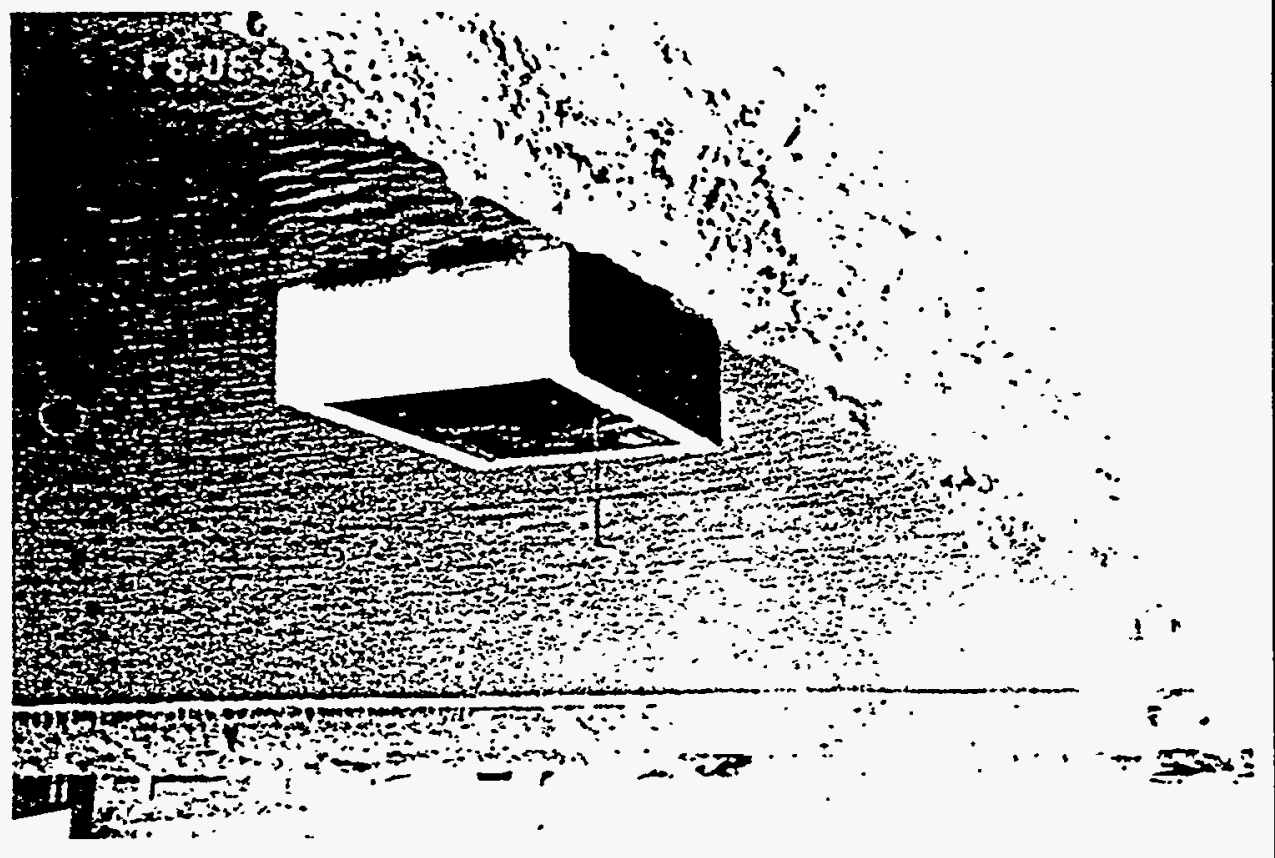

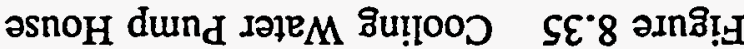

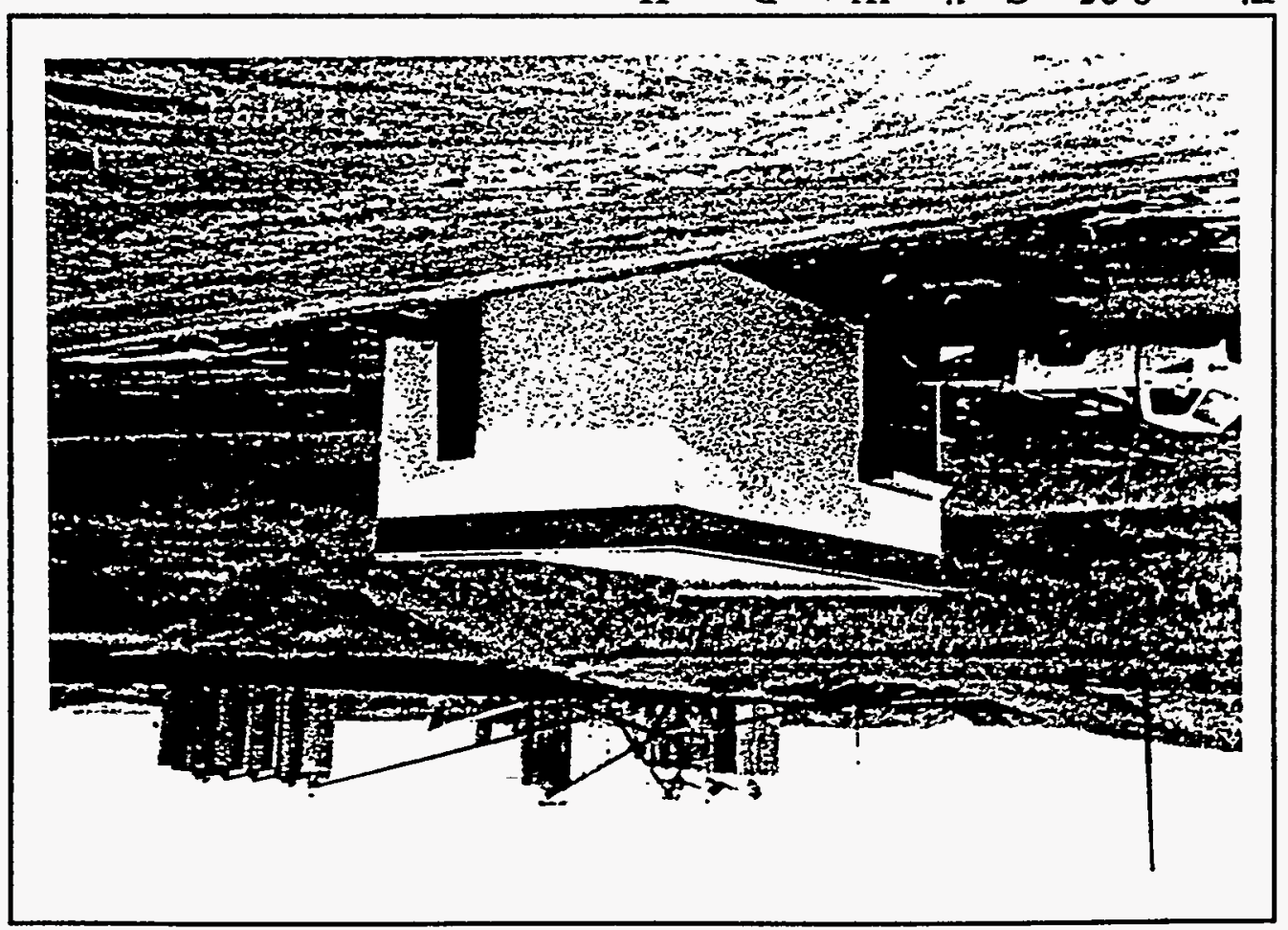


Overall the electrical and instrumentation work went fairly smoothly. There were only minor interface problems with other trades as these subcontractors followed behind and under the erection crews. One constant problem was weld splatter. Welders working overhead had to be reminded to put down fire blankets and use spotters to prevent people on the lower floors from being burned. The same was true for welders on the electrical and instrumentation crews when they were attaching conduit supports to the structure. Most of the motor controls and wiring were in place by January, 1992. Installation of the instrumentation wiring and equipment had to wait on completion of the piping, including flushing and testing. Terminations took place from mid-January through April, 1992, which included hooking up all motors and checking for rotation. The only subcontractor to remain through commissioning, the electrical and instrumentation crews worked closely with ENCOAL's operations staff to get all facilities ready to operate. They also helped calibrate all instruments. Final completion of the subcontract occurred in May, 1992.

\subsection{MISCELLANEOUS}

Several other subcontract activities were dovetailed into the construction effort over the course of the Project. These included the supply and field erection of the two CDL storage tanks (12100 bbl. and 1-15,000 bbl. shown in Figure 8.37) which was done on a turnkey basis. Insulation of the piping and pumps was part of the above ground piping subcontract. Epoxy lining for the CDL storage tanks and ceramic lining of the pyrolyzer cyclone were also done as separate subcontracts. As opposed to the insulation contractor, where there was a lot of interface with the other trades with the scaffolding, the latter two subcontracts were all internal and posed no problems. A railroad siding for up to 10 tank cars was constructed as part of the Project and it was done by a local subcontractor acceptable to the Burlington Northern Railroad (Figure 8.38). This work was done during the dry summer months of 1991 and was completed on August 15. Other small miscellaneous work that came up during the course of the Project was handled by extending the scope of work of existing subcontractors using quoted unit prices.

Although delays in the preferred construction schedule did occur, the overall project was completed two months before the baseline schedule submitted to the DOE, including commissioning and start-up. Figure 8.39 shows the percent completion versus time for the original planned construction period, as revised during the construction activity and the earned progress (actual). Figure 8.40 shows the actual manpower requirements versus the revised plan. The actual Phase I (Design) and Phase II (Construction and Start-Up) costs of $\$ 51,272,000$ were right on budget. 


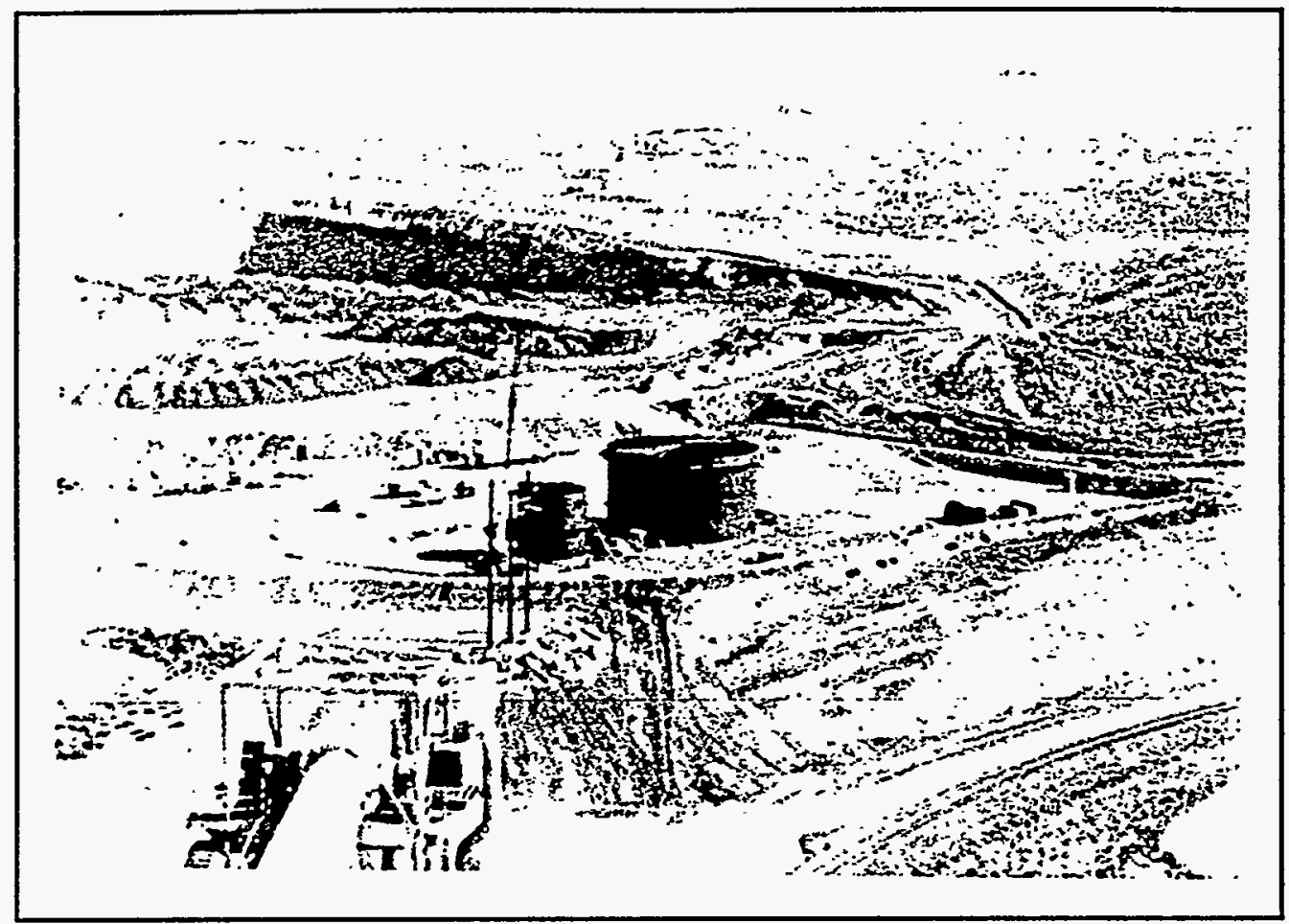

Figure 8.37 CDL Storage Tanks Under Construction

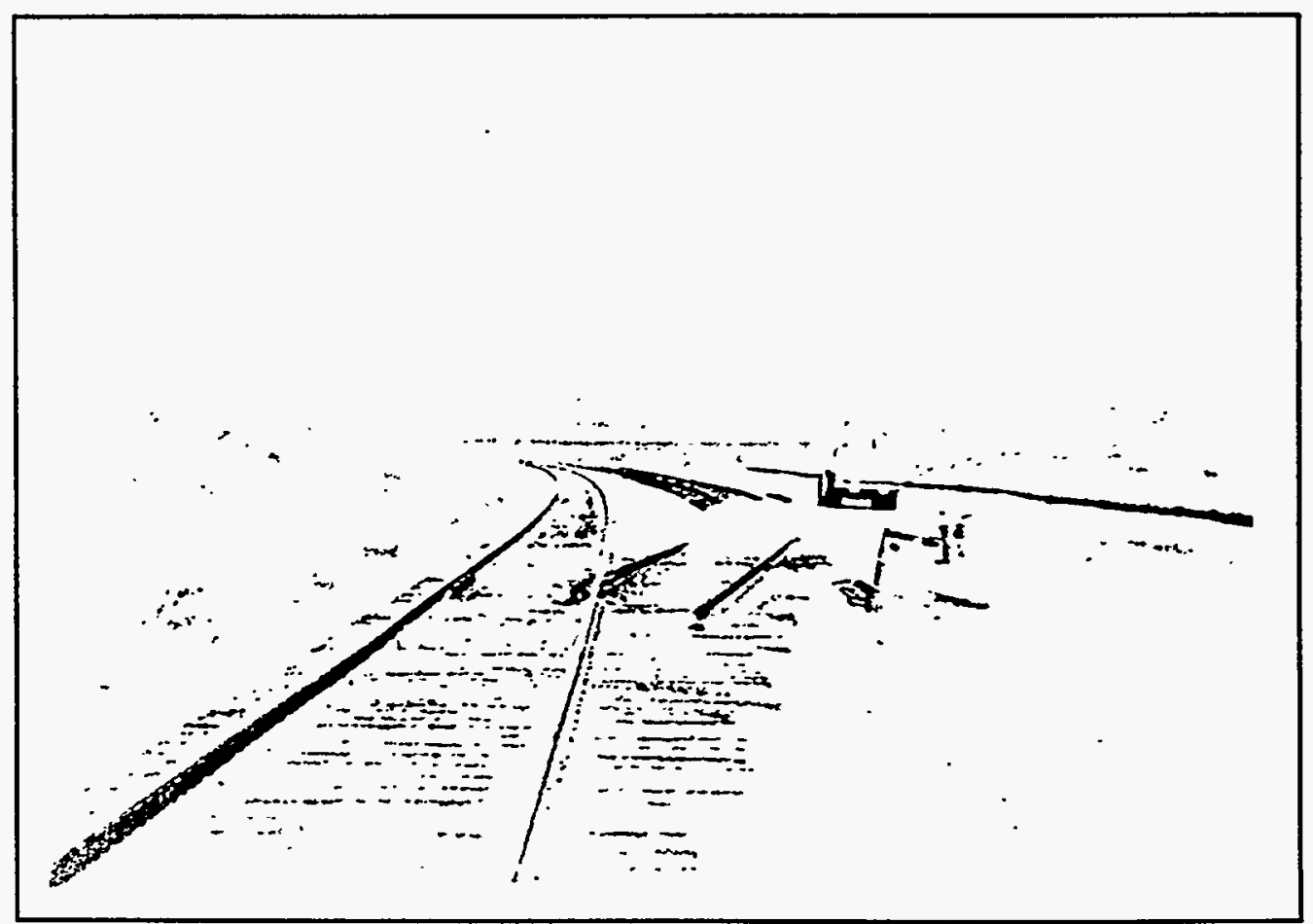

Figure 8.38 Rail Siding Under Construction 


\section{- ENCOAL CORPORATION}

MILD GASIFICATION DEMONSTRATION PLANT

MONTHLY PHYSICAL PERCENT COMPLETE

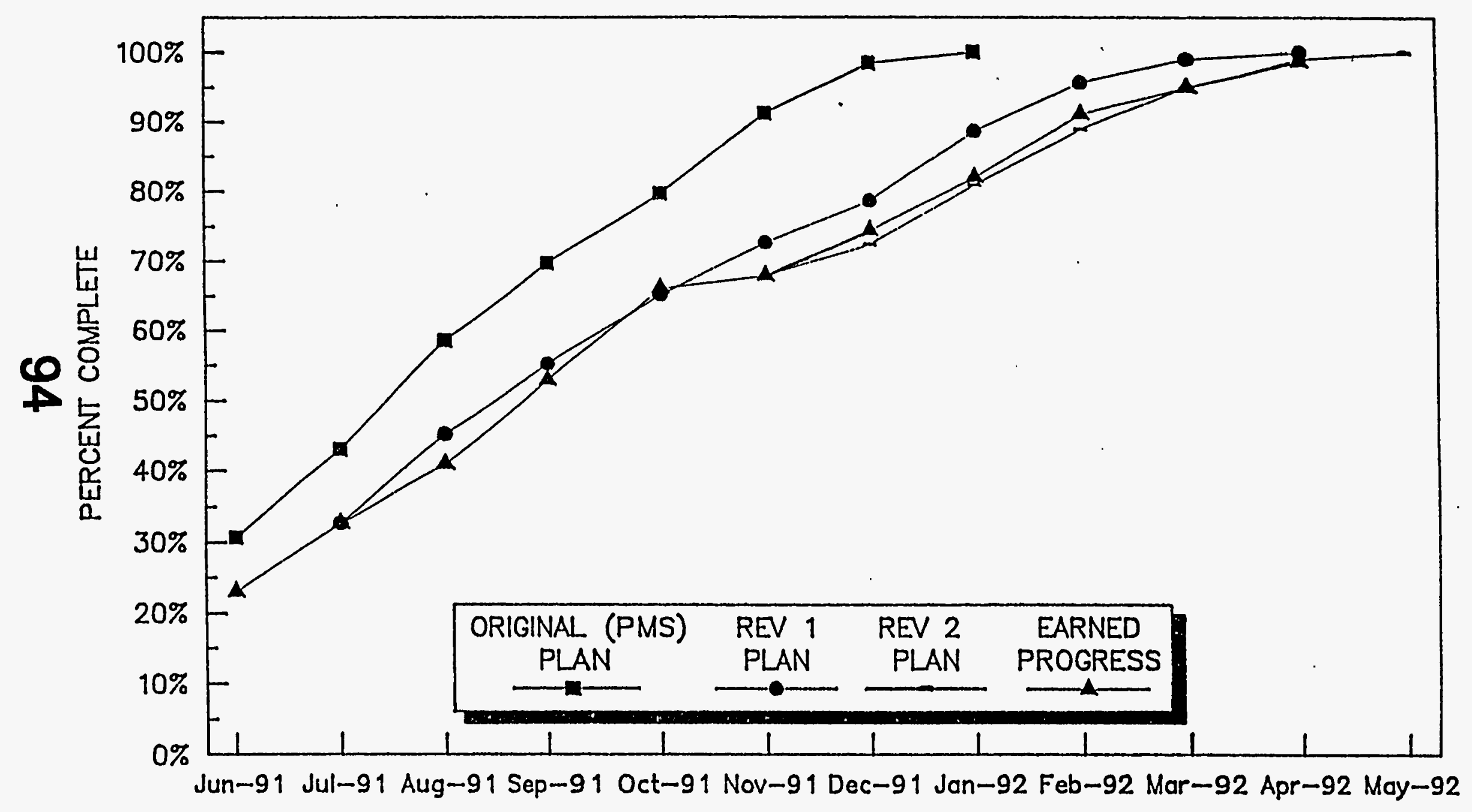

$\mathrm{KCI}$ CONSTRUCTORS, INC. JOB 6683 - GILLEITE, WYOMING

DATA DATE 30 APRIL 1992

Figure 8.39 


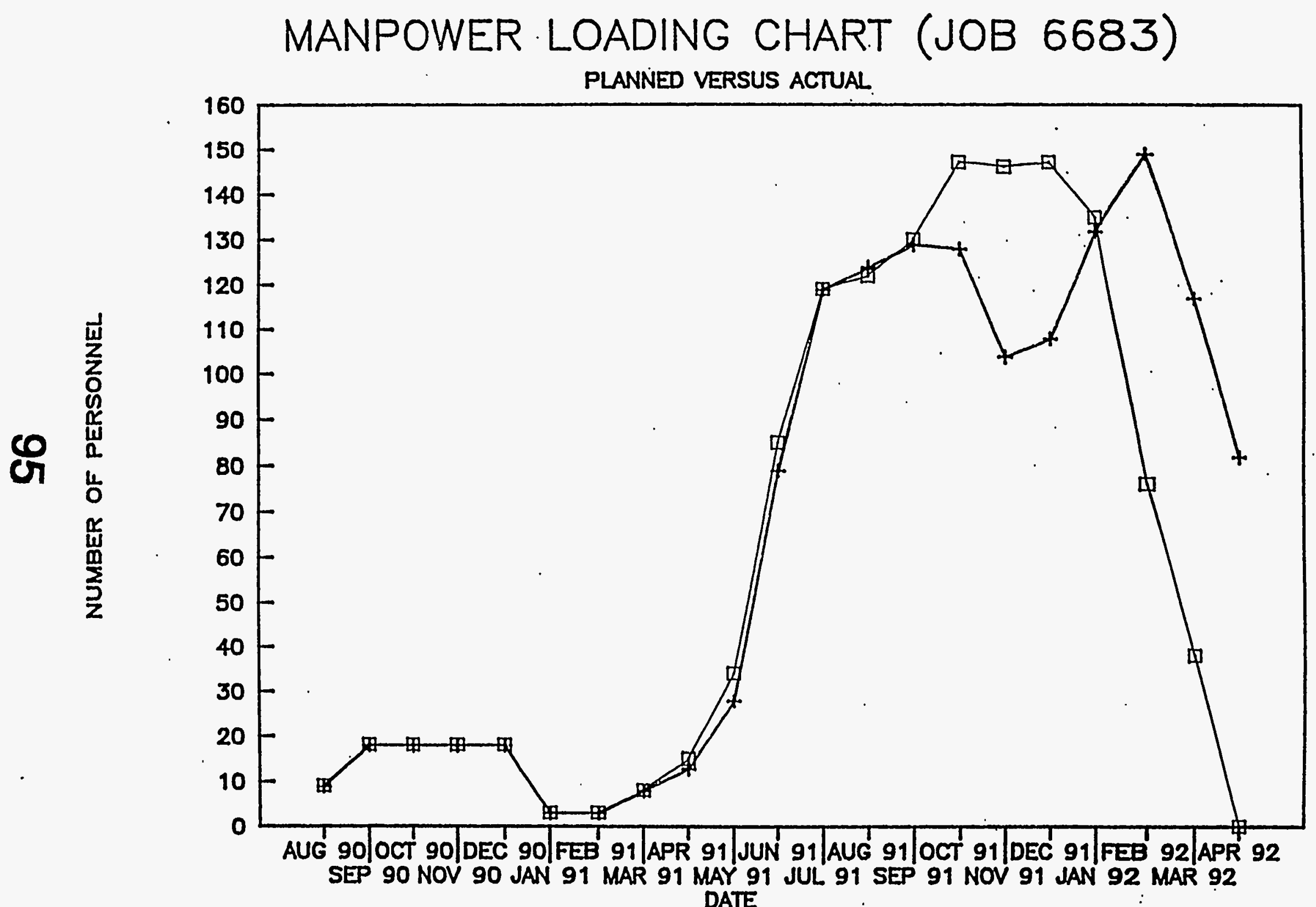

$\square$ PLANNED MANPOWER + ACTUAL MANPOWER

Figure 8.40 


\subsection{ENVIRONMENTAL CONCERNS}

During design, a high priority was placed on the minimization of waste generation. Therefore, no significant environmental impacts or consequences are expected from the Project. All necessary permits for the construction of the facility were secured during the design phase of the Project. The design criteria for the demonstration plant met the Wyoming Department of Environmental Quality's Best Available Technology criteria in every aspect. The following sections briefly highlight the design measures taken in the affected environmental disciplines and their anticipated impacts.

\subsection{AIR POLLUTANTS}

During normal operation, any purge gas that is released to the atmosphere must pass through the desulfurization unit, and any purge gas that is produced in the pyrolyzer loop can be sent to the desulfurization unit only after it has been incinerated in the dryer combustor. Therefore, air pollutants emitted from the PDF building stack consist only of minor amounts of $\mathrm{NO}_{\mathbf{x}}, \mathrm{SO}_{\mathrm{x}}, \mathrm{CO}$, hydrocarbons and particulates. Emissions for each pollutant are below the 100 ton per year level for named (fuel conversion) sources. Rigorous permitting and monitoring requirements were thus avoided. This was achieved through careful selection of appropriate pollution control technologies and process control equipment.

$\mathrm{NO}_{x}, \mathrm{CO}$, and hydrocarbons emissions are minimized by thermal decomposition in the dryer combustor. $\mathrm{SO}_{2}$ and particulates emissions from the process are controlled by the purge gas treatment described in Section 6.13. In addition, particulates emissions from the crushing/screening building, raw coal storage silo, and PDF storage silo are controlled by wet scrubbers. The efficiencies of these scrubbers are over $99 \%$.

\subsection{WATER EFFLUENTS}

The process is designed to operate such that no water will be condensed during normal operation, thus eliminating the generation of wastewater contaminated by hydrocarbons. All liquid effluents generated from plant upsets, such as off-specification CDL or intermediate products, can be recycled back to the facilities and upgraded. Internal recycling of process and clean-out water occurs through collection of such water in concrete floor containment trenches and vessels. This water, along with the pyrolyzer quench condensed water and other incidental streams (i.e., leaks from equipment seals), are collected for process usage.

Washdown water from the solids handling portion of the facilities, (i.e., from the raw coal storage silo, screening building, and solids handling systems in the PDF building), and the discharge from the wet scrubbers are collected in floor sumps located at various areas. It is then pumped to a collection sump in the screening building. This collection sump allows the effluent to pass through a bank of hydrocyclones for separation of solids from the liquid. The liquid portion is pumped to the Buckskin Mine Wastewater Reservoir No. 1 for treatment and settling prior to discharge to the environment. The separated fines are added to the fines storage bin in the screening building which is used to store the undersized material from the triple-deck vibrating screen. The fines are then returned to the Buckskin Mine product via truck or conveyor. When the hydrocyclones are out of service, all solids report to the settling pond. 
The sodium sulfite effluent generated by the purge gas treatment system (described in Section 6.13 ) is pumped to a temporary precipitate storage reservoir. The reservoir provides sufficient surface area to promote natural evaporation of water and oxidation of sodium sulfite to sodium sulfate. This precipitate, in the form of a slurry, is nonhazardous and nontoxic. The temporary storage of the precipitate is confined within a clay liner until a permanent disposal facility is designed, permitted and constructed.

In the conceptual design, the permanent reservoir will be double lined with a leak detection/headbreak system. The liners will be composed of a primary synthetic membrane liner and a secondary amended clay liner separated by a geonet drainage layer. The reservoir will be designed to channel any leakage entering the drainage layer to sumps for return to the reservoir. This design allows both continual monitoring of the synthetic liner integrity and, in the event of a leak in the synthetic liner, maintenance of a minimum driving head on the secondary clay liner, thereby effectively preventing leakage through the liner system.

As discussed in Section 7.3, cooling water is obtained from Buckskin Mine Sedimentation Reservoir No. 1 for indirect cooling applications, make-up water, and washdown. The existing Triton water allocation rights encompass the net consumption that may be needed to supplement the cooling/make-up water stream. It is anticipated that the cooling water return to the reservoir will increase the reservoir temperature by 8 to $10^{\circ} \mathrm{F}$. No environmental effects are predicted under the National Pollutant Discharge Elimination System (NPDES).

\subsection{SOLID/HAZARDOUS WASTE GENERATION}

No solid hazardous waste is expected to be generated from the process as explained in previous sections. Sodium sulfite solution will be sent to the temporary precipitate storage reservoir. If complete evaporation of water from the reservoir is assumed, a nonhazardous solid waste of coal fine/sodium sulfate mixture is obtained. Current design philosophy plans for the eventual on-site disposal of this material. The $1 / 8 " \times 0^{\prime \prime}$ rejected coal collected in the screening building is returned to the Buckskin Mine as a salable product, thus avoiding the generation of additional solid waste.

\subsection{SAFETY PRACTICES}

Safety is integrated into the design and operation of the facilities. The on-site safety program, established at the Buckskin Mine, was carried over to this Project. Specific ENCOAL safety procedures were developed which specify actions required during operation and maintenance of the facilities to protect workers' health and safety. During construction, the safety program was managed by KCI. There were a number of elements to their highly successful program that are discussed in more detail below. 


\subsection{INDUSTRIAL HYGIENE}

Every effort was made during design to reduce worker exposures to potential hazardous materials or conditions. This was achieved through engineering controls. Monitoring will aid in evaluating the effectiveness of the engineering controls. The monitoring program will include personal monitoring of workers potentially exposed to a hazard as well as area and/or source monitoring. Remote air contaminant monitors will detect unsafe levels of $\mathrm{CO}, \mathrm{H}_{2} \mathrm{~S}, \mathrm{SO}_{2}$ and $\mathrm{CH}_{4}$. These monitors trigger audio signals to warn of air contaminants. They are part of the control systems that initiate and record alarm conditions and alert plant operators to initiate response procedures. A physical inspection and gas detection evaluation of the plant is conducted at least twice daily to ensure that areas are safe for workers.

\subsection{PHYSICAL HAZARDS}

The primary physical hazards associated with the project are noise, extreme temperatures, and combustible materials. Design efforts were made to select equipment that generate low sound intensities. Noise monitoring and surveys were conducted during startup to identify areas with noise levels which exceed the MSHA time weighted average limits. A hearing conservation program has been established for these areas.

Heat stress will be evaluated during plant operations to determine if design measures (liners, coatings, insulation and ventilation) provide sufficient protection for the workers. Cold stress may be environmentally induced in excess of design considerations (siding, heating and ventilation systems). Additional operational measures will be determined pending the results of these assessments.

Combustible materials are inherent in any coal handling and processing facility. The major hazard is the accumulation of coal dust. Regular clean-up procedures must be practiced to prevent the accumulation of coal dust. Daily inspections are required throughout the facilities to ensure that no combustible material accumulates.

\subsection{CONSTRUCTION SAFETY PRACTICES}

The safety program administered by $\mathrm{KCI}$ during construction was very successful as documented by Figure 10.1 which shows the lost time and reportable incident rate for the construction phase of the Project. Basic construction safety practices were developed jointly by ENCOAL and KCI incorporating MSHA requirements and Triton's established practices. This effort resulted in a document that became part of all subcontractor's terms and conditions. In addition to the contractual requirements, a number of safety enhancement programs were institutionalized by KCI. These programs were a balanced combination of recognition/awards and positive, fair enforcement of all safety practices as follows;

(1) Enforcement Universally applied policies and rules together with appropriate discipline when needed. 


\section{LOST TIME INCIDENT RATES (ENCOAL CORP.)} MILD GASIFICATION DEMONSTRATION PLANT

$\mathscr{8}$

INCIDENT RATES

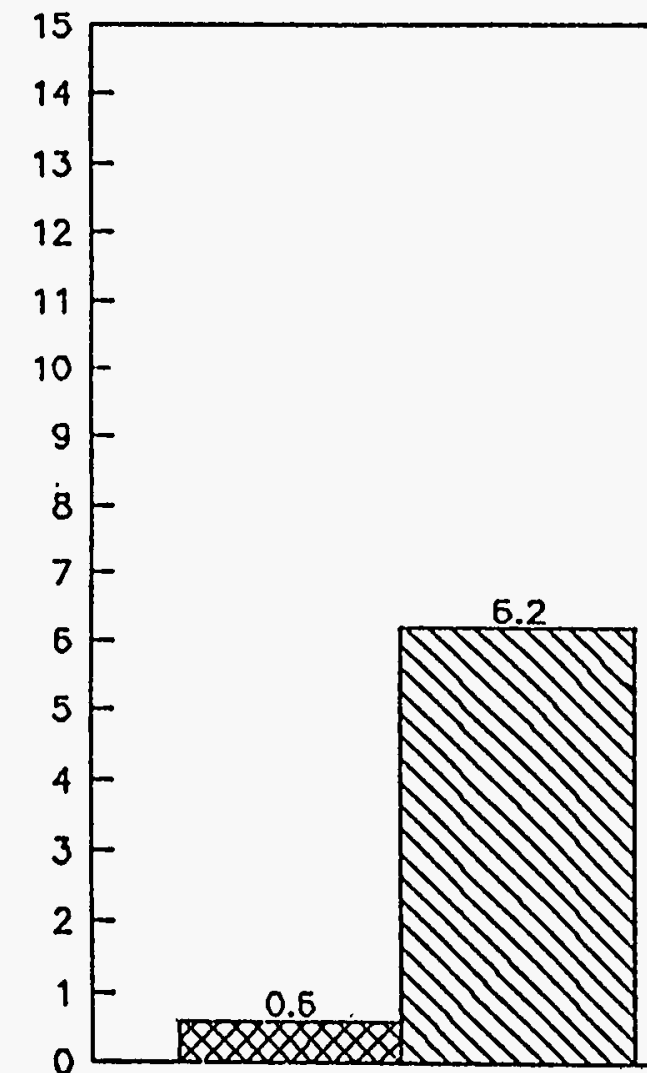

L.OST TIME INCIDENT RATE
K.C.I.

DIV MATIONAL AVERAGE

The Incidence rates represent the number of injurles and illnesses or lost workdays per 100 full-time workers and were calculated as: (N/EH) X200,000, where

N

= Number of injuries and lilnesses or lost workdays.

EH $\quad$ Tolal hours worked by all omployees during calendar year.

$200,000 \quad$ Base for 100 equivalent fuil-time workers (working 40 hours per week, 50 weeks per year).

Figure 10.1 
(2) "Kelway"

(3) "STOP"

(4) Meetings

(5) Case Management

A safety and productivity enhancement program that involves all site personnel and their families. At ENCOAL, safety awareness and involvement was achieved through a safety committee made up of representatives of each subcontractor, $\mathrm{KCI}$ and ENCOAL. A safety suggestion program, safety crew of the month, employee of the month, safety poster contests for children, family site tours, picnics, milestone celebrations and an awards program were all used to increase safety awareness. Periodic awards that were given included dinners for the employee and their spouse, caps, jackets, sweatshirts and belt buckles. A monthly site newsletter was also published with pictures and stories highlighting safety events and awards.

Safety Training and Observation Program originally developed by the Dupont Company. Three series of classes were conducted during the construction period.

Daily "toolbox" safety meetings were held by each subcontractor and attended frequently by KCI/ENCOAL. A weekly safety committee meeting with minutes and action items was held and attendance was required by representatives of each subcontractor.

When an incident did occur, $\mathrm{KCI}$ worked with the subcontractors and local health providers to insure the employee was properly treated, but that no unnecessary prescriptions or treatments were directed that would increase the time away from work or elevate the level of an incident to a lost time. Local doctors visited the

- site to discuss working conditions, MSHA regulations and safety practices so they would be in a better position to judge an employees ability to perform their work safely.

It is believed that all of these programs contributed to the excellent safety achievements on the Project. Several of these programs were adopted by subcontractors and ENCOAL for on going use.

\subsection{CONCLUSIONS}

The process engineering, detailed design and construction have been completed for the 1000 ton/day ENCOAL Mild Coal Gasification Project. The plant has processed subbituminous Powder River Basin low-sulfur coal and produced PDF and CDL. PDF is a premium solid fuel with good burning characteristics and low sulfur content. CDL has properties similar to a lowsulfur heavy industrial fuel oil.

The design of the demonstration plant is based upon pilot plant studies which provided operating data and properties of products. Mechanical equipment selection resulted from many discussions with equipment vendors, as well as from the knowledge and experience of members of the design team. 
The major design accomplishments for the process are:

(1) drying coal on a rotary grate by bringing it into direct contact with hot gas.

(2) pyrolysis of dried coal on a rotary grate by bringing it into direct contact with hot gas.

(3) cooling of pyrolyzed coal by direct water quenching and indirect heatexchange with cooling water.

(4) condensation of high boiling hydrocarbons from a gaseous stream by direct vapor/liquid contact in a packed-bed column without condensation of water.

(5) treatment of a purge gas stream before its release to the atmosphere.

Sufficient operating flexibility is built into the plant to permit extensive evaluation of the major process variables. Environmental concerns and safety practices were given a very high priority in design considerations.

Construction of the plant was accomplished with few problems other than minor equipment delivery delays. The total construction from start to finish was less than 18 months due to the successful fast-track approach and the work was done within budget. An exemplary safety record was achieved.

It is believed that this process represents acceptable technology and marketing risks. Commercial plants should provide attractive investments. Both products are environmentally superior, and are viable fuels to help utilities meet the Clean Air Act Amendments of 1990. 


\section{APPENDIX A}

Simplified general civil designs for the ENCOAL facilities are shown in Figure A.1 to Figure A.14. Figure A.1 describes the general layout of the facilities. The dimensions of each structure and its relative position are approximated. The control room for the facilities is shown on Figures A.2 and A.3. Figures A.4 to A.13 show the PDF structure and its simplified floor plans. The relative dimension and position of each piece of equipment are approximated. Figures A.14 and A.15 describe the screening building. The equipment numbers shown on Figure A.6 to Figure A.14 are cross referenced to their general descriptions in Table A.1.

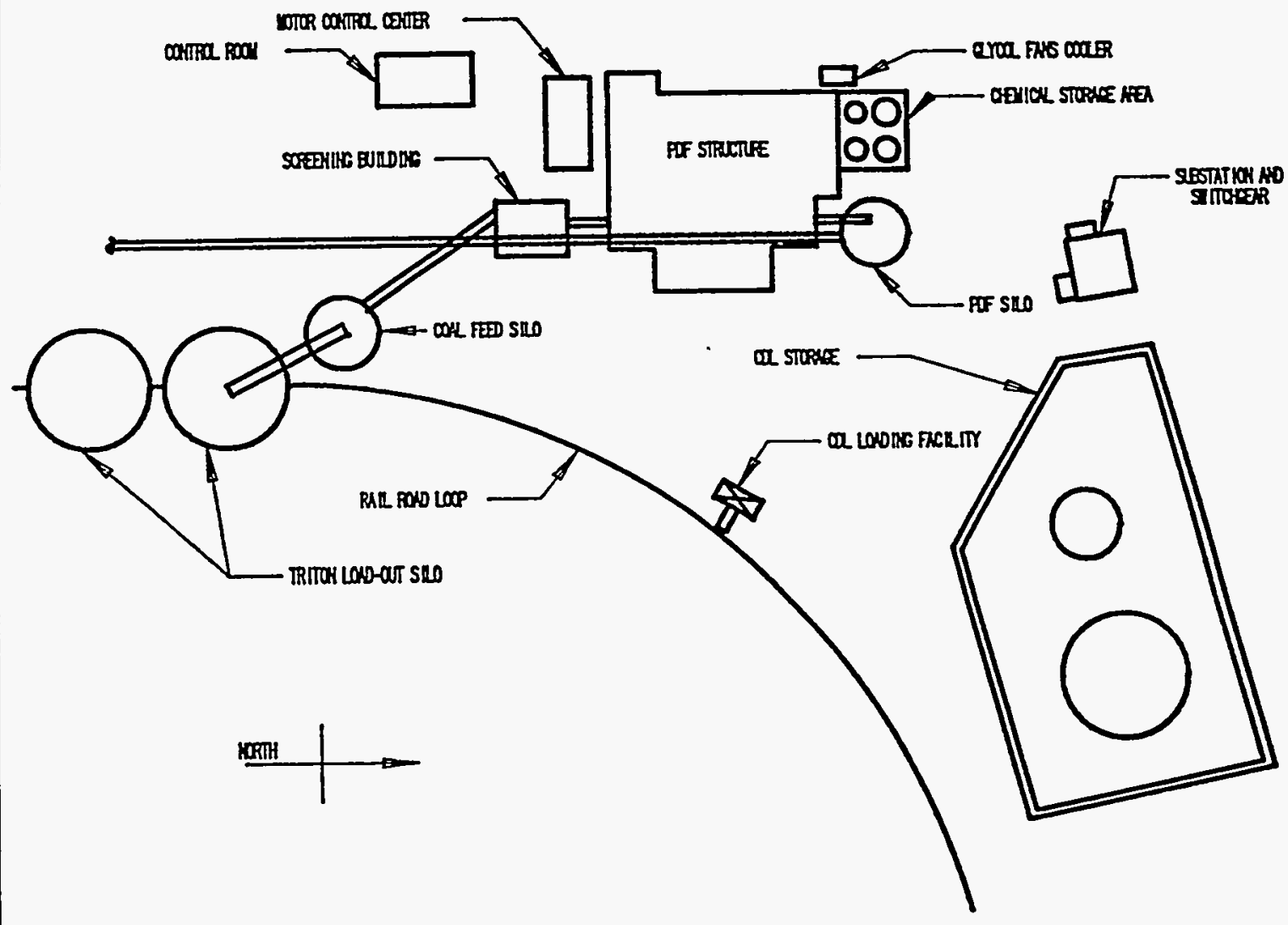

Figure A.1 ENCOAL Facilities Layout 


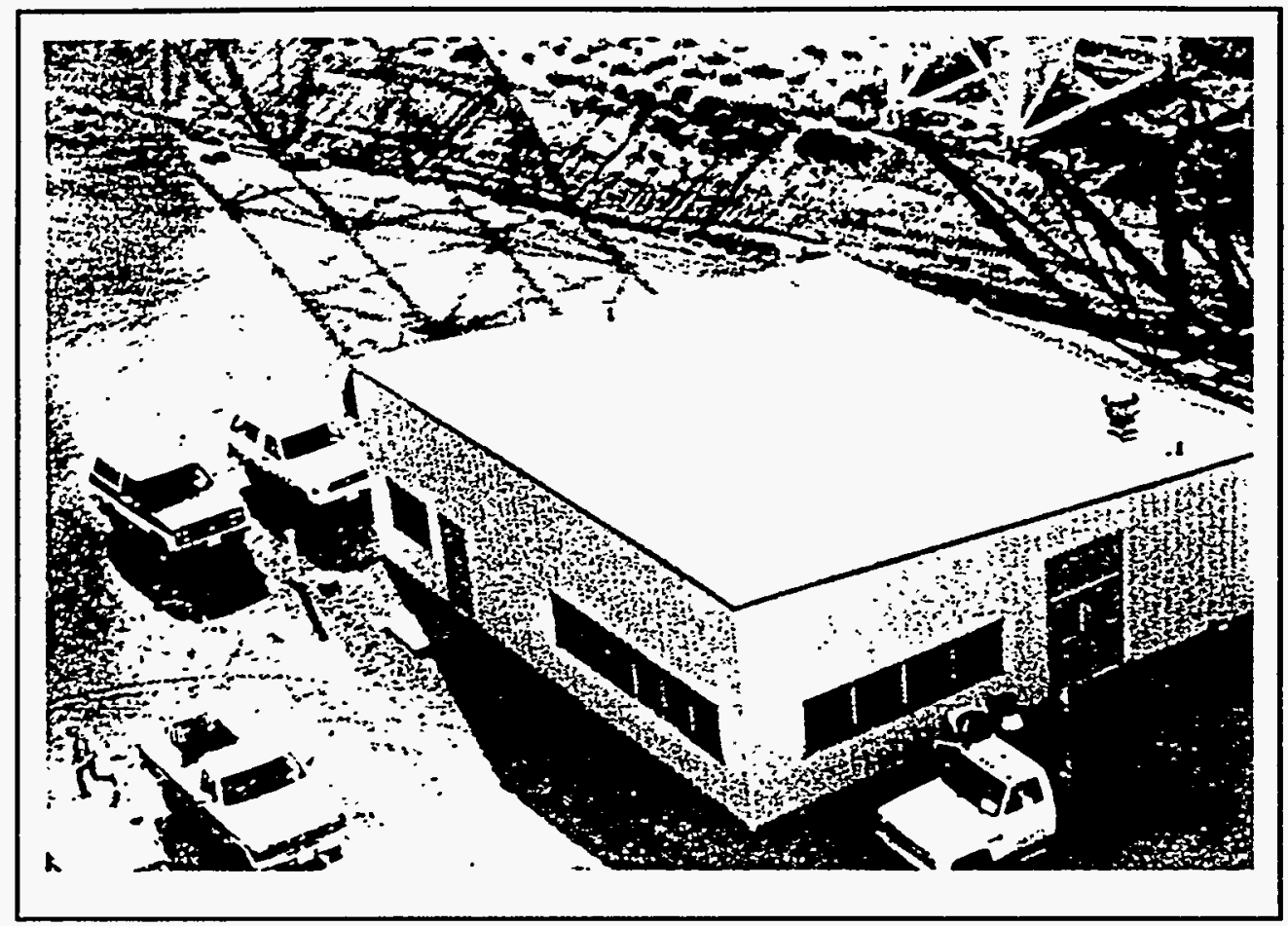

Figure A.2 Control Room

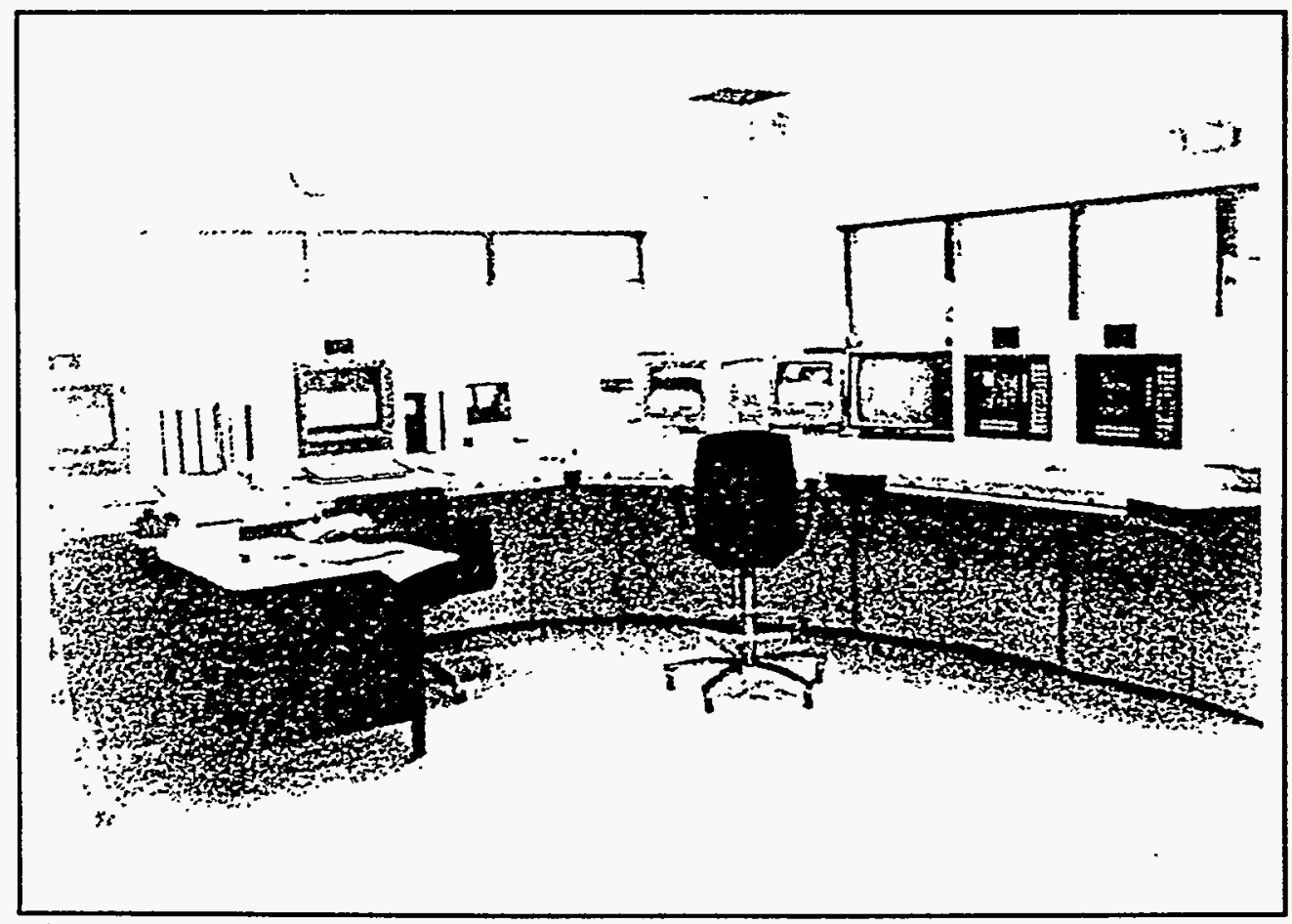

Figure A.3 Interior of the Control Room 


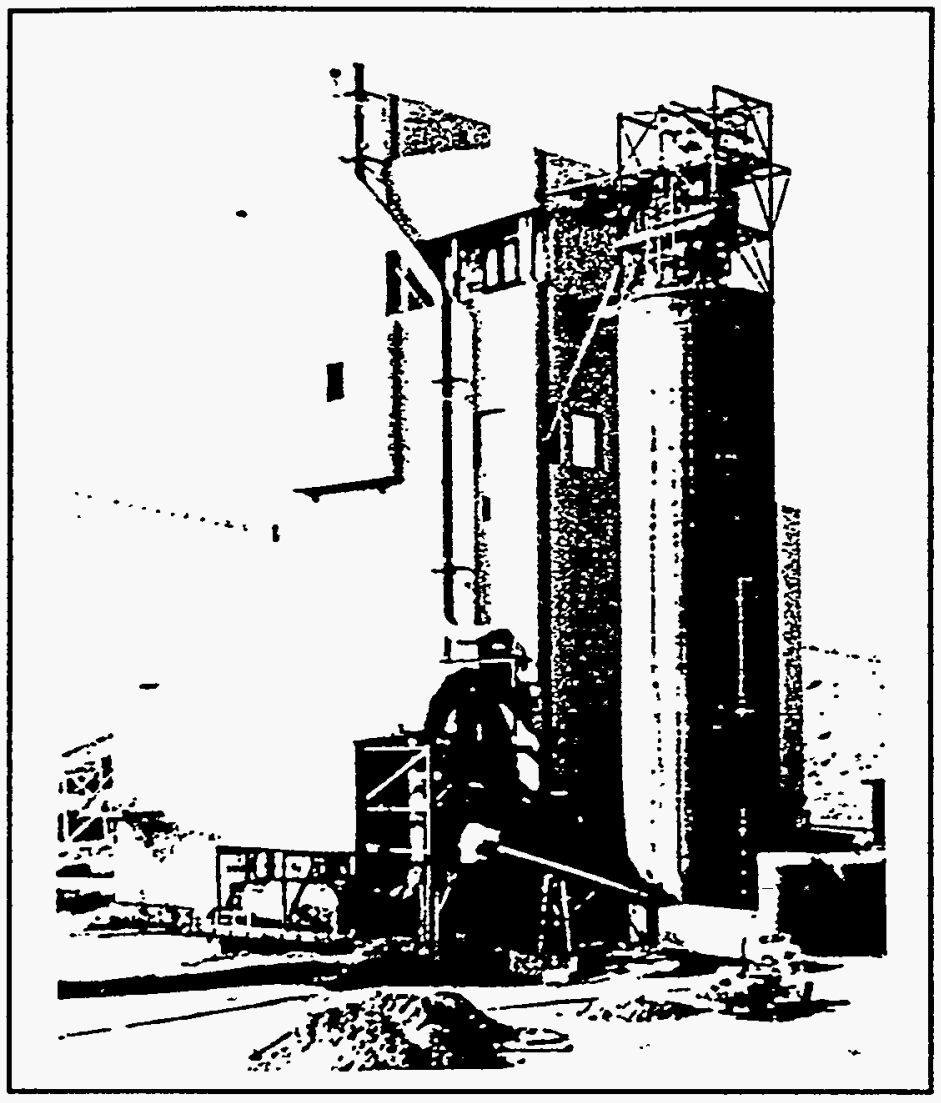

Figure A.4 PDF Structure Looking Southwest

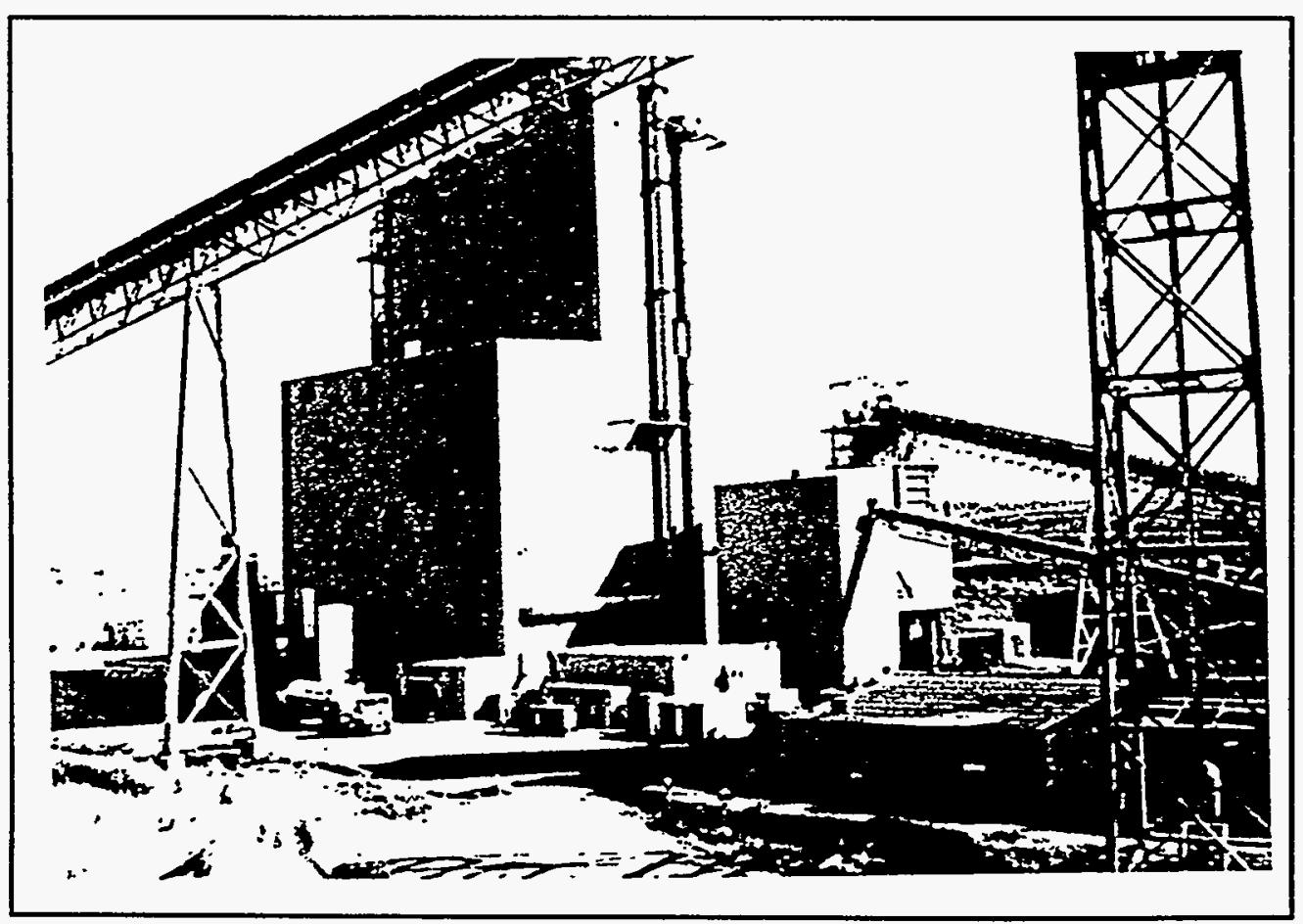

Figure A.5 ENCOAL Facilities Looking Northeast 


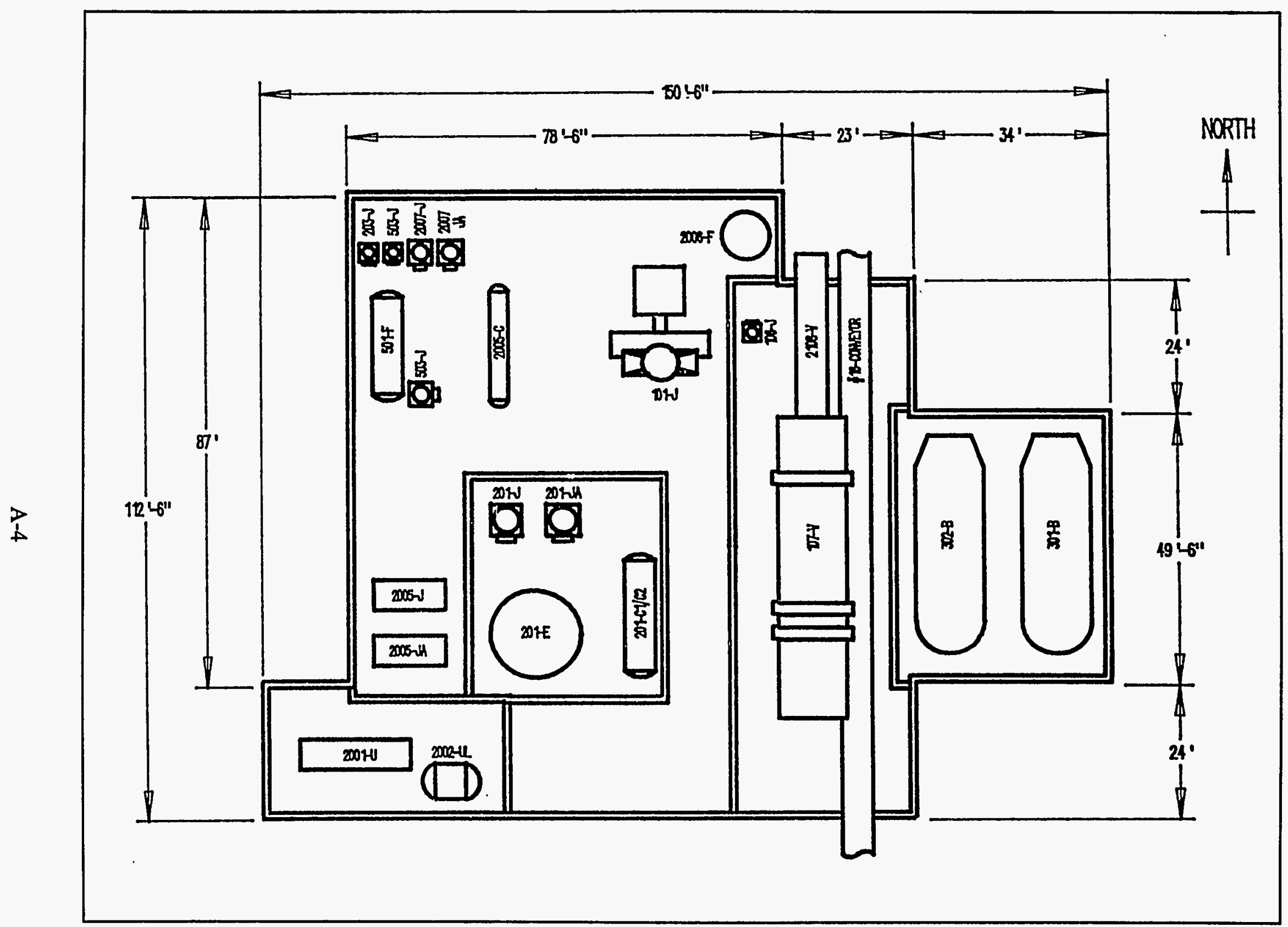

Figure A.6 PDF Structure Floor Plan (Elevation 100'-6") 


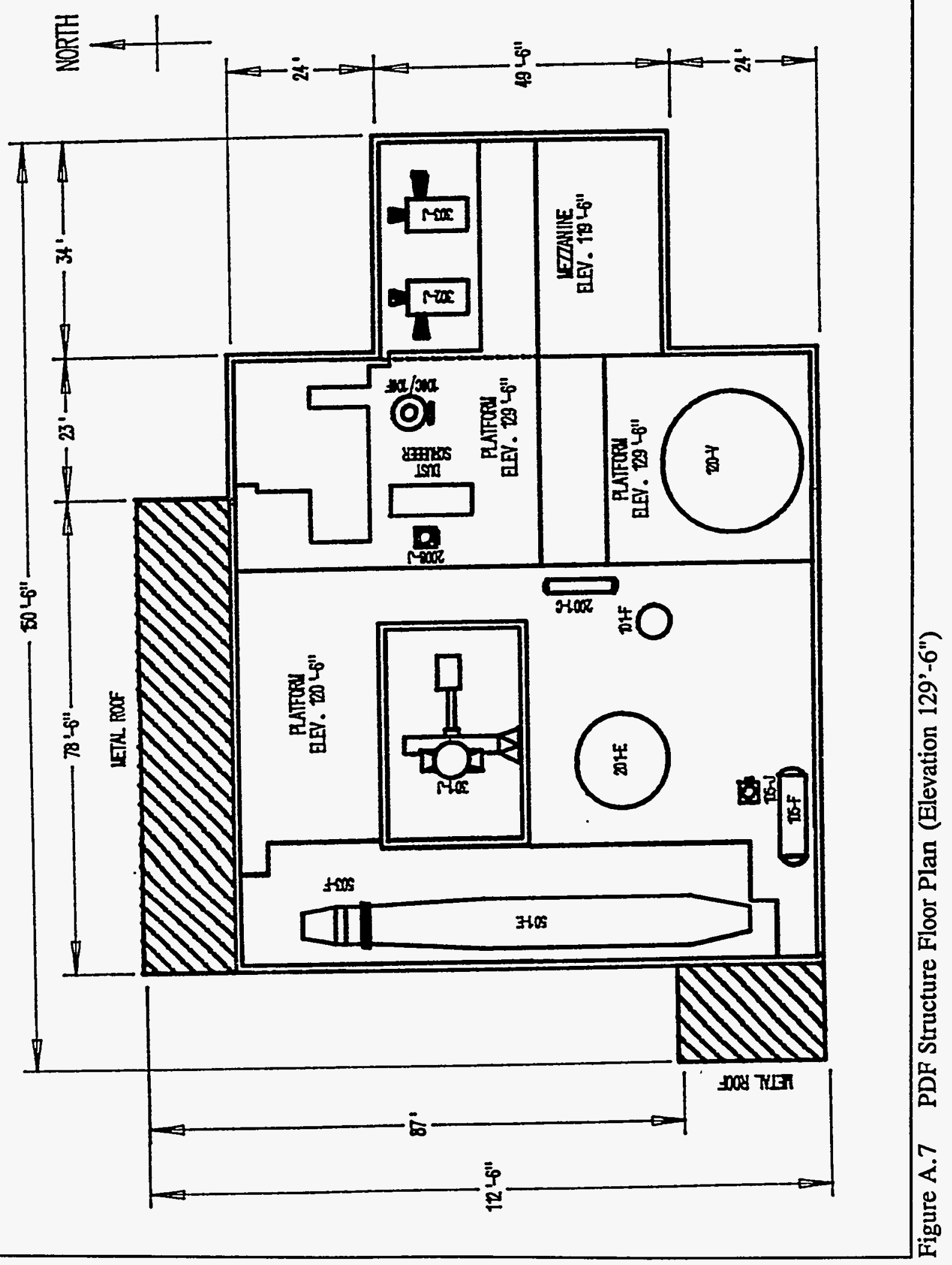




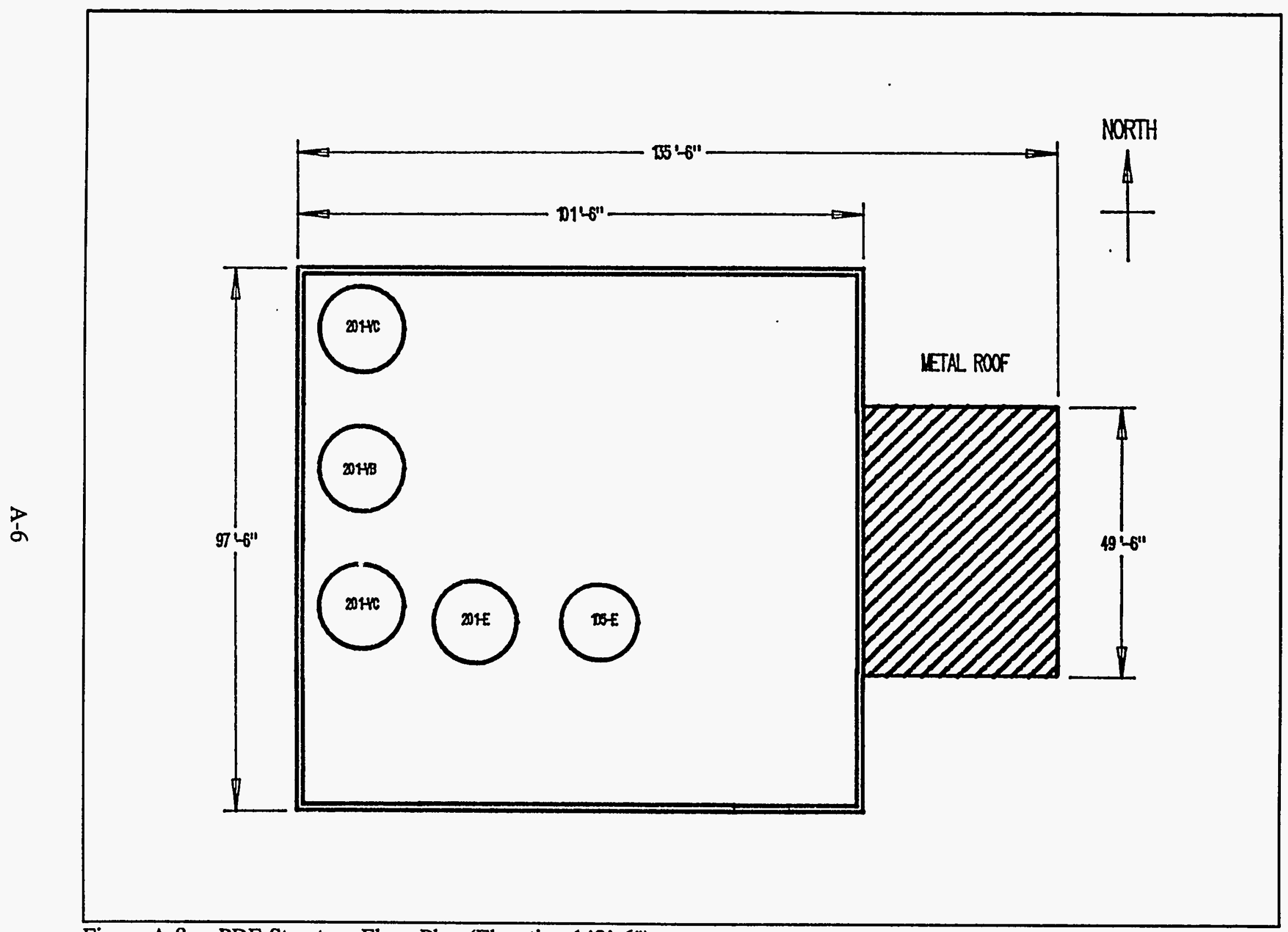

Figure A.8 PDF Structure Floor Plan (Elevation 142'-6") 


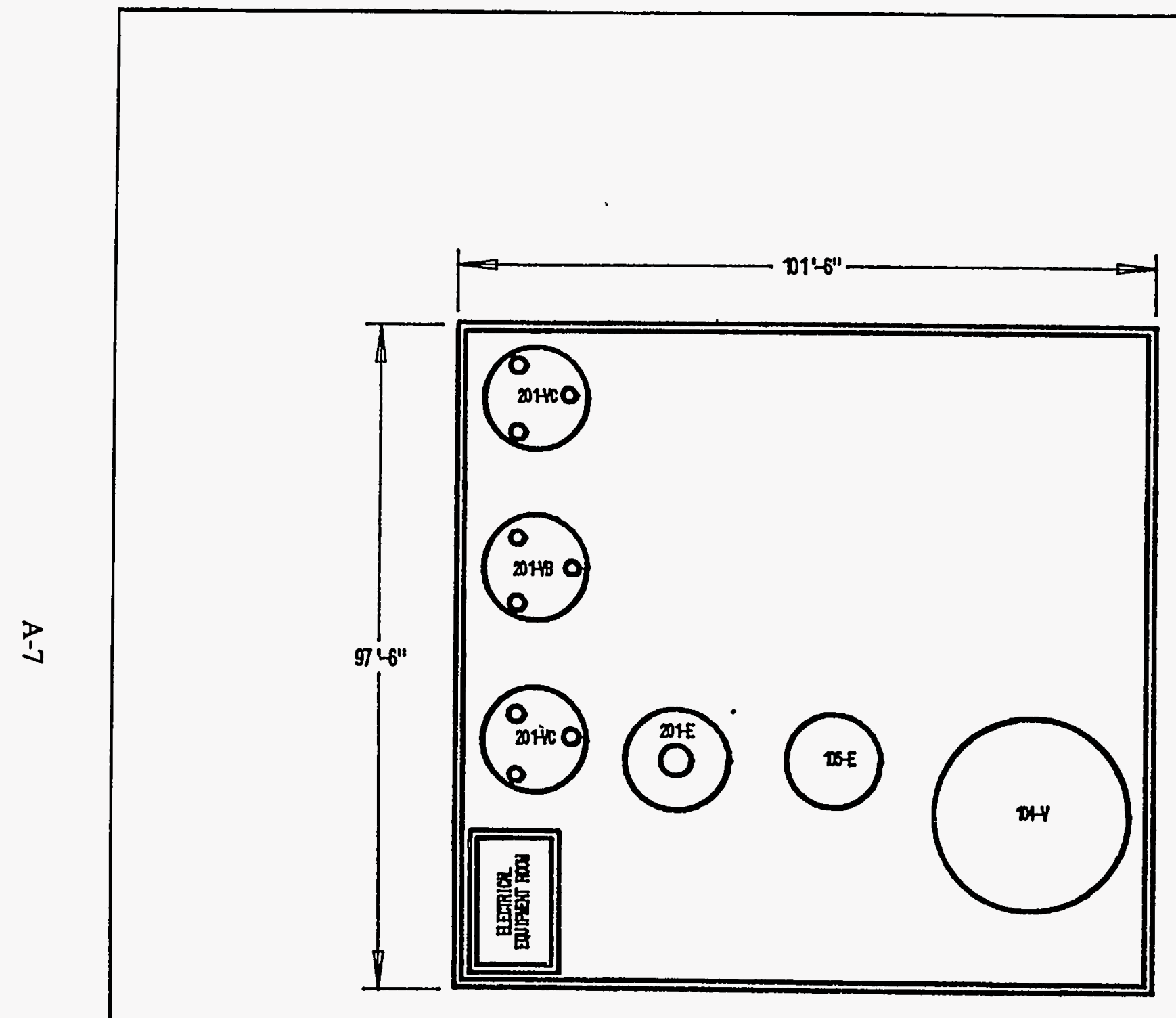

$\stackrel{4}{\text { NORTH }}$

Figure A.9 PDF Structure Floor Plan (Elevation 162'-0") 
焉

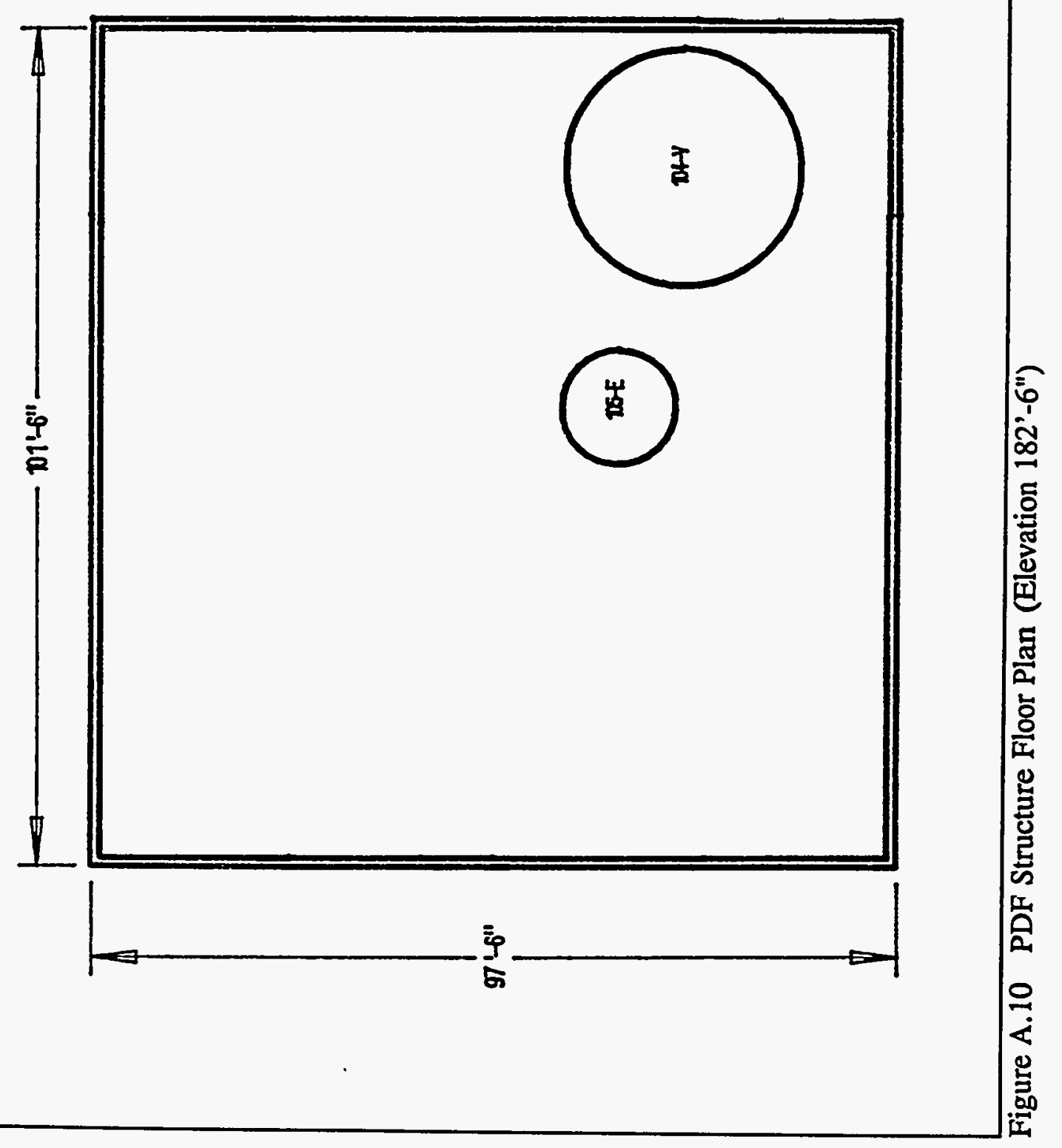

A-8 


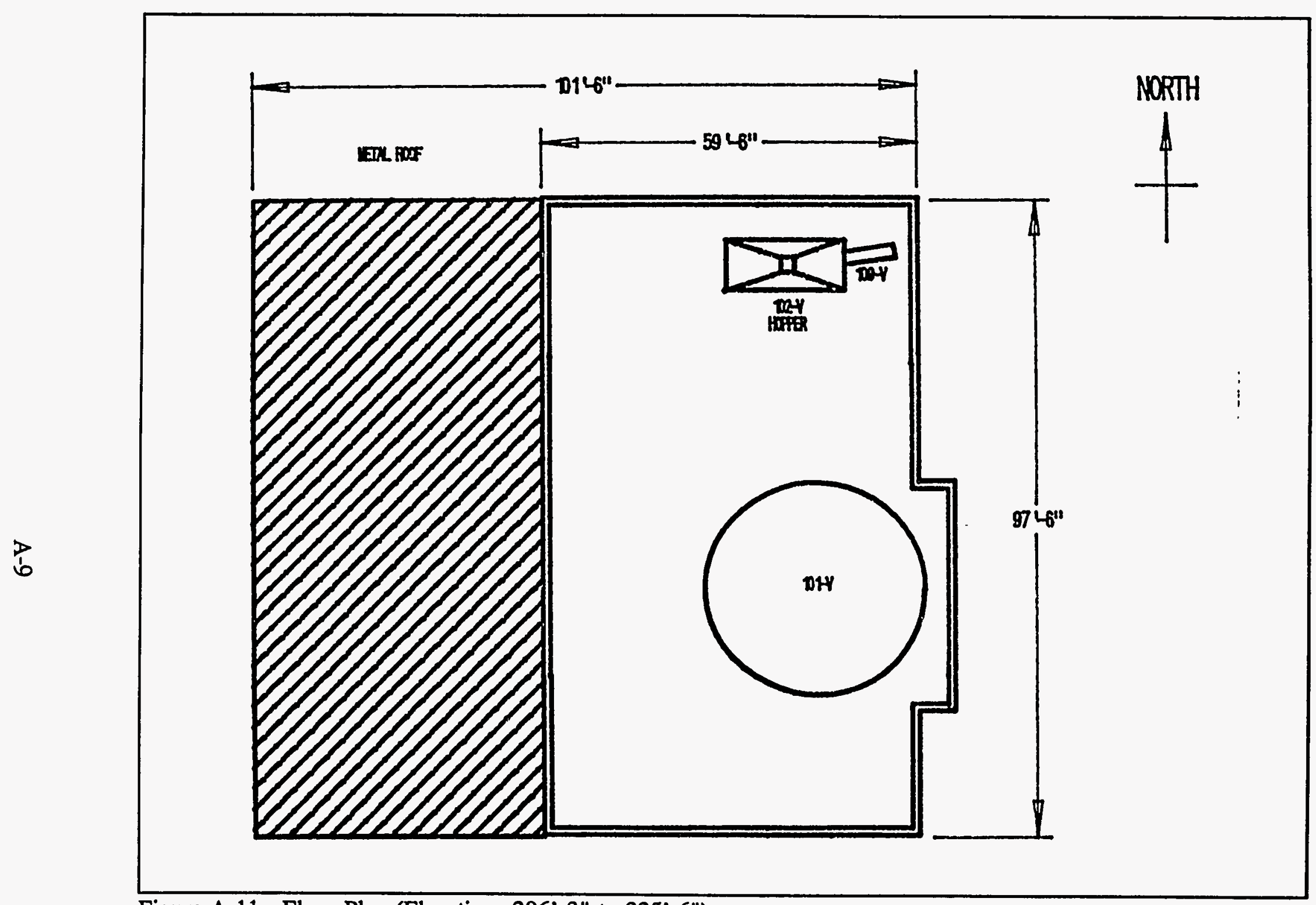

Figure A.11 Floor Plan (Elevations 206'-3" to 225'-6") 


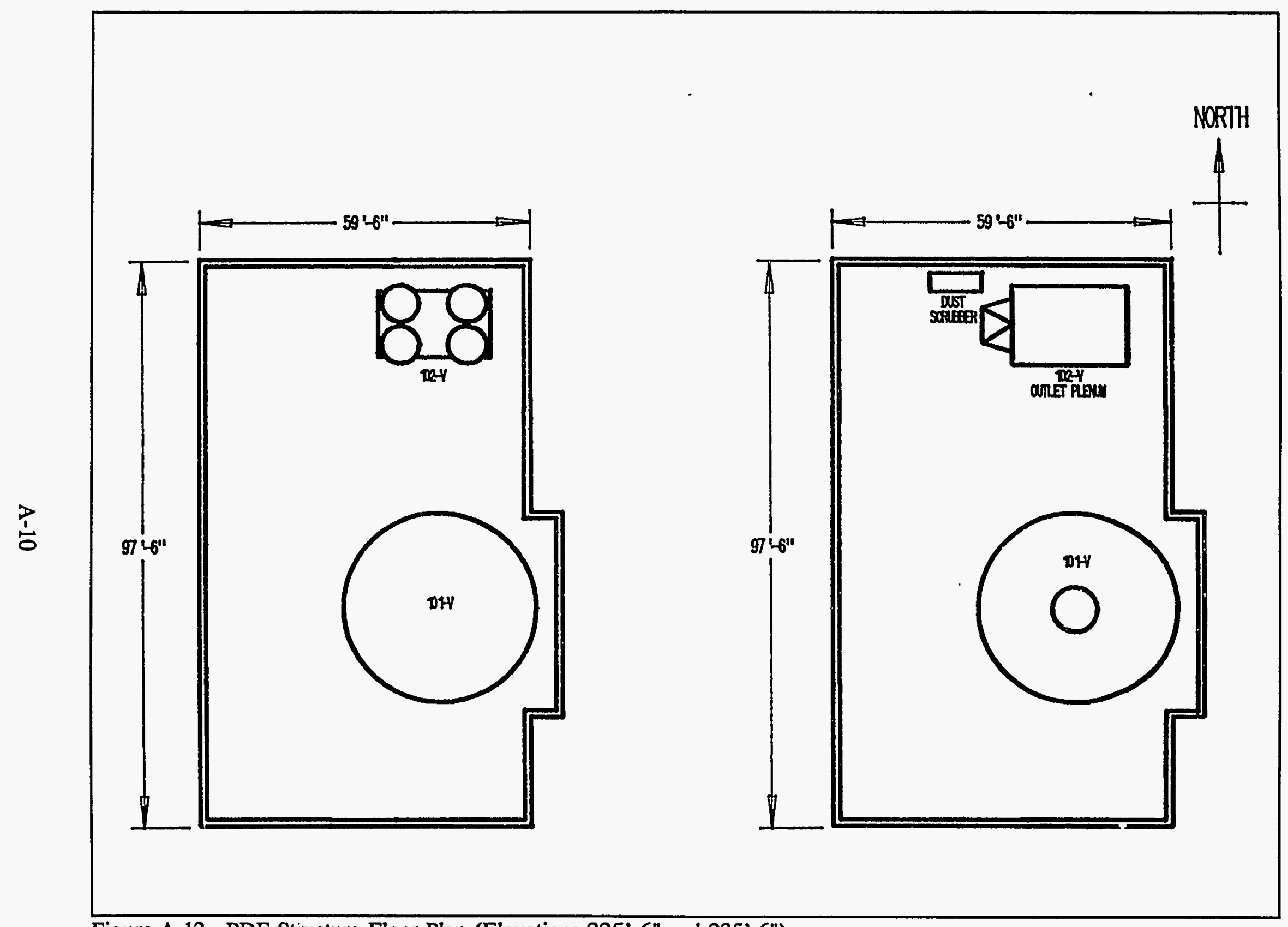

Figure A.12 PDF Structure Floor Plan (Elevations 225'-6" and 235'-6") 
壁致
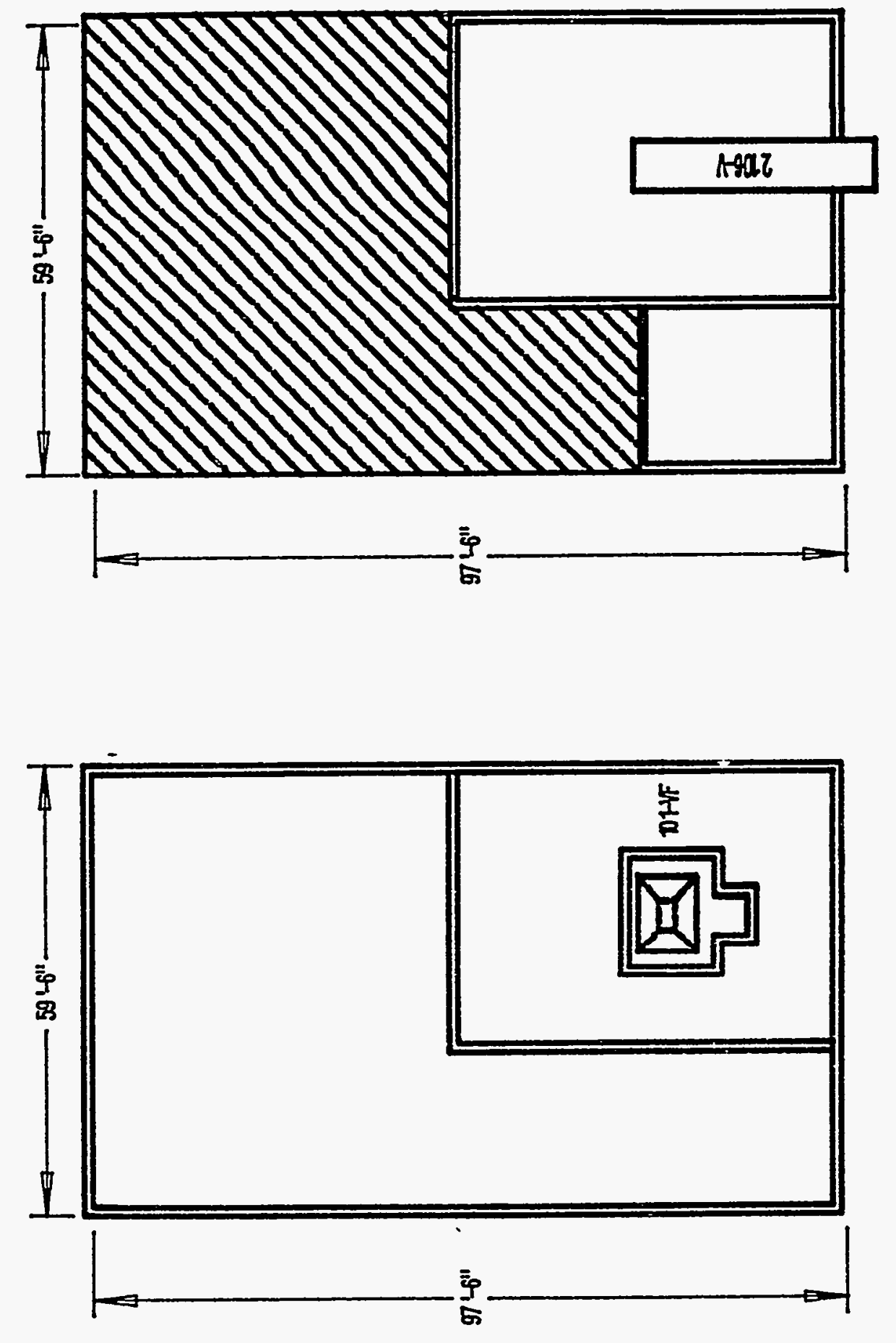

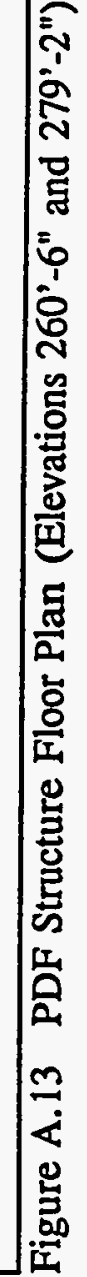




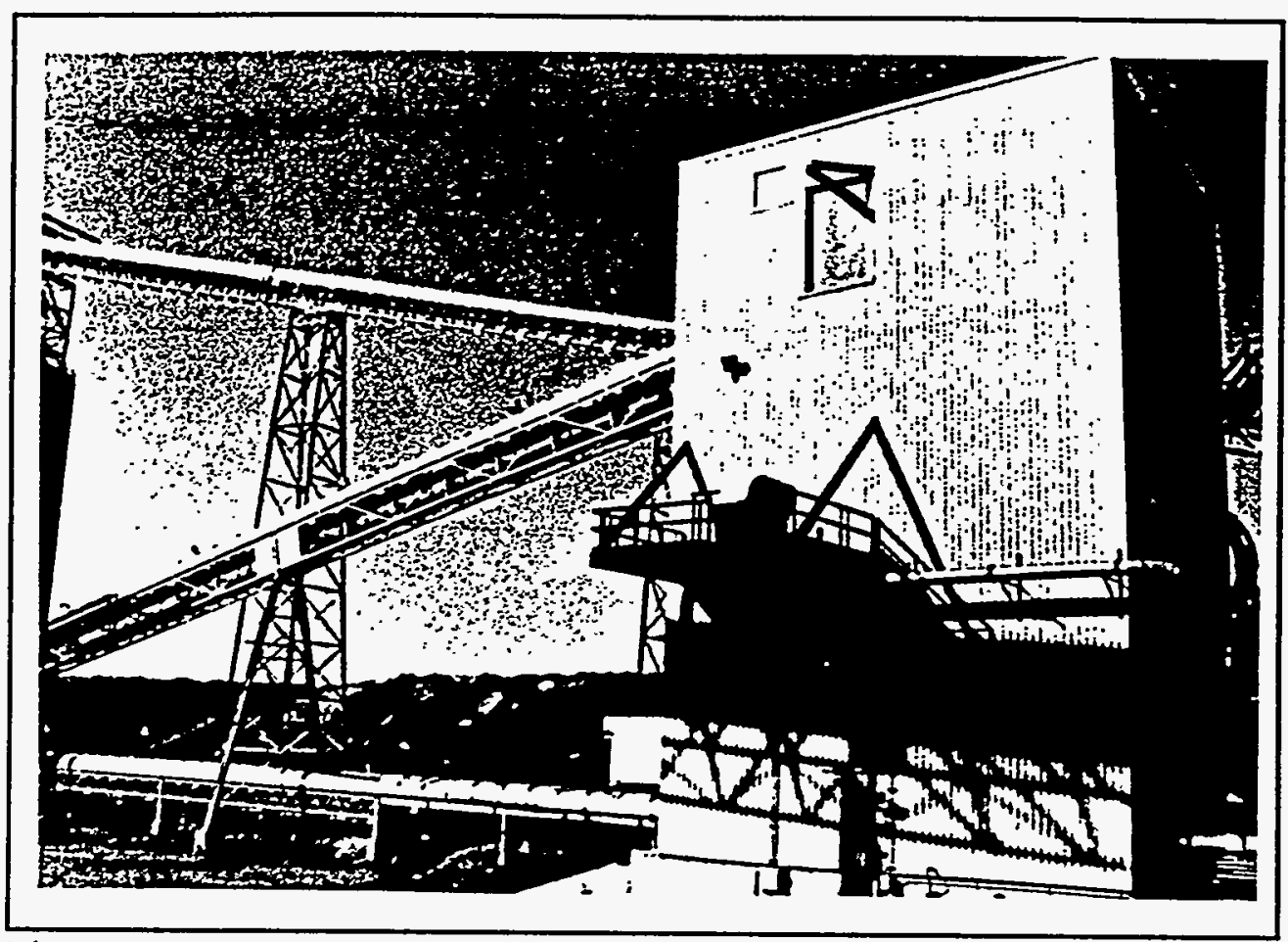

Figure A.14 Screening Building 


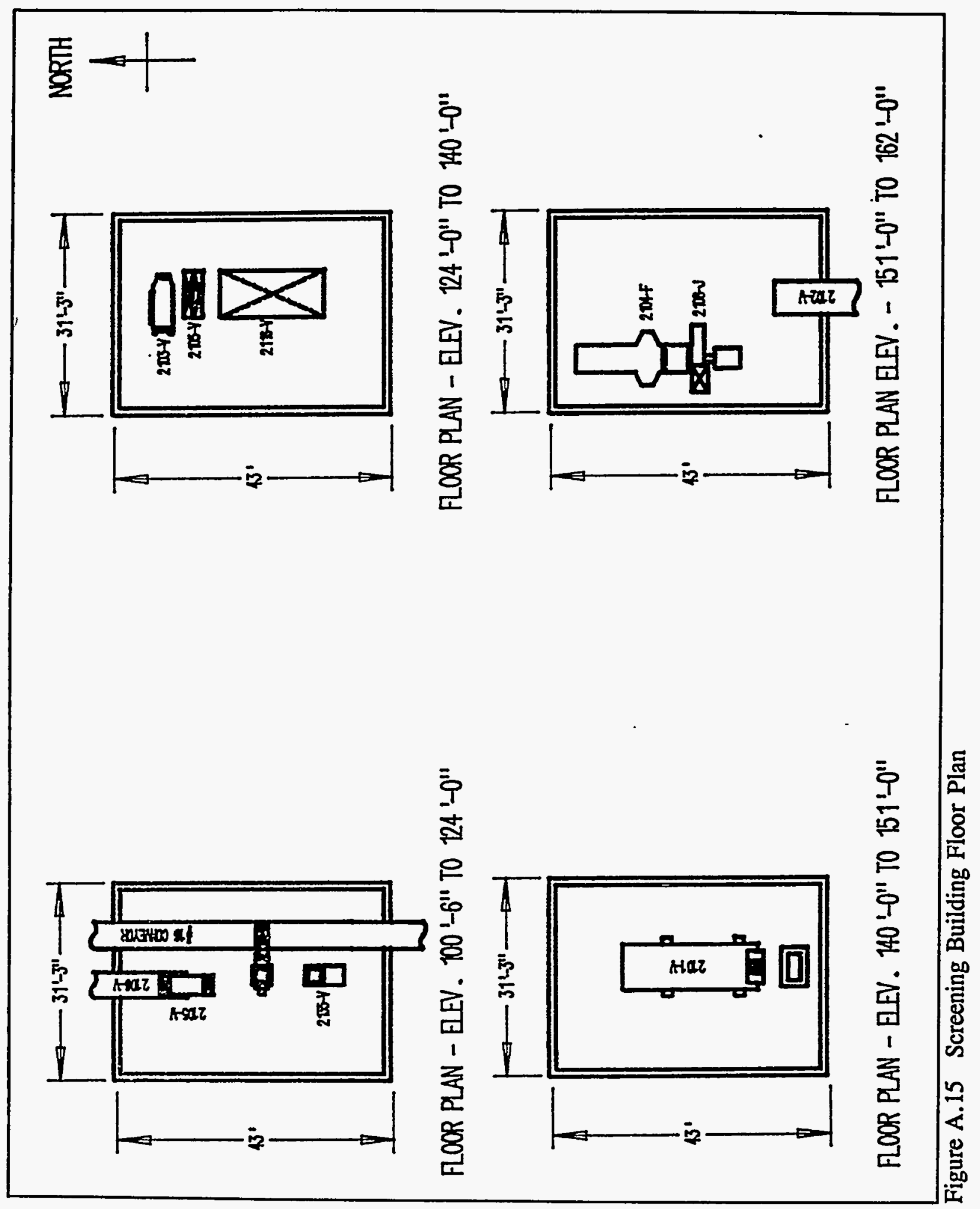


Table A.1

Equipment List

\begin{tabular}{|c|c|}
\hline Equipment \# & Description \\
\hline $101-\mathrm{F}$ & Fine Slurry Mixing Tank \\
\hline $101-\mathrm{J}$ & Dryer Recirculation Blower \\
\hline $101-V$ & Coal Dryer \\
\hline $101-\mathrm{VF}$ & Dryer Feed Hopper \\
\hline $102-V$ & Dryer Cyclone \\
\hline $104-V$ & Coal Pyrolyzer \\
\hline $105-\mathrm{F}$ & Seal Water Surge Tank \\
\hline 105-J & Seal Water Circulation Pump \\
\hline $105-V$ & Pyrolyzer Cyclone \\
\hline $106-\mathrm{C}$ & Pyrolyzer Quench Steam Condenser \\
\hline $107-\mathrm{V}$ & PDF Cooler \\
\hline $109-V$ & Dryer Fine Screw Conveyor/Cooler \\
\hline $120-\mathrm{V}$ & Pyrolyzer Quench Chamber \\
\hline 2001-C & Steam/Glycol Heat Exchanger \\
\hline $2001-U$ & Steam Boiler \\
\hline 2002-UL & Steam Boiler Deaerator \\
\hline 2005-C & Glycol/Water Trim Cooler \\
\hline 2005-J & Air Compressor \\
\hline 2005-JA & Air Compressor \\
\hline 2006-F & Oily Water Storage Tank \\
\hline 2006-J & Oily Water Pump \\
\hline $2007-J$ & Glycol Circulation Pump \\
\hline 2007-JA & Glycol Circulation Pump \\
\hline 2008-J & Cooling Water Booster Pump \\
\hline $201-\mathrm{C} 1 / \mathrm{C} 2$ & CDL Cooler \\
\hline 201-E & Quench Tower \\
\hline $201-\mathrm{J}$ & CDL Circulation Pump \\
\hline
\end{tabular}


201-JA

201-VA

201-VB

201-VC

203-J

2101-J

2101-V

2102-V

2103-V

2104-F

2106-V

2108-J

2108-V

2116-V

2117-V

2119-V

301-B

301-J

302-B

302-J

303-J

501-E

501-F

501-J

503-F

503-J
CDL Circulation Pump

Electrostatic Precipitator

Electrostatic Precipitator

Electrostatic Precipitator

Wash Oil Circulation Pump

Firewater Booster Pump

Triple Deck Coal Screen

Coal Feed Conveyor

Coal Crusher

Screening Building Dust Scrubber

Feed Coal "S" Belt Conveyor

Screening Building Dust Scrubber Blower

PDF "S" Belt Conveyor

Coal Fine Collection Bin

\#16 Conveyor to Triton Facilities

Vibrating Feed Under 2116-V

Dryer Combustor

Pyrolyzer Recirculation Blower

Pyrolyzer Combustor

Pyrolyzer Combustion Air Blower

Dryer Combustion Air Blower

Horizontal Scrubber

Scrubber Surge Tank

Sodium Carbonate Circulation Pump

Wet Gas Scrubber

Sodium Carbonate Makeup Pump 
Appendices B, C, D, and E Omitted 